\title{
A FOUCAULDIAN DISCOURSE ANALYSIS of an ENGINEERING PROGRAMME
}

\author{
By \\ Craig Alan Watterson \\ A thesis submitted to the Victoria University of Wellington in fulfilment of the \\ requirements for the degree of Doctor of Philosophy \\ VICTORIA UNIVERSITY OF WELLINGTON \\ Te Whare Wānanga o te Ūpoko o te Ika a Māui

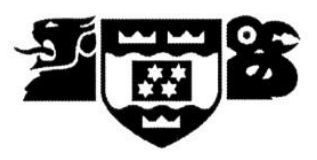 \\ 2019
}





\section{Abstract}

The extensive literature relating to student barriers within the Science, Technology, Engineering and Mathematics (STEM) fields and, in particular, engineering education illustrates that STEM education has a widespread problem in retaining students. A plethora of studies have concentrated on placing the student at the centre of the problem - for example by focusing on student academic ability, work habits and social background. By analysing staff interviews, and investigating pertinent factors from the surrounding institutional, cultural and social environment, I shift the focus away from the phenomenological experience of individuals to examine the way power relations affect the teaching and learning environment. Foucauldian Discourse Analysis (FDA) offers a theoretical and methodological basis for critically exploring networks of power, through the investigation of discourse and can provide insights into the complex situation in the School of Engineering and Computer Science (ECS).

I use FDA to ask: how is power experienced and manifested by lecturers in the Bachelor of Engineering with Honours (BE) first-year teaching and learning environment at Victoria University of Wellington (VUW), New Zealand. I do this by analysing transcripts of interviews with teaching staff, as well as ECS, University, and Government documentation. By adopting an FDA approach to lecturers' experiences of power, situated in the New Zealand neoliberal educational context, I aim to identify issues that impact the teaching and learning environment. These include academic practices relating to Government and University pressure to increase engineering student recruitment and retention numbers, an academically diverse incoming student cohort, course design, teaching and research. From a Foucauldian perspective, the New Zealand Government, the University, its lecturers, and students are all part of an educational setting comprising a complex network of power relationships active in the operation of the teaching and learning environment.

By placing lecturers at the epicentre of the situation and by understanding how lecturers both experience and exercise power in the teaching-learning environment, the issue of student retention may be re-framed. This study offers a unique perspective from which we can assess these problematic experiences at the source, whether that be at government, institution, department, teacher or learner level. As such, by exploring the operation of power, this thesis explores an important aspect of the retention problem which has never been fully investigated in NZ engineering education. 


\section{Relevant Publications}

A full list of my publications is at the end of this thesis, following the references section. The following list specifies the international peer-reviewed publications that relate to specific chapters of this thesis. All work included in this thesis is mine. Work included in the publications from this thesis has been led by me, with the co-authors (my thesis supervisors or colleagues) contributing assistance in proofreading, and contributing to discussions.

Chapter 1: Watterson, C., \& Carnegie, D. A. (2013). Pastoral care and student support: Developing a method of retention. Paper presented at Frontiers in Education Conference (FIE). https://doi.org/10.1109/FIE.2013.6685006

Chapter 2: Watterson, C. A., Carnegie, D. A., Wilson, M., \& Knewstubb, B. (2016). A potential theoretical method for exploring the engineering first-year retention problem. Paper presented are the IEEE Engineering Education Conference: EDUCON. https://doi.org/ 10.1109/EDUCON.2016.7474660

Chapter 4; 6; 7 \& 8: Watterson C., Knewstubb B., Carnegie D., \& Wilson M. (2017). Who owns the teaching and learning environment? In: Auer M., Guralnick D., Uhomoibhi J. (Eds.), Interactive Collaborative Learning. ICL 2016. Advances in Intelligent Systems and Computing, vol 544 (pp. 294-308). Springer, Cham.

Chapter 5: Eldridge, J., Watterson, C., Lukefahr, H., \& Carnegie, D. A. (2017). Are introductory courses suitable pathways for success in the BE(Hons). Paper presented at Frontiers in Education Conference (FIE). https://doi.org/10.1109/FIE.2017.8190574 



\section{Acknowledgements}

I would like to express my gratitude to all of the people who helped me on this journey. Maree, my partner and best friend, thank you for inspiring me to spend the time required to complete this thesis and offering your continued support. Dear supervisors, Dale, Marc and Bernadette, I am indebted to you for your determination to help me and your expertise. I feel privileged to have had your support through the fun and the hard times. I would also like to say thank you to my friends and colleagues who provided advice and companionship which meant the world to me. Thank you all for being there! 



\section{Contents}

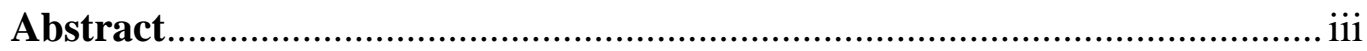

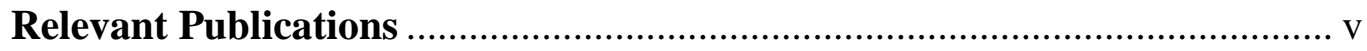

Acknowledgements ................................................................................ vii

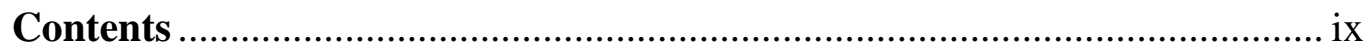

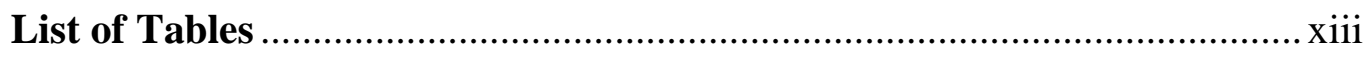

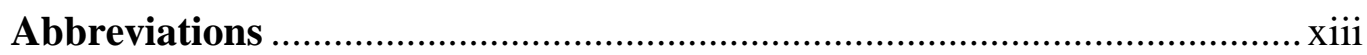

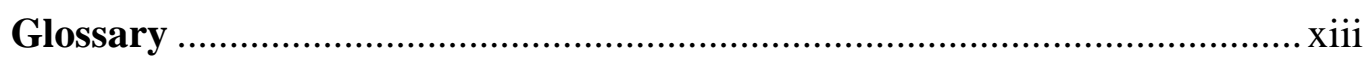

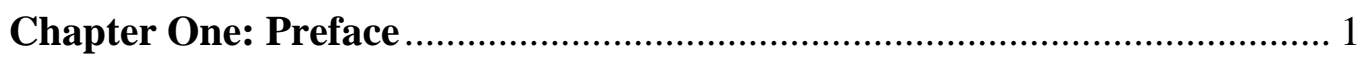

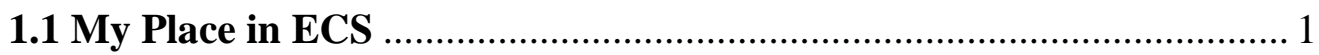

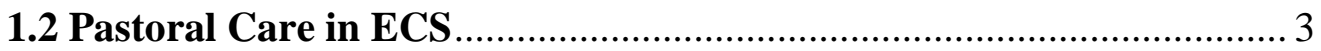

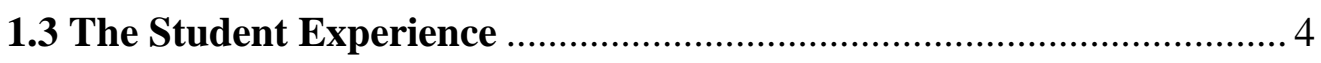

1.4 First-Year Teaching and Learning Environment ............................ 11

1.5 Existing Research on Engineering Education .................................. 12

1.6 Neoliberalism, Government and Educational Policy........................ 18

1.7 Performance-Based Research ..................................................... 21

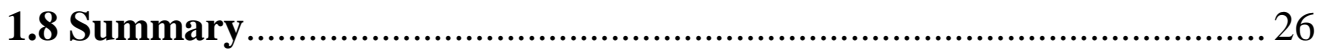

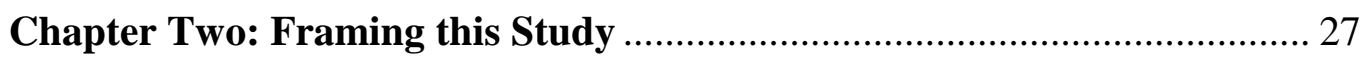

2.1 An Overview of Foucault's Theoretical Contributions ...................... 27

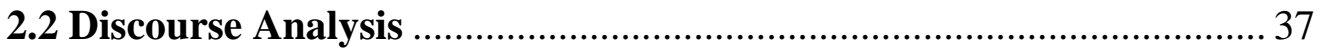

2.3 Foucauldian-inspired Discourse Analysis...................................... 40

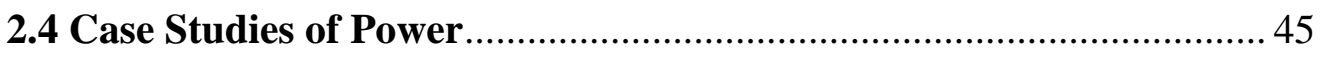

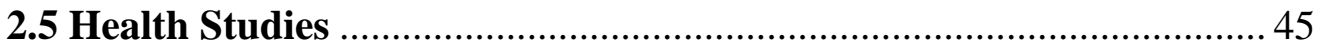

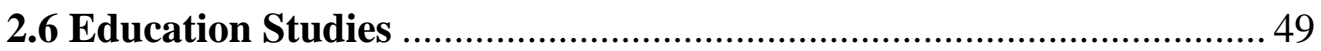

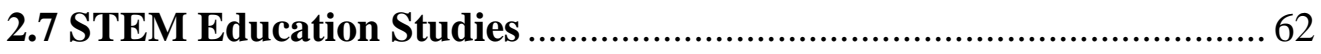

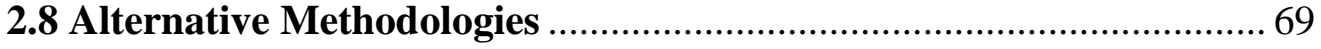

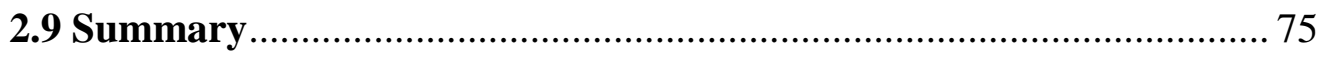

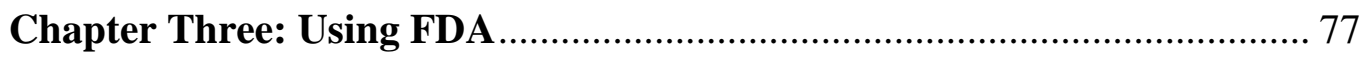

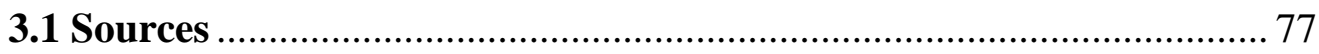

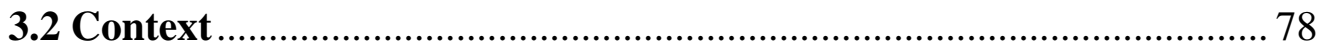

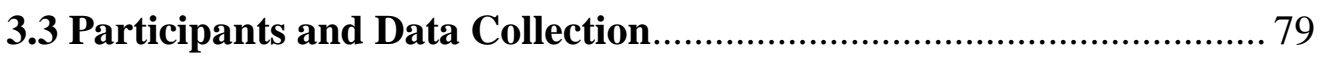

3.4 Text Collection and Interview Schedule ............................................ 80 


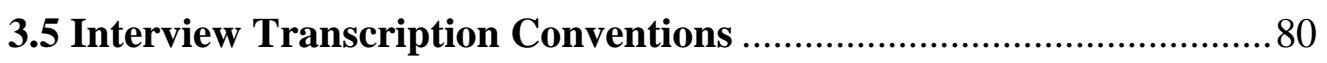

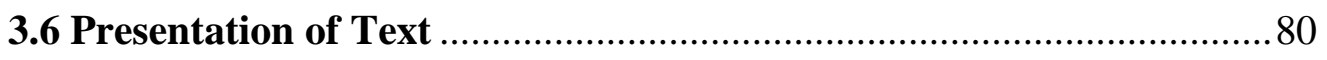

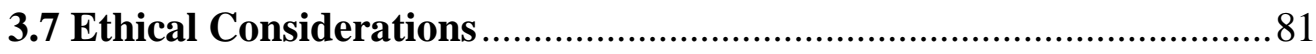

3.8 The Researcher's Position and Limitations ....................................... 83

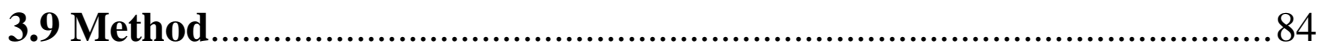

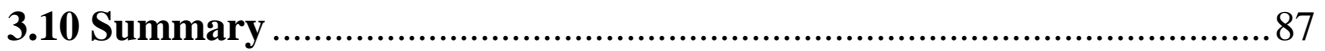

Chapter Four: Ownership and the Discursive Field ....................................8 89

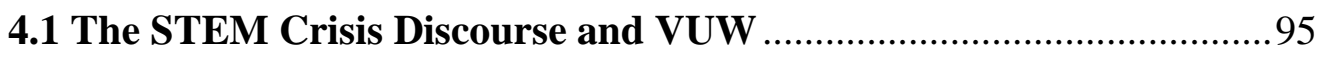

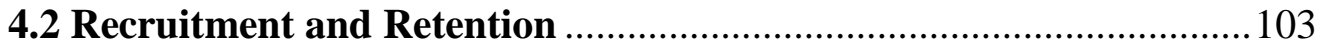

4.3 The Need to Increase Underrepresented Groups............................. 109

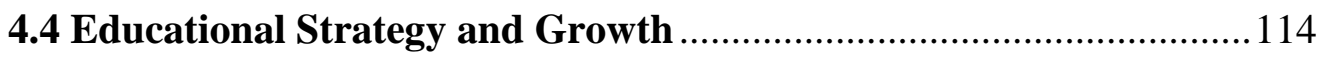

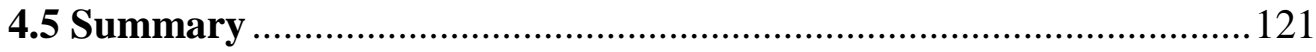

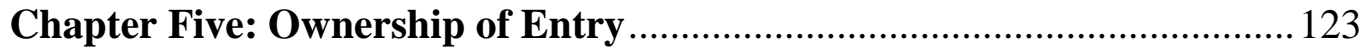

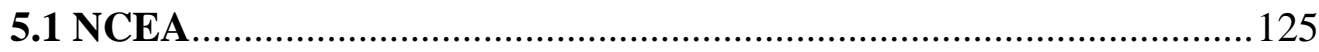

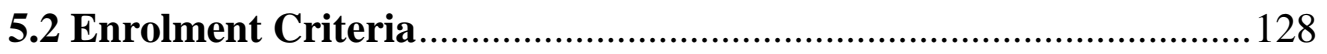

5.3 Lecturer Perceptions on Enrolment ….............................................. 133

5.4 Educational Expectation Mismatch ............................................... 139

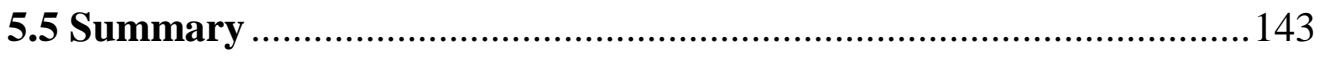

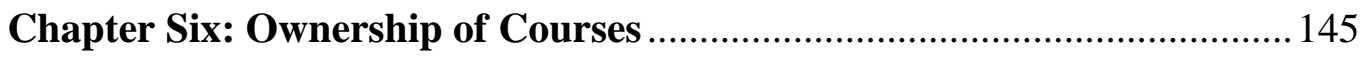

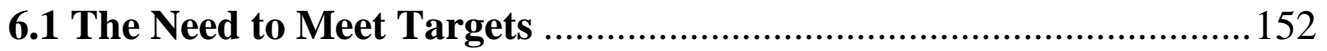

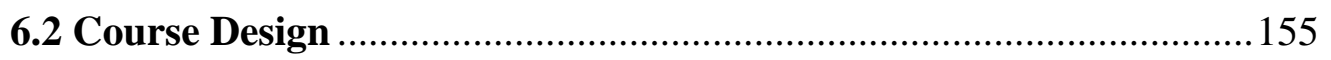

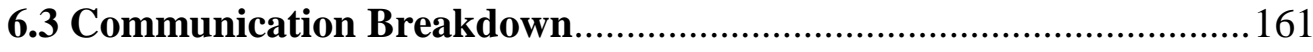

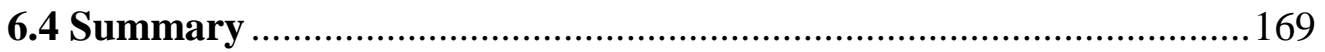

Chapter Seven: Ownership of Teaching and Learning ........................... 171

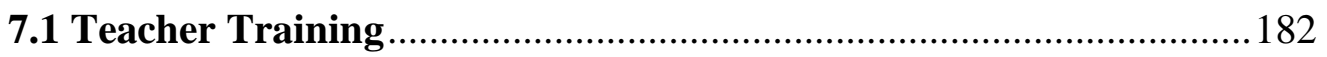

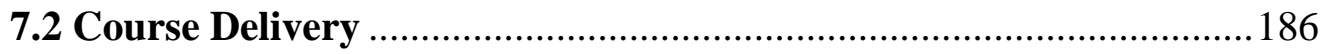

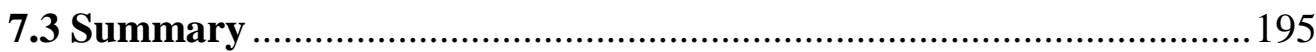

Chapter Eight: Ownership of Academics ................................................... 197

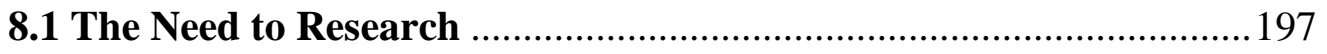

8.2 Too Many Demands - Too Little Time .........................................2212

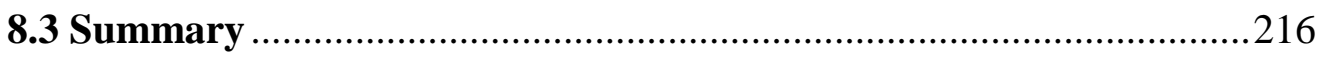

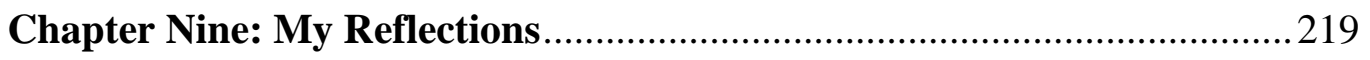


9.1 The Contribution to Existing Research ......................................... 224

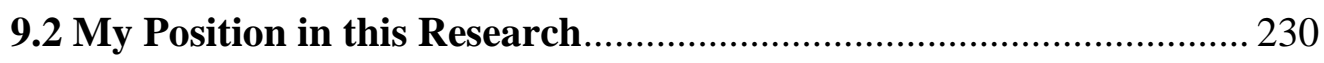

9.3 Recommendations and Future Research ...................................... 232

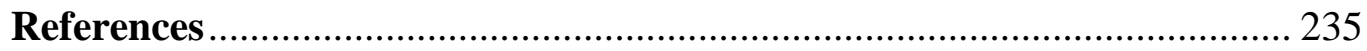

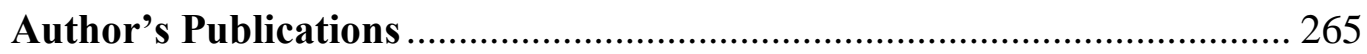

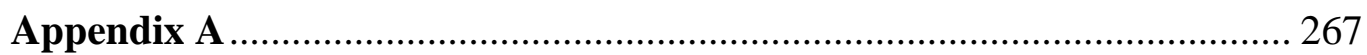

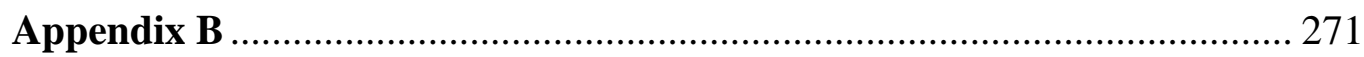





\section{List of Tables}

Table 4.1

\section{Abbreviations}

BE Bachelor of Engineering with Honours

ECEN Electronic and Computer Systems Engineering

ECS School of Engineering and Computer Science, Victoria University of

Wellington

EFTS Equivalent Fulltime Student (Government funding measurement)

EPP Tertiary Education Commission: Engineering Pathways Project 2009-2012

FDA Foucauldian Discourse Analysis

GES Guaranteed Entry Score (University entry calculation)

IPENZ Institute of Professional Engineers New Zealand

NCEA National Certificate of Educational Achievement (NZ High school assessment system)

NWEN Network Engineering

NZ New Zealand

STEM Science, Technology, Engineering, and Maths

SWEN Software Engineering

TEC Tertiary Education Commission

VUW Victoria University of Wellington

\section{Glossary}

Trimester VUW uses a three-trimester calendar teaching year. March to June, July to October and November to February.

Lecturer This term is used alongside academic in this thesis and encompasses all staff employed to lecture on courses.

$\mathrm{Lab} \quad \mathrm{A}$ lab is short for a laboratory, and it is a classroom environment where students complete exercises to connect lecture concepts to practical problems. Unlike a tutorial, lab work often involves using a computer, electronic hardware or in the case of physics physical and chemical materials to undertake experiments or activities. 



\section{Chapter One: Preface}

This thesis presents an account of a systematic investigation of how power is experienced and manifested by lecturers in the Bachelor of Engineering with Honours (BE) first-year teaching and learning environment at Victoria University of Wellington (VUW), New Zealand. The goal is to gain insights into the operation of the workplace and work practices that lecturers operate within and develop an understanding of the impact of this on the process of education.

This chapter provides introductory background and motivation for undertaking this research. I originally began investigating the barriers students were encountering in completing their first year of engineering at Victoria University of Wellington (VUW). My initial investigation involved interviewing first-year students and academic staff involved in their teaching. During my initial analysis, I was struck by the way the academic staff referred to the problems related to student success. The academic staff framed student success issues in regard to their situations and as a result of institutional problems. As a consequence, I shifted my research focus to investigating institutional and academic staff factors I believed were more significant to what I was witnessing in the educational environment. Though this initial analysis of student experience is not the focus of the work presented here, I shall elaborate upon it in order to illustrate the reasons for my shift in focus.

\subsection{My Place in ECS}

I returned to study in my mid-thirties completing an undergraduate degree, then Honours and finally Master's in History which focused on the development of higher education in British West African colonies. After completion of my Master's, I was employed by VUW in both a Continuing Education role and in teaching on our pre-degree Certificate of University Preparation Bridging Programme. In 2009 I was seconded to the School of Engineering and Computer Science (ECS) at VUW as the Project Manager for a Tertiary Education Commission (TEC) Priorities for Focus Project, developing a bridging programme for engineering students (further detail on this can be found in Carnegie \& Watterson, 2012). In New Zealand, a bridging program is a course of study offered for 
students who do not meet the entry requirements for university undergraduate programmes. Typical students who enter a bridging programme are missing specific high school subject qualifications. Completion of a bridging course allows a student to enrol in an undergraduate degree. Shortly after my secondment to ECS, I was employed fulltime as a project manager with an additional educational research role.

Early in the project, the New Zealand Government removed funding to universities for bridging courses and, after renegotiation, the TEC allowed us to focus the project on investigating the barriers students face in studying engineering. My role changed to that of project manager and researcher and, along with staff from VUW ECS, Mathematics, Physics and Education, we began exploring potential transition issues affecting first-year students and researching educational literature in the Science, Technology, Engineering and Math (STEM) field. Our work focused exclusively on trying to find out why our first-year students were suffering poor pass rates in their first year of engineering.

Victoria University of Wellington (VUW) in New Zealand is a publically funded university with around 2,000 staff and 22,000 students, and is ranked within the top 250 universities in the world (Victoria University, 2017). VUW accepts students with a wide range of incoming academic ability, from New Zealand and internationally. The School of Engineering and Computer Science at VUW has been teaching Engineering degrees in the 'digital fields' of Software (SWEN), Networking (NWEN) and Electronic and Computer Systems Engineering (NWEN) since 2007. Engineering students in ECS are required to obtain an above average B grade (70\% or above) over their core first-year engineering subjects (Part 1) to continue with the BE. Historically, a majority of any incoming student cohort has failed to achieve this B average degree requirement to pursue engineering beyond their first year. As a consequence, ECS does not retain or produce sufficient engineering graduates to meet its internal goal of 100 graduates per year (Victoria University of Wellington, 2011).

Using grade analysis of both first-year university results, and student high school results, we investigated whether there was a connection between high school and university grade performance in related subjects. We also conducted surveys of students twice a year and held focus groups run by science education researchers from Waikato University (see our previous work, and in particular: Carnegie \& Watterson, 2012; Carnegie, Watterson, Andreae, \& Browne, 2012). One of the outcomes of this earlier work, consistent with existing literature, was the acknowledgement that there appeared to 
be multiple issues affecting student success. Our work identified the fact that academic ability was only one of the issues affecting students' study success. Other factors, included illness, loneliness, family issues, homesickness, relationship or financial problems, work and social commitments, the method of teaching and the increase in workload at university when compared with high school to name a few. As a result, ECS committed to develop new first-year courses and build an outreach and pastoral care programme aimed at advising and supporting future students and existing students. In 2013 my employment position changed to that of Pastoral Care and Outreach Manager, in charge of developing pastoral care, and high school student outreach in ECS.

\subsection{Pastoral Care in ECS}

I helped develop and implement a pastoral care system in which I currently hold the primary pastoral care advisory role (Watterson \& Carnegie, 2013). This system was trialled in the 2012 and has operated in full since 2013. Alongside other staff at ECS I conduct regular analysis of student grade performance data and trends across individual assignments, courses and years, and regular surveys to obtain information on course feedback. In 2015, a Pastoral Support Senior Tutor was also employed to assist with student subject help, and I took over the additional role of first-year enrolment advice and processing of our incoming engineering students. The pastoral care team increased to three senior tutors in 2017 and will increase again by the end of 2018.

My role encompassed identifying at-risk students within the first two weeks of university classes, and then as part of an ongoing daily pastoral care process for the remainder of the year. The first assessment of potential at-risk students takes the form of a diagnostic test given to all first-year engineering students in week one. The hour-long test largely covers math and physics-based questions. It is ECS' experience (Carnegie et al., 2012) that many students perform poorly in the math and physics components of the BE. Therefore, a cut-off below 50\% in the diagnostic test is used to select potential atrisk students for pastoral care interviews, following which I email all at-risk students and ask them to attend an interview. Ideally, this first interview is held within the initial two weeks of the trimester so students can alter their courses or degree choices without financial penalty. 
The second, and most significant, aspect of pastoral care for at-risk student identification comes from ongoing checking of the "StudentVis" student grade monitoring system. StudentVis compiles student assignment, laboratory, test and grade data from courses throughout the first year of the BE on a week-by-week basis. I consider an at-risk student to be a student who shows continued poor performance, or who suddenly declines in performance in one or more courses. Importantly, most students, even those with excellent grades may get sick, miss an assignment or get the odd bad mark - these students are often contacted despite the focus on at-risk students. After a student is identified as being at-risk, in the role of Pastoral Care Manager, I contact them with an offer of assistance and an interview via email or by phone and, if necessary at labs or tutorials.

The primary task of the interview was to assist the student rather than gather research data. In these interviews, I would discuss subject choices, motivations and academic background with the student and a study plan is made. The student is also informed of the various forms of help available at VUW. For example, Student Learning Support Service, Te Rōpū Āwhina whānau which offers mentoring primarily for Māori and Pacific Island students, Disability Support, Counselling, Financial Services including Accommodation, Recreational Clubs and online and in-person tutorials and academic help sessions. In some cases, with student permission, I take them straight to counselling, disability support or student health.

In my position, I interacted with a significant number of our first-year student cohort. Generally each year I have interviewed over fifty percent of our incoming cohort. While these interviews were not recorded and relied on my experience and perception, they did point to many possible factors affecting student progress and indicated the potential for further research.

\subsection{The Student Experience}

I originally set out to do something quite different for this research. My thesis aimed to extend the information gained in my pastoral care experience to include a systematic investigation of both student and staff interviews. The aim was to identify barriers to student success at first year by primarily focusing on the students. As such, I sought ethical approval, and in 2014 I began recording pastoral care interviews where students 
approved. In 2014, I interviewed 120 out of the total 176 first-year engineering students, recording 74 students. In 2015 I reduced the number of recorded interviews and targeted specific grade performance groups (five low grades, five medium grades and five very good grades). However, the focus of my intended thesis changed because, while the student interviews highlighted a plethora of issues, one factor stood out to me - many of the issues the students identified appeared outside of their immediate control within the teaching and learning environment. These factors included, change in workload, how the learning experience was delivered, and what was expected of them at university when compared with high school. To illustrate I provide some extracts of those interviews and articulate how they led to the topic I ultimately followed:

Student A: ... It's fairly relentless and I... almost hate to think what it's gonna be like getting towards the test and the exam times. 'Cause it's gonna be the one that everyone is gonna be like (.) 'we have no idea what we're doing' kinda thing 'cause there's just so much (.) there's just so much. Um (.) I'll be honest we have two lab reports due on Friday I've done neither (.) um 'cause I've been busy doing other stuff basically.

Int: Yeah so what (.) Comp or?

Student A: Yeah um well comp assignments have taken a lot longer (.) like you're looking at like four or five hours to get like up to (.) you know maybe one of the challenges done. And that's something I'm generally aiming for you know. I think so far in my three assignments I've got A on one and then A plus on the other two. And it was like I'm always kinda aiming for that (.) that A range. Um but sometimes you just kind of (.) you know the week goes on and it's like 'okay I just I need to sit down and do this' and you don't actually have the time to do it ... One thing that I do find tricky especially is that like my least busy day is four hours of contact time and then my most busy day is like (.) I think six hours of contact time and when you're expected to be spending (.) um you know sixty hours a week doing stuff. And then actually almost half of that is just contact time (.) then that really makes things hard.

Int: ... So is the workload your biggest barrier to getting through your stuff and succeeding in your studies?

Student A: ... I think sometimes it is (.) I think sometimes just the sheer 'oh my goodness (.) I just have so much stuff to do'. Um and part of it is 
that I just need to get past that (.) and just be like 'I do have all this stuff to do (.) so let's get it done' you know whereas and I (.) that's something that I'm still not particularly good at is actually just kind of convincing myself (.) okay (.) we're just gonna sit down (.) we're gonna get it done. Int: So it's a bit of procrastination?

Student A: Oh yeah (.) it is definitely a lot of procrastination just because sometimes the task feels so insurmountable (.) you know it's just so big And it's like 'oh' I just 'how am I ever gonna get through all of this'.

[Student Extract 1]

Student A above is an academically capable student who explained that they were struggling with the workload and with managing their time. The major effect of this workload on them appeared to be procrastination as a result of not knowing where and how to start. Another way to look at this is that the student procrastination is a 'resistance' to the overwhelming pressure they are experiencing within the teaching and learning environment of ECS (I shall expand on this notion of 'resistance' in later chapters). They are explaining the operation of a clear power dynamic at work here within the university system. For example, Student A, while suggesting that they are procrastinating also describes a constant course workload demand by the ECS courses. The constant workload is a demand of the system, and the student is experiencing a sixty hour per week workload. There appears to be no free time, and in this scenario, if the student became sick, or faced some other impediment to their study, they would not be able to cope.

Student B below also identifies the workload as a problem but suggests that there are major differences from what they experienced at high school to what they experience in ECS. This reinforces the idea that there are different educational systems at work. It also suggests that the systems affect the social behaviour of the student who must adapt to this new university system.

\section{Int: So is it [University study] different to school?}

Student B: Um definitely a lot more self-management. Like no one's gonna chase you up unless you really ask someone to chase you up. Um (.) everything's a bit harder and a bit more formal. - I think there's a lot more work (.) um I didn't have to do homework really in high school. So that has been a big change. So from no homework in high school to regular homework at university.

Int: Really (.) is that sort of like everyday homework or? 
Student B: Um (.) not every day (.) it probably should be but yeah just a lot more homework than ever before really and a lot more work in general.

Int: So a lot more assignments every week (.) a lot more?

Student B: Yeah

Int: Okay, is there ever a bit of a break in that or is that sort of relentless?

Student B: Some weeks will be easier than others but I'm not sure if that's from postponing stuff 'till (.) Like so a three-week assignment put off 'till the last week. So there are definitely weeks that are hard and weeks that are easy. [Student Extract 2]

Student C explains that they prefer learning on a one-to-one basis or in smaller groups as was more common in high school classrooms.

Int: Do you find the lectures helpful? Do they explain what's going on or are they introducing new material as well all the time?

Student C: Yeah um (.) I think the lectures are good but I personally find it hard to learn in lectures. I find it easier if I'm being explained like one-onone or like smaller groups. [Student Extract 3]

Student D experienced a relationship breakup which adversely affected their ability to complete the work, falling behind but failing to do anything about it. The university system does not usually pick up on the life issues affecting students, in the way a high school teacher can monitor the performance of a smaller classroom of students. Student D's situation described below indicates that the system is predominantly impersonal and does not take into account the life factors that may affect a student.

Int: They [courses] seemed to be going okay but everything plummeted what happened? What's going on really?

Student D: Um (.) that was when I broke up with my girlfriend (.) of two years so that was a bit tough

Int: Yeah that is tough. Do you think you're gonna be okay? Are you doing the work now?

Student D: Yeah I am. I'm like 'cause it was kind of hard now because I'm like sort of behind and I need to like catch up on everything.

Int: So have you gone and talked to the people about catching up with your assignments?

Student D: Um not yet no. [Student Extract 4] 
Student E was having difficulty understanding an international lecturer whose English was not very clear. Unlike New Zealand High schools, NZ Universities have a large proportion of international lecturers which is another aspect of the difference in the two educational systems. Students, like Student E, have no choice but to find ways to gain the material needed to succeed on their own as there is no help given to them if they cannot understand a lecturer's English.

Student E: [Lecturers Name] quite difficult to sort of understand Int: Is that a big problem?

Student E: Um it's not (.) too bad it just I can't understand. A few things [they] says sort of confuse most the class (.) as far as I'm aware.

Int: Does anybody ask [them] to re-explain it?

Student E: Um occasionally someone does but.

Int: Is that explanation usually good or is that hard to understand as well?

Student E: Also hard to understand. [Student Extract 5]

Student F could not follow a mathematics lecturer whose style was to just read from slides. Similar to Student E, this excerpt reveals a system of education that involves attendance at lectures where information is provided. However, the student is experiencing difficulty gaining this knowledge, either in note form or from the lecture. This student felt that they had to go home and do the work again by themselves.

Student F: But I'm not finding the lectures useful at all. I'm having to go back and do it all in my own time to actually understand it.

Int: Okay so what's the problem with the lectures?

Student F: Um I think it's [Lecturer's Name] is [there] name. All [they] does in the lectures (.) basically copies out [their] notes. I think they're written by [them] or someone else. Um, and [they] just explains them as [they] goes through. But I find I can get the notes online. So I go to the lectures but I don't make notes [they] sort of goes through them too fast for me to work out what's actually going on so I end up going through them at home.

Int: So [they] just too fast or?

Student F: Almost ah, yeah it's almost it like the way [they] goes through and explains it you don't really get much more from that than you would from just reading through the notes on your own.

Int: Okay so there's no sort of explanation? 
Student F: [They] writes them out (.) yeah [they] writes them out sort of word for word on one of the overhead cameras off the projector. [Student Extract 6]

Student $\mathrm{G}$ found that they were not enjoying the course as it was not what they thought it was going to be. This student was a software engineering major who was surprised by the amount of coding in the degree.

Student G: I don't (.) I like (.) I don't think I'm (.) bad on my maths or physics or anything like that. It's just the enjoyability and being able to keep myself on track.

Int: So if you had to say which was the biggest factor?

Student G: Probably more the enjoyability

Int: So you're not enjoying it. Is that because it's not what you expected? Student G: Yeah.

Int: Mm what did you think it would be?

Student G: I didn't expect so much of the um (.) the coding like I thought it would be a little bit more designing. [Student Extract 7]

Student $\mathrm{H}$ was living at home over an hours travel each way from university considered this and their time management as barriers to their study. They felt that they were bad at time management because of their experience in a New Zealand high school. Student $\mathrm{H}$ identified that you have to be more self-driven as a university student.

Int: What was the trouble in your study this year?

Student H: Physics probably Um (.) I live in Kapiti still so I have an hour commute. Physics was nine am lectures. Ah, so I have to get up at like five or six for that um so that probably affected a bit. And I tried to ride on knowledge from physics in high school a bit too much so (.) I think I dropped it a bit there. Um and I sort of lost motivation for the course a little bit so I just scraped by really.

Int: Is the motivational loss because you couldn't always get to the nine am lectures?

Student H: No I think it's because I thought I already knew part of the content (.) but then there were parts I didn't know of the content as well. Int: So what about the teaching was it good?

Student H: Um the teaching was a bit different to what I was used to for that course because it was also different to the other engineering courses 
slightly. It was definitely just a different style and like provided lots of examples but no less hard equations and stuff were provided like what I was used to in physics. So that one also threw me off a little bit.

Int: What has been the hardest thing for you?

Student H: Um (.) either time management or attendance probably (.) one of those things

Int: Yeah and that you think is a lot related to the fact that you're not living locally?

Student H: I think that's affected it but then the time management also stems from high school. Like high school's not exactly pushing people hard. Int: So a lot of students describe it to me as they cruised through high school would you describe yourself as that?

Student H: Yeah it's definitely hard to change the motivation. Education in like high school is just like chugging along but then here you actually have to self-drive and self-motivate yourself and actually try a lot harder.

\section{[Student Extract 8]}

These representative examples, drawn from pastoral-care interviews indicate that there are many reasons why students believe they are performing badly. All students noted major differences in the way the university operated, compared to their high school experience, with many suggesting that here at university they were expected to 'teach themselves'. Also common was that they frequently felt responsible for their poor grade or study performance, often attributed to their inability to keep up with the workload at university compared to high school. As a result, these interviews suggest that there are systemic differences outside of the control of the students in many cases. The interviews reinforced my conclusions gained from working at ECS and interviewing hundreds of students; there is a significant disconnect at first year between the expectations we have of students and those they have of us, academically, environmentally and behaviourally. It became clear to me that often these themes were outside of a student's ability to affect and related to factors in the wider teaching and learning environment, resulting in a shift of my thesis focus. I decided to focus my research on how the policies and practices of the university and its lecturing staff affect the teaching and learning environment. 


\subsection{First-Year Teaching and Learning Environment}

In my role I have been heavily involved in the Engineering and Computer Science (ECS) programme reviews, the ECS review of our first year BE and the teaching group meetings for our majors. During these reviews, it became clear to me that the students had no real idea of what was going on in the teaching and learning environment outside their immediate experience. I also became aware of structural and organisational issues occurring inside the culture and environment of VUW and ECS that affected teaching and most definitely could impact on student learning without the students ever being aware. Anybody who has worked for a period within a university teaching and research department would recognise the multitude of processes that sit outside a student's awareness. For example, the scaling of marks, the reason for changing a teaching method or assessment approach, or that the university placed financial targets on their learning outcomes. This is not to say that the effects of lecturer or institutional actions in the teaching and learning environment are not experienced by students.

The interviews allude to a social system surrounding the student that utilises forms of control over what the student experiences, and the students had unknowingly explained this when they described that university was different to high school (e.g., extracts 2, 6 and 8). It was at this point my focus changed, from an interest in student interviews, as I wanted to know more about the university system and the lecturers' role in it. I also realised that I am embedded in the system, albeit with a unique perspective, and I had the opportunity to interview staff members about their experiences and find out what they thought about what might be going on, as well as to investigate relevant policy documents that might explain these processes.

My focus on the teaching and learning environment and academic staff teaching first-year students was for several reasons. The first was my existing background knowledge of, and concern for, improving first-year ECS. I knew the lecturers well and was in a position to approach them. I also had extensive 'insider' knowledge of our administration and teaching processes in the first year, and was witness to some of the effects on staff and students of the way these processes impacted teaching and learning. My pastoral care role gave me an intrinsic interest in improving our understanding of the issues in the first year which may be contributing to the poor numbers of students achieving their Part 1 in the BE. Part 1 is the set of first-year core courses a student must obtain a B average across to continue in the BE. It is the most important stage of a BE 
degree for students. Failure to achieve Part 1 effectively removes a student from the degree (chapter three contains a more detailed description and discussion of Part 1).

I was also aware, as the next section will elaborate, that the bulk of the educational research conducted in STEM education and retention is student-centred and, therefore, academics' experiences and their possible impact on student success is left unaddressed. It seemed to me that there was a gap in our understanding of what was occurring in ECS and this gap related to the experiences of the academic staff.

\subsection{Existing Research on Engineering Education}

The literature on engineering education exists within the broader field of STEM educational research. It is commonly accepted that there is a shortage of STEM graduates, and deficit is attributed to poor recruitment and retention in the academic fields of STEM at tertiary institutions, and in particular within the engineering subset of STEM (King, 2008; Unesco, 2010; House of Commons, 2009; Ministry of Education, 2009; IPENZ, 2009; Royal Academy of Engineering, 2012). Researchers have attempted to investigate the issues surrounding STEM retention with limited success for more than twenty years.

A large body of international research has attempted to answer the question: Why are there so few people, both studying and graduating, with STEM tertiary level qualifications? The STEM student retention and academic success literature has tended to focus on investigations of pre-tertiary academic performance and diagnostic testing to predict performance of potential students (For example, United States Congress Commission on the Advancement of Women and Minorities in Science, Engineering, and Technology Development, 2002; Zhang, 2004; Astin, 1993; French, 2005; Ackerman, Kanfer, \& Calderwood, 2013; Veenstra, Dey, \& Herrin, 2008; Scott, Tolson, \& Huang, 2009; Thompson \& Bolin, 2011; National Research Council. 2011; Crisp, Nora, \& Taggart, 2009; Lam, Srivatsan, Doverspike, Vesalo, \& Mawasha, 2005; Whalen \& Shelley, 2010; Wai, Lubinski, Benbow, \& Steiger, 2010). These studies generally follow a deficit model, assuming there is something lacking in the students or the teaching methods in a course. As such, many of the studies that currently inform our understanding of student success and retention in STEM adopt a student perspective and seek to address student needs, and shortcomings, as inferred from self-reported student experience. These studies have generally considered stronger academic performance in high school and 
tertiary entry diagnostic tests to be directly related to tertiary student success within the STEM fields.

International STEM educational researchers have also attempted to understand student perceptions towards their learning environment (Fantz, Siller, \& DeMiranda, 2011; Shapiro \& Williams, 2012; Soldner, Rowan-Kenyon, Inkelas, Garvey, \& Robbins, 2012), their aspects of transition, and teaching styles and methods (Graham, Frederick, Byars-Winston, Hunter, \& Handelsman, 2013; Tai, Sadler, \& Mintzes, 2006). These studies point to many multiple issues that can contribute to student success or failure. For example, Shapiro and Williams investigated the effect of negative gender stereotyping, by parents and teachers, and how this affected the success of female students in STEM. Studies in this area have also investigated the manner in which STEM subjects are taught in pre-tertiary educational environments, from pre-school through to high schools (Subotnik, Tai, Almarode, \& Crowe, 2013; Wang, 2013; Heilbronner, 2011; Nathan, Tran, Atwood, Prevost, \& Phelps, 2010; Sanders, 2009; Brody, 2006). For example, Subotnik, Tai, Almarode \& Crowe examined specialised STEM subject high schools to see if students from these performed better in STEM tertiary institutions. They concluded that students who attended specialised STEM focussed high schools were more likely to enter tertiary STEM study.

Research has also focused on factors pertaining to students' educational or financial backgrounds, parental and cultural influence, ethnicity and gender (Museus, Palmer, Davis, \& Maramba, 2011; Cheryan, Siy, Vichayapai, Drury, \& Kim, 2011; Shapiro \& Williams, 2012; Hernandez, Schultz, Estrada, Woodcock, \& Chance, 2013; May \& Chubin, 2003; Palmer, Maramba, \& Dancy, 2011). Studies have also endeavoured to provide solutions as to why, for example, engineering has few women students (Seymour \& Hewitt, 1997; Hill, Corbett, \& St Rose, 2010; Tietjen, 2004; Hersh, 2000; Marra, Rodgers, Shen, \& Bogue, 2009; Ong, Wright, Espinosa, \& Orfield, 2011). Most authors locate the problems of retention and subsequent success in either the students not having access to early STEM education or there being a problem in the teaching they encounter. Solutions include the need to develop or tailor the classroom setting for the ability and type of student audience, be it gender, ethnicity, culture or age, and through appropriate teaching methods, increase retention (Nelson \& Rogers, 2003; Beutel \& Nelson, 2005; Burke \& Mattis, 2007; Boles, 2009; Thomas, 2000).

All this international research suggests that the reasons for students having difficulty vary across the many different socio-cultural contexts surrounding a student. 
There appears to be no typical case, with complex combinations of factors in many cases. Examining the problem from either a student position or from a student deficit position is problematic as often the cause of the deficit situation may be beyond rectifying through direct support of the student. While there have been attempts to connect these issues to a larger context such as gender, racial or financial inequality or high school curriculum an even broader understanding of the teaching and learning environment may offer a different perspective.

In New Zealand, there is a considerable body of educational research that tends to follow the blueprint of the international field. While some research maintains that a student's academic achievement at high school is a predictor of a student's success in STEM bachelors-level study (James, Montelle, \& Williams, 2008) the bulk of the research identifies a multitude of complex reasons for the lack of recruitment and retention in STEM. For example, there have been discussions which investigate the New Zealand high school National Certificate of Educational Achievement (NCEA) assessment system, and the methods by which it has been implemented in some schools (Nash, 2005; Shuruf, Hattie, \& Tumen, 2008; 2010; Vannier, 2012). For example, Shuruf, Hattie and Tumen (2008) identified some associations between student grade point average at NCEA and student performance in tertiary study, but also noted that the curriculum structure at high school encouraged students to adopt a strategy of credit accumulation rather than higher performance in subjects. The result of this is that NCEA grade marks cannot be relied on to accurately predict a student's success in higher education.

In ECS we have had limited success in identifying a relationship between a student's high school grades and their performance in the BE (see Carnegie et al., 2012). The current belief held by ECS staff is that NCEA qualifications do not strongly correlate with capability and performance in mathematics, physics and engineering, reinforcing the idea that student performance at university cannot be reliably predicted from grade performance in high school alone. This view is supported by other STEM research in New Zealand (Vaughan, 2008; Godfrey, 2001, 2009; Cronje \& Coll, 2008; Clark, Dodd, \& Coll, 2008; Coll \& Eames, 2008; Campbell, Künnemeyer, \& Prinsep, 2008; Forret, Eames, Coll, Campbell, Cronjé, Stewart, \& Prinsep, 2007; Eames \& Stewart, 2008; Madjar, McKinley, Deynzer, \& Van Der Merwe, 2010; Smaill, Godfrey, \& Rowe, 2007; Ussher, 2007; Hipkins \& Bolstead, 2005; Hipkins, Bolstad, Baker, Jones, Barker, Bell, Coll, Cooper, Forret, Harlow, Taylor, France, \& Haigh, 2002; Hipkins, Roberts, Bolstad, 
\& Ferral, 2006; Schagen \& Hodgen, 2009) that argues that good high school grades are not the only factor relevant to subsequent student success. Similar to their international counterparts, New Zealand researchers note barriers for student success are linked to issues such as ethnicity, gender, poor academic background, cultural differences, institutional educational culture, students' beliefs, perceptions of the teaching and learning experience. The research above often note the significance of individual teachers on a student's perception, enjoyment and subsequent learning. They also emphasise that student success in tertiary institutions is affected by the quality of the learning environment and the student's experience of the teaching methods used. This connection between the role of the teacher and that of the teacher or lecturer suggest that the learning environment is in part structured by the lecturer. Understanding the experience of the lecturer is vital to understanding the problems occurring in the teaching and learning environment.

A study, undertaken by Massey University in partnership with four high schools, investigated the STEM learning environment at high school and first-year university (Parkinson, Hughes, Gardner, Suddaby, Gilling, \& MacIntyre, 2011). The authors noted that the use of best practice pedagogies, such as active learning, and more relevant contexts for science subject matter that connects to real-world examples would promote greater student engagement within secondary and tertiary institutions, and result in better success. This research primarily identified that the relationship between how teachers and lecturers teach affects how students learn in the classroom. This report briefly touched upon the relationship between teaching and research for lecturers, noting that there was a tension between an institutional requirement and an individual's need to do research over the development of teaching practice. In part, this research reinforces the notion that NCEA and student diagnostic testing cannot provide the entire answer to predicting student success in New Zealand university STEM study.

The studies discussed above are student-centred, focusing on the students themselves or their observable outcomes and behaviours, and while reporting on effects within their context, do not typically examine in detail what might be occurring to create a specific situation outside of the student's immediate perceived experience. By comparison, relatively few studies have looked at the tertiary educational community: its staff and environs, and considered their experiences and the impact this might or does have on the teaching and learning environment outside curricula or teaching practice 
(Beddoes et al., 2013). These situations and processes do not occur in isolation and have received limited attention in STEM research.

One New Zealand study stands out in contrast, however, that of Campbell, Künnemeyer and Prinsep (2008), who highlighted staff perceptions in their study of higher education science and engineering learning communities. The background work for this publication was conducted as part of a larger study by Forret, Eames, Coll, Campbell, Cronjé, Stewart and Prinsep (2007) that focused on learning communities in tertiary education in science and engineering. The larger, 2007 study conducted a literature review and gathered both quantitative and qualitative data from interviews, focus groups and questionnaires with staff at the University of Waikato, Auckland University of Technology, Waikato University and the Christchurch Polytechnic Institute of Technology. Campbell et al. (2008) focused their specific study on interview data from semi-structured one-on-one interviews. To support this, they also observed student and staff behaviour in lecture and laboratory classes. They then conducted both quantitative and qualitative data analysis.

Campbell et al. (2008) identified a complex teaching and learning environment that is frequently beyond the control of students or staff to affect. For example, they noted that staff have conflicting demands on their time and that there is a conflict between the demands and requirements of teaching, and of research. Lecturers believed that incoming students were poorly prepared for higher education and that this only increased the difficulty of teaching for lecturers by impacting on the time they needed to spend on teaching a diverse student body. Lecturers also identified larger class sizes as a factor which made teaching more difficult, as there was a decreased opportunity for direct contact with students at the early levels of university study. Staff also noted that they believed first years needed to be more independent learners, but that the courses were not set up that way within institutions.

Campbell et al. (2008) drew attention to several key dimensions of the way staff perceive students but also noted several areas of concern involving staff reactions to their work environment. For example, the reported inability to spend enough time on teaching due to other conflicting responsibilities underscores a critical gap in the STEM crisis literature, that of the investigation of academic practices. The inability of staff to apply best practice or to influence the composition of their student class sizes or incoming ability also reflects ways in which the learning and teaching environment may be affected by system procedures. 
While Campbell et al. (2008) point to the role lecturers and university organisational processes have in affecting the teaching and learning environment significantly, they did not investigate this aspect beyond stating the observations of the lecturing staff and students. There is very little research that attempts to understand the impact of processes on lecturers and how this influences their processes or operations within a STEM teaching and learning environment. As Umbach and Porter (2002) note, the impact of university on students and their satisfaction has been studied for decades, but the impact that different departments have on student outcomes appears to have been mostly ignored. They go on to state: "In fact, most major theoretical models explaining the effects of college development on students overlook the impact of academic departments" (p. 210). As such, these studies typically place the focus of the study on student experiences of learning without digging into the power structures and systems within which the academic staff who teach them operate.

Outside of the STEM context, Berger (2000) attempted to bridge this divide by examining different types of U.S. universities with differing educational goals and ethnic populations. Berger linked organisational behaviour, which he states are "the actions of organisational agents at a college" (p. 180), to student outcomes through a quantitative analysis of student and college administration survey data to produce a grounded theory analysis of dependent variables. This student-focused study analysed the effects of organisational behaviour at colleges "on both psychological and behavioural outcomes (humanistic values and community service involvement, respectively)" (p. 177). Humanistic values in this instance are a belief in the individual and collective importance of ethical, democratic, political and cultural values. Berger concluded that organisational behaviour differed amongst universities and that when universities operated on a more managerial basis, this difference negatively impacted both student grades and humanistic values. In institutions where organisational behaviour reflects humanistic values in its practices, student performance improves. In summary, Berger claims:

Issues of administration, management, leadership, and other variations of organisational functioning are important means to the ends of educating students. As such, they should be evaluated by how effectively different levels of organisational behaviour promote specific outcomes. (Berger, 2000, p. 195)

For Berger, there is a connection between higher education processes and the introduction of managerial models in universities. This connection is central for this study, as the 
lecturing staff, and the teaching and learning environment is viewed as being part of a larger system of university and government policy in New Zealand. Academic staff are employees within this system and have to work within a particular framework of rules and expectations. The following section discusses this broader educational nexus and its effects.

\subsection{Neoliberalism, Government and Educational Policy}

There is considerable research that focuses predominantly on investigating the governmental and educational policy context in which education takes place. Many of these studies specifically consider historical background, at a broad national or international level, and argue that higher education has been adversely affected by the rise of neoliberalism since the 1980s (Olssen \& Peters, 2005; Barry, Osbourne, \& Rose, 2005; Crocombe, Enright, \& Porter, 1991; Shore, 2010; Connell, 2013; Fitsimmons, 2000; Naidoo \& Jamieson, 2005, Ball, 2001, 2008, 2012, 2015, 2016). Neoliberalism in education refers to Education policy reforms that, since the 1980s in New Zealand, Australia, the UK, and the US "have been underpinned by efforts to establish an education marketplace. This has seen the normalization of a managerial focus on efficiency, effectiveness, and accountability in relation to education and educational institutions" (Youdell, 2004, p. 409). This neoliberal turn in education has seen the re-focusing of educational institutions to incorporate economic goals. Central to the neoliberal educational agenda has been the altering of the educational discourse so that investment in education means future economic growth (Peters, 2009; Carter, 2016; Tobin, 2011; Youdell, 2004; Connell, 2013).

Ball a noted sociologist of education who has examined Foucault and neoliberalism in higher education articulated what he believes neoliberalism in the university represents in his (2015) brief article, Living the Neo-liberal University. He argues that the over the last 25 years funding and accountability requirements (such as reviews, league tables, rankings, expanding recruitment and research impact narratives) coupled with who can now access higher education has created an environment of competition. Ball believes that these changes "are the effects and conduits of contemporary neo - liberalisation. They constitute the big - neo - liberalism, 'out there' in the economy, and the little - neo - liberalism, 'in here' — in our daily lives and in our 
heads" (p. 11). Ball explains that the effect of 'big' and 'little' neoliberalism in higher education dramatically effects academic staff, described as 'we' in the excerpt below: The former increasing renders 'truth' into a commodity — within what we now call the knowledge economy and informational capitalism. The latter is realised in a set of local practices which articulates the mundane rhythms of our email traffic, our form - filling, our peer reviewing, and re modulates the ways in which we relate to one another as neo - liberal subjects, individual, responsible, striving, competitive, enterprising.... Indicators, indexes and measures insinuate themselves both into our sense of what we are and into our practice and decision - making as writers and researchers and teachers.... Increasingly, we make decisions about the value and distribution of our time and effort in relation to the measures and symbolic and real rewards that are generated by us and about us. The pace and pattern of our work are constantly changing in relation to the oscillations of measurement and are further related to a pressured and speeded up need to tell about our research which is enabled by Websites, blogs, tweets, press releases, etc., but which generates, at that same time, a whole other set of measures which we can quote back to funders and paymasters as numbers of hits, re - tweets, followers, likes, downloads, etc. (p.11)

For Ball, neoliberalism in higher education has effectively changed what it means to be an academic. Professional values have been displaced by commercial values, with academics no longer being a community of scholars. Ball sees the complex competitive nature of the neoliberal university as a "particular configuration of the relationship between truth and power and the self (and thus ethics), a set of contact points 'between reflexivity and government' "(p.11). This is, perhaps especially, apparent in STEM education where the connection with a business agenda is synonymous with a qualification that directly provides graduates for a hungry global technology workforce.

The need for increased graduate numbers to obtain an economic advantage in a globally competitive economy is a 'standard' STEM discourse (Henderson, Beach, \& Finkelstein, 2011). In recent years this has become known as the 'STEM crisis' which, broadly speaking, refers to the belief that there is a worldwide shortage of people trained in the STEM fields - so much so, that it is widely accepted that unless this crisis is 
addressed, many countries will face economic and security challenges (National Research Council, 2012; National Academy of Sciences, National Academy of Engineering, and Institute of Medicine, 2007; President's Council of Advisors on Science and Technology, 2012; U.S. Department of Commerce, Economics and Statistics Administration, 2011; U.S. Department of Education, 2008; Thomasian, 2011; Harrison, 2012; House Of Lords (HL) Paper 37, 2012; Roberts' Review, 2002; Harold, 2007; HM Treasury \& BIS, 2011; Bosworth, Lyonette, Wilson, Bayliss, \& Fathers., 2013; The Australian Industry Group, 2013; Carnevale, Smith, \& Melton, 2011; Building Engineering \& Science Talent (BEST) 2004, King, 2008; Unesco, 2010; House of Commons, 2009; Ministry of Education, 2009; IPENZ, 2009). These reports focus on the need to 'solve' low recruitment and graduate numbers for economic benefit and are evidence of the neoliberalisation of education in the STEM literature.

In New Zealand, there is a consistent and clear message from the Government that there is a shortage of engineers in the workforce and that the number of engineers must increase to meet current and future economic demands (Ministry of Education, 2009). The New Zealand Government's call for more engineers is underpinned by reports such as the Department of Labour's (DOL) Engineers in the New Zealand Labour Market 2008, and the recommendations of the New Zealand Government Treasury Education Key to Economic Growth and Equity 2013 - which is based on the OECD Economic Surveys: New Zealand 2013. The most influential report was the Tertiary Education Commission's (TEC) National Engineering Education Plan 2010 (NEEP) authored by the Institute of Professional Engineers New Zealand (IPENZ).

Government initiatives to increase the number of graduate engineers have taken the form of monetary support for tertiary engineering education providers. The Government have expressed this in the New Zealand Government Budget 2012 and 2013, and in directives from the TEC to tertiary providers (Ministry of Education, 2013; TEC Educational Performance Indicators, 2013; TEC General Supplementary Plan Guidance for 2013 Plans for all TEOs, 2012). These initiatives are a clear indication of the neoliberal educational context in New Zealand. Importantly these indicators included not only incentives but also the potential for future penalties to tertiary providers if performance, regarding recruitment and retention through to degree completion, is not satisfactorily met.

It can be seen that the state is exerting more control over education by focussing its support in key economic areas of interest, like engineering. The New Zealand 
Government has linked public tertiary institutions to economic goals by setting financial targets and penalties on enrolment numbers, student educational outcomes and academic research (Ministry of Education, 2013; TEC Educational Performance Indicators, 2013). One can only surmise that there would be a follow-on impact to the core educational process of institutions and staff as they are forced to adapt to these demands. STEM educators in ECS exist within this context. There is a distinct lack of STEM educational research that focuses on organisational systems and processes such as neoliberalisation of education and their impact on academics (That said, there are a few examples, see: Slaton, 2012; Nieusma \& Riley, 2010).

Shore (2010), like Ball above, notes that universities have been subjected to funding cuts as governments have linked university research to commercial opportunities in the 'global knowledge economy'. Shore also sees these changes as shifting the role of the university and its staff from places of critical enquiry and autonomous learning to transnational businesses enforced by government policy that has "introduced new funding mechanisms and auditing systems designed to render universities more economical, accountable, flexible and more responsive both to industry and to government itself" (p. 15). According to Shore, these changes have dramatically reshaped the way universities internally operate to meet these new forms of accountability. The consequence of this is that, rather than addressing the broader issue of what factors may be creating ineffective educational outcomes for all parties, power operates across the institutions assigning accountability, penalties and competition (Peters \& Fitzsimons, 2001). As this thesis will discuss in later chapters, the effect of this use of power is to reduce an emphasis on educational needs by institutions who instead focus on targets rather than pedagogies. Common examples of targets, self-imposed or applied by Government, include enrolment targets, funding requirements and degree offerings, and various assessments of research performance.

\subsection{Performance-Based Research}

A major area of critique of neoliberalism and government educational policy in New Zealand focuses on the effects of New Zealand's Performance-Based Research Fund (PBRF) on academic staff and departments (Boston, Mischewski, \& Smyth, 2005; Roberts, 2007; Hicks, 2012; Hall, Morris, Matthews, \& Sawicka, 2003; Smart, 2009; 
Hodder \& Hodder, 2010; Waitere, Wright, Tremaine, Brown, \& Pausé, 2011). The PBRF is the New Zealand Government investment mechanism for raising the quality of research in degree-granting tertiary education organisations (TEOs) and is one of the major mechanisms by which the Government provides funding and accountability to tertiary organisations.

The UK has a similar system to PBRF called the Research Assessment Exercise (RAE), and Australia has the Excellence in Research for Australia (ERA). The higher-education performance-based research assessment exercises of the UK, Australia and Hong Kong were models for that of New Zealand (Ministry of Education, 2015). There is a major difference between these funding assessments compared with that of New Zealand. For example, both Hong Kong and the Australian ERA assesses the research discipline, while UK's RAE assesses the department. In contrast, the New Zealand framework assesses both university metrics and, importantly, the individual researcher. This is a key difference as every academic in the New Zealand university system is expected to be research active and contribute, rather than some individuals being primarily teaching focused. Smart and Engler (2013) explain that the New Zealand Government's aims in introducing the PBRF were to:

- increase the average quality of research

- ensure that research continues to support degree and postgraduate teaching

- ensure that funding is available for postgraduate students and new researchers

- improve the quality of public information on research outputs

- prevent undue concentration of funding that would undermine research support for all degrees or prevent access to the system by new researchers

- underpin the research strength in the tertiary education sector. $\$ 2.7$ billion funding was allocated between 2004 and 2016 based on TEOs being evaluated on three indicators that together assess both quantity and quality of research. The first indicator, Quality Evaluation was an assessment of the research quality of staff and was based predominantly on peer review of staff members research portfolios and outputs, such as journal papers or conference submissions, and accounted for sixty percent 
of the fund. The second indicator was Research Degree Completions and related to the number of postgraduate research degree completions and comprised twenty-five percent of the fund. The final indicator was based on External Research Income and accounted for fifteen percent of the fund. (Smart \& Engler, 2013, p. 2)

Research into the effect of PBRF has predominantly considered the effect on staff by focusing on the impact of PBRF on the quality of research and the real or perceived threat of PBRF to academic freedom (Savage, 2000; Olssen 2002; Butler \& Mulgan 2013; Duncan, 2007; Ashcroft, 2007). Roberts (2007) exemplifies this research and its typical conclusions, noting the changing role of academic staff in institutions as a result of PBRF:

On the one hand, neoliberal policy makers have advanced a strongly individualist ethic and the PBRF process has reinforced this. In a neoliberal environment academics are encouraged to pit themselves against their colleagues, to carve out a distinctive niche for themselves in the tertiary education market, and to sell themselves effectively in seeking better salaries and conditions of work... Taking risks - for example, in pursuing lines of research that may not lead to the production of "quality assured outputs" - could become not merely inadvisable but impossible for those who wish to retain their jobs. The form of individualism fostered by neoliberalism and the PBRF thus rules out, or discourages, other forms of individualism.... (Roberts, 2007 p. 360)

The effect of PBRF and similar systems have led to investigations that question the very connection between research and teaching. This debate is ongoing worldwide with proponents who say research and teaching are connected, and those who say it is not, since the seminal work of Hattie and Marsh (1996) whose meta-analysís of 58 studies demonstrated that the relationship was zero (see also Lucas, Healey, Jenkins, \& Short, 2008).

Research in this field has coined the phrase 'research-teaching nexus' which has seen considerable uptake in the UK and Australia, whose tertiary sectors are akin to that of New Zealand (Brew \& Boud, 1995; Ramsden \& Moses, 1992; Jenkins, Healey \& Zetter, 2007; J.M. Consulting, 2000; Henkel, 2004). The literature on the researchteaching nexus, including that cited above, often asks academics questions similar to those posed by Durning and Jenkins (2005, pp. 407-408): 
- What do academics conceive as the relationships between teaching and research?

- Is the 'link' between teaching and research to be valued?

- Do disciplines affect the nature of teaching/research relations?

- What are the issues staff experience within their departments that support or threaten them in establishing effective links between these 'two' activities?

- What are the implications of these findings for future research, practice and policy?

Durning \& Jenkins (2005) interviewed academic staff at four tertiary institutions in the UK and acknowledged that effective teaching/research links were potentially important for students in developing complex knowledge of high order academic and professional skills. They were, however, unable to ascertain the "extent to which all staff need to be involved in high-level research, or whether 'scholarship' is adequate to effectively underpin student learning in these disciplines" (p. 407). They noted that there were distinctive features of government policy that impacted on the separation of teaching from research. Importantly though, the study revealed the significance of department organisation and culture and stressed how this policy works to separate the connection between teaching and research by emphasising research funding.

The 2008 report by Lucas, Healey, Jenkins and Short for the Higher Education Academy in the UK also presented interviews of academics at three universities. They explored the experiences and perceptions of 'research' and 'teaching' within three separate institutional/departmental and disciplinary cultures. Senior managers at the institutions claimed that there were good connections between research and teaching, yet they found few explicit policies that linked the two. Significantly this study reiterated a common theme within the broader literature - that there are differences between institutions regarding policy and priorities with major differences in the specific culture of each department studied. Additionally, the institutional context was extremely relevant to the way departments assigned priority to activities. For the authors, course teams and departmental cultures needed to have common goals and aims to ensure greater cohesion and collaborative effort within departments that linked research to teaching practice. They noted that departments that were cohesive and had a strong collaborative and academic culture and a positive connection with departmental and institutional goals exhibited a 
beneficial research and teaching relationship. The report makes a convincing argument that:

if we want to understand academics' experiences and perceptions of research and teaching and the links between them, we need to view them from the perspective of institutional and departmental contexts, policies and cultures... The role of institutional policies and departmental organisational cultures is key to shaping that experience. (Lucas et al., 2008, p. 56)

In the New Zealand context, Robertson's (2007) work stands out as an example of a study that looked specifically at the experience of academics in one institution, in relation to the concept of the research and teaching nexus. Robertson interviewed 14 men and 10 women academic staff and identified a significant variation in the academics' experience. The study revealed that the staff had varying interpretations of the connection between research and teaching. This depended on the staff member's particular understanding of institutional policies and their epistemological and ontological beliefs. Robertson noted a dislocation between institutional rhetoric promoting teaching, and local disciplinary practices which serve to meet institutional metrics. The result of this disconnection was an institution which ultimately privileges a uniform or common behaviour across its academic staff. Robertson considers this common behaviour to be negative as it:

fuels concern regarding the extent to which the current emphasis on performativity in research and in teaching may be constructing each as discrete, competing and risk averse activities - thereby undermining for many the very notion of what it is 'to be' an academic. (pp. 553-554)

Robertson's work highlights the need to investigate the connections between research and teaching, the value of diversity and academic community, and their links with institutional power structures in the form of policy and reward structures. It is clear that there is a great opportunity to focus a research lens upon the higher education teaching and learning environment and, in particular, upon academic staff, to develop an understanding of their complex role. 


\subsection{Summary}

In summary, research on STEM recruitment and retention has tended to focus on students. While some researchers have focused on the political or institutional pressures such as the effect of research on teaching, there has been little research to date that connects the educational practices in the STEM teaching and learning environment to the surrounding educational context. The importance of this STEM teaching and learning context is a missing gap in the STEM research. As is, investigation into the way the dominant neoliberal educational policy framework and institutional, operational activities within a university impact on the operation of an engineering programme. It is also significant that there has been no engineering research that has questioned the operational impact of these demands on academics or explored how these academics experience this operation of power. The aim of this thesis, then, is a unique investigation of a specific educational context in a particular New Zealand university in a way that has received little attention in the student centred STEM educational literature. This work is uniquely placed to extend the traditional organisational analysis by revealing the operation of power within a broader teaching and learning environment and its impact on academics both as subjects of that power and of instigators of power in their classrooms.

Therefore, this thesis asks the following question: how is power experienced and manifested by lecturers in the Bachelor of Engineering with Honours (BE) first-year teaching and learning environment at Victoria University of Wellington (VUW), New Zealand. In particular, the following chapter will elaborate upon my reason for adopting this focus, while simultaneously illustrating the epistemological and analytical framework that will be used to address this research question. 


\section{ChAPTER Two: Framing THIS STUdY}

In this chapter, I discuss Foucault's theoretical contribution and then elaborate upon the broader field of DA, with a particular focus on the types and use of Foucauldian-inspired discourse analysis (FDA). I further describe and discuss the uses of FDA in higher education studies, and their relationship to the concept and portrayal of power. This chapter aims to locate my research within this body of knowledge. Due to the relationship between my research focus and methodology this chapter differs from a more traditional methodological chapter or standard literature review chapter. In FDA, and for that matter, all DA the research focus and methodology are intertwined and as such this chapter is part methodology and part justification for my research question.

\subsection{An Overview of Foucault's Theoretical Contributions}

The late post-structuralist Michel Foucault (1926-1984) is regarded as one of the foremost French theorists and intellectuals. Foucault's work has been important in highlighting and understanding the connections between power and social life (Gutting, 2005). Foucault's work has been extremely influential in the humanities and social sciences. His work has been, for over forty years, considered fundamental for any theorist of power relations. Foucault's contribution as a philosophical theorist and historian has been to encourage the questioning of the operation and role of power within the social construction of knowledge, subjectivity, and social norms through an examination of discourse (Hicks, 2004; O’Farrell, 2013; Stokes, 2002; Schrift, 2006).

\section{The Early Years}

Foucault's association with discourse originated in his earlier works, first published in French, Madness and Civilization (1961), The Birth of the Clinic (1963), The Order of Things (1966), The Archaeology of Knowledge (1969) and later translated in English. This period of Foucault's work is dominated by what Foucault calls his Archaeology method, explained at length in The Archaeology of Knowledge. Foucault himself was opposed to a prescribed method for his work because single methods produce truths that are of a similar nature (Foucault, 1972). Archaeology was a label he used to describe the process of analysis that examines and compares discursive formations over 
time (Foucault, 1972). Evidence of the application of these ideas can be seen in The Order of Things, History of Madness and The Birth of the Clinic. It is clear from Foucault's much-cited section on discourse within The Archaeology of Knowledge that discourse is a term used to describe language, codes, representations of, or particular modes of, belief or behaviour that exhibit meaning within specific historical situations that removes the role of the individual subject as the primary creator of discourse (Foucault, 1972).

Foucault pioneered the investigation of power through the examination of discourse allowing for texts (interviews, documents and other sources of meaning) to be separated from the opinions of specific individuals - seeing these texts as creations of discourse - the places where meanings reveal power and knowledge in operation. The particular standpoint or opinion of the individual is not seen as the view of the individual as such but as a reflection of the subject's position within the discourse. An understanding of the operation of power, and how knowledge works can be gained from examining this meaning in relation to the subject's position (Foucault, 1983).

Foucault's inaugural Collège de France lecture The Order of Discourse (1970) marked a shift, partly in response to criticism that archaeology as a form of analysis was limited to comparing discursive formations throughout history, but which could not explain the reason for the change from one mode of thinking to another. This new approach he called genealogy: a term he used to describe a change to the archaeological approach allowing for examination of the causes of these shifts in thinking from the perspective that they were not inevitable consequences but rather were reactions to multiple contingent forces (Foucault, 1975). Thus Foucault seeks to put forward alternative conceptions of knowledge through critique to encourage new ways of thinking about events to consider how, and why, things are the way they are in a contemporary situation (Foucault, 1983).

\section{Discipline and Punish: The Birth of the Prison}

Foucault's (1975) work Discipline and Punish: The Birth of the Prison is a good example of his use of genealogy. Foucault examined the historical discourse around how the concept of criminal punishment and discipline in Western civilisation shifted over time from being primarily the torture of the body to being now the rehabilitation of a person's mind - their behaviours and attitudes. What was considered true in a particular context changed over time. This particular context where discourse can be witnessed operating can be expressed as a discursive field. A discursive field is where a particular set of actions and meanings combine to produce an accepted truth of power and 
knowledge in society — for example, the criminal justice system. A discursive field describes a combination of processes shaped by institutions and disciplines that interrelate as overlapping discourses that give meaning to society. Importantly, these can change over time, and also be intersected by other discursive fields (Rouse, 2005). For example, in Foucault's Discipline and Punish the criminal justice system was influenced by the discipline of medicine and requiring convicts to be treated differently, leading to a change in understanding of correct behaviour. Separate discursive fields intersected to produce a new operation of power.

This intersection is an example of how genealogy marks a major shift in Foucault's conceptual framework. The change in understanding within the criminal justice system takes place as one form of discourse evolves to exclude another type of discourse. In this case, a once-dominant discourse of physical punishment of the body is replaced by a new discourse that shifts punishment over time, to rehabilitation. Thus genealogy looks at the relationships between discourse and resistance, examining the change as a site of production. It is here that change, seen as resistance to, and dominance of, meaning in society cannot be separated from being connected to the operation of power, as such, is also connected to politics.

Thus, it is with Discipline and Punish, that Foucault articulates this conception of power as an alternative to the Marxist concept of ideology (Olssen, 2014). Unlike Marxism, which conceived of social control through a lens of class struggle where one class dominates another, for Foucault power operated at multiple levels of society and as a disciplinary and productive force:

The individual is no doubt the fictitious atom of an 'ideological' representation of society; but he is also a reality fabricated by this specific technology of power that I have called 'discipline'. We must cease once and for all to describe the effects of power in negative terms: it 'excludes', it 'represses', it 'censors', it 'abstracts', it 'masks', it 'conceals'. In fact, power produces; it produces reality; it produces domains of objects and rituals of truth. The individual and the knowledge that may be gained of him belong to this production. (Foucault, 1975, p.194)

In Discipline and Punish Foucault suggests that the modern form of prison was adopted by society as a means of disciplining behaviour. Foucault explains this through discussion of Jeremy Bentham's model for a prison: the Panopticon. Through observation, judgement and examination inmates in the penal system are created as subjects and 
categorised as types of criminal. Significantly this occurred not as a result of a deliberate or planned process, nor as a result of sovereign power, but rather through the spread of new scientific ideas from seemingly separate institutional systems such as medicine criminal justice. It is here that Foucault illustrates how modern society has enacted its disciplinary process over individuals and society (comprised of populations of individuals that are constantly changing in response to the operation of power) through three controlling practices: hierarchical observation, normalising judgment, and examination. Thus people become the focus of disciplinary power by government through a set of practices that are historically contingent, as in Foucault's examples of the criminal justice and medical systems.

The History of Sexuality, Volume 1

Foucault's (1978) continuation of his genealogical project, The History of Sexuality, Volume 1 included a major reconceptualisation of his understanding of power that has impacted on researchers across a wide range of fields and is perhaps his most important contribution (Gutting, 2005). Foucault explained that his objective in The History of Sexuality. Vol. 1 was to "analyze a certain form of knowledge regarding sex, not in terms of repression or law, but in terms of power" (Foucault, 1978, p.92). In doing so, Foucault examined how power over a person's body and the processes by which they were disciplined and controlled revealed broader operations of power within society and the state. Foucault's interpretation of power up until the publication of The History of Sexuality, Volume 1 was to see it in operation in a given situation, a specific place or institution and visible within discourses that reveal its strategic process in the creation of a subject. In The History of Sexuality, Volume 1 Foucault expanded and explained his concept of power to include the subject in the operation of power-relations. People are active in this process through practices of the self in accepting or resisting normalising processes of subjectification. That said Foucault makes it explicit that "this does not mean that it results from the choice or decision of an individual subject" (p.95). Rather powerrelations are both intentional and nonsubjective and come into being through a combination of complex strategies and tactics across multiple sites of operation throughout society that come together and form comprehensive systems. Foucault (1978) describes power as a constantly moving and changing force which as a result of its emergence creates inequality in relation to its specific situation. Power as such comes into being in social situations from multiple points which are interconnected which gives it a 
sense of omnipresence but it is not, and neither is it the result of a single source. Rather as Foucault (1978) states:

Power is everywhere; not because it embraces everything, but because it comes from everywhere. And "Power," insofar as it is permanent, repetitious, inert, and self-reproducing, is simply the over-all effect that emerges from all these mobilities, the concatenation that rests on each of them and seeks in turn to arrest their movement. One needs to be nominalistic, no doubt: power is not an institution, and not a structure; neither is it a certain strength we are endowed with; it is the name that one attributes to a complex strategical situation in a particular society. (p.93)

With this operation of power in mind Foucault is making it clear that the production of power in society is not a negative or positive force but rather a productive force, producing meaning and in doing so, it also represents knowledge. Power/knowledge (Foucault's combined term for this concept) sees the operation of power being used through the construction of knowledge, which itself relies on an acceptance of truth often encompassed by scientific thought. Thus power/knowledge operates in all interactions between people, and in the institutions and systems, we create.

Integral to Foucault's conception of the operation of power through genealogy is the act of resistance (Foucault, 1978). Resistance is central to understanding the operation of power-relations (where power/knowledge processes take place) and is itself an operation of power, being present at any point where the operation power is taking place. The act of resistance can also present itself as a target or adversary of the operation of power or even as a form of support to the operation of power-relations. As such, there is no escape from the operation of power/knowledge or resistance. For Foucault one way to see the effects of power-relations was to look at the discourses (contingent social systems producing power/knowledge):

Indeed, it is in discourse that power and knowledge are joined together. And for this very reason, we must conceive discourse as a series of discontinuous segments whose tactical function is neither uniform nor stable.... It is this distribution that we must reconstruct, with the things said and those concealed, the enunciations required and those forbidden, that it comprises; with the variants and different effects-according to who is speaking, his position of power, the institutional context in which he happens to be situated-that it implies; and with the shifts and reutilizations 
of identical formulas for contrary objectives that it also includes. Discourses are not once and for all subservient to power or raised up against it, any more than silences are. We must make allowance for the complex and unstable process whereby discourse can be both an instrument and an effect of power, but also a hindrance, a stumbling-block, a point of resistance and a starting point for an opposing strategy. Discourse transmits and produces power; it reinforces it, but also undermines and exposes it, renders it fragile and makes it possible to thwart it. (Foucault, 1978, pp. 99-101)

Thus in The History of Sexuality, Vol. 1 Foucault sets out a clear agenda for examining the operation of power in discourse, not from a top or bottom direction but from multiple directions. This included the study of the individual as a site of the operation of power, and also bodies of individuals as populations and institutions and the state. The method to do this still largely followed Foucault's earlier articulation of archaeology and genealogy, but the scope had shifted through introduction of biopower.

\section{The Later Years}

In The History of Sexuality, Vol. 1 (1978) coupled with Foucault's Collège de France courses, Society Must Be Defended 1975-76 (2003), Security, Territory, Population 1977-78 (2007) and The Birth of Biopolitics 1978-79 (2008) Foucault develops this idea of biopower operating at different levels by connecting the notion of biopolitics with that of governmentality (a combination of government and rationality) and neoliberalism (Gutting, 2005). Foucault conceived of biopower as the transition of sovereign power, during the seventeenth century in Europe over the life and death of subjects, to a modern form of power that "exerts a positive influence on life, that endeavors to administer, optimize, and multiply it, subjecting it to precise controls and comprehensive regulations" (Foucault 1978, p.137). Thus, biopower as the operation of power over life can be seen as the management or administration of people's lives.

This control over life, shared between the anatomic and biological effectively revealed the dispersion of power/knowledge networks across a society operating at all levels, albeit not as a directive and sustained process but rather as an outcome of social changes in discrete areas combining into a seemingly cohesive process. This normalising of society was ultimately based on developing technologies over life. Biopower was the control of individuals or bodies and how this occurred in sites such as hospitals, workplaces, prisons, and educational institutions through the practices of experts like 
criminologists, psychologists, psychiatrists, and educators. This process was about maximising the human body as an efficient system. Regulatory power (biopolitics of the population) was a form of control of a population as a body through economy, migration, public health and was typically conceived of through scientific advances by economists or social scientists. The multiple points of power in these overlapping notions are connected but importantly can also act independently producing both norms and resistance to these norms at various levels of society.

According to Foucault (1978) the control over the population through biopower was enacted throughout society at multiple points rather than from a top down or bottom up manner and has an important connection to the development of capitalism which: "would not, have been possible without the controlled insertion of bodies into the machinery of production and the adjustment of the phenomena of population to economic processes" (Foucault, 1978, p.140). This is an example of dominant power-relations acting to normalise society with certain shared behaviours across individuals, families and institutions. Foucault develops this idea further in his lectures on Security, Territory, Population 1977-78 (Foucault, 2007) and The Birth of Biopolitics 1978-79 (Foucault, 2008; Gutting, 2005). It was here that he turned his attention to addressing how the modern capitalist state become the normalised replacement for the earlier sovereign rule. Biopower was a central concept in Foucault's explanation of this process, whereby over time, throughout multiple sites (institutions through to families and individuals), states had been able to shape the lives of people through the interconnected ideas of security and economy.

In Foucault's, 1978 lecture, titled Governmentality he further explained his views on how modern capitalist state developed its form of government and how this differed from that of Machiavelli's (1513) The Prince by describing how the modern state has through connecting the economy to individuals enabled a plurality of forms of government to operate (Foucault, 1991). Foucault explains that you must be able to govern yourself (your goods and patrimony), if you are to govern others such as the state and if the state is well-run individuals will govern themselves and their families well. This process takes place through enactment of pastoral care by the state that orders people's lives (through biopower) by promoting key ideas of security and economics as necessary for peoples' happiness and wellbeing.

The state and its multiple institutions works alongside individuals in multiple sites at all levels of society to discipline and manage social practice and belief through the act 
of constant surveillance. This is akin to the form of surveillance described in Discipline and Punish (1975) which uses hierarchical observation, normalizing judgment, and examination to discipline social behaviour. However, this form of power-relations seeks to control the conduct of others through productive force. For Foucault, the law does not disappear, but shifts to be more of a norm that is "incorporated into a continuum of apparatuses (medical, administrative, and so on) whose functions are for the most part regulatory. A normalizing society is the historical outcome of a technology of power centered on life" (Foucault, 1978, p.144). The state becomes the economy, and this is comprised of individuals that form populations, regulated and self-regulating across multiple levels. Individuals are implicitly connected actors to the state in this process, and without this, the state could not function ((Foucault, 1991).

According to Foucault, the process of governing conduct essential for the operation of power takes place through having citizens take on board shared ideas and practices and replicating them throughout society within a discourse embedded in economic interests. Central to this concept is the shift from the idea of a liberal docile subject created through sovereign control and government to a subject who has rights to a wider choice of actions because power is a strategic and mobile but at the same time controlled through concepts of freedom or liberty. Freedom or liberty in this sense is constituted by economic subjects capable of autonomous behaviour: "a spontaneous bond between the individual and the others which is not constituted and willed by the state" (Foucault, 2007, p. 352). The conception of power-relations working throughout multiple levels of regulatory processes within the state, but not reliant on it alone for the action of power/knowledge institutions and individuals as a normalising function leads to the notion of government as governmentality.

Importantly, government is not the 'Government', and power can no longer be seen as purely a manifestation of government through sovereignty. Government shifts to governmentality where the state (such as judicial, or educational institutions) are no longer the centre point for the operation of power. Society becomes a set of processes to be managed in an economic sense, with economic wellbeing and the apparatus of security acting to normalise society towards acceptance of the principle of governmentality.

Governmentality and its integral notion of biopower, then, is part of the continued development of Foucault's form of analysis (Gutting, 2005). It represents a further step from Foucault's earlier archaeological and genealogical works which examined how through discourse power/knowledge networks established the subject, to incorporate the 
subject's role in this process. This is a significant factor, pertaining to how the individual is both constructed by power and involved in the process of construction as a subject. Governmentality is where the strategies of individuals intersect with strategies of others, including institutions and state. As such it takes the analysis beyond a (micro) setting, such as a family or classroom to both the institutional (meso) and state (macro) levels of society. The use of 'micro', 'meso' and 'macro' here refer to the level of the social structure under analysis and, as such, differs from the term "micro-analysis" in a linguistic sense which looks at language structure (syntax, rhetorical devices or metaphor).

One of the most interesting things to come from Foucault's work on governmentality was that in his Collège de France lectures on The Birth of Biopolitics 1978-79 (Foucault, 2008) attention to the way in which society and the state shifted from jurisdiction as a means of rule to rule through rational economic regulation of life (Gutting, 2005). Foucault compared the operation of governmentality and neoliberalism in German post War liberalism and the liberalism of the Chicago School (Foucault, 20018). In doing so, he argued that what was taking place in the modern state was the development of neoliberalism which enabled the state through the merging of economic forces to individuals across all areas of the population (the operation of governmentality and biopower). The result of this shift to neoliberalism enhanced the state's connection with social processes rather than reducing its role. The marketplace becomes the behavioural 'truth' model for the interconnection between the rationality of government and individual behaviour. In this sense, Foucault again questions the notion of individual free will and the operation of power/knowledge by suggesting that people become subject to exercising their freedom in relation to the normalising process of a dispersed neoliberal economic reality. In effect, people choose their actions in relation to notions of cost versus benefit, in a social world ordered by concepts of competition for wellbeing through economic security. Significantly, this conception of governmentality also offers a site to examine resistance to economic forms of control and normalisation. Foucault's notions of governmentality and biopower do not supersede his archaeology and genealogy as a method of analysis, but rather offers the researcher additional ways to conceive of society and the power-relations within it (O'Farrell, 2005; McIlvenny, Klausen \& Lindegaard, 2016) .

\section{Summary}

Foucault's work represents a broad multi-decade process of examining the operation of power in shaping meaning within society. His contribution to the humanities 
and social sciences was an alternative way to look at conceptions of power/knowledge, as the establishment of normalisation of behaviour as a truth-making process. Revealing the operation of power at work in society is revealing accepted truths (Foucault, 1980). In this sense, truth must not be seen as absolute truth but rather a revelation about the role that 'false' or 'true' plays in revealing moving power structures, economic, political and social.

Foucault shifted the focus of truth from the traditionally dominant Enlightenment conception of Immanuel Kant's Enlightenment-oriented threefold question: "What can I know?", "What should I will?", in relation to exercising my will to perform an action, good or bad, and "What may I reasonably hope for?" to "How are we constituted as subjects of our own knowledge?", "How are we constituted as subjects who exercise or submit to power relations?", and "How are we constituted as subjects of our own actions?" (Norris, 1994). In doing so, Foucault encouraged a historical approach to understanding that does not place the individual, and their understanding of truth or reality, at the centre of knowledge claims. For Foucault, these (and all) claims are historically situated and contingent truth claims (Foucault, 1972; Norris, 1994; d'Entrèves, 2000).

As discourse is where meaning and truth-making practices are enacted, discourse then represents the very thing that is being fought over. Foucault makes the significant connection that discourses are not solely ways of speaking or in written texts, but are also connected to multiple sites (individuals, families, workplaces, institutions, and the state) of the creation of meaning and resistance (Foucault, 1973). In doing so, Foucault was not interested in the functional aspects of speech, that is, what it is saying and why, but on how language conveyed power-relations, constructing the rules and meanings in social settings and how this had changed over time (Foucault, 1991).

Despite Foucault's early death in (1984) his theories of power and his focus on discourse analysis have been extremely influential across a multitude of disciplines. Researchers using Foucault have a wide range of places to situate themselves within his extensive corpus of work. And unlike Foucault's work which can be seen as an evolution of ideas, his work has become more of a theoretical toolbox for academics to choose from. One area his work has been extremely influential is in the field of discourse analysis (DA). The following section looks at the broad field of contemporary DA, and discusses types of Foucauldian-inspired discourse analysis (FDA). 


\subsection{Discourse Analysis}

Before discussing the field of Discourse Analysis (DA) it is worth having a brief discussion on what discourse and DA are. Tenorio (2011) identifies at least six interpretations of "discourse":

- discourse-1 is the highest unit of linguistic description; phonemes, morphemes, words, phrases, clauses, sentences and texts are below;

- discourse-2 is a sample of language usage, generally written to be spoken, that is, a speech;

- discourse-3 refers to the communication expected in one situation context, alongside one field and register, such as the discourse of law or medicine;

- discourse-4 is human interaction through any means, verbal and nonverbal;

- discourse-5 is spoken interaction only;

○ discourse-6 stands for the whole communicative event. (pp.184-185)

Intrinsic to all DA approaches is an understanding that language-in-use represents strategies that produce social and cultural processes, values and norms, and thus all DA examines the operation of power in the construction of meaning (Smith \& Bell, 2007). In keeping with this goal of uncovering the operation of meaning within language-in-use DA as defined in this section is exclusively qualitative rather than quantitative (Fairclough, 1992). Text is often used as a starting point of examination and is seen as a representation of features of the groups and situations being examined (Titscher, Meyer, Wodak and Vetter, 2000).

DA is both method and methodology, combining an interpretive analysis of how society operates (Parker \& Burman, 1993). While a strict definition of discourse is not universally agreed upon in DA the description used by Fairclough, Mulderrig and Wodak (2011), gives a good indication. For these authors, discourse is more than a category for representing an aspect of social life it is a social practice with a

dialectical relationship between a particular discursive event and all the diverse elements of the situation(s), institutions(s), and social structure(s) which frame it. A dialectical relationship is a two-way relationship: the discursive event is shaped by situations, institutions and social structures, but it also shapes them. To put it a different way, discourse is 
socially constitutive as well as socially shaped: it constitutes situations, objects of knowledge, and the social identities of and relationships between people and groups of people. It is constitutive both in the sense that it helps to sustain and reproduce the social status quo, and in the sense that it contributes to transforming it. Since discourse is so socially influential, it gives rise to important issues of power. (Fairclough, Mulderrig \& Wodak, 2011, pp.357-358)

The influence of Foucault's connection to the operation of power by examining discourse, discussed previously, is quite clear in Fairclough, Mulderrig and Wodak's interpretation.

Since Foucault's death, DA has grown to be a field of research which crosses multiple disciplinary boundaries in the social sciences and humanities and, significantly, has attracted multiple interpretations and methodological approaches. For example, Van Dijk (1997) lists the following approaches to discourse analysis: Ethnography, Structuralism and Semiotics, Discourse Grammar, Sociolinguistics and Pragmatics, Ethnomethodology, Cognitive Psychology, Social Psychology and Discursive Psychology, and Communication Studies (see also Titscher, Meyer, Wodak \& Vetter, 2000).

Despite the varieties of approach, and focus, discourse analysts (like Foucault) generally consider that discourse operates at all levels of society: micro (e.g. individual or small group setting), meso (e.g connected groups or institutional settings) and macro (e.g. broader society-wide, national or global settings) - so it is perhaps appropriate that it is investigated at multiple levels. Comparing five DA approaches Stubbe et al (2003) noted that, while there were some differences in theoretical orientation and analytic approach, four of the five shared an attempt to understand the "interaction between language and social structures, but draw on the situational context and broader sociocultural factors to inform the analysis more or less explicitly, and to different degrees" (p.376). Conversation analysis differed in that it restricts its scope of analysis to only the participants in the conversation and their words and does not look for connections to a broader social environment represented through other forms of text., Conversation Analysis as mentioned above tends to focus on only one level of textual analysis - that of the participant's text.

Stubbe et al. (2003) also noted that "conversational analysis, interactional sociolinguistics and politeness theory all, at least in part, take a 'bottom-up' approach which is grounded in a turn-by-turn analysis of the interaction from the perspective of 
each participant in turn" (p.378) whereas CDA and DP allowed for more connection to context beyond the immediate text. For example, CDA may look across many social levels of discourse connecting peoples spoken or written discourse showing the connections between micro and macro analysis of social phenomena.

These levels of discourse analysis are not just split between the immediate and the related text, but also differ in the aspect of the discourse being examined. For example, DP uses discourse analysis to examine how discursive patterns in language and communication from a linguistic form reveals social psychological issues and how these in turn shape people's beliefs and social conduct. It is commonly used to examine concepts of identity, memory, belonging, discrimination and often looks to broaden these findings out to include dimensions of investigation in interpersonal and group relationships (Potter \& Hepburn, 2007).

While there is attention given to the role of power within all of these areas of DA investigation, DA is often not contextualised beyond the micro-social setting to include a connection to the meso or macro level of power-relations (Potter \& Hepburn, 2007). This is in part, because there are central differences in the various forms and epistemeologies of DA which centre around the goal of the research question, method of analysis and the scope of the discourse level or context they wish to consider for analysis (e.g. social policy across a whole country or social practice in a specific classroom, or a combination of contexts). For example, DA in linguistic studies (often termed sociolinguistics) according to Fairclough focuses on phonology, grammar, vocabulary and semantics but can also look at the broader structure and cohesion of texts (Fairclough, 1992). The theory generated by linguistic analysis is often only applicable to the specific site or level of analysis undertaken. Gee (2004) summarises the differences of focus in discourse analysis, describing two fields of enquiry: discourse analysis with a capital ' $D$ ' (analysis of text, conversation, events, actions and places that have meanings for people in sociohistorical contexts) and discourse analysis with a small case 'd' (analysis of language-inuse in a local interaction within a context). However, despite differences in some of the approaches taken and what they reveal there remains a central goal of understanding language in use amongst all DA.

The next section discusses Foucauldian-inspired Discourse Analysis (FDA) and how people use aspects of Foucault's work. 


\subsection{Foucauldian-inspired Discourse Analysis}

Foucauldian Discourse Analysis (FDA), or Foucauldian-inspired (or informed) Discourse Analysis is not one single approach to DA. FDA is a term used to encompass doing discourse analysis in a manner which uses aspects of Foucault's theoretical work (Given, 2008). Wetherell, Taylor and Yates (2001) note that FDA is part of the larger field of research that uses the term Discourse Analysis as a general term to describe research approaches which consider discourse to be where meaning is constructed. Despite the multiple traditions and interpretations of discourse analysis, it is clear that "the study of discourse is about the discovery and theorisation of pattern and order" (Wetherell et al, 2001, p. 5). Moreover, for these authors the study of pattern and order, in turn, focuses on the study of three central topics for social scientists (Wetherell et al, 2001, pp. 5-6):

1. Social interaction - concerned with talk and communication and what people do with language.

2. Minds, selves and sense-making - concerned with construction of identity, making sense and the emergence of forms of mind and of social actors

3. Culture and social relations - concerned with historical and institutional features of discourse and how meaning has shaped over time through processes.

For these authors, meaning is evident in spoken language, written text, social actions, beliefs and practices and even in the very architecture surrounding us. All of these meanings suggest the operation of rules and as such reveal an operation of power to connect people to specific ways of action and thought. Furthermore, discourses can have multiple truths - multiple meanings and even multiple analyses.

FDA usage, as both theory and method differs widely with examples in psychology, educational, nursing and counselling research (Wilson, 2001; Heaton, 1999; Traynor, 2006; Stead \& Bakker, 2010; Winslade, 2005). It is as much a theoretical position as a potential method for investigation - a toolbox rather than a prescribed system (Kassl, 2007). FDA analysts see meaning in the world as being in part socially constructed (Potter, 1996), which means there may be no single truth or single correct view of reality (Berger \& Luckman, 1991). Foucault did not consider the result of this questioning to be absolutely correct or true - rather the suggestions put forward from the research are seen as critiques of the currently accepted truths which shape society (Foucault, 1983). 
Thus the FDA theorist seeks to put forward alternative conceptions of knowledge to encourage new ways of thinking about events (Foucault, 1983). DA with a Foucauldian perspective focuses on Capital ' $D$ ' discourse using a Foucauldian perspective, concerned with examining the specific mechanisms that produce discourses which function as true in particular times and place. In FDA, discourse goes beyond a linguistic analysis, narrative reading and psychological phenomena and investigates systems of meaning operating in language or text regardless of speakers' intentions (Georgaca \& Avdi, 2012). Discourse is not a reference to what language is saying in a literal sense, but rather the ways rules are presented in a body of knowledge or discipline. Researchers using FDA attempt to unravel how discourse manifests as power and knowledge relations in society. FDA enables the researcher to go beyond an individual's factors to see a wider view of what may be occurring outside the immediate person, how this plays on individuals, or legitimising those behaviours. The focus of Foucauldian-inspired discourse analysis has a key focus on power and its operation in social settings. Wodak and Meyer (2009) have an excellent description of what power means for the discourse analyst:

Power is about relations of difference, and particularly about the effects of differences in social structures. The constant unity of language and other social matters ensures that language is entwined in social power in a number of ways: language indexes and expresses power, and is involved where there is contention over and a challenge to power. Power does not necessarily derive from language, but language can be used to challenge power, to subvert it, to alter distributions of power in the short and the long term. Language provides a finely articulated vehicle for differences in power in hierarchical social structures. (p.10)

This theoretical positioning by the researcher within Foucault's work is the key to all analysis in FDA.

It is not surprising, then, that many authors note that the field of DA that incorporates (or is influenced by) the ideas of Foucault is not an integrated field (DiazBone, Bührmann, Rodríguez, Schneider, Kendall \& Tirado, 2008; Titscher, Meyer, Wodak \& Vetter, 2000). Diaz-Bone et al. (2008) note that there are numerous strands of Foucault-inspired discourse analysis, often taking differing perspectives in different countries. For example, the UK has three main DA perspectives using Foucauldianinspired theory, 'critical linguistics and sociolinguistics' (exemplified in the work of Norman Fairclough and Ruth Wodak which look at social relations of power and how 
language is used in processes of social change); 'social psychology' (typified by Ian Parker and Erica Burman who support the use of radical theory and practice in action research); and 'ideology and discourse analysis' (embodied in the work of Ernesto Laclau and the understanding of discourse as a social practice interconnected to political orientations and hegemonic strategies that create dominant views of reality).

However, within this sub-field of discourse analysis, it is possible to see that there is a commonality of intention to examine discourse to explore the operation of power in society. Yet, the wide range of methods associated with FDA all rely on the individual researcher's interpretation, informed by their understanding of and interpretation of Foucault to generate new questioning of knowledge (Potter \& Wetherell, 1987; Wiggins $\&$ Potter, 2008). This raises a common criticism of FDA, and for that matter all DA: How then can the source material or the interpretation of it, be considered 'true'? (Given 2008).

The proliferation of methods for both DA and FDA share in the desire to present robust analysis, and while there are no single ways to undertake FDA there are some helpful guides (e.g., Kendall \& Wickham, 1999; Billig, 1997; Potter \& Wetherell, 1987; Parker, 1992; Willig 2001; Potter, 2003; Wiggins \& Potter, 2008; Thomson, 2011) and I use one by Thomson which is discussed later in my method section. One central approach in which FDA analysts have attempted to align with Foucault and at the same time establish a sense methodological veracity is by establishing a set of questions that are asked of discourse, be it in text or another form.

For example, Parker (1992) gives a twenty stage outline for the analysis of texts suitable for both DA and FDA. Parkers guidelines represent a set of questions focused on the following key notions: Discourse is realised in texts, is about objects, contains subjects and is a coherent system of meanings. Discourses reflect specific ways of speaking, are historically located and support institutions, reproduce power relations and have ideological effects. Applying this notion of what DA is to the textual sources can turn Foucault's theories into one possible method. The method is interpretive and relies on an openness to the research project, process and results. Furthermore, it maps a particular discourse on DA revealing its focus on examining discourse through text as a place to see the operation of power and its effects.

Critical Discourse Analysis (CDA) is one Foucauldian inspired form of discourse analysis, in that it has a focus Foucault's theories of power in discourse, although it also incorporates other theories and fields of analysis, such as linguistics or sociology, and importantly the work of Louis Althusser (theories of ideology), Mikhail Bakhtin, (genre 
theory), Jürgen Habermas (Frankfurt School, social theory and philosophy), Karl Marx (class struggle) (Titscher, Meyer, Wodak and Vetter, 2000; Tenorio, 2011). CDA like all other approaches claiming to analyse discourse has itself differing approaches based on the extent to which contributing theory or philosophy the analyst favours (Wodak \& Meyer, 2009). (Despite this all proponents of CDA according to Wodak and Meyer in their book on Methods of Critical Discourse Analysis have a shared belief which is that "social theory should be oriented towards critiquing and changing society as a whole, in contrast to traditional theory oriented solely to understanding or explaining it (Wodak \& Meyer, 2009, p.6).

CDA analysts point out the importance of the term 'critical' in CDA which stands for the ideological desire to use critique to both explain social phenomenon and change it. According to Fairclough, Mulderrig and Wodak (2011) DA is not an objective science but is a form of social intervention "that openly and explicitly positions itself on the side of dominated and oppressed groups and against dominating groups" (p.358). For these authors CDA does this this without compromising academic values of objectivity and rigour. CDA incorporates this notion of ideology into its critical analysis of language. The CDA analyst sees language as a dialectical understanding, where language conceptualises the world. The discursive practices of language produce and reproduce ideological effects, such as sexism or classism and this may not be openly visible to people. By understanding the ideological process through examining language in use CDA analysts reveal the way discourses contribute meaning to social practices. In doing so the CDA analyst is centrally focussed on addressing inequality in society and looking for ways to solve it.

Tenorio (2011) states there are three central concepts for all CDA analysts: power, history and ideology. Wodak and Meyer, for example, focus their work on Foucault's more historical approach and claim their core concepts are that: "Critical Theory should be directed at the totality of society in its historical specificity" and "Critical Theory should improve the understanding of society by integrating all the major social sciences, including economics, sociology, history, political science, anthropology and psychology" (Wodak \& Meyer, 2009, p.6). For Wodak and Meyer, the historical approach focuses on how discourse (both language and semiotics - the analysis of communication through signs and symbols beyond language) is used by those in power as a form of domination over others. Wodak has used this approach to examine racism and ethnicism are used in anti-Semitism (Wodak, 1990; 1991; Reisigl, \& Wodak, 2005). Wodak's particular brand 
of CDA can also be called Discourse-Historical Analysis as it directly incorporates sociopolitical and historical analysis and in this sense attempts to connect dominance over others in micro, meso and macro discourse across a period of time (Wodak \& Meyer, 2009).

In contrast to Wodak and Meyer, Fairclough focuses more on Foucauldian textual discourse analysis with a strong focus on the analysis of language within a specific communicative event (e.g. it could be a university lecture, examined from grammar, vocabulary, phonology and semantics). Fairclough then connects these events to orders of discourse (e.g. a discursive field such as a university, its lecturers, and students, and also the practices such as teaching, or lecturing). This textual analysis is connected to broader social contexts such as the wider institutional environment (e.g. higher education in New Zealand or globally). This is an interpretive process always connected to the operation of power, as a result of hegemony where what is at stake is the domination over orders of discourse. This process of domination is where social practice is shaped and ordered and as such is inherently political. It is here that Fairclough reveals the neoMarxist approach (also common in CDA) which views social change as an ideological class struggle (Fairclough, 2013). The identification with Marxist thought was deliberately avoided by Foucault, who did not want to be aligned with a particular schools reading of Marx though as O'Farrell notes he was not above using ideas from Marxist theory and was most certainly influenced by his teacher Louis Althusser who is regarded as a Marxist philosopher (O’Farrell, 2005).

While CDA can be described as a Foucauldian-inspired Discourse analysis, it is not the only way to approach Foucauldian Discourse analysis (Diaz et al., 2008). CDA focuses on power and also on how the discourse produces/reproduces domination of one group over another and how they, in turn, resist domination (Wodak \& Meyer, 2009). Foucault, while interested in power-relations did not see power as explicitly 'dominating' in a solely negative sense. Foucault's (1982) articulation of power does not act to repress individuals but produces them as subjects through specific practices that are visible in a local and historical setting. Importantly these subjects are not determined by the discourse in the sense that they must act a certain way because the operation of power is not a repressive ideology, and it does not operate as a planned totalising force. That the outcome of power-relations or the operation of power is not part of a grand scheme is an important aspect of Foucault's thought. Resistance to the process of power is a key aspect in making the social situation, and means that power cannot operate with an accepted pre- 
planned strategy. People may act in different ways in response to the discourse. For example, a person may have a subject position as a lecturer, be seen in a particular way, and have particular responsibilities or rights that suggest a certain action but may see themselves as more of a teacher and associate with the subject position related to this which is common in discourse related to teaching. What does remain is the operation of power in the social situation and the struggle for normalisation through the process of discourse.

The following section discusses related literature that have used DA and FDA to examine power-relations.

\subsection{Case Studies of Power}

Foucault's work on discourse and its relationship to the operation of power has inspired numerous studies in a wide range of academic and practical fields, including Government, Economics, Business and Management, Development Studies, Mathematics, Arts and Social Sciences, Criminology, Nursing and Health and Education and, to a very small extent, Engineering. The following sections take a closer look at some of these studies that have all utilised an interpretation of Foucault's ideas and provides an understanding of where this approach has added new knowledge. Almost all of the studies I have looked at contain a relatively lengthy discussion of Foucault's theories and how each research project seeks to apply them, emphatically noting, as this thesis does, that there are multiple ways to interpret and use Foucault's ideas and in particular discourse analysis. This section provides examples of the application of Foucauldian-inspired research.

\subsection{Health Studies}

Foucault's influence has been strongly felt within nursing and health studies (e.g., Carmichael, 2010; Fejes, 2008; Yates, 2002; Kavanagh, 2008; Riley and Manias, 2002; Winch and Creedy, 2002; Matthews, 2009; Johnson, 2013; Springer and Clinton, 2015; Whitehead, 2011; and Wilson, 2014. Foucault's interest in the power/knowledge relationship is extremely useful in the medical context as many of the interactions between patients and medical staff involve the exercise of power and control, ethical questions as well as concepts of surveillance and monitoring. 
Wilson's (2014) research investigated how different parties in mental health crisis institutions were treated, and how this was informed by practice and policy. Wilson's analysis utilised interviews with service users, and their families, and mental health nurses and senior members of the police. Analysis indicated that participants experienced differing amounts of inequality, and had limited control over their decisions, care and the way services were delivered. At the same time, people involved in the mental health system (patients, family, mental health workers and the police) are often held disproportionately accountable for events and actions that occur in the community and clinical setting. Parallels can be drawn between the education system and the medical system; for example, there are dominating discourses at work within each working to establish norms of behaviour and action that produces power and knowledge but at the same time can also affect some participants negatively.

Wilson's (2014) work offers an interesting comparison with my study. Wilson was embedded in the practice of mental health nursing, having been a nurse for over twenty years and become aware of discrepancies between what was being said in mental health policy and literature, and what was happening in practice. Like myself, Wilson faced the challenge of finding a way around the ideological positioning of such work which maintains that it is possible for us to understand an individual's point of view; their lived experience, and as researchers be able to write this lived experience down. Wilson's position was to look for a methodological framework to go beyond the belief that there is some singular truth or reading of social experience, identifying the theories of Foucault and the methodology of discourse analysis as the best approach.

The use of context as a focus is a central consideration in Foucauldian studies and helps to locate viewpoints and analysis within specific practices and specific viewpoints (Georgaca \& Avdi, 2012). The concept of what is happening, or truth of a given situation, automatically becomes one of multiple perspectives - multiple truths. This is an essential aspect of Foucauldian qualitative studies, enabling the researcher to be both valid and invalid at the same time depending on perspective. As such this philosophical positioning opens up what is being studied to a broader critique where the positions of investigation provide a perspective that has often been considered false or incorrect.

Wilson's (2014) perspective as a mental health nurse informed her research question: "What are the converging and competing discourses, strategies and technologies involved in the field of mental health crisis intervention?" (p. 23). In doing so, Wilson offered a critique of the way reality, for the subjects involved, was enacted in 
the mental health crisis intervention arena. She identified that those involved - from patients to family, friends, nurses, counsellors, doctors and police - can be seen to behave and think in certain ways in specific mental health situations as a product of the many discourses that institutionalise and regulate their relationships, associations and disassociations. For example, different groups of medical professionals have particular educational backgrounds and institutional rules that determine practice both amongst themselves and with other people, such as patients and their families. Wilson identifies and draws attention to the ways these different groups' practices and rules affect participants. She suggests that the behaviour and actions of educational and operational practices should be critiqued to provide better opportunities for all involved in mental health to reframe current practices in care and the education of medical professionals.

Riley and Manias' (2002) reframe the way practices in health care could be viewed using Foucault's concepts of power, discipline and subjectivity to illustrate how operating room nursing is constructed as a discipline. Their research data comprised interviews of nurses and textual analysis relating to the professional practice of nurses in the operation room. Their study examined nursing practice and related it to the operation of disciplinary technologies of power - those techniques, operations and procedures that bring about certain behaviours in an individual or group.

For Riley and Manias (2002), hierarchy within the medical profession works to make individuals into objects in a process, with specific roles to perform. For example, the surgeon, the nurse and the patient. The demonstration and fulfilment of specific roles by people in the operating theatre place them in particular social roles under specific governance. In this situation, the individuals involved are rewarded or disciplined for their performance in their role by authorities to manipulate or transform behaviour. It is an act of normalising a set of behaviours. The operating room processes and layout further specified the permissible actions of those in it. For example, the layout of surgical tools, the specific manner in which they are cleaned or even given to a surgeon, exhibit modes of disciplinary technologies and reveal power in operation. According to Riley and Manias, doubt exists amongst the medical profession that the speciality of operating room nursing is even nursing. The relative invisibility of operating room nurses to patients due to anaesthesia contributes to the lack of widespread knowledge about what they do.

Riley and Manias (2002) suggest that, contrary to the commonly held belief among medical professionals that operating room nurses are little more than surgeon's assistants, lacking independent thought and practice, operating room nurses exhibit 
considerable power over their practice and that of surgeons. This study is important in that it presents the usefulness of Foucauldian concepts in unpicking the operation of power in a work setting, providing an alternative view of how power is being used and enacted, and challenging the belief that power is only a top-down process. This alternative view was essential in reframing the current discourse surrounding operating room nurses that perpetuates the illusion that these jobs are poorly skilled with no creativity or power.

In addition to the study of patient interactions, or that of medical professionals, health research using Foucault also includes examples of exploring areas of policy and management practices. For example, Johnson (2013) investigated discourses around workplace bullying in organisations, regulatory agencies and hospital nursing unit managers, and used methodologies from both Critical Discourse Analysis and Foucauldian Discourse Analysis. Her study analysed interviews with 15 hospital nursing unit managers, 14 documents from their hospitals, and eight documents from websites of official hospital regulatory agencies. She noted that while research has identified bullying as a problem in hospitals, little is known about how hospitals address this issue and whether their resolutions are effective. Johnson was unable to find any study that examined the content of anti-bullying policies in US hospitals. Existing research on nonspecified organisations did suggest, however, that policies offered inadequate protection for people being bullied and that "what human resource professionals believed was communicated in these policies was quite different from what was actually communicated in these policies" (Johnson, 2013, p. 5).

Johnson's (2013) examination of the discourse also concluded that managers interpret, and act upon, official documents in ways not sanctioned by the official policies, and restricted the roles of other staff in responding to bullying practices. Managers were able to operate in three ways in response to bullying; do nothing, offer progressive guidance (actions aimed to facilitate an employee's resignation or termination of employment), or actions other than progressive guidance. In part, these responses were due to the nature of often ambiguous bullying situations that were difficult to address with the given guidance. This difference between 'official' policy and actions highlights the nature of the separation between organisational or managerial intent and practice. Johnson also noted that the study was limited in scope to those interviewed and the documents examined and that the organisational discourse - the informal conversations and undocumented meetings, emails and other unofficial communications remain a contributing factor that should be considered to gain a more complete picture. Obtaining 
ethics approval to conduct this type of research is of course, difficult to achieve. This very notion illustrates the importance of Foucauldian Discourse Analysis in offering a critique of how social situations are and how they came to be, and notably to suggest that they perhaps do not have to be this way.

\subsection{Education Studies}

Alongside these (and other) nursing and health studies there are numerous examples of educational studies drawing upon Foucauldian ideas, including Pearse, 2014; Gruenewald, 2004; Ball, 2006; Fairclough, 1993; Anderson and Grinberg, 1998; Peters, 2007; Fimyar, 2008; Belzile, 2008; Bradbury-Jones, Irvine, and Sambrook, 2007; Lather, 2006; Meabon Bartow, 2013; Gale, 2001; Anderson, 2001 and Comber and Nixon, 2009.

An illustrative example of educational research using FDA is that of Lise Marie Belzile (2008) examining teacher's attitudes toward inclusive policies and practices in Canadian children's special education. Belzile questioned whether special education was really including these children. Despite recognition in Canada of the need for inclusion over the last twenty years, she noted that special education discourse in policy documents, and teacher practice, shared similarities in meaning but differed considerably in practice - much like Johnson's (2013) study discussed earlier. Interpretations of special education and inclusion varied from school to school, and district to district, as educationalists and government educational employees interpreted what inclusion or best practice was. A significant finding was that educational policy acted as a constraint on teacher practice, in effect limiting the teacher's voice and ability to exercise their knowledge.

Furthermore, while teachers typically maintained a positive attitude towards inclusion they often demonstrated mixed understandings of what inclusive behaviour was resulting in poor classroom practice. Belzile (2008) noted that she did not set out to 'blame' teachers, recognising that teachers were working within their interpretation of the policy framework. Similarly, my work does not set out to blame either, but to understand a social situation. This aspect of Foucauldian-inspired research is helpful for understanding how social situations and practices come into being in an organisation or setting such as education. Interpretation of rules can vary between individuals within an institutional setting, and these individual interpretations can become dominant as they spread and become accepted by people, affecting practices across institutions in a very 
different way than was intended. The practice of interpretation is often connected with a certain amount of individual workplace autonomy.

Similarly, in my context, it is clear that a certain amount of freedom in workplace practice is exhibited by academic staff. This freedom is not complete, as there are always constraints that allow a sense of freedom, but within certain boundaries. For Belzile (2008), these boundaries operated through mechanisms of power that include monitoring teacher practice, through reviews such as Special Education Programming Standards Reviews or the Severe Disabilities Realignment Review designed to evaluate processes. Belzile explains that this process both reinforced special education as a selected social place and group and at the same time created a sense of otherness for those being scrutinised. In turn, this resulted in individual interpretations of the policy framework.

Like Belzile (2008), Comber and Nixon (2009) utilised a Foucauldian-informed approach to investigate educational discourse and showed that the process of educating is hindered by the effect of influences outside the classroom. They interviewed and met regularly over several years with thirty middle school teachers (three teachers per school) that were attempting to design and implement a new curriculum and pedagogy that would engage and connect with their year "seven to nine" students (Comber \& Nixon, 2009). The project was inspired by low completion rates in the schools concerned and was aimed at providing insights into the complex culture and practices within the teaching and learning environment.

Analysis indicated that the teaching and learning environment was interconnected with educational and governmental policy and that these affected teachers' practice (Comber \& Nixon, 2009). These policy matters were identified as being related to corporate discourse, bureaucratic administrative duties, increased surveillance and policing, and the need to raise performance for reporting needs. They described these as "apparatuses of control" (p. 339) that make it difficult for an oppositional discourse. For example, teachers were reluctant to discuss pedagogical matters unless compelled - a factor that was surprising to the authors, given the fact that the project focused on redesigning pedagogy and curriculum. For Comber and Nixon, the teachers never embraced pedagogy reform as it was "drowned out" (p. 336) by other dominant pragmatic discourses such as those around educational standards and a need to improve test scores. There was simply no room for serious involvement in pedagogy, and in order to make a significant change, they noted that "pedagogy needs to be situated and cannot be pursued in isolation from teachers' everyday working lives" (p. 343). 
Pearse (2014) conducted a qualitative case study using a Foucauldian discourse analysis methodology to answer the following questions: What knowledge is found in the discourse(s) of American traditional and non-traditional university websites? Moreover, what internal and external concordances or contradictions exist in the discourse(s) that contain(s) the knowledge found on these traditional and non-traditional university websites? This study utilised FDA to analyse website self-identity texts, such as 'Home', 'About', 'History', and 'Mission Statement' pages on university websites. This study was based solely on 'published' text, rather than on interviews, and illustrates that discourse exists wherever meaning is conveyed.

Pearse concluded that all of these American universities conformed to forms of discourse entwined within Humboldtian ideals - ideals that underpin the moral justification for modern universities and can be dated back to Wilhelm Von Humboldt's university reforms in the 1800s. It is a historical notion that a university is a not-for-profit organisation, supported by state and private funds, that is legally authorised to provide a holistic combination of both research and study opportunities for people in higher education. The aim is to improve the education of people for the public good, resulting in social, scientific and technological achievements (Pearse, 2014). For Pearse, modern universities operate within a Humboltdian paradigm, needing to justify research, teaching, and civic duty alongside an imperative to operate as a profitable and accountable business. The historical, educational concept of universities of places for the public good has been merged with business goals.

Pearse (2014) noted that universities have identity narratives and "in order to legitimize themselves, perpetuate ideas, worldviews, and behaviours that should be subjected to critical examination" (p. 231). These identity narratives place universities into particular educational spaces with often insular educational practices and policies. For Pearse, the US higher education landscape needs to be evaluated by education authorities to challenge whether universities' educational narratives are valid for a diverse and increasingly large number of students requiring tertiary education. The selfgoverning manner of US universities has allowed them to decide what section of the public they want to educate while at the same time propagating the discourse that they are serving the greater public good. This is a discourse that perpetuates a connection to a historic discourse of legitimacy while operating a discourse of discrimination. It is this discourse that, in turn, evidences no real incentive for universities to alter their outward presentation or internal business orientated practices. 
A key conclusion was that universities seem unable or unwilling to question their own narratives and roles in an era of rapidly changing society. This inability to be reflexive explains, in part, how power is used to produce a particular reality that is itself a self-fulfilling situation. Legitimacy for these institutions is the product of generations of construction, projecting certain outward messages that have brought rewards both financial and educational. At the same time, however, these messages work to exclude certain other interpretations. Only the future can tell how these institutions will transition as education continues to transform.

Hoareau (2011), for example, used discourse analysis to explore modes of governance in higher educational reform. The author examined literature on policy and educational reform in European higher education and compared this with the way the French Government and French higher educational institutions underwent a “globalization by stealth' despite an outwardly spoken opposition to moves toward globalised educational reform. This reform discourse "concentrates on two main justifications: first, that embracing globalization is necessary for France to remain one of the main global players in higher education, and second, that globalization is also necessary for France to remain an economy of innovation, key to economic competitivity and sustainability" (p. 235). Hoareau employed Foucauldian concepts of discourse analysis of policy level text and governmentality to examine the ways ideas and values were implemented. Hoareau noted that the "article concentrates on two aspects of mode of governance: 'who' governs, looking at the relative role of the government versus higher education institutions, and 'how' governance occurs, opposing binding regulation to a more subtle governance by indicators, which uses comparisons as a steering tool" (pp. 222-223). This research was focused on the high level or macro level of analysis and did not connect to individual people-subjects other than to summarise its impact from an institutional standpoint. Instead, the research was geared to examining power from a policy transfer nature, that is how does institutional policy operate.

Shore and Wright have written on the audit culture in higher education since the late 1990s using a Foucauldian-inspired theoretical approach to investigating how audit and accountability shifted from the financial domain to the public domain and higher education (1999, 2000, 2003 and 2015). They describe how the notions of "new managerialism' (a large field of study in its own right, particularly in sociology of higher education, see for example, Randle \& Brady, 1997; Exworthy \& Halford, 1998; Deem, 1998, 2001; Trowler, 1998, 2001; Shore \& Wright, 2003; Clegg, Hudson \& Steel, 2003; 
Peters, 2013), a term used to signify the adoption of private sector management techniques in public institutions is described as a negative form of governance, are evident in universities. Shore and Wright's analysis throughout this period has concentrated on how audit systems as an analytical framework have come to operate as a rationalised form of political technology through techniques of governance. Their work has covered areas from higher education, to accountancy and the military. They identify for example in their 2015 work:

The spread of the principles and techniques of financial accounting into new systems for measuring, ranking, and auditing performance represents one of the most important and defining features of contemporary governance. Audit procedures are redefining accountability, transparency, and good governance and reshaping the way organizations and individuals have to operate. They also undermine professional autonomy and have unanticipated and dysfunctional consequences. (p. 421)

For these authors, who use a Foucauldian genealogy to investigate the impact of audit across institutions and an understanding of power within Foucault's work on governmentality, reveals a series of 'audit effects'. This is that the approach normalised through the governance of peoples actions within the broad sphere of organisations has embodied: "domaining effects," "classificatory effects," "individualizing and totalizing effects," "governance effects," and "perverse effects" (Shore \& Wright, 2015, p. 425). And in doing so has created within organisations, particularly at a managerial level a coercive dimension where organisations perceive themselves as assessors of performance and where people are forced to rethink themselves in the face of an audit culture. For example, a good employee is a productive or contributing employee who meets measurable targets and goals. All this assessment is also connected to governance by the state which seeks to scrutinise organisations. For them the:

Governance effects are a corollary of these individualizing and totalizing mechanisms. Setting performance indicators and assessing against benchmarks and best practice are instruments designed to make organizations more "accountable" to funders, government, stakeholders, consumers, and the public. (Shore \& Wright, 2015, p. 427)

Importantly, in relation to my own work, they examine the connection of these practices to universities. They noted that in the University of Auckland, senior management instituted new criteria of numerical and quantifiable measures to assess academic 
standards for promotion, aimed at increasing research outputs and income-generating activities. According to Shore and Wright (2015), these measures, guised as making promotions transparent and objective, actually favoured academics in STEM subjects over those in social science or humanities whose major access to funding through the Royal Society of New Zealand's Marsden Fund overwhelmingly funds STEM projects. Furthermore, the transparency of promotion assessment resulted in an increased input into promotion committees by HR personnel reducing qualitative and professional judgements of academic work.

Shore and Wright (2015) also discuss university ranking systems (Times Higher Education's World University Ranking; US News and World Report's Best College Guide) as an audit space. They explain that university Dean's while being sceptical of their academic worth or relationship to the college, ultimately end up supporting them. This support comes from the realisation that funding, student numbers and prestige are intertwined and thus "such measurements are simultaneously individualizing and totalizing and illustrates their coerciveness - and why they are so impervious to criticism" (p.428).

These authors' final higher educational example discusses how the Danish government made a series of reforms in 2003 aimed at making universities: the drivers of Denmark's competitiveness in the global knowledge economy (Shore \& Wright, 2015; Hoareau, 2011, above). Universities were to be accountable for their use of public money and how they supported both industry and society. To do this, the government instituted policy and committees within academic disciplines to assess teaching, research and knowledge exchange. Shore and Wright describe how the points system around this met with academic resistance bring change, though the change was ultimately a worse system privileging publication in elite journals with small readerships. This work illustrates that a new form of government through the normalisation of operating in an audit based normative order created a government of conduct through numbers. They point out that this process has been occurring in different places and institutions but has similar effects. It is a totalising and at the same time individualising discourse, which also has elements of resistance.

They conclude by suggesting that this new form of governance is related to neoliberalism:

While not confined to neoliberal polities, the characteristics of this new order include all of neoliberalism's key ingredients - including "governing 
at a distance"; a relentless pursuit of economic efficiency; deregulation, outsourcing, and privatization; marketization and the privileging of competition over cooperation; increasing separation between an empowered managerial elite and a deprofessionalized workforce; the objectification of human labor-combined with increasing emphasis on calculative practices aimed at promoting individualization and responsibilization. In this way, the political technologies of financial cost accounting wedded to the project of management have been highly effective in producing accountable and transparent subjects that are simultaneously docile yet self-managed. (Shore \& Wright, 2015, p. 430)

By way of perhaps negating the overly pessimistic discussion the offer a possible form of resistance by suggesting that one way of opposing this is to use numbers against this numbers discourse in the form of collective academic and professional values. Their work is a good example of FDA, combing several aspects of Foucault's theories, in particular, an approach to discourse, genealogy and governmentality (and associated biopower/biopolitics) and above all a focus on the power-relations taking place that normalise discursive practices. The academic staff discussed above who must act a certain way, operating within a framework that becomes self-defining, is an example of the Foucauldian notion of subjectification.

Fairclough (1993) sets out Fairclough's particular view of CDA as a method, and to illustrate public discourse in higher education in Britain. Fairclough explains that his concepts of power are influenced by Foucault's understanding of how power has shifted between pre-modern and modern societies and in particular how biopower (the modern form) is embedded in the social practice of institutions. Fairclough does not rely solely on Foucault for inspiration and notes that while he uses the theory of discourse analysis also combines this with Antonio Gramsci's concept of hegemony. Gramsci's hegemony conceived of the capitalist state as one that rules by coercive ideology where the population is shaped by the ruling elite through institutions which grant concessions to people through institutions that shape belief by manufacturing and reproducing consent. The main difference between Foucault and Gramsci here is that Foucault focused more on seeing power-relations at a micro-level, and tended to ignore one totalising theory and the notion of a class-based society (Kreps, 2016). Thus for Fairclough, his analysis is political in that it attempts to focus on the power-relations and domination of discourse in social practice - in particular using CDA against exploitation and domination. 
Fairclough argues that the primarily publically funded universities in Britain have made major organisational changes to increase funding from external sources as well as adjusting their internal processes to reflect an internal market. University administration through to individual departments have increased managerial processes and alongside this academics have been encouraged to see students as customers, develop learner-centered models of teaching practice, and as a result, their professional identity has changed.

Fairclough sees these changes as being very top-down but affecting both staff and students. In example one of four, Fairclough examines, university advertisements for academic posts, both new and old and reveals that the language in the advertisements shifts from academic qualifications and required subject knowledge to include promotional messages aligned with business operations and the incorporation of a measure of an applicants personal qualities: "With your ambition, energy and expertise, you will be committed to teaching..."(p. 147). For Fairclough, this type of language "is a potentially face-threatening prediction about professional ethics as well as behaviour of the potential employee" (p. 147). Fairclough includes a discussion on the use of grammar, clauses and vocabulary and ties this discussion into what type of discourse he sees them relating.

In example two, Fairclough analyses discourse in programme materials from a conference. Fairclough examines a conference outline and notes that it contains a specific discourse that is aimed at having the participants see information in a particular context. The context here is one of viewing the conference as a means of promoting a specific publication of "having like minded people authorise the legitimacy of an 'imminent' and 'celebrated book' one of the most influential and best selling works of post-war European sociology" (p. 150). For Fairclough, this has more to do with promotional objectives in higher education than academic research and discussion.

In the third example, Fairclough examines his own curriculum vitae and the procedural rules surrounding its content and construction for the notion of self-promotion it contained. Alongside his own work he made observations on his investigations into the appropriate content through discussion with colleagues and by looking at their submissions. For privacy reasons, he could not include his colleagues work. Fairclough noticed that the procedural rules spelt out what was broadly required, for example, there was a section titled: Contributions to the Department. Interestingly for Fairclough, he deduced that a lot of the content of the CV like in the section listed in the previous sentence was about planning and administration. The text was full of clauses that were 
active or relational to promotional items, for example, "I was Head of Department" or "I have submitted...", "I have stimulated research" (p. 152). Fairclough summarised that the process of developing the $\mathrm{cv}$ was one of being colonised to write in a self-promotional discourse where the discourse aligned with a managerial process. Though, Fairclough admitted that he was aware of the need to say things in a certain way and deliberately converting though not quite realising by how much.

Fairclough's final examples were extracts from Lancaster University's undergraduate prospectus from 1967-8, 1986-7 and 1993. Fairclough looked at the entry requirements in English and Linguistics, focusing on aspects of authority and identity. The early language is dominated by what he calls obligation and permissive statements like "no specialisation... is permitted", "are required" or "will choose", whereas later language shifts to more personalised "You take at least three" (p. 154). The language transitions across time to negotiate a mixed wording that becomes more personalised but still retains the institution as a passive agent. It is the student that becomes identified as an individual within an institution: by 1993 the focus has become one of selling the university in the prospectus rather than telling the nameless student the rules. Fairclough also notes that the presentation of the prospectuses content has become glossy with more images and multi-coloured in keeping with its new promotional and advertising agenda, representing the shift in the discourse towards a university as a business with managerial goals that has consumers and clients.

In summary Fairclough's work exemplifies CDA in illustrating critically how staff and students in university institutions are affected by discursive managerial practices aimed at the marketisation of higher education. Triangulation of the process occurrs across several levels, though it still has a very top-down approach despite connecting with his own experiences in promotional documentation. The focus on specific linguistic aspects helps to give Fairclough a justification for his findings though it was unclear to me where resistance existed in this study, which largely depicted the operation of power as unchallenged. Fairclough, noted himself that there was no real alternative presented, in particular, this would be difficult in prospectuses and job advertisements. There is a departure from Foucault's ideas here, with the CDA approach having a focus on the operation of power through domination of a hegemony. Foucault sees the operation of power being also located where there is resistance. This comment may seem critical, and it is not meant to be, rather it shows a variation in forms of knowledge presented in Foucauldian-inspired DA. Fairclough is not omitting information but has focused on an 
area where change can be seen in the discursive practice and the fact that it can be seen occurring across multiple sites of higher education does reflect a normalisation process is occurring and it is taking shape slightly differently in the four areas he examined. Fairclough's work shows just how difficult it is to see a resistance to the operation of power within related discourse.

Similarly, Morley (2003) looks at the development of higher education, and its connections to new forms of management and business agendas. Morley examines "power relations that organize and facilitate quality assurance in higher education" (p. vii). In doing so, she covers how macro (accountability, surveillance and regulation) and micro processes (organisational life, culture, relationships, subjectivities and identities in the academy) reflect the manner in which quality has become an overarching truth in the discourse - a form of discursive orthodoxy in higher education. For Morley, quality assurance is a lens to view aspects of academic life.

Morley (2003) locates her study in the following fields: "The empirical field is quality in the rapidly changing academy in Britain... the sociology of higher education, organization studies, feminist and post-structuralist theory" (p.xi). Her study is in this sense interdisciplinary, uses discourse analysis and is connected to the key concepts of post-structuralist theory of which Foucault can be considered a key founding member. She used semi-structured interviews of 18 male and 18 female academic and administrative staff across twelve academic disciplines and 35 higher education institutions (many of the administrative staff were also academics such as pro-vicechancellor, heads of department and registrars)

Morley's (2003) work could be considered highly thematic, and shares many similarities to my own (as the reader will see later my decision to view the discursive field through a concept of ownership is in some ways similar to Morley's use of quality assurance). For example, Morley refers to accountability as a major form of power in higher education systems which has threatened and changed the concept of autonomy for academic staff. Morley draws attention to the role of a globalised framework of neoliberal policies coupled with higher educational institutions forms of management as having distinct effects on promoting accountability and quality assurance. This spread of business values and processes into the public sector (new managerialism) has increased processes that her interviewees see as negative forms of governance.

Morley's interviews revealed multiple tensions, one example was that accountability had a negative effect by encouraging the desire to fake reporting, another 
was that autonomy had a positive effect for women who felt that quality and accountability furthered their interests in a traditionally discriminatory workplace. This is the operation of discourses at work. Morley's textual analysis identified the relationship between performance indicators for recruitment, retention and course and teaching quality from internal and external management and funding bodies and a strategy of domination. Academic staff and administrators find themselves in situations where they feel they are under constant pressure to improve numerous outcomes. The discourse of improvement or betterment is woven into the notion of quality assurance and accountability. Morley describes the very act of resistance as being problematic in higher education:

Resistance involves standing outside the parameters, logic or frameworks that name, classify and value in the first place. The power relations are such that to name quality assurance as undesirable carries the risk of naming yourself as undesirable. Furthermore, with competition, the binary divide and sectoral diversity, it is questionable as to whether a political community to co-ordinate resistance exists in academia. (p. 49)

Morley does, however, see resistance by the staff interviewed, but it is not coordinated against the dominant discourse of quality assurance. Morley notes that management staff are required to have skills in dealing with resistance, and resistors are corrected and rehabilitated through a process of denying the resistor a platform to speak such as in departmental meetings and then conducting individual meetings. The tools of quality assurance are then used alongside a morality inherent message of individual enhancement, development or improvement that makes any notion of a staff members resistance synonymous with fear of change. The paradox for Morley is the quality assurance discourse in higher education has decreased quality.

Stephen Ball, a noted sociologist of education, has been a long-time proponent of using Foucault throughout his extensive writings on education and neoliberalism since the 1980s. Ball's work has focused on tackling power-relations, policy issues, gender and inequality, with a strong focus on globalisation issues in education such as the adoption of neoliberal ideals and new managerialism. In a 2012 article Ball extended his earlier discussion on 'performativity' (2001, 2003, 2005, 2008). Performativity for Ball is "a powerful and insidious policy technology that is now at work at all levels and in all kinds of education and public service, a technology that links effort, values, purposes and selfunderstanding to measures and comparisons of output" (Ball, 2012, p. 19). This concept 
is the way Ball describes the process of academic work in the neoliberal university, placing demands on academics to spend time more being accountable for their actions than perhaps doing the jobs of teaching and research. In this environment, Ball sees the academic as a performer charged with acting a certain way in a regime of performativity, where production is paramount. The academic must always improve and for Ball, this makes academics governable subjects who comply because to not do so is immoral - after all, who wants to be irresponsible in an environment where to be an academic makes you responsible to yourself, other staff and students, and importantly to your university.

While not explicitly stated, Ball is drawing on the Foucauldian notion of governance, and where power is operating as a productive normalising force. It is also acting at multiple levels of an institution with the academic staff. Ball notes that the performative process re-orients pedagogical and scholarly activities towards measurable outcomes and thus away from social, moral and emotional outcomes which have limited measurability as performative actions. Ball's example is metrics over teachers' judgements in the classroom. Also, performativity works to make the commitment to action contractual. Research and teaching outcomes are calculable and can be written into contracts to measure performance. There is a strong connection here to Foucault's concepts of biopower and for that matter his broader notion of how power-relations work. This is quite clear in Ball's realisation that the academic staff "are produced rather than oppressed, animated rather than constrained! We take responsibility for working hard, faster and better as part of our sense of personal worth and the worth of others" (Ball, 2012, pp. 19-20).

Ball expands his notion of commitment to contract with the example of the offshore university. In this case, he discusses the expansion of UK universities in Asia, noting that they illustrate a demarcation between a public university and a private enterprise. Profitability, not increased academic or research quality, is the goal. The creation of an international 'expert' education market through the exporting of training and qualifications is part and parcel of globalised neoliberalism. For Ball this results in the further interconnection of performativity:

there are 'an increasing number of symmetries between academia and business'. UK universities are involved in complex 'border-crossing' relationships with the private sector, state agencies, international consortia and other national states. Partnerships, linkages and networks 'join up' state organisations with commercial ones and create discursive capillaries 
through which the sensibilities and dispositions of enterprise, competition and profit flow and the ontology of neoliberalism is generalised. Complex relationships built upon contract rather than collegiality and aimed at profit generation rather than knowledge for its own sake or public service enfold public universities into the field of commerce. (Ball, 2012, p. 24)

The expansion of universities and the marketisation of qualifications has seen a transformation of universities over the last twenty-five years, marked by governments in the UK, USA, Canada and New Zealand who have connected education with an international student revenue. University outputs are export commodities.

Ball further sees the way these universities have become part of the modern neoliberal enterprise by discussing how the commodification of university-life has been impacted on by the UK Research Excellence Framework (REF). This is the UK's means to assess research funding and is a form of accountability for the public investment in university research. For Ball, REF represents a disciplinary process where the behaviour of academics and universities is managed marking a removal of any notion of independence that universities, or academics had over their scholarly outputs, as these are now managed to be accountable and financially beneficial.

In 2016 Ball concluded his series on performativity in education (2001, 2003, 2005, 2008, 2012, 2013, 2015), noting this as a further exploration of Ball and Olmedo's (2013) discussion on resistance to neoliberalisation. Ball and Olmedo (2013) used the theories of Foucault to argue "that subjectivity is a key site of political struggle in the contexts of neoliberalisation and neoliberal governmentality" (Ball, 2016, p. 1129). Ball (2016) examined email exchanges with teachers, and illustrates how discourse reveals power-relations through more of a thematic analysis of the discourses in text than a linguistically oriented examination. Ball backs his argument up with a connection to multiple secondary sources and contrasts the texts against institutional texts and policy. Ball sees his work as an attempted to enter "the 'theoretical silence' of governmentality studies around the issues of resistance and contestation" and outline the risks of a refusal to resist neoliberalisation (p. 1129). The aim was to show how resistance to neoliberalism was a political struggle and in itself was a struggle against subjectivity. Thus it fits in with Foucault's notions of power-relations and the role of the individual as a place where the multiple strategies of power operate through discourse as truth making practices. Subjectivity is as Ball notes the "point of contact between self and power" (p. 1131). 
The focus on teacher discourse enables Ball (2016) to consider their statements as resistance to the anonymity of power expressed in the education system through a 'numbers game', which is a reference to the systems of measurement. And for Ball, a significant aspect of resisting control through performativity lies in the teachers' criticism - their ability to speak differently about the situation and realise alternative possibilities. This is a concept I see in my study of discourse where academic criticism of the system represents resistance, and this resistance exists in this thinking rather than in any physical act of resistance.

Ball's (2016) analysis identifies the struggle, and it is at this point where the text suggests alternatives. For example, one teacher ('Walter') attempts to write his selfperformance review differently than the way the review system operates. This alternative articulation of how Walter sees himself in relation to the system's categories and measures is interpreted by Ball as an attempt to loosen the connection between subjectification and subject. This is where Ball sees a connection between the emails and the concept of freedom being used as resistance, in which resistance becomes an ethical struggle. For Ball, this ethical struggle is akin to Foucault's conception of truth-telling where the ethical value is not in it being the truth but in how something is spoken. The form of resistance, or counter truth, Ball (and Foucault) is suggesting is resistance in context within discourse. The resistance in this manner is situational and as such presents new knowledge and is productive, and is a form of power.

Ball's work points out that neoliberalism has places of resistance and this is where individuals come into contact with subjectification. In doing so, Ball's work contributes to Foucauldian-inspired discourse analysis by giving the researcher a place to examine the sites of conflict where power-relations occur.

\subsection{STEM Education Studies}

Within STEM educational research the theories of Foucault do not have a wide uptake. Despite this, the limited number of academics in STEM education that use Foucault's theories have produced valuable research examining power-relations within educational spaces. This section examines a few key examples and discusses how they used Foucault and what their contribution was. 
One particular researcher in STEM education has used Foucault in an attempt to reframe educational debates rather than as a tool to examine discourse in micro-settings. Bazzul's work has consistently over the last decade used aspects of Foucault's toolbox to investigate issues in Science Education (Bazzul, \& Siatras, 2011; Bazzul, 2012, 2014a, 2014b, 2015a, 2015b, 2016, 2017a \& 2017b; Bazzul, \& Carter, 2017). Bazzul shifts between theoretical discussions on Foucault and other theorists work to the broader field of science education, and how to apply these considerations to look at how science is taught. Many of Bazzul's works appear to be arguments presented as a synthesis of political thought coupled with higher educational and philosophical theory rather than discrete discourse analysis. They represent elements of discourse analysis combined with Foucault's concepts, in particular, bio-power and governmentality, coupled with a broader critique of globalisation and neoliberalism. Bazzul argues for a reconceptualization of science education as a politicised space in need of examination and the adoption of new approaches (like that of Foucault) to challenge the dominant power-relations inherent within science education. His is a politicised agenda motivated in-part by Foucault's conceptual framework. Bazzul is seeking in his research to introduce a discussion on how education and ethics are intertwined to have educators engage with social and ecological justice issues.

Bazzul's research represents a use of Foucauldian theory as a means of presenting and attempting to stimulate uptake of these theories in science education to re-frame the way educators consider how education is produced and produces subjects. Bazzul (2017) describes this science education system as designed to give people skills, for example through lab work that both prepares people for their chosen career path but at the same time prepares them for integration into the workforce as labour ready. This is, in a Foucauldian sense, the subjectification of students through control of their biopower body and mind. It is also subjectification of teachers who find themselves as complicit in the system as educators. It is not that this is a bad or, for that matter, explicitly good, but rather is a way of looking at the system to ask questions of what is occurring. It is a starting point from which to reimagine the education system and reveal what may be occurring in it. In this case, it is a normalising process that can be seen to be achieving a “subject ready for science work" (Bazzul, 2017, p. 884). Bazzul portrays Foucault's work as a 'new' way of questioning practices in STEM education, and an appeal for science educators to utilise this in a field which has increasingly avoided this type of introspection. 
Foucault's theories in STEM education have been used most prominently in understanding discourses, identities and subjectification in gender issues for women (e.g., Henwood, 1998; Riley \& Sciarra, 2006; Phipps, 2007; Riley 2008; Riley, Pawley, Tucker, \& Catalano, 2009; Riley \& Claris, 2009; Claris \& Riley 2012; Beddoes, 2011; Beddoes, Schimpf \& Pawley, 2013).

Henwood (1998) uses Foucauldian Discourse Analysis to explore how women are underrepresented in STEM, through a review of the debates around this issue and examination of the subject choices and occupational decision-making processes of two groups of women in a technology college. Henwood argues that traditional approaches to examining the operation of power in social situations tended to be understood as a commodity and disproportionately distributed and wielded by specific groups over others and thus Foucault's notions of power as more diffuse offers a better approach:

a post-Foucauldian model of power as found in discourse theory is more fruitful for understanding the position of women in engineering in particular, and the relationship between gender, sexuality and work, more generally. What is required for an understanding of the lived experiences of women in education, training and work, is a theoretical framework that can offer a new approach to the relationship between the 'individual' and the 'structural'. It is in this context that insights from post-structuralist approaches, which attempt to transcend the individual-structural dualism, can prove helpful. (p.39)

For Henwood, individuals seen through the lens of subject positions are a result of a complex interconnection of discourses and not unitary subjects with power positions understood as relative solely to a material or institutional position. As such discourses struggle against one another and it is through this struggle that power relations can be seen providing insight into gender relations.

Henwood's analysis of the interviews of women studying and working in the context of software engineering revealed that discourses "structure and limit the positions women are able to take up and the space they have to speak of the contradictions and conflict they experience in their study and in their decision-making regarding future work" (p.40). The women studying software engineering were separated into one group, while men were split into two groups (one being more 'elite'). This group was deemed aggressive and, saw the women as a threat reinforcing the stereotype of engineering as a male job, while the other group of men were more supportive but in a more protective 
and paternalistic way. Both groups of men portrayed discourses of gender difference towards the women, who did not see themselves as different. Henwood notes that the limitations placed on women by the gendered discourse places them in a position of counter identification where they reject the notion of being different but are in part unable to achieve this change with speed as it would require undermining the dominance of conventional heterosexuality. Henwood recognises that equal opportunity initiatives in non-traditional educational areas for women will only be improved gradually as more women enter these fields and gain opportunities to challenge the dominant discourse.

Phipps (2007) uses FDA to build upon Henwood's work, argueing that there has been a distinct lack of progress in promoting the participation of women in science, engineering and technology (SET - a term synonymous with STEM). This disturbing lack of progress according to Phipps can be attributed to the fact that "that the "Women in SET' discourse reinforces traditional and essentialist notions of gender, many of which are implicated in the symbolic incompatibility of women and SET" (p.769). For Phipps, the conceptual underpinnings of the discourse around women in SET work to undermine equality.

Between 2001 and 2005, Phipps mapped the discourse taking place in Europe and North America at both a macro and micro level. In doing so, she identified major policy and funding agencies, more than 300 activist groups and 400 educational projects and 20,000 individuals. Her research at the macro level consisted of questionnaires sent to individuals and groups, and document analysis of reports, articles and guides in both web and print form. Micro-level discourse analysis was conducted on the interview texts of 16 women activists. Phipps (2007) gives a clear narration of how she uses FDA:

Foucault's concept of discourse will be used in this paper in order to imagine the 'Women in SET' framework as a collection of ideas and meanings and also as a structure which prescribes and prohibits various different activist and educational practices and makes available certain subject positions whilst closing down the possibility of others.... The underlying assumptions of the 'Women in SET' framework will be examined in the context of Foucault's theorisation of the interaction between knowledge, power, and practice (see for example Foucault, 1977) and the co-production of knowledge, power, and the subject (see for example Foucault, 1979). The conclusion will make some suggestions about the possible implications of how the 'Women in SET' framework is 
structured, raising fruitful questions for further research on the practices being developed in the field and the conditions of possibility these create for the production of bodies, subjectivities, and educational and gendered identities. (p. 770)

As such her work is in keeping with a standard discourse analysis approach used in FDA that focuses on power-relations in social situations. Importantly, Phipps also notes that her research does not represent the entirety of the field but can be considered indicative.

Many of Phipps' interviewees saw the issue of underrepresentation of women as related to the stereotypical gender conceptions they experienced beginning at an early age, such as encouraged interests, toys and potential career roles. The women continued to experience this gender stereotyping behaviour throughout their study and in the workforce. This behaviour from an early age is a form of indoctrination that acts to construct subject identities that are often passive in comparison to the experiences of males, and does not encourage uptake of SET subjects, interests or careers. This discourse normalises masculinity and femininity in society. The interviewees identified the difference for themselves as women who have experienced a lack of something including lack of exposure, role models or opportunity. Her interviews and document analysis identified that women see themselves as having been constructed in response to gendered social norms with their experiences and truths being different from that of men.

Phipps argues that the desire to remain within a binary discursive framework acts to promote the very binaries that the activist wish to break down. In conclusion, she argues that SET needs to become gender-neutral to challenge the barriers that keep women out of SET, though Phipps does acknowledge that achieving this within the current binary discourse is problematic. Phipps work is a good example of how FDA can challenge the traditional understanding of social situations and the role of power-relations in them. This research does this by using FDA to ask questions of what is being said and what may be going on which reposition normalised views in a different light. The work of Phipps is thought provoking and is not an example of solving a problem but is an example of challenging established thought patterns and introducing new ways of thinking about issues and as a result, increasing knowledge of how we occupy subject positions in society that act to govern and normalise behaviour often beyond our conscious awareness.

Beddoes, Schimpf and Pawley (2013) use Foucault's theories to examine gendered forms of power in the underrepresentation of women in engineering faculty. These authors analysed semi-structured interviews of 29 STEM faculty members and text 
analysis of relevant documents. They identify Foucault's notion that power is not only repressive but is also a productive force in society and that it can be examined through analysis of discourse. This is the analysis of what can be thought and said and by whom and what this tells the researcher about power relations. Beddoes and colleagues focused their particular investigation around female career pathways and experiences with parental leave policy.

Importantly, and in some ways similar to my research they did not originally start with the intention of using Foucault but arrived at this point from examining the data at hand and realising that Foucault's theories could help examine the power relations they saw in the texts. They also used axial coding practices akin to those promoted by grounded theorists or thematic analysts to identify aspects of power relations in a Foucauldian sense within the text rather than a linguistically inspired Foucauldian analysis like CDA.

They identified micro-practices within the institution that created negative behaviours and beliefs amongst female staff about having children or pregnancy as academic staff members. The female staff identified a stigma that made it difficult to openly admit or discuss issues around pregnancy or children for fear of being considered unproductive or of acting inappropriately. Taking advantage of parental leave policies was seen as opening the female staff member to negative judgement. A result of this was a low uptake by female faculty in using what were supposedly supportive policies of parental leave. The result of these practices is evidence of a gendered workspace with a dominant set of norms that place women staff members in a disadvantaged position as career academics. The very act of not taking parental leave out of fear around damaging their careers or ability to have tenure inadvertently reinforces the notion that to take leave is bad. In this way, Foucault offers a way to identify discourses and understand how they work against equality contributing to the underrepresentation of female staff in STEM faculty positions.

One of the prominent uses of Foucault and his notions of power-relations in STEM educational literature is in critiquing science education from a theoretical standpoint (e.g., Bencze \& Carter, 2011; Pierce, 2012; Sharma \& Muzaffar, 2012; Melville \& Bartley 2013). For example, Melville and Bartley (2013) use a Foucauldian-inspired Discourse Analysis to "understand the work of three teachers who have constituted identities that have allowed them to challenge the contemporary discourse of science education" (p.171). Melville and Bartley considered that school science education operates as a 
discourse that is not as has been historically portrayed, objective, mechanised or decontextualised.

Furthermore, the authors maintain that science education has remained relatively static for the last fifty years, resulting in its failure to train and attract young people. This discourse centres around the concept of disciplinary rigour which the authors claim "continues to be a major impediment to reform efforts within science education" (p.173). Coupled with this idea of rigour is the way school science is organised along compartmentalised disciplinary lines with separate professional domains where knowledge is constrained and at the same time legitimised. Melville and Bartley see that science education trains teachers to restrict "their notions of "what science is, who does science, what belongs in the science curriculum, and how best to 'deliver' the content' " (p.174) and as such conditions their identities. For Melville and Bartley (2013) science teachers and educators can through an understanding of how they are constructed as subjects in this process, form resistance to the normalised science education discourse by constructing alternative professional and personal identities.

Melville and Bartley (2013) used Foucault's concept of power/knowledge to analyse semi-structured interviews of three career science teachers. Power and knowledge are mutually reinforcing concepts that do not exist independently, power cannot be exercised without knowledge and knowledge always gives rise to power. They note that: "this understanding is important, as it guided our consideration of the narratives in terms of the teachers' changing relationship to the contemporary discourse, the evolution of their identities, and associated questions relating to power and agency" (p.178). The authors incorporated an analysis of the relationship between the display of emotions in the texts as a determinant of identity construction, relating this to how the teachers connected with contemporary discourse in science education. They determined that agency was the key to identity construction for the teachers.

The work of Melville and Bartley (2013) crosses boundaries within the field of FDA taking concepts from Foucault in particular notions of governmentality and biopower, and connecting them to discourse analysis in a genealogical manner. At points, I see a similarity in their work to Discursive Psychology and its aim to understand how mental processes are constructed in social interaction. This too has common ground with Foucault's understanding of the ethics of action and the self in his concept of biopower. Melville and Bartley bring the discussion back repeatedly to the operation of power in the discourse and its complex effect, deriving three conclusions from their study. The first is 
that teachers need an environment where the discourse supports educational practices that challenge contemporary science education and allows for an awareness of teachers emotional involvement in teaching. Secondly, that mandated curriculum in science does allow for the possibility of teachers to challenge its contemporary discourse. Finally, they conclude that while the possibility of change exists in the curriculum, teachers may lack the power as individuals to affect change within the current infrastructure of pedagogical science beyond localised settings.

This final point is an example of how power-relations and resistance occur in micro-settings. While Melville and Bartley (2013) identify that these local sites may not offer teachers a chance to gain more formal and widespread power in altering the dominant discourse, the possibility for enough of these sites to combine and create resistance in national-level curriculums remains.

In summary, the use of Foucault's theories and FDA in STEM is underdeveloped but important, and growing. Foucault's theories offer ways of looking at power-relations within STEM by examining faculty practices both educationally, and as workplaces, be they examined in isolation or as part of wider connected networks that have traditionally been ignored in STEM literature. In doing so, they offer the researcher an opportunity to question practices that have been normalised and ask how and why things are a particular way. FDA does not offer in many instances concrete solutions but it can point to alternative conceptions and new possibilities of understanding particular social situations, and from here alternative realities or solutions may be conceived.

\subsection{Alternative Methodologies}

The FDA studies described above reflect a different approach than other qualitative methodologies, such as Ethnography, Grounded Theory, and Hermeneutic Phenomenology. What follows is a brief discussion of these three methods, the type of research outcomes they produce, and why I chose FDA as my approach. In qualitative research, there are multiple interpretations of these methods largely determined by the subject matter and the theoretical position of the researcher, so what follows is, by necessity, a broad generalisation.

\section{Ethnography}


Ethnography (originally developed in anthropological and sociological research) aims to understand what is taking place in a specific group or social context, in context, and how this may relate to broader social contexts. For the most part, ethnographers investigate the complex relationships between individuals and communities by directly observing linguistic and cultural practices. In order to understand cultural phenomena, the researcher should be embedded amongst their subjects for a reasonable length of time to gain a full understanding of what is occurring. From this position the researcher can listen, observe, ask questions, participate and incorporate this experience with their notes and interviews to gain a personal view of the cultural phenomenon. As such, the personal view of the researcher is incorporated into the findings (Gold, 1997; Madison, 2011).

For example, Brown and Holloway (2008) conducted an ethnographic study of 150 international postgraduate students at an English university, to understand what they term the 'insider perspective' of the student adjustment experience. Ethnography offered the authors the opportunity to interview and observe the students over a long period. It also allowed the researcher to be embedded in the experience, participating in interviews throughout the year, and witnessing students not only in the classroom but in other social settings. The study aimed to cover the students across the whole year, and as they note in particular, they wanted to see the intense emotional experiences the students would have adjusting to the new environment. The study revealed insights into the journey international students take and developed a model to help illuminate the psychological and sociocultural adjustment stages of international students' experience.

Like Brown and Holloway (2008) I could have adopted ethnographic methods to investigate my research question. For example, I am embedded in the department, and I observe staff members in multiple social situations. I could also have selected questions to interview the academic staff that target their understanding of their experience. The focus of ethnography on multiple forms of cultural phenomenon could be used to investigate how power is experienced and manifested by lecturers in the social context of Victoria University, and could also be used to reflect on the wider processes occurring. Conducting an ethnographic study like this would place the primacy of what the academic staff perceive or explain at the forefront of the study. However, my focus is on the way the academics experience and manifest power in the teaching and learning environment. And, importantly for me, I was interested in how this could be seen in their discussions without directly drawing their attention to this. Ethnography could certainly enable me to gain an understanding of the experience of power as experienced by these individuals, 
but FDA enables me to go beyond this to see the operation of power in a larger social system. FDA specifically asks questions of the way power operates beyond the experience of individuals in a way ethnography does not by focusing on discourse. FDA is a more directly relevant toolkit for understanding how language reveals the operation of power.

Additionally, Ethnography places primacy on the person as a subject of the research, as opposed to going beyond the subject to investigate how the discourse/discursive practices shape situations and practices. To examine discourse and the operation of power in a manner that could keep my participants safe in their work environment it was also necessary for me to separate the individual as the subject from my research and focus on the discourse to reveal power structures and struggles. By using FDA, I can focus on discourse analysis in the broadest sense while reflecting on my participation.

\section{Grounded Theory}

Grounded Theory originated in the sociological work of Glaser and Strauss during the 1960s, and has since grown and morphed into several different theoretical strands; Glaser and Strauss both now hold differing interpretations. Despite the internal debates on which is the most appropriate version of Grounded Theory, all versions share a common aim: the process of identification and integration of categories of description and the analysis of the connections between these (Charmaz, 2000). The result is the creation of theory to explain particular phenomena. It is an iterative process involving data acquisition, usually in the form of interviews, and intensive data coding of the transcribed texts and other records, followed by constant comparative analysis. Traditional Grounded Theory aims to reduce the researcher's preconceptions through the constant coding of data, leading to the generation of themes and a hierarchy of abstraction to generate a theory, ideally done alongside other researchers (Kempster \& Parry, 2011). The aim is to make the researcher neutral from the data and allow for the data to generate a new theory (from the coding process) devoid of author bias (Glaser and Strauss, 1967). Traditional grounded theory believes there is a true reality to be revealed (Mills, Bonner, \& Francis, 2006).

Charmaz's relatively recent revision of Grounded Theory: Constructionist Grounded Theory allows for the position of the researcher to be accounted for and explained as it relates to the project's findings - in part addressing the issue of reflexivity by incorporating it into the findings (Charmaz, 2000; Charmaz, 2006). It also recommends studying a particular context (Charmaz, 2006). Constructivist Grounded 
Theory, unlike Traditional Grounded Theory, sees that reality is relative and truth, or what we think we know, is subjective (Mills, Bonner, \& Francis, 2006). All knowledge is acknowledged as in some way biased, and the researcher's position will always bring a perspective to the questions asked and the subsequent findings.

My current position and background in researching ECS places me in a potentially biased position. I am a participant in the discourses at work. By using Constructivist Grounded Theory I could elaborate on this personal connection with the subjects and subject matter, and at the same time develop a theory which would make sense of what is occurring from these interactions. There are however a few issues which make Grounded Theory problematic. Again, I specifically wish to examine the effect of and operation power in a specific context. As such, I do not, as a Grounded Theorist would, seek to generate a new theory, rather I am using an existing theory on a specific form of data (discourse) to examine a particular social situation. FDA considers discourse to contain evidence of processes of power and focuses on examining how these discourses facilitate what can be said, by whom, where and when. The questions and theory already exist and does not emerge from a constant iterative process of coding but from a constant searching of discourse for the operation of power in what is said or not said in a particular context.

FDA provides a discourse-analytic methodology with an inherent theoretical opposition to the very idea that language can be treated as a neutral information source from which generalizable theories can be developed in an objective/semi-objective way. FDA does not see language as neutral but rather a place where the operation of power and resistance can be witnessed and examined.

For example, Ellis and Chen (2013), conducted a study of 11 undocumented immigrant college students (people living without legal documentation to reside in the USA) using Constructivist Grounded Theory. The authors used transcribed interviews as their main source of data along with the notes developed by the researchers during the data collection and analysis stages. Themes were iteratively identified, then refined until the authors were satisfied that data saturation (where no new themes emerged from the data) was achieved, before proceeding to generate a theory from the final themes. In common with my research Ellis and Chen (2013) acknowledge and recognise that there were political and social issues that were inherent in the lived experiences of the undocumented individuals, living in a social situation that was affected by power relationships. 
Ellis and Chen's (2013) study considered a wide range of issues concluding that the students had complex emotional states and lived experiences which contributed to their understanding of their own identity. Their social situation in many ways shaped their actions and perceptions of potential actions and was an ongoing psychological negotiation between the students and their situations. The benefit of this type of study lies in its ability to inform psychologists, community workers and government employees in how to help people in these situations and as such is extremely helpful. While there are similarities to my investigation into the operation of power, there are also important differences. The most significant is that while this study can generate a theory about individuals and what they experience, there is little or no questioning of the discourse regarding what can be said, by whom, where and when in order to examine the way power operates in the wider social system. Rather the focus is on the individuals in a situation not on the system. The FDA analyst is more interested in examining discourse to reveal the systemic use of power that forms social norms and the knowledge that people use to control peoples understandings, meanings and actions.

\section{Hermeneutic Phenomenology}

Researchers adopting a phenomenological perspective seek to provide an understanding of peoples' lived experiences, as experienced by them (Laverty, 2008). Hermeneutic studies also often involve the gathering and review of interview data along with supporting contextual data. Hermeneutic Phenomenology considers that understanding is central to who we are and that this is related to one's background or 'situatedness' and through it, we determine what is real. In this way, there are some apparent similarities to Foucault and, again, there are major differences.

Foucault was critical of Phenomenology (and the same criticism can be levelled against Ethnography and Grounded Theory) because of their focus on "commentary on everyday life, and in its related form of deep exegesis of what everyday practices cover up" (Dreyfus \& Rabinow, 1983, p. 27). A good example of this is an education study by Volkmann and Anderson (1998) who conducted a study of a chemistry teacher's yearlong personal journal. They investigated how this teacher created a professional identity by considering how the teacher explained their feelings and experiences through metaphors about the dilemmas they faced. Combined with an extensive literature review and textual analysis they concluded that the teacher had struggled with three major dilemmas: "feeling like a student versus the expectation to act like an adult; wanting to care for students versus the expectation to be tough; and feeling incompetent in 
knowledge of chemistry versus the expectation to be an expert" (p. 293). These all related to the teacher's desire to adhere to an identity conception of what being a professional teacher meant to herself and what she thought others would perceive it as being. For example, the desire to make chemistry appear understandable and also fun and inspiring for students, but also maintaining the position of a subject expert while not feeling confident. This study concluded that new teachers required more institutional and collegial support both in pre-teacher education and while beginning their career teaching.

Again, the reason I have not adopted this phenomenological toolkit concerns its propriety for studying my research question, focusing as it does not just on individuals. Volkmann and Anderson (1998) focused primarily on the individual as the subject, and attribute meaning based largely upon an individual's experience to infer issues, rather than looking at the wider discourse affecting these actions or thoughts. The conclusion that there was a lack of training or support, while potentially valid, does not draw upon analysis of the wider discourse affecting this person's actions other than their description of why they did something. Foucault and FDA try to go beyond this to examine the discourse of 'individuals and systems' for meaning, rather than focus on an individual themselves. Thus FDA allows for a connection to the wider social structures in historical periods which create truth-making processes. For example, an FDA analysis of the same situation would have asked the questions: how has this situation in teaching come to be and what alternative ways of thinking or acting are allowed in this space. Foucault was concerned with what made social practices normal, and truth-bearing. By focusing on how culture acts to affect behaviour and normalise people as subjects and objects through rationalisation, Unlike hermeneutics or the other approaches discussed above, FDA research is important not just for what it tells us about something, but in that it can open up discussion and critique about the rules that shape or govern a situation (Foucault 1972). In FDA it is not only about what the discourse means but what does the discourse do and could what it does be done differently (Foucault 1972). These are questions of power and politics. 


\subsection{Summary}

In this chapter, I have detailed the theoretical aspects of FDA, and my reasoning in adopting FDA rather than other common methodologies that have been used in qualitative research. I have given examples of studies that have used FDA and have described their focus on the study of discourse and power relations. A significant theme across all of these studies is the lens that Foucault provided each of the researchers.

The work of Foucault in all of the studies discussed in the chapter has been used to provide a theoretical basis for discussions on the role of power, be it in a particular site (such as a workplace or classroom setting), or as a particular subject (for example, an employee, student or academic). Common themes exist in the work discussed above - a focus on forms of normalisation, domination and subjectification. There is also the notion of critique as a site of resistance. The primary method for using Foucault's theories as a research tool has been discourse analysis, primarily text-based either in interviews, emails or policy documents. Foucault's toolbox has led to some studies focusing on archaeological and genealogical approaches, while others have focused on biopower or governmentality, while others have combined these and other notions. The way discourse is examined has varied from an integral linguistic examination of text whereas others have used a more thematic approach, but all have attempted to connect the information under analysis to power-relations as processes within discourse.

Foucault's theories enabled concepts of knowledge and the operation of power to be examined, not to provide answers that can be considered "truth" but to facilitate examination of topics in new ways that enable the researcher to reconceptualise a different way of looking and understanding power-relations. The presentation of ideas, or research as a form of critique, is of central importance in all of these studies. As Foucault (1998) noted:

A critique is not a matter of saying that things are not right as they are. It is a matter of pointing out on what kinds of assumptions, what kinds of familiar, unchallenged, unconsidered modes of thought the practice that we accept rests. (p. 155)

FDA is a way of looking at, and questioning accepted norms to explore power-relations in practice within social situations. In the following chapter, I shall explain how I use the conceptual framework discussed in this chapter and describe a way of using Foucault's theories as a method. 



\section{ChAPTER THREE: USING FDA}

In this chapter, I shall discuss the particular approach I have used for FDA and describe the sources of text used for analysis in this thesis. This research aims to examine how the first-year teaching and learning environment is impacted on by the operation of power revealed through FDA. This research, while considering the impact of power on students, seeks to look at the teaching and learning environment using a non-student centred approach. In particular, the focus is on how lecturers experience and manifest the operation of power resulting from a STEM crisis discourse within a neoliberal educational context. As such, the research question for this thesis is: How is power experienced and manifested by lecturers in the Bachelor of Engineering (Hons) first-year teaching and learning environment at Victoria University of Wellington (VUW), New Zealand.

\subsection{Sources}

This investigation focuses on the historical and temporal context of ECS with a particular focus on 2015, as this was when I interviewed the academic staff. The primary sources of text for analysis comprise interview transcripts from 15 academic staff involved in Part 1 of the first-year BE programme. Also, textual material from NZ government reports, VUW reports and documents, such as course materials, programme reviews, strategy and policy documentation, and forum correspondence are used. As noted in chapter one I have a perspective of the context I am studying by virtue of being embedded in it. I have been employed in ECS since 2009 and have previously held a project management and researcher's position, and a pastoral care and outreach role where I developed our pastoral care system. I am currently the Student Development and Engagement Manager, with managerial oversight of our pastoral care and tutorial support programme, I am a course coordinator and lecture on two courses in ECS. In addition, in 2018 I became the Programme Director for our first-year programme coordinating the management of the teaching programme and joined the Faculty Executive management group. My employment position, since I started in 2009, has allowed me access to the teaching, managerial and social context of ECS and VUW. 
Due to my ethics requirements, I cannot include email or forum conversations by staff or provide direct textual information for all the meetings I have been in. It was made clear to me in several situations by some staff that I would not be able to gain ethics approval for certain information, such as email correspondence, as it could portray some staff or the university in a negative light. Where I have been unable to provide verifiable evidence for the things I have witnessed in ECS, I have kept my discussion of this material to a minimum.

\subsection{Context}

Typically, 150-200 students enter the first year of the BE programme. They each select one of the three majors we offer, either Electronics and Computer Systems (ECEN), Network Engineering (NWEN), or Software Engineering (SWEN). These students must attain a B average grade ( $70 \%$ or above) across Part 1 (a set of specific first-year courses) to continue in the BE. This requirement was set by ECS as a quality assurance process to satisfy the Washington Accord accreditation criteria.

Part 1 consists of a core set of papers (individual courses within a degree major) that all students in the Engineering Programmes complete, alongside a small set of specified papers tied to each major within the BE. All students are required to complete two introductory engineering papers (ENGR 101 and ENGR 110), an engineering mathematics paper (ENGR 121), and two papers on programming (COMP 102 or COMP 112, and COMP 103). Those students in the Electronics and Computer Systems Engineering major are also required to take a physics paper (PHYS 114), a further engineering calculus paper (ENGR 122), and an engineering physics paper (ENGR 142). Alternatively, students in the Software or Network Engineering majors take an engineering logic and statistics paper (ENGR 123) and an introductory physics paper (PHYS 122).

Part 1 is intended to be completed over one year but, in reality, it is often completed over two years, and in extreme cases three. In part, this is due to students electing to not take the full suite of courses during their first year. For example, some are unable to enrol in some courses because they have not met the entry requirements for particular core papers. Some students also fail a course or courses and do not achieve the B average grade across their papers. Less than $50 \%$ of students of an initial enrolling 
cohort have ever passed Part 1, and therefore been able to continue in the degree, and typically less than $25 \%$ of enrolling students ever graduate with a BE degree (Watterson, Browne, \& Carnegie, 2013; Victoria University of Wellington, 2016). As a result, we have never been able to meet our internal target, set by the inaugural Dean, of graduating 100 engineers each year.

\subsection{Participants and Data Collection}

The participants were selected by determining who was doing the most teaching on each of the first-year courses during the year. I verbally approached the teaching staff and emailed those that indicated interest in participating. At least one lecturer from each of these 11 courses, and where possible two, participated in unstructured interviews (up to 50 -minutes in length) resulting in a total of 15 interviews. The only exception to this was for the Physics (PHYS114) and Engineering Physics (ENGR142) papers. For these two papers, I interviewed an academic who had been involved in Physics (PHYS114) but had since transferred to the role of Engineering Senior Tutor for both of these courses. One of the Math academics also had the dual role of Senior Tutor in the Math Department. A senior tutor role is an academic position which involves lecturing or teaching with additional activities such as organising course tutors, teaching subject tutorials and laboratory classes, and running additional non-assessed subject support sessions for students. The current Physics (PHYS114) and Engineering Physics (ENGR142) lecturers were approached voluntarily and were not interviewed because they either declined or did not respond to the invitation.

The participants included senior academic management staff in ECS, such as the Head of School (department or programme head in charge of the School of Engineering and Computer Science (ECS) within the Faculty of Engineering(FOE)), Associate Dean Academic (a role which oversees administration of academic matters, including academic quality in the school and faculty) and Associate Dean of Students (a role which oversees administration of student affairs in the school and faculty), a Programme Director (a staff member who is in charge of one of the subject majors within the BE degree. For example, ECEN, SWEN, and NWEN). I also interviewed our first year BE Programme Director who oversees the courses for the first year (a role I now hold in ECS). 


\subsection{Text Collection and Interview Schedule}

The interviews were individual unstructured interviews (see Appendix A). Interviews were up to 50 minutes in length. They were conducted in my office and recorded for transcription. The interviews focused on asking the staff what they thought were the barriers to engineering student success at first year. Participation was voluntary, and there were no incentives provided. The interview schedule received VUW ethics approval before academics were invited to participate (see Appendix B)

\subsection{Interview Transcription Conventions}

Audio-recorded interviews with academic staff involved in first-year teaching and policymaking for ECS were anonymised and presented in a turn-taking manner during transcription. The interviews were transcribed verbatim in accordance with the approach used by Braun and Clarke (2013). The interview excerpts presented in this thesis have been adjusted for ease of reading and presented conversationally by agreement with my supervisors. Repeated words have been removed. Three ellipses at the end of a word represent the deletion of some text from the speaker when deemed repetitive or if the topic shifted away from my research area. A bracketed ellipse (.) is when there has been a pause in the conversation. A full stop is used to symbolise the end of a sentence. Bracketed laughs ((laughs)) means the person laughed. Non-verbal speech has been rendered phonetically, for example, Hmm or mm. Reported speech is shown through the use of inverted commas. Square brackets are used when I have introduced material relevant to understanding the context of the conversation.

\subsection{Presentation of Text}

Due to the nature of FDA, much of the analysis was conducted on large bodies of text. The staff interviews each often generated over 10,000 words of text and as a result had to be reduced for presentation in this thesis. Despite this, this thesis remains text heavy by necessity, and I have included information in the text excerpts that I believe are relevant to understanding my analysis. I have also limited the number of examples to ones I feel are the most applicable. The themes presented are common across the interviews, and I 
have selected specific examples rather than provide each lecturer's opinion. Also, I have applied this same process to the textual evidence from written documents. I have attempted to provide enough information for the reader to understand my analysis. In some cases, this has resulted in a large quotation. I have been reluctant to reduce some of these as I want the reader to appreciate the material in the broader context.

\subsection{Ethical Considerations}

As noted above this research was approved by the VUW ethics committee (see Appendix B). This section discusses some of the ethical considerations that specifically relate to my involvement as a researcher in my workplace.

Within engineering education much of the current research has been undertaken within what can be best described as positivist (Case \& Light, 2011). Positivism, as Denzin and Lincoln (2008) note, considers that "there is a reality out there to be studied, captured and understood" (p. 14). Positivist studies predominate in science and propagated a discourse which perceives knowledge as identifiable, objective and measurable. Such studies tend to focus on quantitative data through grade analysis or questionnaires. These studies are not very effective at understanding social processes but are very good at describing the relationships between variables.

Being embedded as a researcher in my workplace, I had a unique opportunity to apply a qualitative approach to investigating the social situation and so offer an alternative perspective on this complex issue. Moreover, crucially discourse analysis and Foucault's theoretical position provided me with a methodological framework that could account for my position as a researcher and my position embedded in the place of research. I am located within the discourses operating in the teaching and learning environment at VUW and behave in accordance with my pastoral care role. I have a political and ideological position which focuses on trying to facilitate the best possible educational and social outcomes for students. To do this, I have positioned myself in terms of a problem solver between the academic staff and the students. This role has been legitimised by ECS and VUW management. My role in pastoral care is a subject position that helps define my identity within the teaching and learning environment. FDA enables me to utilise my perspective and analysis of events as being from a particular position (which must be acknowledged) while keeping the individual interviewees safe by separating them from 
the text as individuals with personal opinions. FDA's concentration on discourse separates the focus from being attributed to the speaker's personal opinion, seeing it instead as a reflection of the rules and procedures within a system allowing me to protect the anonymity of individuals, an important aspect given their potential vulnerability as staff members (Willig \& Stainton-Rogers, 2007; See also chapter two).

Education research on your workplace and colleagues can bring into question the reliability of the findings. Rogers, Malancharuvil-Berkes, Mosley, Hui and Joseph (2005) note within social science the notion of validity has often been embraced with a so-called scientific focus to strengthen the rigour of the investigation and researchers often use a reflexive research paradigm to achieve this. This process involves the researcher openly acknowledging his or her position while also conducting triangulation of data, peer review of analysis and creating a solid paper trail to establish that the analysis is a valid representation of reality. The main intention of this process is to counter the ambiguity of the researcher and the fact that language can be interpreted in many ways. However, Rogers et al. also notes that while reflexivity is crucial for the discourse analyst in educational research, it is also difficult:

Education researchers are often researchers of familiar educational settings. As members and ex-members of the school communities that we study, we bring with us (often successful) histories of participation in those institutions as students, teachers, and parents. Thus we have embodied what Fairclough (1992) refers to as "members' resources," or what Gee (1999) refers to as "cultural models" around our participation in school that includes beliefs, assumptions and values within these contexts. Thus the classic tension between distance and closeness in the research setting is often blurred in education research. (p. 382)

I agree with Rogers et al. (2005) that the tension between distance and closeness can become blurred for a researcher. It is impossible for me to be completely neutral in my research.

The nature of my pastoral care role in resolving disputes and working to improve the learning outcomes for students within ECS gives me a particular viewpoint. My involvement in improving teaching practice and in working closely with the academic staff on courses also gives me a viewpoint on the practice and behaviour of academic staff. I am a trusted member of staff and believe that most staff are very open and honest with me. Students also feel they can confide in me. As a result, I am privy to people's 
behaviour, beliefs and the operation of their processes and reactions to organisational policies and activities.

More significantly my participation in this research, and as a staff member in my role, directly contributes to the way power operations take place in ECS. Over time I have come to believe that my pastoral care role is to improve the situation for students and in some ways, this can set me in an oppositional mind-set to some academic staff practices and institutional policies. My interest in Foucault and my experience of working in ECS made me re-think my assumptions of what was occurring in ECS. I realised that the academic staff were subject to specific discourses that shaped their behaviour. By focusing on the relationships where power affects processes, as revealed in the discourse, I have found a way to examine what was shaping behaviours of academic staff and how this impacts on the teaching and learning environment in a structural sense.

\subsection{The Researcher's Position and Limitations}

Due to my employment position, I have access to a lot of information relating to staff as individuals working at ECS and VUW. I witness many of their actions and learn their opinions. Added to this I also see the administration, business, research and teaching and learning operations of ECS and to a lesser extent VUW. In doing so I have access to information which I am unable due to ethical concerns to include in this thesis. I cannot escape that these will have coloured my presentation of data, and given my role and place in ECS, I cannot assert that my findings are neutral. However, that does not suggest that they are not a valid interpretation of the social situation I am examining. There are both benefits and disadvantages of being 'close' to the research. I have attempted to clearly explain the analysis and texts used, and a process of discussion with my supervisors was undertaken to ensure that the analysis was sensible. I am a historian, and my three supervisors comprise of a linguist and academic developer, a psychological scientist and an electronic and computer systems engineer. This mixed-disciplinary team allowed me to discuss and question the data from differing viewpoints and question what lecturers experience and how this discourse can reveal the various power structures apparent and not consciously apparent in the first-year teaching and learning environment. Bearing in mind the central thesis of FDA, that this is only one view of reality as we see it and it 
does not attempt to invalidate any other but to offer a new perspective. The following section discusses how FDA was applied to the texts.

\subsection{Method}

All analysis depends on the use of a sound methodology and the ability to present reliable evidence in support of an argument in a rigorous manner (Carter \& Little, 2007). However, unlike traditional scientific quantitative research, the sources of evidence in qualitative research are open to multiple interpretations. FDA is a Foucault - orientated procedure which can be interpreted in a wide variety of ways. Despite the absence of an agreed approach to FDA, there are a variety of guides and approaches (e.g., Kendall \& Wickham, 1999; Billig, 1997; Potter \& Wetherell, 1987; Parker, 1992; Willig 2001; Potter, 2003; Wiggins \& Potter, 2008; Thomson, 2011). What is common to all guides is that FDA analysts hold to a particular understanding of discourse as defined by Foucault. And almost all explorations using FDA focus on the enactment of power in a particular socio-historical context as explained in chapter two. However, a brief summary follows to assist the reader. FDA treats discourse as a representation of reality that has been culturally constructed, and in itself constructs knowledge that functions to allow and disallow what can be discussed, and acted upon and by whom. As such discourse acts to create and reproduce acts of power and knowledge. Power and knowledge are intertwined in FDA. FDA also acknowledges that while a hierarchy in society exists the discourse shaping action and belief is both top down and bottom up. Discourse reveals how some cultural and societal practices have been taken to be true and others have been disregarded. Discourses also change over time. (Thomson, 2011).

Thomson (2011, A Foucauldian notion of discourse, para 2) has an excellent summary of how a researcher can use FDA as a tool for investigation by asking the following questions of text:

1. What is being represented here as a truth or as a norm?

2. How is this constructed? What 'evidence' is used? What is left out? What is foregrounded and backgrounded? What is made problematic and what is not? What alternative meanings/explanations are ignored?

What is kept apart and what is joined together?

3. What interests are being mobilised and served by this and what are not? 
4. How has this come to be?

5. What identities, actions, practices are made possible and /or desirable and/or required by this way of thinking/talking/understanding? What are disallowed? What is normalised and what is pathologised?

This summary is similar to the methods discussed in Kendall \& Wickham, 1999; Billig, 1997; Potter \& Wetherell, 1987; Parker, 1992; Willig 2001; Potter, 2003; Wiggins \& Potter, 2008).

In this thesis, I examined texts related to the teaching and learning environment. These documentary texts were broadly comprised of staff interviews, forum conversations, course syllabi and material from first-year ECS courses, enrolment and marketing material from VUW and ECS, together with Government and VUW information relating to tertiary strategy and policy. This contextual material relates to the areas identified in the staff transcripts and was subjected to analysis with the categories above to identify discourses and their effects. A theme was identified when the data suggested a common recurrence across texts (inductive approach) and when I perceived a similarity to my personal experience of processes and discussions in ECS (a priori) (Fusch \& Ness, 2015; Walker, 2012; Ryan, 2003).

This process can be described as somewhat akin to that commonly applied in a Constructivist Grounded Theory approach, where the data is constantly questioned for similarities, and then coded (Chamez, 2000, 2006). My process also has similarities to a thematic discourse analysis in that I sought to identify specific themes and group similar texts together for questioning (Taylor \& Ussher, 2001; Potter \& Wetherell, 1987). It is within this process that the themes are examined within the texts, rather than a linguistic analysis, and these themes are then subjected to a series of questions from a Foucauldian theoretical standpoint. This is where the discourse analysis becomes a Foucauldianinspired form of discourse analysis.

I analysed the text by asking the questions suggested above by Thomson (2011) and was informed by my understanding of Foucault's ideas. This resulted in the selection of specific passages in the texts that related to each other and reflected an association with my area of research. In doing so my aim was to locate objects (such as NCEA exams, tutorials etc) and subjects (lecturers, teachers etc) within the text. When these were located it was a matter of looking for what could be expressed or said by the object or subject while considering what was acceptable or not within a set of rules and processes that constituted a norm. 
The next stage of this process was to map a larger picture of the discursive environment (this mapping process led to the construction of Table 4.1 discussed in the following chapter). For example, what existed in the educational, socio-political and cultural teaching and learning space both within and beyond the classroom experience. This process is central to seeing how practices are both enacted and resisted within the text. For example, how would a lecturer react to a change in enrolment criteria, what could they say or do and what connects or surrounds their actions and the variability of their responses. The mapping of the situation reveals an interconnected web of ideas connected to other forms of discourse. One way to see this is to consider the education system at a university and then, for example, to look at the discourse relating to employment for graduates versus non-graduates. This action expands and alters the framing of a discourse in relation to other discourses. There is a tension between desiring to limit this scope while at the same time revealing the processes at work. Importantly, for the researcher, while this research takes place one must be cognizant of one's own inherent framing of the discourse. For example, I could see things from a particular racist discourse when in fact it may be more or less than this.

One aspect of this discourse analysis, inherent in FDA, is to look for where the discourse supports the role of institutions as this is a way to see how a pattern or development has occurred historically in places that reflect significant societal influence. Foucault's classic examples are mental hospitals, Madness and Civilization: A History of Insanity in the Age of Reason (1961) and prisons, Discipline and Punish: The Birth of the Prison (1975). Often a discourse can be revealed through the reproduction of ideologies and acts of resistance to ideologies, and this can be seen historically in many social upheavals. Religious upheaval, such as the Protestant Revolution is one example of this. These questions align with Foucault's theories about knowledge and power and can be applied to the textual sources.

The aim of this research is to uncover the operation of power in a social situation, how a situation has come to be and what interests, identities, practices and actions are encouraged or disallowed. From a Foucauldian perspective, these power relationships produce norms of behaviour that are both visible and invisible to participants. Invisible norms constitute processes of which individuals are not consciously aware but which they are actors in producing (Dunkle, 2010). By following these processes, discursive practices which may affect the first year teaching environment were revealed. These provided a 
counter position to the traditional narrative of engineering educational discourse, which has placed the student at the centre of a dispersive and pervasive 'regime of truth'.

\subsection{Summary}

This chapter has detailed the FDA method I have used to examine the discourse, and the issues involved in doing so. It also outlined my place as a researcher and the ethical considerations and limitations related to this. This chapter has also detailed the form of my data collection and the sources used for analysis. The following chapters present this analysis. In order to provide a narrative framework for the reader, the following chapter describes my framing of the discursive field, within a conceptual framework of ownership to identify the operation of power at work. 



\section{CHAPTER FOUR: OWNERSHIP AND THE DISCURSIVE FIELD}

University, lecturers and students are all part of an educational setting, that along with the Government and businesses constitute a complex network of power relationships. As discussed in chapter two this educational setting and context can be conceptualised as a discursive field. This chapter outlines my framing of this discursive field.

In FDA it is important to establish the context of what is going to be examined. Rather than conduct a comparative analysis of the changes over time, as with Foucault's treatises, Madness and Civilization: A History of Insanity in the Age of Reason or Discipline and Punish: The Birth of the Prison, in accordance with other forms of FDA (see chapter two) I focus on a specific discursive field and limit my investigation to a particular period. This context is the social setting where the examination of discourse will take place. It is what Foucault termed a discursive formation or field: the place where knowledge and ways of thinking are ordered by rules. These are rules that determine what people believe and how people act in a given system and often go beyond a person's conscious understanding of why they may do certain things (Foucault, 1972). Discursive fields can be seen in specific disciplines or domains such as, medicine, a religion, a legal system, higher education to name a few. Discourse operates within particular aspects of these contexts, for example, the way language and processes within an operating theatre define what is acceptable or not, who can do something or not and what specific roles subjects play such as the surgeon or patient. What is important is that these are places where the construction of meaning about correct or incorrect behaviour are developed, and these meanings formulate truths.

A crucial aspect of my analysis was to understand the context for my study and map the discursive field. To do this, I re-examined my literature review looking for specific instances where I could identify connections between factors in the discursive field. This was largely based on my personal experience working in a university environment and in relation to my interpretation of student interviews. In addition, I examined the lecturer interviews for discourse that indicated connections to institutions or systems. As noted previously, Foucault notes that discourses are not solely ways of speaking or in written texts but are also connected to institutions (Foucault, 1973). The aim was to contextualise the web of interconnected factors in a teaching and learning 
environment to examine the operation of power through discourse. In doing so the aim is to develop an understanding of the way factors, such as, how the lecturers connected to, for example, the Government need for more engineering graduates. Thus, an understanding of the context: the teaching and learning environment, was crucial to framing the operation of power.

The tertiary education teaching and learning environment is perhaps most commonly considered to be the classroom, lecture, laboratory and tutorial (Entwistle, McCune, \& Hounsell, 2002), however broadly speaking the teaching and learning environment refers to the context in which a university operates, as well as the classroom itself. The teaching and learning environment is part of a broader academic system. Patterson (2001) uses Clark's (1983) model to suggest that the tertiary: “...academic system has three main segments: the understructure, consisting of the operating units and departments; the middlestructure, which is the institution itself; and the superstructure, which is the wider system and its inter-institutional links" (p. 164). Patterson describes the academic system; as a complex interaction of interpretation and behaviour between these three groups:

The understructure segment is made up of a disunited aggregation of disciplines and professional fields, a loosely coupled system. The superstructure comprises the state-constructed administrative pyramid, which, in contrast to the understructure, seeks to impose order, to coordinate, to systematise, to make more uniform the otherwise fragmented segments, enterprises and sectors. It stresses hierarchy and formal links. Requiring the formulation of goals and their articulation in institutional charters and formal statements of mission, and the measurement of performance through goal achievement are methods by which the superstructure can achieve order and impose its priorities on the system. (pp. 164-165)

I consider VUW to be part of this broader system or network where rights and responsibilities are interpreted and enacted.

For example, VUW is a publicly-funded NZ institution operating both nationally and internationally as part of a global tertiary sector. The university environment includes the immediate situation such as the operating practices and policies that encompass the business of an educational institution, for example, funding, research, administration, teaching and public engagement (New Zealand Government, Education Act, 1989). 
These practices and policies are in turn translated by disciplinary departments into dayto-day processes and behaviours which impact the practices of lecturers. Lecturers experience the operation of power within their larger network, and in turn, they manifest or react to power in ways that impact the learning-teaching environment.

The tertiary education teaching and learning environment is a discursive field with its own rules and regulations. Foucault describes discursive fields as having an apparatus - which is the operation of a central or dominant strategic function within the discursive formation (rules, regulations, practices) that connects all the elements through the operation of power (Foucault, 1980). In the context of this study, the strategic need for the retention of engineering students through to graduation to meet national economic goals forms the central apparatus in the discursive field (Ministry of Education, 2014). The discursive formation is ordered by the practices of the multiple parties involved, and their interpretations of the rules, regulations, practices, and beliefs. These practices regulate behaviour and norms in a social space and become representative of 'correct' knowledge. ECS is a part of the discursive formation of tertiary education at VUW, in New Zealand. ECS is connected to the system or 'apparatus' in Foucault's terminology, which stretches from enrolment through to classroom practice all the way up through a succession of educational micro-contexts to the NZ government. The NZ tertiary educational environment is also connected to the wider global economic and tertiary educational environment.

Table 4.1 below is the result of my analysis, from the literature described in the preceding chapters, documentary texts and the lecturer interviews, of the discursive field, represented as the teaching and learning environment. It is an overview of the context and also represents a snapshot of the power networks at work in this context which is discussed throughout this thesis. Table 4.1 outlines ownership, which is the right to act, to use privilege or power, or to not use them and the responsibility or accountability between various groups and individuals who impact the tertiary education teachinglearning environment. This allows us to see who owns (or can exert power) over specific aspects of that environment. There are, of course, many groups not mentioned that also effect (and are affected by) this, such as student tutors, administration staff, as well as outside influences like family. This study focuses on the lecturers and as a result limits investigation to the groups identified in Table 4.1. 
Table 4.1

Ownership and the Discursive Field: Rights and responsibilities operating in the first-year tertiary teaching and learning environment

\begin{tabular}{|c|c|c|}
\hline Group & Rights & Responsibilities \\
\hline $\begin{array}{l}\text { Business \& } \\
\text { Professional } \\
\text { Bodies }\end{array}$ & $\begin{array}{l}\text { Numbers of graduates; Graduates with } \\
\text { certain adequate skills }\end{array}$ & $\begin{array}{l}\text { Employment of } \\
\text { graduates; feedback to } \\
\text { Government and } \\
\text { university sector on } \\
\text { quality of graduates; } \\
\text { Accreditation and } \\
\text { recognition of Degree }\end{array}$ \\
\hline Government & $\begin{array}{l}\text { Demand for Quality Education for } \\
\text { national and International standards; } \\
\text { Demand of quantity of graduates; } \\
\text { Demand of accountability; Provide } \\
\text { funding; Right to withdraw funding; } \\
\text { Make laws that govern conditions }\end{array}$ & $\begin{array}{l}\text { Funding; Negotiate with } \\
\text { the business } \\
\text { community; Authorise, } \\
\text { legitimize and provide } \\
\text { educational certification }\end{array}$ \\
\hline University & $\begin{array}{l}\text { Interpret Government policies into } \\
\text { institutional strategy and policy; } \\
\text { Disburse resources according to } \\
\text { priorities; Expect academics to meet } \\
\text { policies; Expect Government to support } \\
\text { through funding; Expect Government } \\
\text { to support through policies; Expect } \\
\text { Government to set reasonable } \\
\text { accountability targets }\end{array}$ & $\begin{array}{l}\text { Provide a teaching and } \\
\text { learning (including } \\
\text { research) physical } \\
\text { space; Provide lecturers } \\
\text { with appropriate } \\
\text { workload (jobs); } \\
\text { Provide an opportunity } \\
\text { for lecturers to research; } \\
\text { Facilitate } \\
\text { communication of } \\
\text { processes; Meet } \\
\text { Government } \\
\text { accountability targets; } \\
\text { Set policies to meet } \\
\text { needs of all students; } \\
\text { Meet accountability } \\
\text { reporting demands }\end{array}$ \\
\hline Lecturer & $\begin{array}{l}\text { Prepared students (from High School); } \\
\text { Adequate funding; Academic freedom; } \\
\text { Ability to conduct research }\end{array}$ & $\begin{array}{l}\text { Teach; Produce } \\
\text { adequate and aligned } \\
\text { curriculum; Design } \\
\text { appropriate assessment; } \\
\text { Deliver quality teaching } \\
\text { in the classroom; } \\
\text { Deliver quality research }\end{array}$ \\
\hline Student & $\begin{array}{l}\text { The expectation that all parties above } \\
\text { will construct frameworks from which } \\
\text { they can learn; Expectation of quality } \\
\text { teaching; Expectation that education } \\
\text { will lead to employment }\end{array}$ & $\begin{array}{l}\text { Arrive academically } \\
\text { prepared for first-year; } \\
\text { Do the required work; } \\
\text { Prepare themselves } \\
\text { when here for current } \\
\text { and subsequent study; } \\
\text { Pay fees }\end{array}$ \\
\hline
\end{tabular}


This discursive field can be understood as a discourse of ownership in the teaching and learning environment. Ownership is my conceptual way to visualise the operation and effect of power in the discourse. Ownership in terms of rights and responsibilities is reflected in many forms of discourse investigated in this thesis and influences the practices and behaviours in the teaching and learning environment by both individuals and organisations (within both Government and University).

Ownership is a well-used concept in business, economics and organizational management, psychology, and behavioural studies (Halonen, 2002; Collin, 1998; Hammer \& Stern, 1980; Graves \& Waddock, 1990; Herman, 1981; Manning \& Ginger, 2007; Boughton \& Mourmouras, 2002; Cotton, Vollrath, Froggatt, Lengnick-Hall, \& Jennings, 1988; Rainer \& Matthews, 2002; Pierce, Rubenfeld, \& Morgan, 1991; Pierce, Kostova, \& Dirks, 2001; Klein, 1987; Lee \& Koh, 2001; Dale \& Burrell, 2007; Thompson \& McHugh, 2009). These studies consider that organisations utilize processes both formal and psychological that impact on employee attitudes and behaviours, though there is no single theory or model.

What is consistent in many of these studies is the role individuals' actions play in shaping the environment. For example, there are a number of studies that take the psychological factors encompassing an individual's actions as a central focus (e.g. Pierce, Kostova \& Dirks, 2001; Van Dyne \& Pierce, 2004; Dagan, 2007). In these studies, ownership is considered to be the action of exercising control over others to facilitate particular practices and is conducted at varying levels by different groups within an institution. For example, business owners, managers or employees. These studies explain ownership as a feeling and behaviour by staff, often encouraged by their employers, of belonging to or 'owning' their position and its duties. There are often positive benefits from these actions, like improved employee commitment, satisfaction and work effectiveness, related to employees' exercising control and being personally invested in the organisation's goals. Negative effects include a resistance to change and cooperation, the misuses of discretionary power, a lack of quality control and a sense of individual possession in a particular role (Van Dyne, \& Pierce, 2004).

Because my research is focused on what the discourse reveals about processes in the socio-cultural setting, it is not a psychological study of behaviour but a study that looks at discourse to see how processes control actions and beliefs and how these become normalised. Foucault offers a theoretical approach to the understanding of power in operation that most behavioural, psychological or organisational studies do not. Foucault 
defined the exercise of power as "...a way in which certain actions may structure the field of other possible actions. What, therefore, would be proper to a relationship of power is that it be a mode of action upon actions" (Foucault, 1983, p. 222). Ownership in the teaching and learning space is the process of enacting power, by various groups and individuals over subjects within a discursive field.

The exercise of ownership, the actions taken, and the perceptions developed through this process demonstrate the way power relations create a subject, create truth (Foucault, 1975). For example, (as will be discussed in more detail in the next chapter) having a set entry criteria for students by the university controls who has access to study. It also sets up an expectation and practices in the teaching environment that the teaching staff will get a student with a certain background. Within this process there are certain rights and responsibilities, such as: the right for a lecturer to expect the university to have selected appropriate students of a particular academic ability; the right of the student to believe they will be capable of success in a course due to having been given entry; the responsibility of the lecturer to design an appropriate level course for the students, the responsibility of the university to make sure that the entry criteria is appropriate and meets the Government Education laws. While there are quite a few more interconnected parts to this example, it does provide a glimpse of how various groups and individuals have rights and responsibilities.

Without the action of ownership and its implied act of control, the process of power does not exist (Foucault, 1983). For Foucault, power does not exist until it is put into action. The form of action that this can take may result from a series of seemingly different situations (disparate possibilities) that all inadvertently act upon seemingly permanent social structures (Foucault, 1983). It is important to realise that resistance to actions of power can also have effects on subjects and so is also a component of ownership. For example, as a later chapter will also discuss in detail, the pressure for an academic to deliver research outputs can come from institutional rules. This pressure effects academics in different ways and one way some academics may cope with this is to reduce the time and effort spent on course design. This act is a form of resistance.

The very relationships between these disparate possibilities within the structure identified in Table 4.1 involve the operation of ownership through the rights and responsibilities of each group.

Power is exercised through ownership in an educational environment by institutions and individuals, and is exerted both consciously and unconsciously as modes 
of control. In this environment there exist multiple hierarchal tiers that operate either independently or in association with other aspects of the educational apparatus. In this sense, ownership provides an active visible process or function in the discourse and can be seen in the statements and messages received.

When the lecturer transcripts, policy documentation and literature were compared, a number of subthemes emerged relating to the operation of power and 'ownership' in the teaching and learning environment: ownership of the STEM crisis; ownership of entry; ownership of courses; ownership of teaching and learning and ownership of the academics. With that said, I would urge the reader to read the following sections and chapters, not as discrete themes but as parts of a greater whole. All of these themes are connected and interact within the discursive field. The separation of these into themes is a way of helping the reader understand what may be happening in the social situation but the themes themselves are not disconnected, but rather blend together.

The following section uses the example of the STEM crisis discourse to examine how the meanings generated from this discourse impact on the processes of teaching and learning at VUW and ECS.

\subsection{The STEM Crisis Discourse and VUW}

As previously discussed (see chapter one) the STEM (Science, Technology, Engineering and Math) crisis refers to the belief by many Governments and technology companies that there is a worldwide shortage of people trained in the STEM fields - so much so, that it is widely accepted that unless this crisis is addressed, many countries will face economic and security challenges. The current STEM crisis, for some, has been linked to similar concerns which began over a hundred years ago, or to the Soviet launch of Sputnik in 1957 (Ostler, 2015). However, it is generally agreed that the crisis began in the 1990s as technology became a more important aspect of the workplace and gained acceptance as a meta-discipline crisis in the early 2000s (Ostler, 2015). The STEM crisis discourse includes the actions taken by Governments and educational institutions to rectify this shortage. This section discusses the effect of this discourse in several key areas.

The political drive to have effective educational programmes in STEM, and in particular, in engineering, frames the context in which ECS operates. Economic need places increasing pressure on educational policy in New Zealand (Tertiary Education 
Commission, 2014). For the Government, there is a considerable desire to increase the number of STEM-graduates to assist in the country's future economic stability (Ministry of Business, Innovation \& Employment, 2014; Ministry of Business, Innovation \& Employment, 2017; McLaughlin, 2003). VUW is a public university, receiving substantial funding from the Government. The New Zealand Universities Council noted that "...universities receive approximately $40 \%$ of their annual income from government grants..." (New Zealand Universities Council, 2016). This funding is attached to what the Government Tertiary Education Commission (TEC) - the body which sets university operating policy - dictates as important (New Zealand Productivity Commission, 2016).

One of the key goals set by the New Zealand Government and the TEC is the recruitment and retention of engineering students through to graduation. This is clear in the messages New Zealand universities receive. For example, in a 2012 press release the New Zealand Minister for Education announced a goal for tertiary institutions to produce 500 more engineering graduates every year from 2017 :

New Zealand has an undersupply of engineers. Historically the number we
have been training is about half the OECD average... The reality is if we
want faster economic growth for New Zealand then we need to invest in
skills that will help grow the economy. Having more engineers will assist
in building a more productive and competitive economy. (Joyce, 2012)
[Non-Interviewed Extract 1]

Similar arguments, based on the desire for economic growth have been made in countries such as, Australia (Senate Committee for Education, Employment and Workplace Relations, 2012, The Shortage of Engineering and Related Employment Skills, Final Report, Canberra, 2012), the United Kingdom (HL Paper 37, 2012) and in the United States of America (US Senate Joint Economic Committee, 2012).

In the case of the NZ Government's press release above, there is a clear discourse at work - that is a direct message that NZ tertiary institutions must increase provision for recruiting and teaching students in engineering and that the country is relying upon them to do so for everybody's economic well-being. This message from 2012 was heard by some of the university institutions given a later press release. On 4 August 2016, the Tertiary Education, Skills and Employment Minister Steven Joyce announced that the tertiary sector was beginning to deliver results that reflected a commitment to The Tertiary Education Strategy 2014-2019, noting that "In 2015, engineering students represented 6.5 per cent of all students studying at that level, up from 4.9 per cent in 
2008” (Joyce, 2016). Joyce announced that: “It's great to see so many students engaged in areas where they're likely to head into a solid, well-paying career where demand is high and likely to continue to grow" (Joyce, 2016). What we see here in the discourse is the operation of power, used by the Government to legitimise what they see as a successful student outcome where the student is "likely to head into a solid, well-paying career where demand is high and likely to continue to grow". Not only is this discourse suggesting what a good student outcome is but it is suggesting that a good tertiary organisation is one that prepares students for this outcome and thus meets the goals of the Government and the STEM crisis discourse.

The STEM crisis is a multi-layered and hierarchical discourse that has an economic goal. The creation of the BE at VUW in 2007 was an attempt to meet the requirements of the STEM crisis for more engineers and was realised as an opportunity by VUW to capitalise on this need. For example, Victoria University of Wellington, Draft Business Case for the Establishment of a Bachelor of Engineering (2005); Victoria University of Wellington, Finance Committee Abridged Business Plan: Draft BE Business Case (2005) and the Victoria University of Wellington, Senior Management Team Memo for Draft BE Business Plan (2005) all argue for the economic and strategic advantage VUW would gain by offering a BE. These reports circulated to senior management at VUW including senior financial advisors identify numerous opportunities to develop the BE through additional funding, connections with Government and industry, the alignment of national goals (e.g. the ICT Taskforce Report, 2003 and the Digital Strategy Report, 2005) and the obvious opportunity to increase funding through enrolments. For example, the Draft Business Case for the Establishment of a Bachelor of Engineering (2005) includes many positioning statements like this one:

Victoria University is taking advantage of increasing opportunities in the engineering/technology sector. The government has a strategic focus on technology; there is high industry demand for graduates in the ICT sector; and strong growth across the New Zealand tertiary sector in engineering and technology enrolments. (p. 4) [Non-Interviewed Extract 2]

This excerpt identifies the Government's strategic focus and strong tertiary enrolments in engineering as an opportunity to be taken advantage of. It can be seen that the need to develop a BE programme does not come solely from the desire to address an educational gap in NZ but also for economic benefit. 
This economic imperative is clearest in the numerous mentions within these reports of the threat to student enrolment numbers and the economic wellbeing of VUW of another tertiary institution offering engineering degrees in Wellington. For example, in the Draft Business Case for the Establishment of a Bachelor of Engineering (2005), there are statements such as:

Students who have previously gone from Wellington to other locations to study engineering will be attracted by the lower cost of staying in Wellington and the strong academic positioning of the Victoria degree relative to the Massey equivalent. (p. 9) [Non-Interviewed Extract 3]

This excerpt, suggests that the yet to be offered VUW BE will be seen as a better choice for students. The location argument is followed up with a statement designed to suggest that the VUW degree will be more prestigious for students: "the strong academic positioning of the Victoria degree relative to the Massey equivalent".

The excerpt below gives more details to this argument suggesting that through academic quality VUW could quickly displace Massey or Auckland University of Technology to be the third-placed engineering provider:

There are seven universities that offer engineering degrees or degrees closely aligned with engineering. Of these Auckland and Canterbury have the largest student enrolments, a broad range of offerings and are highly respected in the market. Auckland University of Technology (AUT) is the next largest, offering a broad range of courses but with a lower target demographic and reputation. Otago has a degree in Applied Sciences that focuses on niche areas and has been successful in building a reputation in these areas. Direct competition will come from Massey's establishment of an engineering degree on its Wellington Campus. Victoria's BE will position itself in a similar way to Otago's relative to other universities. A niche focus with strong research and teaching will position the $\mathrm{BE}$ as the leading Wellington engineering degree for academic achievers. As the degree successfully builds its reputation there is an opportunity for Victoria to be ranked third in PBRF for engineering and technology. (Victoria University of Wellington, Draft Business Case for the Establishment of a Bachelor of Engineering, 2005, p. 10) [NonInterviewed Extract 4] 
Significantly this claim identifies the creation of the BE as an opportunity for VUW to attain success in the Government research ranking system Performance-Based Research Fund (PBRF). This system is discussed in detail in chapter seven but is broadly speaking a Government ranking system for universities that has implications for reputation and funding and also affects individual academic promotions.

The following extract indicates that VUW has performed poorly in its current technology degrees when compared with the strong growth seen elsewhere in student numbers - which are a major funding component of public universities:

- Enrolment in engineering and technology degrees in New Zealand has grown strongly over the past five years.

- The total number of international EFTS in all New Zealand engineering programmes has increased by $333 \%$ since 2000 , while the number of domestic EFTS in the same period has increased by $10 \%$.

- Victoria has underperformed domestically and internationally with negative growth in technology education (BIT and BScTech) since 2003.

- Massey University has developed programmes to meet demands for technology professionals, establishing an engineering specialisation in Wellington (Victoria University of Wellington, Draft Business Case for the Establishment of a Bachelor of Engineering, 2005, p. 13). [NonInterviewed Extract 5]

Poor performance is articulated as a failure to grow student numbers. EFTS refers to Equivalent Full-Time Student Unit and is how the Government calculates university funding relating to domestic student numbers. One Equivalent Full-Time Student Unit is considered to be the full-time workload a student would undertake in a given 12 month period. The workload is based on the credits a course is worth where one credit is 10 hours of study. A single EFTS is 120 credits being 1200 hours (Ministry of Education, 2016).

The Draft Business Case for the Establishment of a Bachelor of Engineering (2005), also identified that there were no short-term staff losses as a result of Massey offering Engineering degrees in Wellington but that: "staff positions will be at risk in the medium term if technology EFTS are lost to Massey" p. 22. All of the language in this report is in keeping with the aims of a business case, as one might expect. However, the 
report does emphasise the interconnectedness of the business agenda to the teaching and learning environment and does suggest that beyond the educational need there is the desire for financial benefit. The decision to develop the programme was not purely for education reasons.

A similar use of language and argument also exists in The Finance Committee Abridged Business Plan: Draft BE Business Case (2005), which also identifies the market demand for graduates and a need to occupy this space to compete for students with Massey University:

The new degree will enable Victoria to capture some of the forecast growth in the market for ICT-professionals, to better apply and market the skills of its existing staff. A further impetus is the commencement in 2006 by Massey of several BE ICT majors in Wellington. In endorsing the BE proposal, SMT have acknowledged this market opportunity and the significant threat posed by Massey. It is believed Victoria can ably compete and succeed. (p. 1) [Non-Interviewed Extract 5]

The fear of reduced income to VUW and staff losses at VUW if Massey teaches engineering in Wellington is also clear:

From 2006, Massey will deliver several related engineering majors from Wellington. These will pose a direct threat to Victoria's existing technology degrees - the Bachelor of Science \& Technology (BScTech) and the Bachelor of Information Technology (BIT). With already low visibility in electronics, the BScTech will become unviable when threatened by a Wellington IPENZ accredited engineering programme. Without action, both programmes will encounter difficulties securing any of the forecast student demand - or even retaining their current share. Given the active recruitment drive by Massey, key staff may also be lost. (Victoria University of Wellington, The Finance Committee Abridged Business Plan: Draft BE Business Case, 2005, p. 3) [Non-Interviewed Extract 6]

Extract 6 contains language that is emotive and designed to create fear. For example, "direct threat", "low visibility" and difficulty encountering...student demand" generate fear of low student numbers. This is followed by the comment that "key staff" may be lost. The use of "key" also generates the fear of losing important people and is stressing 
to the management audience that something urgent needs to be done. Related ideas are also expressed to the VUW Senior Management Team:

There is a national and international trend to develop ICT education within the context of engineering. The University of Auckland ('Auckland'), University of Waikato ('Waikato'), University of Canterbury ('Canterbury) and Massey University ('Massey) have introduced ICTengineering programmes in recent years.

From 2006, Massey will deliver several related majors from Wellington. These will pose a direct threat to Victoria's Bachelor of Science \& Technology (BScTech) and Bachelor of Information Technology (BIT) programmes. With already low visibility in electronics, the BScTech will become unviable when threatened by a Wellington accredited engineering programme. Similarly, the BIT will experience difficulties securing any of the market forecast for ICT tertiary degrees when confronted with the Massey programme. Action is required.

A solution is significant investment in Victoria's existing technology based degrees (BScTech and BIT). A strategy is to upgrade existing offerings and facilities; to recruit new staff; to seek IPENZ accreditation and to market the resulting programme as a Bachelor of Engineering (BE). This will contribute to achievement of national political and economic goals and Victoria's Strategic Plan. The BE will deflect the threat from Massey and lead to increased enrolments of higher quality students. New staff will open new areas for research at Victoria while collaborating with existing personnel and industry. (Victoria University of Wellington, Senior Management Team Memo for Draft BE Business Plan, 2005, p. 2) [Non-Interviewed Extract 7]

This excerpt also connects the VUW strategy to: "a national and international trend to develop ICT education within the context of engineering" and "contribute to achievement of national political and economic goals". These statements are examples of the neoliberal STEM crisis discourse. The connection between education and business is quite clear revealing a competitive tertiary educational environment focused on business goals, targets and strategy.

What is apparent to the reader is that all of these reports describe an agenda to address potential risks through the launching of a new degree. The excerpts contain 
language that can be described as fearful, in the use of language like: "direct threat", "Action is required" or as the next extract which contains "Annihilate".

The most direct competition for Victoria is Massey, which ranked sixth in PBRF. Over recent years it has converted its Faculty of Technology into a new School of Technology and Engineering. It has expanded its offering from Palmerston North to Albany and has launched new offerings from 2006 for Wellington in software engineering, mechatronics and multimedia systems engineering. The driver for introducing these subjects in Wellington is a 'major shortage' (Massey University website) of graduates to meet industry needs, a captive market in Wellington given its lifestyle and growing reputation and the potential to link into the fast-developing creative industries in the region. The introduction by Massey of software engineering and mechatronics programmes in Wellington threatens to:

- Annihilate the low visibility electronics programme at Victoria with consequent flow on to physics enrolments;

- Annihilate the under resourced computer system engineering specialisation in the BIT; and

- Lower Victoria's potential market share of the forecast growth in demand for ICT education.

The attached scenario analysis quantifies the consequences of inaction by Victoria despite the arrival of Massey to the market. (Victoria University of Wellington, Senior Management Team Memo for Draft BE Business Plan, 2005, p. 5) [Non-Interviewed Extract 8]

These reports which were circulated amongst senior management at VUW express the notion that the University has the right to claim or own a disciplinary learning and teaching space. This can be seen in the excerpts above where they refer to "Victoria's potential market share". The question is not asked if it is the right thing to do, or if perhaps supporting the other institution by VUW not offering a BE may be a better use of Government taxpayer funded resources. The impact on Massey or its staff and students is not considered either economically or socially. Though it would be fair to say that the implication that it would affect these groups is implied and in doing so the discourse justifies the correctness of business decisions. This is a truth-making process indicating the power of the neoliberal economic discourse. VUW as an organisation were proposing 
an economic market-driven decision designed to strengthen its position while reducing the position and operation of the other institution and is an example of power operating in the teaching and learning space. This operation of power is an example of the neoliberal STEM crisis 'apparatus' operating in the discursive field.

The ECS foundational documentation reveals what Thornton and Ocasio (1999) argue:

while power and politics are present in all organizations, the sources of power, its meaning, and its consequences are contingent on higher-order institutional logics. Institutional logics define the rules of the game by which executive power is gained, maintained, and lost in organizations.... Moreover, institutional logics are historically variant and are shaped by economic and social structural changes. (p. 802)

As such we can see that ownership of the teaching and learning environment does not solely belong to those teaching in the classroom (if at all). The exercise of power exerted from the Government's drive for economic growth results in direct intervention in 'public' universities' strategic directions and funding. The implications of this act of 'ownership' resulted in the university acting as a business and seizing a market opportunity in the creation of the BE. This is itself, is not necessarily a bad thing, but it does reveal the operation of power in the teaching and learning environment. It also highlights the continued neoliberal educational agenda that emphasises economic growth through the development of educational offerings.

The following section discusses this discourse further in relation to the need for increased recruitment and retention of students.

\subsection{Recruitment and Retention}

Beyond the formation of the degree the STEM crisis discourse and its inherent neoliberal business imperative can also be seen in the discourse around recruitment and retention at VUW. An example of the recruitment and retention discourse can be seen in the background to my employment position in ECS which has a direct connection to the teaching and learning environment. The original Government TEC project PFF838: Engineering Pathways Programme: Digital Engineering, which ran from May 2009 to July 2012, which ultimately resulted in my pastoral care job was directly tasked with 
improving both the uptake of engineering by students and their first-year pass rates. For example, the project's revised milestones approved by the TEC state: "The purpose of this project is to increase the successful completion rate of students in the Wellington region who wish to pursue an engineering qualification and to make such a qualification accessible to a wider range of students than is currently achieved" (PFF838: Engineering Pathways Programme: Digital Engineering, Revised Milestones, 15 June 2010, p. 1). This discourse illustrates an imperative to increase the numbers of students passing and ultimately graduating.

During the TEC project, ECS realised that the need to retain and recruit students was of such importance that improving this situation became a full-time job for me. After finishing my role as project manager in 2012, I then took up the position of 'Project and Outreach Manager', and in 2013 this became 'Pastoral Care and Outreach Manager'. My role has a direct business motivation to effect an increase in the numbers of first-year students recruited and retained. For example, one of my key performance areas was to increase the percentage of first-year students passing Part 1 from 30\% to 60\% (Victoria University of Wellington, 2015). The outreach aspect of my role was directly targeted at increasing the number of new students recruited, and the pastoral care aspect was aimed at increasing the number of these students passing Part 1 of the BE (Carnegie \& Watterson, 2012). In 2017 I ceased to be involved in outreach, and my position focused entirely on student support, and my role title changed to Student Development and Engagement Manager overseeing three Senior Tutors.

My position reports to our Head of School who outlined to me a clear business case for my role within ECS:

I can confirm as Head of School that the core business case around your current position is to:

a) increase the EFTS within the School through retaining students who arrive into our first year, thereby improving the pipeline of students into later years. This is to be achieved both by:

i) improving the quality of the education that the students receive in their first (and more recently, second) year of study through advice to - and working alongside - academic staff; and

ii) pastoral care of students and assisting with their transition to the University system, so as to increase the students' opportunities to succeed. 
This would have the additional benefit (although harder to measure financially) of improving the overall quality of the education provided at VUW, and enhancing the School's reputation and standing in the wider community.

b) in the original role description, increasing the EFTS within the School by increasing the number of high school students aspiring to (and subsequently choosing to) enrol in ECS programmes.

c) a related goal was to improve the equity issues within both student recruitment and retention. In ECS our three equity groups are considered to be: women; Maori; Pacifika.

Student recruitment within the revised role description has now been reallocated to other staff within the School, although the basic principles still stand. (S. Marshall, personal email communication, December 21, 2017) [Non-Interviewed Extract 9]

The Head of School describes the purpose of my role noting the interlinked aspect of student recruitment and retention to increase in EFTS funding. There is an acknowledgement that the role is to help the "pastoral care of students and assisting with their transition to the University system, so as to increase the students' opportunities to succeed". However, this is framed as part of a "core business case", and the result of increasing student success is largely measured by increasing EFTS. This is a discourse that is about numbers. Increasing student numbers, be it through either recruitment or retention is a measure of success for my position.

The Victoria University of Wellington, Academic Programme Review: Engineering Self- Review Document claims that the position is viewed as a success by ECS for supporting students:

The pastoral support position is directed at first year students, but as students move through the programme, many students continue to seek support, and many staff rely on guidance from Craig for dealing with difficult situations with students. We believe that such student support at the school level is unique in the university, and staff consider it to be extremely helpful in dealing with situations where most academic staff are highly underequipped to provide effective support to students. As seen later in the Student Profile Section, we believe this has been a significant 
contributor to the increased student retention out of first year. (p. 31) [NonInterviewed Extract 10]

As this excerpt indicates my position is not solely appreciated for its economic gains for the department. The excerpt offers an understanding that the lecturers have a specific position and this position does not involve dealing with student issues that go beyond immediate academic concerns. My role fits into the business of ECS by offering assistance where academics are unable too. However, we can see that underlying this position within ECS is the discourse about increasing retention numbers. For example: "we believe this has been a significant contributor to the increased student retention out of first year". A key aspect of this discourse centres on money for ECS in the form of EFTS.

The numbers discourse permeates ECS management discussions and is a reflection of the business reality of the publically-funded university financial model in NZ. For example, every year in ECS we have had a strategic planning meeting where the Dean, Head of School discuss and plan the year with key staff, such as programme directors. I attend these meetings and have often been asked to present information on the progress of students through their first year and also on graduation rates. The language and metrics used to measure progress are statistically based, with reporting done on a numbers basis. Unfortunately, there is no paper trail that I have access to for these meetings, but evidence of this language exists in our programme review documentation. Every seven years academic programmes are reviewed at VUW by a combination of internal and external academic staff. This takes the form of interviews, focus groups with staff and students and an examination of data including pass rates and performance and also a brief look at the teaching curriculum and courses. ECS was reviewed in 2016. Initially, ECS gathers data and undertakes a self-review, and then this is used to form a basis for further investigation by the official review committee. The review committee describes this process:

The self-review exercise is designed to involve qualitative reflection by those responsible for an academic programme on issues such as how well the programme is achieving its aims, the future development of the programme and the integration of teaching and research, in the context of the strategic directions of the University and international disciplinary trends. (Victoria University of Wellington, Academic Programme Review: 
Engineering Self- Review Document, 2016, p. 7) [Non-Interviewed Extract 11]

The extract identifies that the programme reflects on the learning community and its fit with the aims and strategic direction of the university - which in the case of VUW is for ECS to grow.

A large portion of the Self-Review contained statistical data and embraced the idea of growth. The following extract titled Growth in the document notes:

The first students were admitted to the $\mathrm{BE}$ (Hons) programme in 2007 . The programme, as common to all programmes associated with ICT, has experienced constant growth since then. Following are highlights of growth over the period 2010 through 2015.

- First year enrolments in the $\mathrm{BE}(\mathrm{Hons})$ have increased an average of $6 \%$ per annum, though most of the increase occurred in 2012. Before then the average first year intake was 108 students; from 2012 on the average has been 162 students...

- EFTS in the undergraduate engineering subjects (ECEN, ENGR, NWEN, SWEN) has increased an average of $17 \%$ per annum.

- An average annual increase of $15 \%$ in undergraduate EFTS in when computer science is added the engineering.

- An average annual increase of $22 \%$ in research student EFTS in engineering.

- An average annual increase of $12 \%$ in research student EFTS across both engineering and computer science. This constant, substantial growth has been an influence on the School and Faculty dictating priorities much of the time. The University has strived to meet the needs of this growth, but it is inevitable that there are factors that create pressure on staff and influence the student experience. (Victoria University of Wellington, Academic Programme Review: Engineering Self- Review Document, 2016, p. 63) [Non-Interviewed Extract 12]

The idea of growth in this text is associated with increases in funding, expressed as EFTS. EFTS were discussed earlier in this chapter and are a constant term in the discourse as addressed in the text above as both an accountability and a goal. The increase in growth 
is noted as impacting "... on the School and Faculty dictating priorities much of the time" and has created "...pressure on staff and influence the student experience”.

The Self-Review also drew attention to the performance of the crucial Part 1 . The following is an extract from the section of the report that discusses Part 1:

The data shows that the percentage of students passing Part One in their first year has grown from $21-23 \%$ in the first years of the $\mathrm{BE}(\mathrm{Hons})$ to $34-$ $38 \%$ in the last two years.... ...the percentage of the first year intake completing Part One started at around 30\% and now fluctuates between 40 and $45 \%$. (Victoria University of Wellington, Academic Programme Review: Engineering Self- Review Document, 2016, p. 66) [NonInterviewed Extract 13]

The focus on Part 1 is an example of the discourse within ECS and VUW that expresses success as growth in student numbers. While this is not the only message conveyed in the educational space, it does play a significant part in the actions of the programme and its staff. It has been made clear to me and all the other staff present at teaching groups, and school and faculty meetings, that ECS has a strategic imperative to recruit and retain students for financial reasons and that we must, therefore, grow our programme.

The strategic imperative to "grow" can be seen in the comments by the external reviewers of our 2016 Engineering Academic Programme Review:

The School is probably not getting the level of support it needs from the University's marketing department, which seems to take a one-size-fits-all approach. In order to improve the recruitment of Maori, Pasifika and women students, as well as clearly communicate the value of an Engineering degree to all prospective students, the Panel sees the need for the School and the marketing department to work closely and collaboratively, targeting areas and themes for campaigns which are specific to Engineering. Since Engineering has been targeted as an area of strategic growth for the University, providing effective marketing should be within the context of the growth plans for the Programme. (Victoria University of Wellington, Academic Programme Review: Engineering Programme Final Report, 2017, p. 14) [Non-Interviewed Extract 14]

The reviewers identify the importance of marketing in increasing the numbers of students. They also reveal the significance of increasing student numbers in engineering - “...not getting the level of support it needs...." “...value of an engineering degree...." 
Engineering has been targeted as an area of strategic growth for the university....". In this situation, ECS “The school”, is described as being accountable for the lack of numbers. The excerpt describes the need to "clearly communicate the value of an engineering degree", but this message is focussed on improving marketing rather than the educational experience. It is marketing that has not supported ECS in achieving their targets. The reviewers draw attention to the need to increase “...the recruitment of Maori, Pasifika and women students..." into ECS. The need to increase the numbers of minority groups is a common message in the STEM crisis discourse. The following section discusses this discourse in relation to ECS and shows how the desire to increase representation of underrepresented groups is embedded in the STEM growth agenda.

\subsection{The Need to Increase Underrepresented Groups}

Women, Māori and Pasifika, are traditionally underrepresented as NZ STEM degree graduates and in particular in the engineering and ICT-related fields (Ministry of Education, 2016). The national discourse advocates for increased participation by women, Māori and Pasifika in STEM (IPENZ, 2010; Ako Aotearoa (National Centre for Tertiary Teaching Excellence), 2014). These arguments echo the same calls for increased participation by women and minority groups in STEM across the world (Pham \& Triantis, 2015; Beede, Julian, Langdon, McKittick, George, Khan, \& Doms, 2011; Royal Society of Edinburgh, 2012; Professionals Australia, 2014; US Congress Joint Economic Committee, 2012; Melguizo \& Wolniak, 2012; Adema, Ali, Frey, Kim, Lunati, Piacentini, \& Queisser, 2014; Kirkup, Zalevski, Maruyama, \& Batool, 2010; Macdonald, 2014; Ramirez \& Kwak, 2015; Burke \& Mattis, 2007; Marginson, Tytler, Freeman, \& Roberts, 2013).

The argument for growing the number of women, Māori and Pasifika in STEM is based on both a need to uplift these groups socially through economic improvement and to increase New Zealand's own economic growth by having these groups trained and employed in STEM (Universities New Zealand -Te Pōkai Tara, 2016; New Zealand Productivity Commission, 2016). McKinley, Gan, Buntting and Jones (2015) point out that in STEM: "The lack of participation and achievement by these communities is seen as being particularly urgent as New Zealand strives for a highly skilled workforce to build a knowledge-based economy" (p. 201). These authors cite the Prime Minister's Chief 
Science Advisor, Sir Peter Gluckman, who argues that science education is fundamental to New Zealand's future economic success and are part of the chorus calling for increases in STEM-skilled graduates. For example, Gluckman's 2011 report to the Prime Minister: Looking ahead: Science education for the twenty-first century, contains statements which connect science education to increasing economic gain:

enhancing science education for the benefit of the whole of New Zealand society and our national productivity. ...the changing nature of science and the changing role of science in society create potential major challenges for all advanced societies in the coming decades. A forward looking science education system is fundamental to our future success in an increasingly knowledge based world.... (Gluckman, 2011, pp. v-vi) [NonInterviewed Extract 15]

These authors reflect the neoliberal discourse that connects economic improvement to education. Economic improvement of the individual through education is believed to not only help the individual but help the economy of New Zealand. As such, the STEM crisis discourse, which has at its core the imperative to increase the number of people in STEM sees minority groups as places to increase participation. This is not necessarily a negative notion. It looks to link economic growth to social improvement and is in keeping with Foucault's notion that power does not always operate to suppress or from a negative position (Foucault, 1975). However, this discourse reveals a particular neoliberal way of looking at social improvement and education. The connection of social to economic improvement has obvious benefits, such as giving minority groups more educational and employment options and increased participation in areas of society. It also often enables their voices to be heard in social situations where they are a minority. Yet the connection of social to economic improvement also suggests that there is a particular accepted model of success in society that works to reinforce this process and privilege it over other alternative models. For example, university education is a place that delivers 'higher learning', socially privileged over high school, or polytechnic or, for that matter, selflearning. This is neither good or bad but rather illustrates a meaning in the discourse and the operation of power-relations.

In keeping with the Government imperative to increase Māori and Pasifika involvement in STEM VUW management supports and disseminates similar messages. There are many examples, but a relatively recent public statement by the Vice-Chancellor 
noted that 'Boosting Maori and Pasifika achievement' was one of his four key achievements for VUW:

Boosting Māori and Pasifika achievement

As reflected in the make-up of our Council and Senior Leadership Team, diversity is an important thread that runs throughout Victoria.

As such, we are actively growing Māori and Pasifika enrolments, improving retention rates and supporting more students to undertake postgraduate study. This is partly due to the success of our network of Māori and Pasifika liaison and outreach staff who visit secondary schools and facilitate mentoring programmes.

On campus, we offer academic support and pastoral care services, such as Te Rōpū Āwhina, a mentoring environment for Māori and Pasifika students in Science, Engineering, Architecture and Design, and Te Pūtahi Atawhai, which provides advice, academic mentoring and culturally safe places.

Our scholarships partnership programme with Māori agencies expanded in 2016, and brought students to Victoria to realise their potential. It also led to research collaborations with iwi and new contributions of mātauranga Māori to the University's curriculum development. Victoria proudly shows national leadership in this area through the roles of Deputy ViceChancellor (Māori) and Assistant Vice-Chancellor (Pasifika). (Victoria University of Wellington, 2016, p. 3) [Non-Interviewed Extract 16]

This text illustrates that the university from its highest levels through to day to day student support takes the issue of increasing participation by Māori and Pasifika as a central task. The statement by the Vice-Chancellor is a good example of meaning being conveyed, reassuring the reader that there is diversity representation at the highest management level of the university. This extract makes it clear that, according to the Vice-Chancellor, VUW has been doing all it can to increase opportunities for Māori and Pasifika success. The text also explains what it considers success to be: "growing Māori and Pasifika enrolments, improving retention rates and supporting more students to undertake postgraduate study". The discussion around increasing participation of minority groups is predominantly framed as a numbers discourse-growing enrolments and retention. As such, the discourse presents a business-like mentality that is interpreted by VUW academic departments like ECS. 
For example, the 2015 ECS Computer Science review identified the low numbers of Māori, Pasifika and women students and staff in the school as a problem that needs addressing (Faculty of Engineering, Computer Science Review, 2016). The problem was identified and presented as a statistical problem with no real strategy or plan identified to address the situation. The Victoria University of Wellington, Academic Programme Review: Engineering Self- Review Document (2016) also contains the same numbers based language: "Government and University policy is to increase the number of Māori and Pacific Nation graduates" (p. 70). While a section of this report focused on the ECS ethnicity enrolment issues the discussion mainly focused on the percentages and statistics of these groups. For example:

If taken as a combined group, one can observe an increase in the percentage of Māori and Pasifika students. The percentages are very small and it is inappropriate to put any significance on the observed increase. In 2015 Maori were 3.6\% or enrolments and Pasifika for 2.5\%. Again looking at more detail there has been a strong increase in first year enrolments of Maori since 2013. There is also an increase in the percentage of Maori at higher levels in later years. This is encouraging. The percentage of Pasifika students is roughly half of Maori and varies greatly. While there does seem to be an increasing trend it is difficult to make any definitive statements. (Victoria University of Wellington, Academic Programme Review: Engineering Self- Review Document, 2016, p. 70) [Non-Interviewed Extract 17]

The review document noted that the overall percentage of women enrolled in engineering courses was $13.4 \%$ and $15.5 \%$ for computer science courses in 2015. And for all genders, Māori comprise 3.6\% and Pasifika for 2.5\% of enrolments in 2015. For contrast, the population statistics for New Zealand as recorded in the 2013 census noted that Māori comprises 15\% and Pasifika 7\% (Statistics New Zealand, 2015). In the total population of all ethnic groups, Males made up 48.7\% and females 51.3\% (Statistics New Zealand, 2015). The numbers of Māori and Pasifika students in ECS is low compared to the national population percentages. However, these figures do not accurately reflect the high attrition rates for these groups in STEM subjects at high school (Ministry of Education, 2018), and this factor is not considered by the Government, University or reviewers when these target numbers are set. 
In the Victoria University of Wellington, Academic Programme Review: Engineering Programme Final Report (2017) the external reviewers recommended strongly that ECS needs to increase its recruitment efforts for Māori and Pasifika of both genders and women of all ethnicities. The panel stated:

The Panel also believes that the School urgently needs to develop strategies to support women, Māori, and Pasifika students. The Panel understands that numbers of Māori and Pasifika students are low across many STEM subjects, and that there are world-wide issues surrounding the engagement of women with engineering. However the School needs to focus on what the Engineering Programme can do to improve its diversity of students, rather than point to the wider problems and view these as outside of their power to solve.

The University's strategic plan outlines ambitious growth targets for student numbers, especially in the Engineering Programme. (p. 9) [NonInterviewed Extract 18]

The authors indicate that ECS must focus on these issues and find internal ways to improve diversity. At the same time, it is acknowledged that the issue of diversity in STEM is a world-wide problem. This is an unmistaken directive, and the desire for the social improvement of these groups is inherent, but the following sentence provides a key message to the staff at ECS: "The University's strategic plan outlines ambitious growth targets for student numbers, especially in the Engineering Programme”. ECS must increase the number of students to meet targets. The demand for increased participation in STEM and the so-called urgent need to improve recruitment and retention of underrepresented groups is all part of a discourse that aligns education to social improvement through economic imperatives. The rhetoric around achieving targets and goals frames the STEM crisis. The ECS teaching and learning environment is immersed in an economic neoliberal STEM crisis discourse which connects educational management and practice to business actions and agenda.

Increasing numbers of Māori, Pasifika and women students to give them opportunities for educational success in STEM is a good goal. However, inherent in this goal is also an urgent need to increase the sheer numbers of people succeeding in STEM which overshadows the other issues in increasing equity participation. And as later chapters will show the numbers discourse argument, and the best wishes of policy makers do not necessarily translate to effective educational practices. FDA encourages looking 
at what is not said. The example of the focus on numbers is an example of where the power-relations privilege a particular discourse over another. By focusing on growth as a numbers agenda, the focus moves away from discussion on the issues which may be causing low numbers. This is of particular relevance in considering how some groups may be advantaged over others or where there may be specific issues which shape the educational and social practice such as, gender or race. While there are direct benefits to equity groups in gaining educational advancement there are also distinctive advantages to the Government and the university from being able to show increased participation. The Government and university can show that they are taking low-equity uptake issues seriously and gain the university gains an opportunity for increased revenue, eventually leading to increased Government economic gain. The following section discusses the way discourse relating to growth is expressed to staff as an organisational goal.

\subsection{Educational Strategy and Growth}

Knights and Morgan (1991) investigated corporate strategy and found that strategic discourse around goals and targets produces power effects in organisations. Their analysis revealed that this manner of discourse in organisations creates what could be termed a vocabulary of success and failure. Organisational vocabulary, which stresses goals, growth and achievements and celebrates success works to rationalise and re-define failure as relative success. In particular Knights and Morgan identify the following power effects:

a. It provides managers with a rationalization of their successes and failures;

b. It sustains and enhances the prerogatives of management and negates alternative perspectives on organizations;

c. It generates a sense of personal and organizational security for managers;

d. It reflects and sustains a strong sense of gendered masculinity for male management;

e. It demonstrates managerial rationality to colleagues, customers, competitors, government and significant others in the environment;

f. It facilitates and legitimizes the exercise of power. 
g. It constitutes the subjectivity of organizational members as particular categories of persons who secure their sense of reality through engaging in strategic discourse and practice. (pp. 262-263)

For lecturers who also have the role of teaching, providing assessment items and assessing learning outcomes of the students, there is another clear message and a visible power directive from the government, and the University, that they need to provide increasing numbers of engineering graduates. Poor recruitment and retention in universities place academic programmes and staff under pressure to take on more students and pass them.

The lecturers I interviewed reflected many of the power effects suggested by Knights and Morgan when they describe the teaching and learning environment. As one lecturer put it, the university is also a business that provides the academics with jobs and needs money to do this:

Lecturer H: Well okay so there's the business thing again because the university wants - if you want to have this many staff then you've got to have butts on a lot of seats. If you want butts on a lot of seats, then you're going to have students who aren't as well prepared ... on average as the ones the tiny universities could get twenty years ago or thirty years ago. [Lecturer Extract 1]

Lecturer $\mathrm{H}$ identifies several power relationships at work here and represents the typical perceptions of academic staff in ECS towards the university. In the nine years I have worked in ECS I have been witness to a multitude of conversations which frame the university policies and processes as a business rather than a place of education. Lecturer $\mathrm{H}$ is one example, who identifies the university as being in charge of setting an agenda. This statement and similar statements by others indicate that the university has a teaching and learning environment, with competing influences, echoing the power effects described by Knights and Morgan (1991).

Lecturer $\mathrm{H}$ identifies the idea that the university has changed over the last twenty to thirty years with a new management focus on growth in the numbers of staff and students. The implication being that in the past university was for a small population of academically well-prepared students - the top cohort. This lecturer's position rationalises the situation that increased student numbers will impact on the academic quality of the cohort: "If you want butts on a lot of seats, then you're going to have students who aren't as well prepared". This way of conceptualising the problem does not allow for a different perspective that an increased population does not necessarily mean a decrease in their 
incoming ability. For example, there are more people nationally now than twenty years ago and more of these people complete high school and enter university.

The idea that an increase in students necessitates an increase in poorly prepared students was shared by all of the lecturers interviewed for this project. What Lecturer $\mathrm{H}$ and these lecturers are describing is a form of resistance to the growth nature of university business practices which encourage increased numbers of students by upholding a belief that universities are places for specific types of people. The people needed from a lecturer's position are "well prepared" and as a result few in number. The notion that the university needs "butts on a lot of seats" in Extract 1, so it can employ lots of staff indicates that the university management makes decisions around employment and recruitment outside the purview of lecturers.

The Lecturer's reflections on the change in educational policy within the university can be seen in Government directives on educational policy and funding. The discourse on growth shown above in the earlier extracts as a numbers discussion rather than educational quality is also made clear in Government publications. For example, The Ministry of Education's Statement of intent 2014-2018 (2014) is full of business-like language and intent. The document begins with forewords by Government ministers, which explains who the Ministry of Education is and what they do, and from the beginning, it is clear that education is viewed as a pathway to employment and that improvements to social wellbeing are seen as a by-product of a wealthy economy. The foreword by the Minister of Education, Hon Hekia Parata, notes that the Government is investing hundreds of millions of dollars in education to create better career pathways, an indelible endorsement that education has a pivotal role in New Zealand's economic wellbeing and success. Success as such is "better career pathways" and economic well-being (Ministry of Education, 2014). Following on from the Minister for Education, the Minister for Tertiary Education, Skills and Employment (Hon Steven Joyce) describes how this broader policy connects to the tertiary education strategy and its interconnected economic agenda:

The new Tertiary Education Strategy 2014-2019 signals a shift toward a more outward-facing New Zealand tertiary education system, with strong links to industry, community and the global economy....We are committed to ensuring the tertiary education system provides students and trainees with real opportunities to succeed and industry with access to the skilled workforce that is essential to their business, so that New Zealand continues 
to prosper and be a highly attractive place to live and work. (p. 5) [NonInterviewed Extract 19]

In this excerpt, education is framed as a strategy, with clear goals to connect education with economic prosperity. Economic prosperity in this statement is also revealed as being connected to industry and the global economy. Education is not described as empowering the learning of an individual to make them a better citizen; rather it gives them "opportunities to succeed and industry with access to the skilled workforce that is essential to their business".

The document further outlines the strategic directions of education in alignment with Government priorities and lists the Education system outcomes as: Education provision of increasing quality and value for all; Every child and student achieves success in education; The education system is a major contributor to economic prosperity and growth and Investment in education provides higher returns. This language is steeped in business and economic phrases such as increasing quality and value, economic prosperity, growth and investment and higher returns.

In fact, this Government language of business strategy continues throughout the six sections which follow and can be seen on almost every page of the 26-page document in explicit language like this example:

The Government's Business Growth Agenda (BGA) is an ambitious programme of work to support economic growth to create jobs and improve New Zealanders' standard of living. We are part of the BGA working group, contributing to three of the work streams in the agenda skilled and safe work places, innovation and export markets. We are working to ensure the education system better equips individuals with the skills and qualifications needed to participate effectively in the labour market and in an innovative and successful New Zealand. (p. 16) [NonInterviewed Extract 20]

The education agenda is a market agenda that connects education to economic wealth, and its position is that social wellbeing stems from economic well-being.

A similar economically-driven educational rhetoric is reflected in the immediate educational environment of the university. Victoria University of Wellington produces an internal Victoria News magazine every week. This magazine includes a section called The Vice Chancellor's Column which contains a message from the Vice-Chancellor or another member of the University Senior Leadership Team - typically a Provost or Chief 
Financial Officer. While the document contains the disclaimer: 'Views expressed in Victoria News are not necessarily those of the University Council or administration' we can be clear that these columns do represent the views of these senior members of the administration. This column has for many years contained inspirational messages about education and its role in society, though they have also frequently been about the 'business' of running the university. As such they contain central communication for staff about what may be occurring and attempt to give broad updates of strategic importance.

While there is a plentiful supply of examples, the following two give an idea of how staff are reminded about the economic nature of the university role. Chief Operating Officer Andrew Simpson gave the 8th of December 2014 address "Investing in strategies for growth", and outlined:

As the year draws to a close, I know it will seem too soon to be turning our attention to the operational imperatives of 2015. However, last week our Council approved the University's budget plan for 2015 and it includes an important change in the way we will manage investment into initiatives that will help us achieve our growth aspirations. Over the past couple of years our student numbers have been relatively static - declining in some areas (particularly international enrolments), offset by modest growth in others. As a result of this, budgets are lean across all the University and each area has been asked to do more with less as we absorb increased costs with limited overall revenue growth. While that situation is likely to remain for 2015, we have set aside some funding for projects that will help us stimulate growth.... If we achieve growth in student numbers by April, we will also look to support additional strategic initiatives. Additionally, if you have a business case for a project that will kick-start growth and support our ambitious aspirations then I encourage you to submit it to your relevant member of the Senior Leadership Team.... As you will no doubt understand, the investment in infrastructure must be undertaken now or space restrictions will hamper our ability to grow.......spare some thought to the year ahead and how we can best harness our collective commitment for achieving our goals for the future of Victoria. (Simpson, 2014, p. 1) [Non-Interviewed Extract 21]

Lecturers, and for that matter all staff, reading these columns are aware of the message of growth as an economic imperative. The language in use here clearly connects all staff as 
part of an organisation. For example, "we" is used to make everybody feel like we the staff have a vested interest and in some sense ownership of the institution's operations and goals. Statements like, "our growth aspirations" or "our collective commitment for achieving our goals" assumes that staff are on-board with this direction as is the notion that staff should think about ways to improve growth.

There is a message in the statement above and below that growth is the key to expansion. Lecturer $\mathrm{H}$ understood this in his statement above. Two years after the Chief Financial Officer pressed for growth, the Vice-Chancellor Professor Grant Guilford was in a position to announce some success in this operation. Professor Guilford gave the 23rd March 2016 address, "Growing Victoria" remarking:

If you think there are more students this year compared to last, you are right - enrolments are growing steadily, in line with our aspirations to increase the scale of our contribution. This week's figures show we are approximately 200 domestic EFTS and 100 international EFTS ahead of the same time in 2015. This is an outstanding achievement in an extremely competitive recruitment market. That growth is coming across the board with most of our faculties having greater numbers than in March 2015. It is particularly pleasing to see Victoria's success in our priority areas for enrolment. Both Māori and Pasifika EFTS are significantly up over last year, with Māori now representing 11.2\% of our student body (up from 10.9\% last year) and Pasifika representing 5.9\% (up from 5.7\% last year). While these increases are very satisfying, we must accelerate these gains if we are to ensure under-represented groups can participate fully in our society.......a heartfelt thank you to all the staff at Victoria who have worked long hours in recent months to ensure enrolment was seamless and successful. We cannot achieve our goals in this area without your hard work and dedication. This growth in students is leading to increases in staffing in those faculties and schools that are not in catch-up mode from prior EFTS declines. For example, we have been recruiting new staff to support expansion in the Faculty of Engineering and the School of Psychology, both of which have recorded strong and sustained growth. (Guilford, 2016, p. 1) [Non-Interviewed Extract 22]

This success reaffirms the university's agenda to expand and grow. This excerpt illustrates what Knights and Morgan (1991) suggest - that corporate management's use 
of language works to bring people together to share similar views: "We cannot achieve our goals in this area without your hard work and dedication". The rewards of this labour are felt in economic gains for departments: "This growth in students is leading to increases in staffing in those faculties and schools that are not in catch-up mode from prior EFTS declines. For example, we have been recruiting new staff to support expansion in the Faculty of Engineering and the School of Psychology, both of which have recorded strong and sustained growth". The message is unmistakable, if you get more students you expand and grow, which is an essential aspect of the business model we operate in. If departments do not get more student numbers and EFTS funding and thus experience growth, they cannot expect to benefit from increases. This is an unmistakable message and an example of power at work, connecting the discourse to expected correct actions. The interconnectedness of the system illustrated in Table 4.1 exists in the discourse; the "we" or sense of belonging stretches out to encompass a set of varied actors in a process of generating collective and normalised behaviour.

The parallels in Government and VUW educational discourse in the excerpts above manifests as pressure on lecturers to support the economic direction of both NZ and the university. This model views education as good for national economic gain and university as the place where people are educated to grow the economy. Moreover, it establishes this as a truth-making process through the discourse.

This truth-making process can be seen in the extract below by Lecturer $\mathrm{H}$. Interestingly, Lecturer $\mathrm{H}$ not only sees the connection between the university and education as a business, they also identify that this process is connected to the wider neoliberal international educational discourse:

Lecturer H: ... therein lies... the dilemma for universities right? Because universities these days are businesses I don't think any of us are naïve enough to say that they're not businesses... And what is it that they're selling? They're selling really two products aren't they?... ... They're selling other products elsewhere, but in the teaching environment, they're selling education and certification... so in the idealistic world, the education may allow anyone who wants to learn to learn, but in the real world where the certification is a big part of the product that's being sold, if you don't maintain standards, your degree becomes worthless. ...under international standards you have to get them to a certain level, so we simply have to work harder and smarter, the management keeps telling us 
this, and it's the solution to everything, work harder and smarter... [Lecturer Extract 2]

Not only does Lecturer $\mathrm{H}$ acknowledge that is there pressure to produce graduates, but that there is also pressure to deliver graduates who have the academic ability to participate nationally and internationally. The degree programme has to meet the responsibility of certifying graduates at an international level. In doing so, Lecturer $\mathrm{H}$ also identifies that a degree is a product being sold to students and at the same time being sold to an accreditation board that it is at a certain academic level and to the government that the programme is worthy of getting funding.

These connections identify varying forms of ownership and as such illustrate lines of control or influence dictating the correct behaviour of groups and individuals. The operation of power here is the connection between global economic forces sharing the notion that a degree is a product, it is something a student purchases, and it should deliver a student a set of 'approved' skills. Lecturers have a role in meeting the competing demands of this while supporting the business requirements of the institution and Government. As Lecturer B notes below, the business agenda was at the heart of the creation of the engineering programme at VUW. The BE degree formation was the result of ECS setting acceptable business targets - targets that would generate money:

Lecturer B: They were targets generated by the school to satisfy the university and government to the point where they would support the creation of the programme... And give us money [Lecturer Extract 3]

\subsection{Summary}

This chapter has shown that analysis of the discourse through a conception of ownership illustrates the operation of power. The interconnectedness of the discursive practices within the discursive field reveal the disciplinary processes at work within tertiary education. These processes take effect as a form of social control. The teaching and learning space is a place where institutions of government, businesses and universities see great potential for economic gain. Moreover, as policy makers and benefactors in this field, they shape the situation for those involved through the action of exercising power. This can be described as the neoliberalisation of the education system (see chapter one). 
The ECS first year teaching and learning environment exists as part of the broader neoliberal educational process that equates social wellbeing with economic prosperity.

The STEM crisis is integral to this neoliberal educational mind-set and is a focus area for economic growth in New Zealand. The discursive field is comprised of various actors - from Government, businesses, and universities to lecturers. It is not an isolated network as its connections are also international. All of these factors push and pull at each other, exerting power through processes which are wrapped in a STEM crisis discourse. Lecturers are at the teaching end of this in the tertiary environment as gatekeepers of quality, learning materials and learning experiences. And while it may seem to them that they are at the epicentre of the educational experience, they are in fact pieces in a large and complex system. The STEM crisis is not of their making, and to a certain extent, they are the inheritors of factors outside of their control that impact on this discourse, shaping the notion of a STEM crisis. Lecturers are participants in this situation and have limited ownership over Government or university administrative policy that sees STEM education as an economic growth opportunity. Academic staff informally discuss the impact of these policies and to some extent act for and against them as later chapters discuss.

The following chapter extends this discussion by looking at how student enrolment processes are affected by a combination of Government and university policies that exert power through ownership over recruitment policies and practices. This chapter further illuminates the discourse at work in the interconnected economic and education network and suggests how this affects academic practice in the teaching and learning environment. 


\section{CHAPTER FiVE: OWNERSHIP OF ENTRY}

In 2016 the New Zealand Productivity Commission presented a draft report which outlined the findings of their inquiry into Crown Tertiary Education Institutions (i.e. universities, polytechnics and wānanga) as well as private tertiary providers. This inquiry looked at "trends, especially in technology, tuition costs, skill demand, demography and internationalisation, may drive changes in business models and delivery models in the tertiary sector" (New Zealand Productivity Commission, 2016, p. iii). The inquiry was convened by the Minister of Finance Hon Bill English and the Minister for Tertiary Education, Skills and Employment Hon Steven Joyce and encouraged to work closely with both the Ministry of Education and the Ministry of Business Innovation and Employment, and was seen as contributing to the New Zealand Government Business Growth Agenda ((New Zealand Productivity Commission). Steven Joyce is the same minister identified in the previous chapter who encouraged investment in STEM education for economic gain. Perhaps unsurprisingly given its progenitors, this report outlined the connection of education to social good and economic wealth. This is an example, of the neoliberal agenda in education discussed by Shore and Wright (1999), and the extensive work of Ball discussed in Chapter Two, in which they argue that the rise in accountability in universities in the UK has been done through the merging of the concepts of public good with economic gain.

This very point can also be seen in the fact that the report also stressed that the current tertiary education system needed major improvement to increase quality and value for money. The report argues that the tuition subsidies paid to universities for students come with specific requirements that result in the Government regulating for a limited range of providers, courses and fee schedules. The authors noted that the current model, while aimed at growth, actually works to limit innovation by risk-averse government agencies:

[the] tertiary education system is controlled by a series of prescriptive regulatory and funding rules that dictate the nature, price, quality, volume and location of much delivery. These controls have extended over time as a result of various financial, quality and political risks. Together they constrain the ability of providers to innovate, drive homogeneity in 
provision, and limit the flexibility and responsiveness of the system as a whole. (New Zealand Productivity Commission, 2016, p. 3)

We can see some evidence of these regulatory practices in the learning environment when the Government and university want to develop and grow STEM education and exert economic goals around enrolment and retention numbers.

VUW (and all NZ Universities) have a student enrolment target negotiated with the NZ Government through the TEC (Tertiary Education Commission, 2013). Individual courses in the Faculty and School also have enrolment targets that determine their financial viability. For example, the minimum number of people required by VUW to run a course is, 30 students for first-year, 20 for second-year, 15 for third-year and 5 for Honours at fourth-year (Dr L. Bakker. VUW Director Planning and Management Information. Personal communication, August 29, 2017). The TEC also has a provision to remove funding for courses that fail to pass more than $60 \%$ of those enrolled $(\mathrm{K} . \mathrm{H}$. Rabel. VUW Manager, Institutional Analysis. May 24, 2016). All these targets are based on business models that focus on revenue against expenditure rather than on student educational outcomes. VUW and ECS through a combination of recruitment and retention procedures endeavours to meet these targets as they must report on these targets to the TEC (TEC, 2016).

Given these targets, one may well assume that a suitable system exists to assess the academic quality and suitability for tertiary engineering study of prospective students. Moreover, one may also assume that, given the need for increased numbers of STEM graduates, adherence to this 'hypothetical' system would be highly recommended to improve the numbers of people getting through. This system would, of course, align our first-year courses with a student's entry preparation to maximise a student's chance of success. However, as this chapter discusses, ownership of the entry criteria of students into ECS, is interconnected to a complicated network of power that provides a specific type of accountability. This network of power-relations exists within the relationships between Government policies, high school, and university systems, impacting on lecturers and students in the teaching and learning environment.

The university entry policy (discussed below) is geared to maximise enrolment numbers through a relative open entry policy that places opportunity of entry ahead of exclusive entry through subject pre-requisites for students. The policies and practices around entry form an important aspect of the greater teaching and learning environment, and describe competing agendas and perceptions in the ECS context. Lecturers have little 
control over government and university entry rules. However, this lack of ownership does have implications for them. The lecturers have the job of educating the incoming students to a perceived international and professionally accredited level over the four-year engineering degree. Thus the lecturers have an implicit responsibility and a sense of ownership around producing quality graduates which is at odds with the operation of the entry discourse which has ownership of enrolment numbers.

\subsection{NCEA}

New Zealand high schools predominantly operate the National Certificate of Educational Achievement (NCEA) qualification for students, and this is used by universities to judge entrance criteria. Students can gain entry to university study through other high school qualifications, such as the International Baccalaureate (IB Schools NZ, 2017) or the Cambridge International Examinations (Cambridge International Association of Cambridge Schools NZ (Inc), 2017). However, students entering engineering at VUW through these means is rare. NCEA represents the national standards required for students at high school and has traditionally been the benchmark that NZ universities use for establishing University Entrance criteria. NCEA comprises three certificates, awarded at Levels 1, 2 and 3. Students begin studying for their NCEA Level 1 in Year 11 and continue through Years 12 and 13 (from ages 15-16 through to 17-18). Year 13 is the final year students will spend at high school in New Zealand (New Zealand Qualifications Authority, 2016), in which they typically study towards NCEA level 3. In this final year, students will also hopefully attain University Entrance, which is a qualification that comprises some basic numeracy and literacy credits and achievement of a certain number of level 3 subjects. For direct entry, most NZ universities now require in addition to University Entrance a combined total of credits gained from approved subjects at NCEA level 3 known as the Guaranteed Entry Score (GES).

NCEA separates subjects, such as Mathematics, at all levels of NCEA into subject areas. NCEA level 3 Mathematics has Algebra, Calculus, Geometry, Probability Statistics and Trigonometry. Each subject area is further split into a series of modular assessment standards. In the case of Calculus in 2015-2016 there were three assessment standards, 'Apply the algebra of complex numbers in solving problems'(in 2017 this standard shifted to Algebra), 'Apply the algebra of complex numbers in solving problems' and 'Apply 
differentiation methods in solving problems' (NZQA NCEA Assessment Mathematics, 2016). Assessment grades are awarded for each assessment standard within the subject, and each is worth a number of credits. Most standards have between 3 and 6 credits. Students may be awarded one of the following grades for each module based on their performance; Not Achieved, Achieved, Merit and Excellence. Additionally, some assessments are assessed internally by the school, while others are examined externally through assessment graded by external examiners (for example, Mathematics has six external and ten internal assessment standards). Some assessments, called Unit Standards, are only internal and can only be awarded the pass/fail grades of Not Achieved or Achieved.

To put this into perspective, NCEA level 3 Mathematics only has one Unit Standard and fifteen Achievement Standards. Students can, out of interest or through encouragement by school or teacher, select some subjects over others, and elect to do specific modules within subjects. This ability to pick and choose influences some schools and students to exhibit a 'game play' mentality which encourages the collection of credits over accumulation of coherent knowledge (Watterson \& Carnegie, 2013; Thrupp \& Alcorn, 2011; Hipkins 2010). NCEA also allows a student a measure of control over their own learning. However, the freedom of choice exhibited in NCEA subject's courses does not match the way university courses are run. At university, a student is expected to complete all assessment topics. The university educational environment has different expectations of students than the high school system.

An example of this difference can be seen in a recent review of University Entrance by NZQA and NZ TEI's in nine workshops that occurred between April and May 2016. An email summary of the feedback noted that:

many attendees raised concerns about numeracy skills. Examples included students being unable to understand basic mathematical concepts, such as being able to order fractions in order of size and difficulties in applying mathematic concepts that they were familiar with through NCEA to other real life examples or disciplines. Numeracy skills were noted as an area of particular concern in not only STEM programmes, accountancy, medicine and other similar programmes but also in programmes such as social sciences, media, earth sciences and business studies. (NZQA. Email communication. 2016) [Non-Interviewed Extract 23] 
The concern that NCEA may not be delivering students with an appropriate academic background is particularly problematic for universities who use NCEA as the standard method for approving student entry. Most universities have slightly different NCEA entry criteria which also suggests that the universities have difficulty agreeing on a consistent NCEA entry level requirement. Universities use high school and NCEA predominantly as the core provider of a students' academic preparation for university study, as evidenced by NZ university's entrance criteria. If a student's academic preparation is poor (either on the part of the student or the part of the high school) but gains entry to a university, it puts pressure on the teaching and learning environment to compensate for this deficiency. This pressure was described by the attendees as concern over the "...tension between performance (achievement rates, reputation and performance linked funding) and volume of students (EFTS) which generate funding” (NZQA. Email communication. 2016). The concern was not raised in terms of upskilling or providing educational support to students in this situation but was discussed regarding "achievement rates, reputation and performance linked funding".

These terms reflect the continued numbers and growth language that is embedded in the STEM crisis discourse. It is also an example of an audit culture that Shore and Wright have discussed at length (see chapter two). The discourse is shaping the way thoughts and behaviours are interpreted and understood as normal. For example, the perception by the university staff that they must meet the TEC demands or the TEC may impose financial penalties for not having enough students or for losing students who have gained entry (Ministry of Education, 2013; TEC Educational Performance Indicators, 2013). Put simply, the university and its staff have to work with the students it gets and find a way to meet the TEC funding requirements. With funding connected to performance we can see the operation of meaning in the discourse that produces an outcome. It is the operation of power. The situation is also not designed to have a negative outcome, but the tension arises from people acting in response to messages and these messages come from different accountabilities within the educational environment. This is what Foucault calls a normalisation process whereby peoples actions in response to messages in the discourse becomes accepted as the correct way to act (Foucault, 1978). This can also be described as an example of governmentality where the conduct of people becomes subject to governance, and in particular to a neoliberal economic form of governance. 
NZ educational providers are linked to neoliberal funding models that have an operational meaning and affect the way high schools and universities understand their accountabilities. High schools are not only financially accountable to the Ministry of Education for operational cost-effectiveness (salaries and operational costs) but a school's performance or efficiency rating is also measured on the number of students passing NCEA, University Entrance and the number of students who achieve Merit and Excellence in NCEA Level 3 assessment standards (Qin, 2016). Similarly, the Ministry of Education and Tertiary Education Commission are responsible for strategies, policy and monitoring the university's academic and financial performance (Ministry of Education, 2015). NZ high schools and universities are both accountable to Government funding regulations that incorporate education targets represented as numbers. Accountabilities, in turn, produce a discourse of demand or necessity and become accepted ways of acting.

An example of the way accountability in the education system affects operational practice can be seen in how enrolment targets affect enrolment processes and criteria. For example, the tertiary workshop participants noted that University Entrance Qualification requirements were: "generic and that the requirements could not be an adequate proxy for success in a wide range of programmes such as STEM, medicine, and engineering. These programmes tend to have specified prerequisites in place" (NZQA. Email communication. 2016). The statement acknowledges that specific programmes, such as engineering tend to have specific entry requirements or standards that are slightly higher than just attaining University Entrance. There is a tension here for operational bestpractice between enrolling students with an appropriate level of academic ability to succeed and also meeting enrolment targets aimed at increased growth in numbers.

\subsection{Enrolment Criteria}

Enrolment criteria at VUW for Engineering is a good example of how operational need and accountability for growth has affected student enrolment criteria. The desire to grow student numbers in engineering at VUW has resulted in low entry requirements for a professionally accredited engineering degree. In contrast with the workshops statement, engineering at VUW has no specified BE entry prerequisites in place to select students with certain pre-requisite skills. While prerequisites are in place for some specific courses 
within the degree, ECS maintains no restrictions, or prerequisites on entry to the BE degree other than those required by VUW. Specifically, to be automatically accepted into programs offered at VUW, students must achieve University Entrance (this comprises a pass in NCEA Level 3, 14 level 3 credits in three approved subjects, 10 literacy credits at Level 2 or above and 10 numeracy credits at Level 1 or above) and achieve the Guaranteed Entry Score (GES) of at least 150 points based on their NCEA level 3 scores, calculated on the basis of their best 80 level 3 NCEA credits in approved subjects. These credits are weighted by their grade result: 4 points for Excellence, 3 points for Merit, and 2 points for Achieved. Students with less than 150 points can still be considered if they meet the University Entrance requirement and demands for increased student numbers by the university have even allowed students who have a GES of lower than the university's threshold of 150 to gain entry to engineering.

There are five other New Zealand universities that offer a BE with majors in software or electronics; the University of Auckland, Auckland University of Technology, University of Canterbury, Massey University and Waikato University. All of them, like VUW, require a student to have the University Entrance Standard. However, there are differences in the entrance criteria for guaranteed entry into the BE. There is a disparity between the Auckland providers and the universities around the rest of the country. For example, the University of Auckland requires a Guaranteed Entry Standard rank score of 260 (University of Auckland. Engineering Entry Requirements NCEA. 2017). Also, they require specific NCEA assessment standards in calculus and physics for all engineering majors: 17 Level 3 Calculus and 16 Level 3 Physics credits. Auckland University of Technology requires a GES of 250 and 14 Level 3 NCEA Calculus and Physics credits (Auckland University of Technology, Study at AUT, 2018).

In contrast, the University of Canterbury, like VUW has a GES of 150 but requires 14 credits in level 3 maths or calculus and 14 credits in both Level 3 physics for core firstyear papers (University of Canterbury, 2018). Massey University has a GES of 140 and for Electronics and Computer Engineering or Mechatronics requires 16 Level 3 math and physics credits with some specific NCEA subject standards (Massey University, Learning, 2018). Waikato University has perhaps the lowest entry criteria, requiring only University Entrance plus an NCEA Level 3 certificate (60 credits at Level 3 and 20 credits at Level 2) for entry. Though for Electronic Engineering they also require 16 credits of level 3 NCEA in mathematics with calculus and a minimum of 14 credits in Level 3 physics (Waikato University, Study, 2018). 
The University of Auckland, and Auckland University of Technology have higher entry criteria than VUW, Massey University and the University of Canterbury have similar GES to VUW but have higher subject-specific entry criteria for the first year. The University of Waikato has a lower guaranteed entry but for Electronic Engineering has higher subject-specific entry than ECS's comparable ECEN major. The University of Auckland and the Auckland University of Technology have higher entry criteria for incoming students suggesting that they are trying to target more academically prepared students whereas VUW, Massey University, Canterbury University and Waikato University have less stringent entry criteria. While there are different levels of entry criteria required by New Zealand universities, it is clear that there is a common theme of engineering providers requiring calculus and physics in their entry requirements.

At VUW, for Software engineering (SWEN) there is no specific academic preparation for first-year papers needed by students in calculus or physics. Like VUW, Massey and Waikato University do not require calculus or physics for their SWEN students. To enter our core first-year engineering mathematics paper students in all majors are required to have 16 credits of level 3 math, but these do not need to be in calculus and can be statistics credits. However, for Electronic and Computer Systems engineering (ECEN) students the core physics paper in trimester one of first-year requires at least 12 credits of NCEA Level 3 math including the calculus standards and 18 credits of Level 3 physics including specific standards (of note is that from 2018 this requirement has also been removed). ECS by maintaining a relatively low entry criteria to the BE controls the academic level of which students may enter the programme.

ECS could instigate higher admission criteria for engineering but has chosen not to do this as senior management wishes to allow as many students as it can the opportunity to enrol in the BE (see Lecturer Extract 4 in the next section). ECS is also viewed as a growth area for VUW with a mandate from senior university management to grow our numbers of students (Non-Interviewed Extract 14). I have attended senior management, programme reviews and accreditation meetings, and also had conversations with senior managers of ECS where the message of growth has been repeatedly outlined. The Lecturer excerpts below also reinforce this position. Chapter one and four have also discussed the STEM crisis need to increase the number of students and in particular those from equity groups. Lower entry requirements are one means to help increase student enrolment numbers. 
Currently, a student could enrol in the VUW BE with a mixture of subjects from NCEA curriculum that contains few engineering-related subjects. In fact, it is even possible to enrol in the BE with no math, physics or digital technology (Computer Programming) background. While the actual number of students who enter with no related skills are small, they do exist. More common are students with poor NCEA results in BE-relevant subjects, such as, physics, math or digital technology, or who are missing key standards (assessment topics) in one or more of these subjects. It is common for many of our students to have either not taken calculus or physics at secondary school before enrolling in engineering.

There is a power structure at work in controlling the entry requirements of students. This structure is underpinned by a discourse of economic gain guised as ethical action. University accountability to the TEC, and ECS accountability to VUW, results in a desire to increase numbers of students to increase income. At the stage of enrolment whether a student is likely to pass or not is removed from the discourse. From a Foucauldian theory of power point of view, this is where the control over what can be said and what cannot be said in a particular situation is occurring (Foucault, 1978). Resistance to this process is very difficult to see as the chance to enrol is portrayed as giving people an opportunity and as such has a moral component. The enrolment criteria acts to allow entry to as many people as possible an opportunity to study in ECS at VUW. Opportunity of entry does not guarantee equal opportunity to succeed.

For example, opportunity also places many students on a particular pathway of study that has real consequences for both students and staff. Due to the lack of entry prerequisites a substantial amount of our first-year cohort do not take all the papers required to complete Part 1 in their first-year due to the lack of entry pre-requisites and are required to take introductory courses. There are two first-year, one-trimester (12-week long) introductory papers that are used in engineering: PHYS122 Introduction to Physics for Scientists and Engineers and MATH132 Introduction to Mathematical Thinking. These two introductory courses designed for people with no knowledge of math or physics which provide degree credits and also act as entry pre-requisites for some of the core courses.

These are not pre-degree bridging courses or programmes, or specific bridging papers as such. VUW's full bridging programme was withdrawn by the university in 2012 due to changes in government funding which removed the government student subsidy for such bridging programmes. The university was unwilling to fund delivery of these 
programmes on its own. ECS is currently unable to offer a specifically targeted engineering bridging programme or courses due to funding and policy decisions by VUW senior management (Professor D. Carnegie. Dean of Engineering. Personal communication, September 6, 2017).

PHYS122 is for ECEN only students allowing entry into the core Physics courses, and MATH132 for all engineering majors into core math and engineering math courses. Roughly $40 \%$ of ECEN students need to take PHYS122, and around 20-25\% of students in all majors take MATH132. In 2014 we had 160 students split across the three majors and of these 22 enrolled in MATH132 (4 ECEN, 13 SWEN and 5 NWEN). MATH132 is the paper students take if they have below-the-entry credits for our core mathematics paper at first year. Also, 19 of 56 ECEN students enrolled in PHYS122. PHYS122 is the core physics course for SWEN and NWEN but is considered an introductory course for ECEN students who lack the entry-level requirements for their core first-year physics course PHYS114 giving the student entry to their trimester 2 ENGR142 engineering physics course. Similarly, in 2015 we had 170 students split across the three majors and of these 27 enrolled in MATH132 (7 ECEN, 15 SWEN and 5 NWEN), and 19 out of a total of 46 ECEN students enrolled in PHYS122.

Students taking these introductory courses have extremely poor success rates in obtaining Part 1 and graduating. Only 37\% of ECEN students who took PHYS122 have ever achieved Part 1 of their degrees. And so far only one ECEN student who has passed PHYS122 has ever graduated with a BE in ECEN from the cohorts which could have graduated between 2007 and 2013. Four went on to graduate with Computer Science degrees. Similarly, only one ECEN student who went through MATH132 has graduated with an ECEN degree; a second student did graduate with a SWEN degree. Interestingly, SWEN students do not fare much better, with those who took MATH132 having a lower $(\sim 30 \%)$ chance of graduating than students that do not attempt this paper. ECS has only graduated $10 \mathrm{NWEN/SWEN} \mathrm{students} \mathrm{that} \mathrm{went} \mathrm{through} \mathrm{MATH132.} \mathrm{Students} \mathrm{doing}$ MATH132 have a consistent $\sim 10 \%$ graduation rate in the BE.

The policy of 'relative open entry' in our Engineering programme allows students to enrol in introductory courses. However, completion of an introductory course does not guarantee success in the core courses. ECS can reliably show that a student entering into the ECEN major without NCEA math and Physics and through the introductory papers (MATH132 \& PHYS122) is unlikely to meet the required B average or to graduate with 
an engineering degree. The following section discusses the impact of VUW and ECS entry policy with regard to lecturer's perceptions.

\subsection{Lecturer Perceptions on Enrolment}

The lecturer excerpts below, coupled with our enrolment policy (discussed above) reveal a discourse around entry requirements that is pervasive in undermining meaningful enrolment practices by placing 'opportunity' as a valid reason for allowing entry to students. ECS maintains the policy of relative open entry to give as many people as possible the opportunity to participate in studying an engineering degree and thus allowing entry to people who may have been excluded on the basis of poor educational background. In addition to the idea of 'opportunity', there is the blunt business need to let in more students to meet financial targets. Lecturer A exemplifies this:

Int: So why do we let a whole lot of people into the BE(Hons) that we think are not academically prepared

Lecturer A: Multiple reasons, one is money... Another is giving people an opportunity... because we don't know... Whether they're going to fail, and giving them an opportunity to try- I think that's important. [Lecturer Extract 4]

However, this opportunity does not mean an equal opportunity for success to all participants (Wolf, 2002). Lecturer M acknowledges that the university is to blame for letting in students who may not succeed:

Lecturer M: Well the university central university allows anyone to come into our courses. If we set a limit and we don't fill our quota the central university will just let anyone in even though we say they don't have the standards, so we are - you know the university is letting in these people. We can't blame the students. [Lecturer Extract 5]

Lecturer $\mathrm{M}$ identifies the idea that the university student entry criteria operates with limits and targets controlled by university management rather than lecturers. Students without good academic entry criteria can enter courses alongside students who have good to high levels of academic preparation. As chapter six and seven will discuss, to be successful these academically less-prepared students will need to achieve at the level of these betterprepared students for whom our courses are intended. 
Lecturer D below elaborates further on VUW university enrolment and the way university management affect this:

Lecturer D: ... here it's completely open entry, and open entry doesn't mean that anybody can come - in theory... In fact, there's a university entry you have to get which is a number of points across a number of disciplines.......now individual subjects could and maybe should put in specific things like points in merit and excellence for physics and maths for engineering... And in theory... university entry and higher education, have its own entry... However, what normally happens is there's something called waitlist... So students come in, we say we've got two hundred spaces in engineering nominally... And this is the target, and we keep filling up those spaces... We have the students that we want to take in terms of what we've set as entry, but the university has its own targets, and for the last six years I've been here I don't think the university has ever early on hit those targets - probably hit the targets later on in the process, but in general it's needed students, and therefore these waitlisted students who are the students who haven't got what we wanted but have got university entrance come in from faculty and no Dean of Engineering has ever turned round and said we don't want the money that these students will bring in 'cause they might stand a chance of passing, and it's university entrance. [Lecturer Extract 6]

Lecturer D's description of the university's failure to hit government enrolment targets necessitating the lowering of entry criteria for incoming students to increase enrolments is a good example of business needs driving operating procedures. Even the comment that "no Dean of Engineering has ever turned round and said we don't want the money that these students will bring in" shows how far through the management structure the messages of targets and numbers go. In this case all the way from senior management to Deans in charge of teaching and learning programmes, and as evidenced by the lecturer's comments the academics are all aware of these meanings too.

These lecturers reveal the thorny economic process at work to meet targets while at the same time noting that these may not be the students 'we' want. The 'we' used here by the lecturer refers to academic staff, and is in contrast to the 'we' used by the ViceChancellor to suggest that the university must grow its numbers (Non-Interviewed Extract 22). The lecturers do not agree with the economic policies and are separating themselves 
from the Vice-Chancellor's perception that groups everybody together as one team focused on growth. Senior staff in ECS have advised me on several occasions that the 150 GES has been sacrificed to meet enrolment targets when enrolment numbers are low. There is a perception of flexibility being applied in the selection of students due to monetary requirements and reveals the operation of power exerted over enrolment decisions that may compromise the process of academic quality assurance for entrants. In part, this reinforces the notion by lecturers that ECS is taking in a weaker cohort, as one lecturer states:

Int: So were you aware we've never actually got fifty percent of our firstyear cohort through part one of the engineering

Lecturer J: Hmm, I'm sure I've heard that some time

Int: So why do you think that is?

Lecturer J: Yeah actually why have we never got fifty percent through, $\mathrm{mm}$, I have to imagine I guess, where my word on all of this is that we're not yet attracting... enough of students who are gonna be end up being really capable as they go through the degree and so there's a lot of I guess weakened intake basically is coming out of schools that we kinda have to take them - they choose us over other places and here they are, and we have to make the best of it. And because we've had this pressure that we must be building a programme, we must be taking in students. [Lecturer Extract 7]

Lecturer J acknowledges the pressure ECS has to take and teach a "weakened" intake which stems from a perception that "we must be building a programme", while at the same time placing the blame partially on New Zealand high schools for the failure of ECS to get enough students through Part 1.

This excerpt, like those above, evidence a discourse which illustrates different levels of ownership. The lecturers describe areas where they are responsible and areas where they are not (for example, building a programme or weak students). The tension described are good examples of where power can be seen in operation; increasing student numbers versus taking on academically weak students. It is in these tensions within the discourse that Foucault believed you could see power-relation in action, and the normalisation of both belief and subjectification (Foucault, 1983). For example, Lecturer J's notion that the cohort is not weak but "weakened" indicates a subjectification of students into a category of student. This category was a commonly used notion for all the 
staff I interviewed confirming a normalisation of thought by the academic staff towards students. This subjectification also places NCEA in a negative category as the academics believe it has adversely affected the academic preparation of students.

These subject positions carry with them very real implications even when those making the assumptions may have little actual evidential basis for their views. Research which explores these issues can be found in studies that investigate discrimination and disadvantage (e.g., Henwood, 1998; Beddoes, Schimpf \& Pawley, 2013). In ECS the disadvantage from placing students in subject positions results in a poor understanding of incoming academic ability for first-year students and a resultant mismatch in educational expectations. This is an effect of power stemming from the discourse. All of the 15 lecturers interviewed were aware of NCEA, including both the domestic and international lecturers. Of the seven that had joined VUW from overseas, some had children currently taking it or had completed NCEA, and others were married to high school teachers. Only two of the seven international lecturers could be described as having no context or experience to expect some understanding of NCEA. Surprisingly, though, our lecturers know little about NCEA despite having quite strong opinions, as Mathematics Lecturer C explains below:

Int: Do you know much about secondary school?

Lecturer C: I know a bit. I wouldn't say I'm an expert

Int: Do you know much about the standards that are taught?

Lecturer C: A bit. I've been learning recently

Int: Okay do you know much about the ability of students to pick and choose papers. Or you know unit standards and things like that?

Lecturer C: Yes ... although I'm constantly finding that's changing a little. But yes, yeah I think I know anecdotally from talking to teachers in [High] schools I have some idea about how it works yep

Int: So do you think secondary school does a good job of preparing students for university?

Lecturer C: I don't think they do to be blunt. I don't think they think that's their role any more. For some students they feel like it is but in general their role's changed from a while back Int: So do you think the students' academic ability has declined as a result of NCEA? 
Lecturer C: That's a good question I don't have any evidence for that. My feeling is that they have more stuff they're busier at high school. In the old days, you could expect someone to come through a particular subject like mathematics and know certain things to get to Bursary or whatever. That they would know a certain amount of stuff whereas that's not clear with the choice and the achieved merit excellence grades. It's no longer so obvious what a student coming out of high school (.) well (.) yeah (.) it's not obvious to me maybe with digging we would know but I've lost the feeling for the cohort.

Int: Would it be fair to say that nobody in maths [department] would know?

Lecturer C: I think so. I don't. [Lecturer Extract 8]

Lecturer $\mathrm{C}$ describes a separation of educational system between the NZ high school NCEA curriculum and NZ universities. The notion "I don't think they think that's their role any more" refers to the impression that high schools do not do a good job of preparing students for university. This relates to the idea that high school is a discrete learning environment separate from university. High school is designed primarily to provide NCEA learning and assessment to all students of which only a subset ever go on to university study. Lecturer C identifies the change as "I've lost the feeling for the cohort" which shows a fundamental disconnect between a lecturer's ability to understand the academic preparedness of students. High school is not accountable to universities for NCEA curriculum or assessment.

Similarly, university lecturers do not have to have an understanding of the content taught in high schools. Almost all of the lecturers interviewed displayed no real understanding of NCEA content:

Int: Okay, so do you know much about what students would have learnt at school before they arrived in your class in terms of subject matter?

Lecturer G: Ah yeah I started to look into it

Int: What does that mean?

Lecturer G: That means I started to understand what is NCEA. What it means by merit achieved and excellence. But all this is in personal capacity which means that you know you just go and ask someone and then say 'hey' you know 'what's this about' and so and so... Yeah, but in terms of content wise no I don't know what they're learning. [Lecturer Extract 9] 
While Lecturer $\mathrm{C}$ and Lecturer $\mathrm{G}$ reveal that they both have on a limited basis picked up some knowledge from other people, there is no formal requirement or method for gaining this knowledge. A recent NZQA University Entrance review acknowledged the lack of NCEA understanding by universities or their staff:

Many attendees [tertiary academic staff] acknowledged that they did not in general have a good understanding of NCEA [subject course content]. Knowledge of NCEA is often held by individuals who have gained their understanding by being a parent, or as administrative staff or, in some cases, by first-year lecturers who have sought to understand the knowledge and skills that their students may present with in their first year. In addition, most TEIs [Tertiary Educational Institutions] did not have structured relationships with schools in their region. (NZQA. Email communication. 2016)

Inherent in this system is a separation between high school and university regarding the understanding of course content. This is extremely problematic for all interested parties. While it is possible that the quality of some students may be poor, to a certain extent the problem of having poorly academically prepared students may relate to the growth nature of the VUW enrolment system rather than the New Zealand high school education system.

For example, lecturers, and the current teaching system at university are not designed to educate students with a wide range of academic ability and as Lecturer $G$ notes, lecturers are not equipped with the teaching skills to cater for this:

Lecturer G: So it's like those really good ones are way up there, and those really bad ones are you know kind of like lost.

Int: Yep. So obviously you see you know a hundred and (.) between a hundred and sixty and a hundred and eighty or so first year students who all have to come in to 101. Is there a gap between the top and the bottom ones?

Lecturer G: Yeah. Mm. But I don't think we are equipped enough in as lecturers to actually deal with that because you know that is er (.) it requires systematic planning to actually address that (.) so I think that we recognise that there are those (.) we try (.) but you know sometimes you know (.) the way we approach it I don't think we have a systematic way of actually dealing with this or we know that that is actually the best practice to deal with that. [Lecturer Extract 10] 
Lecturer $\mathrm{G}$ expresses that there is no systematic way to deal with incoming students of differing academic ability. This is an example, of an educational mismatch of expectations and abilities in the enrolment policies and practices. As such, the lecturer excerpts discussed above illustrate some tensions between the rights and responsibilities in Table 4.1. Students expect the university to have accurate enrolment criteria to maximise their chances of being successful upon entry. To a certain extent the Government, TEC and academics also expect this. The tension in the way this expectation operates illustrates some of the practices operating at the institutional level where the messages of the Government and TEC are interpreted. At this level ownership over the conduct of departments like ECS by senior VUW management practices impacts on both the students and academic staff. Ownership in this sense expects everything in the education system to align, but it does not. This misalignment exemplifies Foucault's notion that power operates at different levels throughout social systems (Foucault, 1978, 1983). While the effect of Government and TEC policy is intended to be positive for the university its students, staff and the country, the relative nature of autonomy exercised within the tertiary environment means that exactly how goals or directives are interpreted is open up to a certain amount of freedom. This is where ownership of entry can be seen as an aspect of autonomy to choose to act in a particular way. The following section discusses some examples of this system mismatch, highlighting that it is also experienced by the students, and lecturers in other NZ universities.

\subsection{Educational Expectation Mismatch}

In contrast with, the lecturer's belief that they are not equipped to teach students of a wide variety of abilities the students generally believe that they will succeed. In my experience interviewing hundreds of students, there is a common belief by many of the new students that the courses they will study will be of an achievable academic level. This belief is typically expressed in the first few months a student attends university, and it is often at this stage, also from my experience, that the courses take a relatively slow start, and become progressively harder after the mid-point of the trimester.

For example, one student I interviewed during their first month at university made the following comment regarding their first year courses: "To get good marks it's actually $\ldots$ in in that sense I could probably not study for any of my exams at the end of the year 
and pass them" (Student I). The confidence exhibited by this student is common in my experience interviewing students and can also be seen in this example: "Um the first couple of weeks have been pretty you know (.) been there done that, I know all of it. I know all the core stuff" (Student J). This confidence in being able to succeed, despite students having never experienced a university course, is based on their experiences of secondary schooling and is strengthened, as the Productivity Commission points out, in the discourse around university entrance. For example, high school contains a qualification called 'University Entrance', a title which indicates to all students involved that is what you need and this is what you should do to progress to tertiary study at universities:

The University Entrance standard is also an unhelpful signal. University Entrance does not reliably signify preparedness for higher-level study. It also implies that a young person who achieves University Entrance is best off attending a university, when this may not be the case. Some universities set higher standards, while others would like to enrol students that do not have University Entrance. (New Zealand Productivity Commission, 2016, p. 31)

This view is echoed by Dr John Boereboom, the director of the Centre for Educational Evaluation and Monitoring (CEM) at the University of Canterbury who wrote about university entrance in the New Zealand Education Review magazine (2016). Boereboom noted: "University Entrance is irrelevant to employers and universities have had to supplement it by introducing rank score requirements that are useful for selection but often invalid for specific programmes" (Boereboom, 2016). Boereboom argues that NCEA rank score is a worthless selection tool for entry and as a predictor for future academic achievement. Boereboom also recommends that universities alter their entry criteria to allow for set prerequisites for programmes that are relevant to a student's actual course of study.

Despite opinions like that of Boereboom, currently, VUW uses the guaranteed entrance score (GES) score for a student to enter the ECS engineering programme and has no specific prerequisites for entry that are relevant to the student's actual course of study. Rather than place quality control at the entry point as the University of Auckland does with its $260 \mathrm{GES}$, quality control over students in ECS is managed through the use of the B average across core courses in the first year. Failure to obtain the B average and pass Part 1 effectively removes a student from the engineering degree. Having both 
relative open entry and placing the B average requirement at the end of a student's completion of a set of first-year core courses creates issues for first-year lecturers when the TEC, VUW and ECS management all expect achievement of both enrolment and retention targets.

Ownership of student entry is exerted by the Government and university management in a way that sets the scene for the situation academic staff find themselves in when they design, and teach, a course having flow-on implications for the academic programme as a whole. The discourse around entry is relatively clear in its meaning:

- ECS must grow its numbers of students to be financially viable enough to employ academic staff and run its teaching and research programmes

- To do so, ECS must take students of a wide range of academic abilities that meet our generic entry criteria

However, there are competing goals in this discourse. For example:

- ECS lecturers must pass $60 \%$ of students in a course to meet TEC requirements

- ECS lecturers must maintain quality through the use of the B average across the first year

Faced with these requirements, academic staff find themselves having to deal with a complex system that has competing demands. As mentioned in Lecturer Extract 2 (p. 94), academic staff have to educate these students to a perceived internationally accepted standard within the four-year engineering degree. This discourse poses an interesting quandary as the lecturers assume, and expect, a certain level of academic ability in the student body (see Lecturer Extract 33, pp. 174-175, 34, pp. 175-176 and 35, pp. 176-177 discussed later).

The misalignment of goals is not specific to the ECS VUW environment. Morton (2013) interviewed sixty academic staff from Lincoln University regarding their perception of TEC policies, from a stakeholder perspective. Morton analysed the findings both quantitatively and qualitatively and concluded that: "The quantitative findings indicated general agreement amongst the participants with the policy intentions, while the qualitative responses identified a misalignment between the values and priorities of government and academic staff” (p. 1). There are interesting parallels between what the Lincoln staff said and what ECS academics noted above.

For example, Lincoln University participants noted that they had little knowledge of NCEA but were certain from their experience teaching new students that the entry 
requirements were inadequate. This sentiment was even reflected by the Lincoln ViceChancellor who commented that current university entrance standards were unhelpful (Morton, 2013, p. 204). Morton quotes two lecturers, whose statements are similar to ECS staff. One lecturer stated: "I'm not sure exactly [what the standards mean], but they are appallingly low". Another noted: "They are not high enough! I don't know, a certain number of NCEA credits... I think one of the problems is that the education system is not preparing people well enough for university level study" (pp. 203-204).

It is clear from Morton's work that Lincoln staff felt that NCEA was not preparing students for tertiary study and that the staff believed that the TEC requirements to increase retention rates was seen as a major problem:

Participant 60 offered the comment: TEC keeps telling us to improve our retention rates, it's all our fault. My answer to [them] is, OK we'll comply and pass the lot [of students] but our degrees, our qualifications will be worthless in the international market. (Morton, 2013, p. 205)

There are parallels between the comments from Lincoln staff and those of the ECS academics. Government and institutional processes, particularly in enrolment, act to separate the first year course and lecturers who teach them from incoming students. There is an institutional disconnect between a student's NCEA results and a meaningful understanding of ability in relation to first-year tertiary course knowledge and assessment requirements. This illustrates the lack of synergy between high school curriculum and university curriculum and a broader disconnect between educational ideals. It also reflects the idea that power-relations in systems can be both interconnected and disparate: high school and tertiary education in NZ the systems are connected and independent, with little-integrated curriculum or teaching overlap. So, ownership of high school teaching curriculum and teaching methods belongs to the high school system and teachers whereas university curriculum and teaching practice belong to the university department and academic. While there are certainly connections to the Government and their funding and regulation bodies, these operate at a higher level and do not have a body that is designed to integrate or oversee curriculum alignment. In this manner, they delegate ownership away from themselves to schools and universities as semi-independent bodies.

The Productivity Commission (2016) maintains that the tertiary quality assurance system inhibits innovation through its regulatory practices that focus on course approval processes rather than on student outcomes, and makes the statement that: "The system appropriately seeks to ensure minimum standards are met, but overall the system lacks a 
mechanism for rewarding quality or responsiveness to students" (p. 4). The report also notes that ideas of quality in education come to be defined by existing practice in an organisation: "So quality assurance processes can reinforce existing practices, rather than supporting new ones. Equating traditional models of delivery with quality also reinforces cultural resistance to change within providers" (p. 4). Evidence of this process exists in the VUW relatively open entry policy for students, which lets poorly prepared students into ECS courses that are not set at a level where these students can achieve success. Ownership of enrolment and entry criteria does not belong to the lecturing academics but to the Government and senior university management.

\subsection{Summary}

This chapter has discussed problems relating to relative open entry, and the effect of this on lecturers and the teaching and learning environment. I have explained that ownership over enrolment criteria by both the Government and the university has created a complex educational environment that places the lecturers and the students in a difficult position. This neoliberal education drive for STEM graduates has a direct impact on the teaching and learning environment. The lecturers experience the pressure to increase recruitment and retention of students and at the same time are faced with relative open entry that has changed the traditional and somewhat exclusive enrolment and classroom landscape. Furthermore, the lecturers by their own admission lack the skills to provide for a diverse student body with a wide range of academic ability and pre-university preparation.

The following chapter further explores the way power is experienced in the teaching and learning environment by focusing on ownership of courses and their design. 



\section{CHAPTER SIX: OWNERSHIP OF COURSES}

Within VUW, Faculties and Schools such as ECS administer and conduct the day to day operation of course design and delivery. Courses represent the individual units of study (sometimes referred to as papers) that comprise a programme of study within a degree major. However, overall approval of these courses including that of design, evaluation and teaching belongs to various sub-sectors of the tertiary education system beginning with government and the Education Act and its tertiary administrative arm the TEC, through to the university charter and its administrative department the Academic Office. According to the VUW Academic office it "leads the development and implementation of the policies and processes necessary for a comprehensive quality framework in learning and teaching at Victoria University" (Victoria University of Wellington, Academic Office, n.d.). They do this through the five-year Academic Quality Agency for New Zealand Universities audits, the coordination of academic statutes and policies, course and qualification approvals on a five-yearly cycle, graduating year reviews, grievances and disciplinary appeals and the internal seven-year academic programme reviews on the quality of learning and teaching in each discipline and the teaching excellence awards. These processes are part and parcel of the VUW Learning and Teaching Strategy and Strategic Plan.

The Learning and Teaching Strategy 2010-2014 document (which was still current through the period of my analysis being replaced mid-2017 with the Learning and Teaching Strategy, Te Rautaki Maruako, 2017-2021) contains a detailed description of VUW goals for the learning and teaching environment. A rather condensed version of these was available at the time of my research on the VUW website:

Victoria is committed to providing a high-quality research-led learning and teaching environment, and rewarding and celebrating excellence in all its forms

Excellence in learning and teaching is one of the University's core institutional values and is one of the eight key goals of the Strategic Plan. The Learning and Teaching Strategy objectives are to:

- provide a distinctive and excellent learning experience for students

- take a student-centred view of learning

- draw on Victoria's strong culture of research 
- balance educational breadth, student choice and sustainability of programmes

- develop learning and teaching practices that meet high international standards and take account of emerging global trends

- develop assessment and feedback policies and practices that enhance the curriculum and encourage deeper student engagement with learning. (Victoria University of Wellington, Learning and Teaching, n.d.) [Non-Interviewed Extract 24]

Additional and supporting documentation relating to VUW's official position and policies on learning, teaching, and course design is included in the more specific VUW Centre for Academic Development and Academic Office publications: Programme and Course Design Handbook (2014), Assessment Handbook (2015), Academic Approvals Handbook (2014) and Evaluation and Review Handbook (2015).

Together, all of this documentation represents a substantial body of text supporting VUW's values and goals around learning and teaching. The overall 'educational' goal is to produce graduates who meet VUW's graduate profile. This profile contains a list of generic attributes which are expected to be embedded in curricula alongside the specialist subject knowledge required by a particular degree major (Victoria University of Wellington, Graduate Profile, n.d.). Individual programmes such as ECS are expected, as outlined in the Programme and Course Design Handbook to have conducted constructive alignment and curriculum mapping to interconnect Victoria's graduate profile to the Programme/Major profile to Course Learning Objectives and assessment.

There is a top-down university senior management expectation that the guidance provided within these handbooks will be embraced as policy and used to provide quality educational practice in course design and assessment. For example, the Programme and Course Design Handbook explains its purpose in the first paragraph of the Introduction as:

The purpose of this handbook is to set out the University's expectations and to provide assistance for programme and course design, to support high quality teaching and learning as expressed in the four key elements of the Victoria Learning Partnership: excellence, engagement, enquiry and experience (approved by the Academic Board, June 2013). It belongs 
to a suite of academic handbooks, providing policy, guidance and quality assurance... The handbook applies to all taught courses and programmes offered within Victoria University qualifications. (Programme and Course Design Handbook, 2014, p. 1) [Non-Interviewed Extract 25]

This text makes it clear that the handbooks(s) are to "set out the University's expectations" and "applies to all taught courses and programmes offered within Victoria University qualifications". It has been approved by VUW senior management at Academic Board and as such is a VUW policy document.

If one reads the VUW Handbooks, it becomes clear that there is a considerable amount that needs to be done by both managers of programmes (senior managers within a school like ECS with regard to the degrees and majors offered), and individual lecturers when developing and teaching a course to meet the needs of all of these goals. For example, within individual courses, academic staff developing these courses are expected to, as the Programme and Course Design Handbook notes, take into account the prior knowledge of students, develop content and assessment that facilitates pathways between courses, and manage the workload levels for both themselves and the students. In addition the course needs to align with the programme objectives and goals as set out by programme management. For example, programme management in ECS comprises of the Dean, Head of School, an Associate Dean of Teaching and Learning, Associate Dean of Students and several Programme Directors who administer the subject majors of ECEN, NWEN and SWEN. The Programme and Course Design Handbook contains lots of advice and examples for doing this and recommends following the Assessment Handbook's guidelines for ways to connect assessment to learning objectives. And yet, despite these guides, they remain only recommendations (chapter seven contains further discussion on teaching tensions related to this).

While the guides suggest that the university owns programme or course design through to assessment, in actuality it is a more complex situation. There is more of a bottom-up approach in course design which begins with the lecturer. Once a course has been designed by an academic staff member approval of course design, and assessment is then signed off internally by other departmental staff before gaining official university approval and subsequently funding approval from the government (Programme and Course Design Handbook, 2014; Assessment Handbook, 2015; Academic Approvals Handbook, 2014). 
The interviews with academic staff suggest that there is some resistance to control or input into course design and teaching by lecturers:

Int: How much is academic freedom and the nature of the way we structure things here, how much of that's the barrier to first-year students?

Lecturer A: I don't think it's a barrier - I don't think that's the barrier. I think that's the reason barriers won't get torn down easily... The different views and attitudes of staff and in some case straight poor teaching methods or attitudes, that's not the barrier, students don't have to interact with that at all. What they interact with is the lectures and the assignments and the exams and the assessment and the labs the things the course design. Int: Yes, but ... does that not come out of those other things?

Lecturer A: Yes it does... But those things are the barriers... And how you change - how you reduce those barriers? I do not want to even think about taking a head-on attack on those issues of academic freedom and... teaching things. I would much rather put requirements in place for our first-year programme... Say 'look we're going to do all the first year courses like this'... 'Cause this is engineering, and you want a job don't you we've got to get you your students so we're going to try this' and let's put these external structures in place to try and remove the big barriers. It's the most we can do. And if I can get more staff to think more effectively on teaching, so that they do it better, that would be good. [Lecturer Extract 11]

Lecturer A discusses the idea that Academic Freedom, or the rights of an academic to design and teach with relative freedom of choice, can prevent courses from having welldesigned teaching materials and assessment items. For this lecturer tackling the issue of poor teaching can only be done through addressing what is being taught and assessed. One solution, noted by this academic is to have course requirements set across the first year programme rather than by an individual lecturer. However, this is difficult as the university or programme ownership, and input into courses is limited by how much a lecturer accepts input. In this sense a lecturer can work alongside the programme and their colleagues or they can resist.

An alternative solution would be for the academic staff to willingly engage in course design and improvement amongst themselves or alongside the university's Centre for Academic Development (CAD). The (2014) Programme and Course Design 
Handbook suggests many ways to develop courses, but as I mentioned earlier, it is a guide, not an official mandated method. As such, academic staff are relatively free to have different opinions about what constitutes a good course, appropriate content and delivery methods. In the current ECS and VUW teaching and learning environment agreement amongst academics staff over course design and delivery is problematic.

Diffusing ownership through academic freedom of courses to individuals makes the task of coordination and educational reform difficult. The issue of why academic staff use academic freedom as a means to resist input into their courses is a difficult question to answer. The following extract suggests one reason:

Int: Well, essentially what you're saying there is your academic freedom, you would like to retain in terms of what you teach. How does that sort of freedom impact on the students or the way we organise our courses?

Lecturer F: I don't know. I really don't have a strong opinion, I mean I feel that so like, you know if I had my way I'd work the students quite a lot harder... maybe I should just do that anyway. But I don't know so I would rather that there is, sort of diversity amongst lecturers, than an agreement that this is the right way to do it. [Lecturer Extract 12]

Extract 12, above suggests that freedom of diversity is preferable to an agreed course design approach. It accentuates a desire for autonomy and freedom and also suggests that there may not be a right way to teach a course. The lecturer also reveals that they can if they like choose to work the students harder.

In all the lecturer interviews there was no connection to the expectations of the VUW handbooks around course design to actual course design. Rather there was a constant reference to ideas of autonomy and freedom encompassed in ideas of personal belief. For example Extract 12, and Extract 13 below contain statements around what 'I' (the lecturer) thinks or wants: "I would rather", "what I would think is best practice". The same sentiment exists in Extract 14 below: "you get used to the autonomy you have". These are statements about ownership and the right to believe and act in a particular manner that exists within the understanding of what it means to be a lecturer and have academic freedom.

Int: If we fixed first year or we changed papers and teaching styles (.) do you think they should align across all their papers?

Lecturer C: Pfffft (.) so ((laughs)) (.) ah (.) so I don't want anarchy ((laughs)) anarchy's not great (.) but I'm not I'd be happy with high levels 
of uniformity 'cause I'm not sure it would align with what I would think is best practice ((laughs)).... The problem is it's a lot of work to have connections between the courses so that they're interlocking a little bit but with still enough freedom for the lecturers to decide. [Lecturer Extract 13]

\section{Int: I mean will people actually change their courses?}

Lecturer N: Possibly but it's going to take a coordinated approach it's gonna take leadership (.) and you get used to the autonomy you have right, and so somebody coming in and saying 'you need to do x' particularly when there's no immediate benefit to you for doing that.... ... the second year ECEN courses are being re-formulated for next year. At the moment those changes are very much in terms of the curriculum and the technical content, but they also give an opportunity for how that content gets presented 'cause new resources new lecture notes will be written (.) um. Int: So there's a really good opportunity then to go and bring in people from say, CAD, the Centre for Academic Development you know the professional teaching sort of help (.) I mean do you think there's an impetus for that?

Lecturer N: Um (.) probably not

Int: And is that that autonomy thing (.) or is that 'cause as engineers, you guys can solve the problem ((general laughter))

Lecturer N: Maybe both of those (.) um (.) at at the end of the day what we need is (.) new lecture notes new labs new projects (.) now you can take a little bit of people telling you 'this is what you should be doing (.) this is how you should be doing it' (.) but at the end of the day what you really want is somebody who is going to do the work. So yeah (.) you could have a little bit (.) um

Int: 'Cause they don't know the subject they are not as useful?

Lecturer N: No you're stepping into a minefield because there are different opinions... [Lecturer Extract 14]

Lecturer $\mathrm{N}$ expands on this idea of freedom clarifying that you can resist doing things people ask or suggest for courses through this autonomy: "you get used to the autonomy you have right and so somebody coming in and saying 'you need to do x' particularly when there's no immediate benefit to you for doing that". This autonomy even extends to 
not engaging with the university centre for academic development whose role is to support lecturers in teaching and course development. Lecturer $\mathrm{N}$ also illustrates the way academic freedom, while allowing for diverse opinions, can also be used as a desire for autonomy and a lack of intrusion or input by others. In this lecturer's case collaboration on course design with people of different opinions is seen as a negative experience and framed as a 'minefield'.

This desire for diversity in course design in part relates to the constructed identity of academic freedom/ownership, as generated by the role of lecturers within a broader tertiary educational environment. This broad framework is emphasised in the New Zealand Government Education Act 1989:161 to which VUW adheres to as a publically funded NZ University. This act states, that academic freedom includes:

(c) the freedom of the institution and its staff to regulate the subject matter of courses taught at the institution:

(d) the freedom of the institution and its staff to teach and assess students in the manner they consider best promotes learning:

However, academic freedom is not unconstrained freedom, as the Act goes on to say:

(3) In exercising their academic freedom and autonomy, institutions shall act in a manner that is consistent with-

(a) the need for the maintenance by institutions of the highest ethical standards and the need to permit public scrutiny to ensure the maintenance of those standards; and

(b) the need for accountability by institutions and the proper use by institutions of resources allocated to them.

(4) In the performance of their functions the Councils and chief executives of institutions, Ministers, and authorities and agencies of the Crown shall act in all respects so as to give effect to the intention of Parliament as expressed in this section (New Zealand Government, 1990). [NonInterviewed Extract 26]

This Act offers a relatively open and free educational environment which encompasses a set of assumptions by the Government about the role of the university. As section 3 above implies, the Government assumes that the lecturing staff and the university as a whole have in place appropriate educational mechanisms to facilitate student success. Section 3 $\mathrm{a}$ and $\mathrm{b}$ also assume that accountability for these mechanisms is sound. The Act notes that the "institution and its staff" can "regulate subject matter" and "teach and assess 
students in the manner they consider best promotes learning" as long as it is done with "the highest ethical standards" and can be scrutinised and maintained.

Ownership of academic freedom to institutions and staff is given by law with the caveat of accountability. This is ownership with limitations and boundaries. As can be seen in the extracts above there is a tension between the boundaries of academic freedom and accountability in operation within VUW. The academic staff appear to be able to adopt a 'pick and choose' approach to how they interpret what academic freedom means by using it as a means not to engage in forms of collaboration or accountability. However, I argue that this is a form of resistance by academic staff to increased measurement. This is what Ball (2001, 2008, 2012, 2015, 2016) describes as 'peformativity', and Shore and Wright $(1999,2000,2003,2015)$ see as an 'audit culture' - the threat to academic freedom, and educational best practice by universities in the neoliberal environment which are constantly seeking accountability in regard to increased performance of lecturer teaching ratings, research outputs, increased student numbers and course pass rates. The operation of power takes place in the discourse, it is where the tension is described by the academic staff, and the act of criticism is a form of resistance.

\subsection{The Need to Meet Targets}

There are other mechanisms of accountability that are connected to the retention of students in courses that impact on lecturers and students even before a course is designed. The New Zealand Government which has overall ownership of the tertiary strategy and funding policy, and has a TEC low-performing provision (LPP) requirement that $60 \%$ of students should pass individual courses (not a programme of courses) for the course to maintain full funding. Controlling the percentage of students who need to pass a course to be funded by the TEC is an expression of ownership.

The TEC does not arbitrarily withdraw funding but looks at each course on a case by case basis if a course falls below this threshold for two previous years. Included in this assessment is a consideration for the reasons relating to poor performance (K. H. Rabel. VUW Manager, Institutional Analysis. May 24, 2016). The TEC has the ability to do this and can in the future claim a return of the funding for courses that have breached the conditions/rules since the inception of this policy into law. If funding were recovered it 
would be the full funding for the course concerned and not only for those students that did not pass (K. H. Rabel. VUW Manager, Institutional Analysis. May 24, 2016).

Even though VUW has never received a formal request for funding to be returned there is a common verbal acknowledgement by staff that they have to ensure that course pass rates do not drop below the TEC funding pass rate percentage. This has on numerous occasions been conveyed to staff in meetings with senior management where I have been present. The result of this in ECS operational terms has been the active scaling of course marks to ensure the target is met. The following lecturers indicated an awareness of the need to take into account pass rates:

Int: So is there pressure on you to pass a lot of students

Lecturer O: Um, no I didn't feel that pressure, um. Okay the truth is that I have this in mind. So if something goes wrong, I think I have to make scalings all these kind of things. [Lecturer Extract 15]

Lecturer F: But that was that was built into the system because it's a curve. So literally me and Lecturer 3 sit there, and we go 'well you know what's typical for Vic' we ask around okay and then we just put them on that... [Lecturer Extract 16]

Lecturer $\mathbf{J}$ reveals how they understand the imperative to address student grades:

Lecturer J: I realise that the pass rates are a cause for concern... both, you know well basically that quality of students entering second year is a cause for concern. I mean a couple of years ago it was it was a great cause for concern about the actual pass rate because we were getting close to that trigger point Where you know fees can be pulled back... [Lecturer Extract 17]

Scaling or moderating is not an unusual occurrence in ECS and is not necessarily a negative thing. However, needing to scale to meet a Government target is not necessarily a good educational practice in a professional engineering degree. Graduates will often go on to work on sensitive and safety-critical systems where a certain level of knowledge and ability is required. The act of scaling to meet Government course pass rates which is not evidence that the students who pass are academically poor, but it is an example of ownership within courses and power in operation. The power-relation here is between the 
economic agenda for increased pass rates due to the connection between pass rates and funding and what action is allowed by academic staff to meet this agenda. We see multiple intersecting levels of responsibility to take action with a normalised practice taking place. The dominant message in the discourse is that lecturers have to take into account a pass rate criteria when grading in courses to meet government and university targets.

Recently I was invited and attended a scaling meeting for one of our core firstyear programming courses. This meeting included the course coordinator, all the lecturers, the course auditor and one of the other first-year lecturers and myself. The student grade data was presented by the course coordinator, and then a discussion was held around the overall pass rate, students on grade boundaries and on special case students (i.e. those that may have mitigating circumstances such as an illness). During this meeting, I asked the academic staff present how each of them scaled their courses. All those present had a different way of doing this to achieve their required logic of grade boundaries - and none knew the guidelines in the VUW Assessment Handbook (Victoria University of Wellington, 2015). The discussion around grade boundaries was also interesting as it revealed that these were generally derived from a gut feeling or from some perceived need to meet a certain target grouping and were often delineated where natural gaps in marks appeared in final course results.

The lecturers (for example, Lecturer Extract 16 above) used their own interpretations of scaling to meet perceived target goals around passing the 'appropriate' number of students at an appropriate grade level. Scaling has been absorbed into the lecturers' notion of 'academic freedom'. However, the academic freedom here in-keeping with Foucault, is the freedom to act in a specific way, and in this case it is the freedom to interpret the dominant message and act in a manner that complies (Foucault, 1983). The fact that the lecturers interpret how to do this in slightly different ways does not alter the common goal. The interpretations of structures and rules by academic staff are where the action of power can be seen. In the case of scaling, we can see the hierarchy between the NZ Government, VUW and lecturers in the way academic staff within ECS interpret the message to meet the pass rate criteria. The power-relations move across this hierarchy according to whose ownership of right or responsibility it is to carry out the dominant discourse agenda. Students do not understand or for that matter see this operation of power in scaling as it is a process that happens to them but does not involve their input. As such, the students are removed from input in the discourse. They do, however, see the results in the grades they get. This operation of power is what Foucault would term as 
being not obvious or invisible power (Foucault, 1975). The discourse has generated meaning and an established set of social processes enact it as a 'truth' making process. Scaling to meet targets is a normal university process.

\subsection{Course Design}

Academic staff have great freedom to design and teach their courses. Controls on course design within ECS are handled by the various degree majors teaching groups and by course auditors. A course auditor is assigned to every course and takes the form of another academic who is supposed to review the course and complete a checklist before signing off the course. According to interviewed lecturers, in many cases the lecturer would not do an in-depth investigation of a course they sign off. Often they are not experts in the courses they audit and have little or only a passing knowledge of the specific course subject area being audited. In ECS the respective teaching groups talk about the content of courses but do not generally get involved in how a lecturer teaches or assesses a subject. Academic freedom acts to reinforce ownership and the belief in 'subject experts'. It also acts to place academics in the position of not being 'subject experts' but being put in positions where they must act as if they are by auditing and signing off on courses they may have no expert subject knowledge of or knowledge of best practise assessment methods.

The VUW Programme and Course Design Handbook is designed to assist lecturers in designing courses. It notes that 100-level courses should follow the following basic guidelines:

"100 level: Preparation. Teaching and learning emphasise broad and introductory enquiry in key areas. At this level there is likely to be more control and structure in teaching, learning activities and assessment tasks. Expectations for students on completion of these courses could include:

- introductory levels of knowledge

- an ability to communicate clearly an understanding of the key concepts

- knowledge of theories and ideas within a subject

- basic discipline skills

- location and use of evidence 
- synthesis, evaluation and interpretation of information from a number of sources;

- sound judgment in accordance with the basic theories and concepts of the area of study

- understanding of academic conventions and integrity (e.g. plagiarism)" (Victoria University of Wellington, 2015, p. 8).

[Non-Interviewed Extract 27]

According to the handbook, a student's first-year courses should be relatively broad and of an introductory level. However, it is difficult to tell if this message has any significant direct effect upon first-year course or programme design in ECS. The course design handbook is a necessary administrative document that shows outwardly that this aspect of the teaching and learning environment is taken seriously, but it does not significantly challenge the ownership of courses by lecturers and pass rate requirements by the university management and Government. This can be seen in the language used above: "likely to be more control" and "these courses could include" when used to advise academic staff on course design rather than more direct and authoritative words like 'must', 'will' or 'should'. The discourse on course design supports considerable freedom of operation by lecturers in course design and operation.

The following excerpts suggest that this freedom results in relatively ad-hoc communication between lecturers and reasonably informal course- and first-year programme design process:

Int: So if we don't know what...they're coming in from school with... In terms of background knowledge, how are we making that? Are we just making an assumption of what they should they should know?

Lecturer E: Yep it seems to be... I mean there doesn't seem to be any change or modification of the course based on the response of the students to the material. So, a classic example here that I could come up with was is Physics-A... So there was little to no acknowledgement that a chunk, so let's say twenty-five of the students in Physics-A had never done any maths previously and weren't enrolled in the Maths-A course. Yet they started in their very first lecture rearranging equations. And sure, for us, that's trivially easy, but it wasn't for them. They didn't cover that until like week four of Maths-A, and even then they spent a week on it... So requiring them to do that at that point in the trimester just throws this 
massive disconnect and we've done the same thing in trimester two with Engineering-A and the corresponding maths content in Engineering-B... It's the right content but taught at completely different times from when it's needed. [Lecturer Extract 18]

The lecturer comment: “there doesn't seem to be any change or modification of the course based on the response of the students to the material" is a good example of the fact that lecturers have a lot of ownership in a course. Lecturer $\mathrm{E}$ by also explaining that the courses are not constructed to align to the incoming students lack of math and importantly the reference to "there was little to no acknowledgement" implies that the lecturer was aware of this but did not adjust their class material or order of material to accommodate this. As the material is not aligned, the students are subject to a "massive disconnect" placing the students at a learning disadvantage. The lecturers appear, according to lecturer E, to be lacking in their responsibility to students and the Education Act. It also appears that this is a common practice: "we've done the same thing in trimester two with Engineering-A and the corresponding maths content in Engineering-B”.

The following excerpts from lecturers' $\mathrm{A}, \mathrm{C}, \mathrm{F}$ and $\mathrm{O}$ continue to illustrate a similar disorganised approach to course design and planning. They contain specific examples of differing lecturer perceptions of course design and teaching planning in the new Engineering math courses, Engineering-A and Engineering-B, cross-disciplinary, multi-instructor courses. The excerpts are taken from interviews with two engineering lecturers and one math lecturer from these courses:

Int: So in terms of being able to understand whether first year is pitched at the right level for incoming students

Lecturer A: That's really hard... No one knows what's in those maths courses, so nobody in engineering really seems to know what's really in those maths courses. I guess Lecturer E, Lecturer $\mathrm{H}$ and Lecturer $\mathrm{N}$ have seen a fair bit from the tutorials... But I don't think they know what's in the heads of the lecturers - the course organisers.

Int: Well they wouldn't for physics either

Lecturer A: Right... welcome to the university, this is how it works. [Lecturer Extract 19]

Lecturer A indicates a sense of business as usual or normalised behaviour around the way ownership allows course organisers and lecturers to retain, rather than share, course information. Ownership of information and course material lies predominantly with the 
lecturer, not the university or ECS programme. The statement: "No one knows what's in those maths courses, so nobody in engineering really seems to know what's really in those maths courses" is concerning given the engineering math courses are a key component of the professionally accredited degree. Furthermore, the grades in these key courses contribute towards students achieving the critical B average across Part 1, and theoretically towards required subject knowledge for second year. It also raises the question of how are these courses held accountable for their educational merit if nobody outside of the courses knows what is in them. There appears to be no commitment to following the ideals of accountability in the Education Act or the VUW handbook guidelines for course and programme alignment. This is a breakdown of the rights and responsibilities in the teaching and learning field outlined in Table 4.1.

In the conversation with lecturer $\mathrm{C}$ it was clear that the lecturer thought that there was some "proper planning" made in the new engineering math courses:

Int: Is there much use of educational pedagogy going on in the design and methods behind what are used to sort of lecture at students or engage students?

\section{Lecturer C: No}

Int: Does that even come up in conversation?

Lecturer C: It might do in the new engineering math papers... Because I think that we have new staff members and I think it was impressed on them how important it was that some thought - actually some proper planning went into it. Most of the other courses tend to run on historical precedent or how the current lecturer feels, thinks is the best way

Int: Yep so do you think that's helpful?

Lecturer C: I have a phrase benevolent dictatorship ((laughs)) the courses at least the courses I know of. [Lecturer Extract 20]

We can see that the concept of ownership becomes quite clouded when individuals in the environment believe that certain things have happened or are going to happen in related courses but actually they do not. There is also the notion of historical ownership versus current ownership, with historical ownership having some potential effect on how courses are subsequently run. These represent two sources of power. Historical precedent refers to courses that have run a specific way for a certain period of time and where lecturers have developed a sense of establishment around this is just the way it is done. This is what Foucault would term a truth-making process where a way of acting or doing 
something take on a meaning that people over time take for granted as being normal and correct (Foucault, 1972). Academic freedom is both the cause of this eventual truth making process and the reason it rarely gets challenged. Course design by "how the current lecturer feels" is as blunt as it sounds. Lecturers through their use of relatively unchallenged academic freedom to do what they believe is "the best way". Both expressions of power suggest that academic freedom stretches to allow multiple expressions of practice.

Lecturer $\mathrm{F}$ offers further insight into the process of course design within the programme:

Lecturer F: I thought at the end of last year everything was a bit weird so Lecturer $\mathrm{O}$ and I were hired we came in we taught this course. We weren't given that much guidance. And we were given... the notes from Engineering-A so we just kind of went with it.

Int: ... are you teaching this course the way you would run this course?

Lecturer F: Engineering-A I'm happy with. Engineering-B I'm doing now, and I'm not super happy with - you know I'm not so comfortable with [it], so we don't have a text book which maybe I should have, like I don't know got them out. Maybe I was a bit passive I felt like other people were in charge of [it], Yeah you know it's the logic, and then it's probability and statistics, and then these can be integrated better than they're going to be... [Lecturer Extract 21]

Lecturer F indicates a lack of guidance from his colleagues and reveals an interesting process; one that indicates that lecturers are reluctant to tell others how to teach and do not appear to be sure of who owns a particular course. Academic freedom in this regard is an attitude that can empower academics to have a sense of freedom of action in course design. However, it also allows for a process where collaboration and integration of course design can be conducted in isolation by the academic staff. Collaboration on course design is done, but there appear to be boundaries of behaviour around how far academic staff will go in challenging or questioning existing practice. The lecturers above indicate the effect of academic freedom when exercised through a lack of clear deliberate educational management results in the promotion of a culture of individualism. This individualism places ownership of specific course subjects, materials and practices within that of the individual lecturer and is part and parcel of academic freedom. For example the statement: "so we don't have a text book which maybe I should have, like I 
don't know got them out. Maybe I was a bit passive I felt like other people were in charge of [it]" shows the flexible nature of academic behaviour which I believe is a result of lecturing staff's understanding of their role. A role in which academic freedom is inherent. Ownership of course materials, such as textbooks, is an expression of this freedom to act and removes power from the students, and staff in related courses who may need to see what is being taught.

The same lack of coordinated course organisation was described by another engineering math lecturer who was involved in the second-trimester engineering math paper that followed on from the paper described by Lecturer F. The lecturer advised the complicated integration of the course between math and engineering. Math academics did the lecturing and ECS staff did the laboratory tutoring:

Int: Do they get much training, yeah-the tutors in your experience?

Lecturer O: About er, the Engineering B, I have no idea, and personally I don't know how to do the labs. And I don't know how to use the equipment. So we visited the labs, and there were personnel there, so they explained, to the tutors how to use the equipment. And what are the rules also they had like a one hour briefing

Int: Yep so you just do the lecturing side of things in setting the assignments and tests and exams.

\section{Lecturer O: Yep.}

Int: But the labs are done by engineering.

Lecturer O: Engineering.

Int: Yep and and there's not a lot of communication?

Lecturer O: So [now] I know exactly what they're going to teach and I will spend one hour of my lecture related to the lab, of course last year it wasn't like that because er I wasn't familiar with the lab and so I couldn't connect the-the... I didn't have time to think about the lab, and now it's better I think and, um. [Lecturer Extract 22]

Lecturer $\mathrm{O}$ in the last part of the excerpt above is referring to the miscommunication between the lab (engineering) teaching staff and the (math) lecturing teaching staff which occurred in 2015. The lecturer could not connect the lab material to the lectures suggesting a disconnect between the practical and theoretical aspects of the course. This is an example of how the balance of accountability shifts from course to course and lecturer to lecturer. 
In the interview Lecturer $\mathrm{O}$ goes on to describe a situation where the checks and balances of course outcomes in relation to student ability and knowledge, as assumed from previous courses is not connected together.

Lecturer O: Mm no, I think they are capable. Um. The truth is that they [students], they're, what I've seen is that they don't have the fundamental knowledge in mathematics. Ah, what I think to be fundamental, ah, I can be more specific so during my lectures sometimes, or during this course, I try to cover things that er, they should have already er, studied before. Ah, er, something else that happens is that probably after passing one course, then they forget everything, or you know maybe the way they learn things, um, is not the most appropriate way. [Lecturer Extract 23]

In the situation described above, we have students shifting from the engineering math Engineering-A to Engineering-B largely unprepared for the follow-on course. The result of this is that the lecturer must recover some of the material students are presumed to know: "so during my lectures sometimes, or during this course, I try to cover things that er, they should have already er, studied before". This lack of student knowledge is expressed as a fault of the students: "is that probably after passing one course, then they [students] forget everything, or you know maybe the way they [students] learn things, um, is not the most appropriate way". There is no questioning of the appropriateness of the previous courses teaching or teaching materials, or any attempt to converse with the lecturer of the previous course to remedy this. The lecturer takes it upon themselves to provide the missing knowledge which must, despite not being mentioned, impact on the ability of the lecturer to deliver the course material already in the course.

\subsection{Communication Breakdown}

The individual nature of course development and ownership in part relates to whether there is a formal mechanism to establish procedures and accountability. In ECS there exists no formal procedures for establishing course development or course alignment. There is a lack of communication between lecturers and a lack of formal processes that encourage communication as a norm:

Int: Do you guys talk about what's going on in your courses? 
Lecturer A: There's some discussion, not a lot. There's that first-year Workload Committee, so that's had discussion. There's informal discussions that I have with people ... But there's little formal discussion. [Lecturer Extract 24]

Lecturer A describes the first year workload committee as an example of discussion around first-year courses in ECS, however, as a member of that committee, I can say with certainty that we have met only twice in the two years of its operation. The intention of this committee was to investigate the first year courses and attempt to understand if ECS was overworking the students. I am also sorry to say we achieved nothing and we were not held accountable by ECS senior management for our lack of progress.

Individualism and a lack of communication can also be seen in the following excerpt. However, there is also a desire for greater communication and shared course design:

Lecturer D: I think the courses could be improved. One of the ways the courses could be improved is by the lecturers starting to talk more together. Whether they should have done this in the past is a moot point because it wasn't done and now it ought to be done. I think one of the reasons when you're developing courses it's important to get the course material there before you worry about how it relates to other things. So you get your core first and once you've got your core you then fine tune it to relate it to others which is definitely the approach we've taken in the engineering mathematics course... Now is the right time to get people to talk to each other and I think it will improve with coherency about what's expected... A more cohesive approach between the courses is good. I would like to think we would get to a cohort approach but I don't think we will, so one of the problems is for example if you're teaching matrices in mathematics it would be good that in engineering and physics in the next week that they use examples of matrices... But that level of coordination is unlikely to ever happen. It's just everything becomes very rigid when you require too many courses to be prerequisites and corequisites to each other. [Lecturer Extract 25]

There are several examples of the way ownership of courses shows the operation of power in the excerpt above. For example, Lecturer D notes: "it's important to get the course material there before you worry about how it relates to other things" which emphasises 
that the "material" content is the most significant aspect of the course. In the lecturer's perception content is important, and it is where ownership of a course begins for the lecturer. From here, as the lecturer explains, you can involve others in conversation. However, in this situation, the reference to conversation taking place is in the context of the course having run for a couple of years: "Now is the right time to get people to talk to each other and I think it will improve with coherency about what's expected". Ownership of the courses has therefore been kept by the lecturers, rather than shared by the ECS programme. While an integrated approach for aligning curriculum across courses is considered beneficial by the lecturer curriculum with joint ownership of course material across courses is unlikely due to the individual nature of the course design prerequisites and corequisites.

Course prerequisites and corequisites are set by lecturers for their courses and require students to have specific entry criteria. For example entry into Engineering B requires completion of Engineering A. Though as we have seen above this does not suggest that the lecturer of Engineering B knows what a student will do, or has faith in the student's ability to know this for their courses. The constant lack of accountability in a pedagogical sense in course design shows how control over courses by lecturers allows this act of control to cause a lack of programme control and ultimately questions whether the TEC or Government has control.

The following excerpt expresses Lecturer A's opinions on the interaction between lecturers about course design:

Lecturer A: I don't think they're especially interested in [course design]...Lecturer $\mathrm{J}$ is not especially interested in [course name]. [They] had to teach it. [They] works at it, but doesn't have a vision of computer science. [They're] not driven by course design. I suspect if you tried - if you asked [them], why we have priority queues in there? I doubt that [they] could tell you.

Int: Is this true across the programme, I mean is it an academic thing?

Lecturer A: When you get to the higher level - When you go to the third year you get much more ownership of material.... It tends to be in the specialist area. So Lecturer $S$ is the [course name] person that's [their] course [they] care about it... Lecturer $\mathrm{T}$ has half of the [course name] course, and Lecturer $U$ has the other half, and they disagree quite considerably on what ought to be in there. And neither of them are happy 
with each other. And they talk, but they don't say what they actually think 'cause then they'd start fighting. First year - our first year's sort of weird because I care about it.

Int: But you don't have control over it either?

\section{Lecturer A: Of COMP I do}

Int: Yes but not over the Engineering or the two Engineering courses?

\section{Lecturer A: No}

Int: The Physics courses or the Maths courses?

Lecturer A: No. [Lecturer Extract 26]

Lecturer A suggests that the academic staff are less interested in the courses at first or second year as they are not as closely related to their own research interests as third or fourth (Honours) year courses. The lack of interest in first-year courses is a form resistance to this aspect of their job, and by choosing where to place "care" is an example of how the individualistic nature of lecturer power can be exercised. When a lecturer owns a course in their area, it becomes the property of that lecturer rather than the property of ECS. Lecturer A identifies a lack of collegial discussion even within lecturers teaching on the same course: "Lecturer T has half of the [course name] course, and Lecturer U has the other half, and they disagree quite considerably on what ought to be in there. And neither of them are happy with each other. And they talk, but they don't say what they actually think 'cause then they'd start fighting". This excerpt indicates that there exists considerable freedom to disagree by lecturers about course content and teaching. By deciding not to "say what they actually think" to each other there is a reflection of the cultural norms in ECS where accountability to a shared understanding of course design or pedagogy is often lacking. Further evidence of this is in the final statements where the lecturer, while noting they care, also reveals that they have no control over anything other than their own courses.

Lecturer $\mathrm{J}$ while confirming the comment above by Lecturer A, also states that they know little about the other courses at first year or those courses which the students directly follow on from the first year course they teach:

Int: So do you know what's taught in any of the other courses?

Lecturer J: Um other than Programming A, no... Yeah, essentially I know how Programming A looks... And that path through concepts that it follows through Programming B 
Int: Yeah, okay, but second-year courses that the students go onto, do you know much about that

Lecturer J: Mm, no I'm ignorant, never taught at second year so I just rely on other academics telling me

Int: So is a lot of this sort of information coming out of your SWEN or COMP group meetings.... Is that where you're getting a bit of a feel for some of this.

Lecturer J: I don't think I don't think I'd say I have a feel for it... I'm very ill-informed about what staff are thinking about their students at second year. I just don't hear it. [Lecturer Extract 27]

In this excerpt, the lecturer while claiming ownership of their course, seems to place ownership on how educationally successful it has been, as preparation for second-year courses, on how staff in the subsequent courses think about their students. This reliance on feedback from other lecturers to determine whether a course is effective shows a breakdown of communication. This breakdown of communication, coupled with the lecturer's own acknowledgement that they have never taught a second-year course describes a disconnected programme where curriculum alignment is uncertain. Engagement with other courses by lecturers is also restricted to informal processes. Lecturer J's excerpt illustrates how siloed the lecturers are as a result of the culture of academic freedom within ECS that has the practice of supporting ownership of courses by individuals without 'active' formal processes of course curriculum alignment, accountability and review.

The informal nature of course accountability allows lecturers to have control over where they place their efforts. Lecturer $\mathbf{J}$ goes on to describe their experience in the teaching and learning environment of ECS:

Lecturer J: ...yeah none of us are trained to teach, none of us talk to each other (laughs), yeah there's no real reason for me to go and talk to a firstyear student about what he she is um, where they're headed at right now, none of them.... Yeah, um, I can contrast this with how I teach at the third year in the AI course which is more like my home ground, I kind of know... what I want them to have 'cause I do teach the following year. And I'm very clear on this and the passion there is much much easier to go and find, so I can sort of go and dial it up... and I would go to the lab and 
talk to five students... ...I wanna be there it's completely easy. [Lecturer Extract 28]

Lecturer J acknowledges that lecturers are not trained to teach, and lecturers do not engage with each other. This implies that they have no control over whether they have or develop teaching and course design skills individually or as a group. Yet, as the lecturer explains there is a difference between the ways the lecturer engages with courses and students at different levels of the degree.

Academic freedom, as understood and enacted by academics, appears to enable the lecturer to equate ownership and responsibility with their passion and interest. Firstyear students are disempowered by not receiving the same level of interest and dedication as third-year students experience from the lecturer. The lecturer is choosing where to place their effort and using ownership to impact the way our courses are designed and delivered. Ownership of courses in the ECS teaching and learning space is part of a complex system that prioritises academic freedom and lecturer choice of action over the establishment of a sound and accountable education system. In the description below we see that this lack of ownership or responsibility translates to a complete lack of direction in a critical first-year course:

\section{Int: What's the purpose of Engineering A which is this compulsory core course all engineers take?}

Lecturer G: Well that's the thing that we have been struggling with for the past three times this thing has been conducted. I think each time we sit down you know there's no one clear vision of what it needs to do. You know it's kind of like we are making it up as we go along ((general laughter))... We come up with what we call a plan, a schedule, okay? But there's no clear vision, you know on what it is actually intended to achieve you know... [Lecturer Extract 29]

The "we" the lecturer is referring to is the three lecturers involved in teaching Engineering A. The "we" is not the ECS programme or respective majors within the programme and as such is further evidence that ownership of courses, while providing a certain amount of freedom for lecturers, also results in uncertainty in course design and direction. ECS has a top-down hierarchy for teaching which is supposed to be active in connecting the courses together to meet (as previously mentioned earlier) graduate and professional accreditation outcomes. 
However, as Lecturer D notes the actual operation of this hierarchy in effecting course design, teaching and accountability remains ambiguous:

Lecturer D: The problem of our fifty percent I don't believe, is on the good to averagely good student... It's the average to poor students that don't have the skills to cope with what we want, and we're not providing the mechanisms to get the skills to get what they want Int: So is that because like most courses are up to two or three people to decide what they're teaching?

Lecturer D: Yeah and I think this was the case 'cause up until last year we didn't have an Associate Dean academic development that could look over it and Lecturer A is looking across, vertically and horizontally across courses, we have programme directors but programme directors worked on specialisations, and there was talk of having an engineering programme director... But that wouldn't have worked because they didn't have the remit to change anything... They couldn't change, across specialisations, whereas Lecturer A has the remit so that works better

Int: So Lecturer A actually has authority to come into, say for example your course, and tell you to teach a certain way?

Lecturer D: I hope [they] has - and I hope [they] does. [Lecturer Extract 30]

Lecturer D identifies and categorises students noting that the "average to poor students" are adversely affected by the lecturers "not providing the mechanisms" for the students to be able to succeed. This is a failure of the lecturers, ECS and university management to meet either the student expectations or their own rights and responsibilities as educators. Lecturer D refers to the ECS Associate Dean Academic who is expected to have an overview of the teaching and courses, and Programme Directors who are essentially academic managers, a step below the Associate Dean. Programme Directors are nominally in charge of specific majors within the degree and are expected to have some input into course design, content and teaching in their major. Responsibility for course design and day to day teaching is the responsibility of individual academics.

For Lecturer D there are supposed to be mechanisms in place to help align course design and teaching, but there is an inbuilt lack of authority in many of these positions "because they didn't have the remit to change anything". This is an example of power at work within the organisation. The power in this situation is that lecturers and their courses 
are not able to be held accountable. Even in the situation Lecturer D describes for Lecturer A it is unclear that Lecturer A could enforce any change to a lecturer's course or teaching. This fact was illustrated by Lecturer A in Extract 26 above when they noted that they had no control over courses or lecturers they were not involved in. The result of this is a constant tension between the educational imperative of ECS and lecturer ownership of courses.

The net effect of the lack of coordination and communication between lecturers and courses is that there has been no clear design and delivery of an integrated first-year curriculum. There is a lack of communication of course content, best-practice or the use of pedagogical theory in the first year courses which marks a clear shift from the government, business and university goals of delivering both quality and quantity of students. Academic freedom has in effect, resulted in the relinquishment of the means to effect a comparative and measurable quality education. There is no formal way for any senior teaching academic to force a course change, in design or teaching methods, unless a course receives extremely bad student feedback. Ownership remains a contested space in the teaching and learning environment in so much as ownership itself is a flexible process. Ownership can be exercised to take control of course content and delivery, or to prevent other staff from involvement in a course, or to refuse accountability.

The contrast between the official VUW message relayed to the TEC and the Government through our investment plan is striking:

"Victoria has rigorous quality assurance processes in place for assessing the perceived quality of the curriculum and its delivery. A course evaluation survey is required every third offering of a course. New or substantially modified courses are required to be evaluated after their first offering. Summary reports on course and teaching feedback are reviewed by senior academic staff" (Victoria University Investment Plan, 20152017, p. 13). [Non-Interviewed Extract 28]

However, there appears to be little evidence in my interviews for a "rigorous quality assurance processes" or for that matter adequate curriculum review or communication processes between the staff at first year (the following chapter discusses ownership in respect to teaching and learning). In ECS, the only formal course review process I have encountered is when a course is audited. For example, I teach and coordinate a second year engineering writing and communication paper, and despite a few informal conversations and a course auditor overseeing the final marks and glancing through the 
course outline, I have been largely left to decide for myself what, and how I teach in it. The excerpts presented above indicate that course or curriculum reviews, do not occur at a formal level but rather exist in informal conversations. Often there is a reluctance to discuss or actively look for opportunities to work together on course development. The university ideals for quality assurance in an educational sense, in practice, as evidenced by the lecturer comments course content and quality control is often poorly monitored by some academic staff, including academic management. Moreover, what monitoring is done largely focuses on the metrics of numbers of students passing courses to meet the TEC requirements (Victoria University Investment Plan, 2015-2017).

The situation in ECS echoes the findings of Knight and Trowler (2000) who undertook in-depth interviews with 26 academics in England and Canada regarding good practice in teaching and learning. Their interviews were cross-disciplinary, including, for example, engineering, physics, deaf and women's studies and education lecturers. They found that departments or sub-units within educational institutions represent the main activity systems for most academic staff and that this central locus is where cultural enactment and construction takes place. Knight and Trowler noted that while lecturers embraced academic freedom and autonomy, they were increasingly occupied with a managerial agenda of growth and research outputs and had to respond to the managerial policies and directions of the department and university. This reaction created environments that isolated academics from educational discourse as they could retreat through this relative autonomy and academic freedom from actively engaging in teaching and learning best practice. Knight and Trowler argue that the fault here is not with the lecturers themselves, but with the culture and that ultimately managers, department leaders and the senior university management have a huge role to play in redressing this. (Knight \& Trowler, 2000).

\subsection{Summary}

This chapter has shown that VUW and ECS has a specific culture that is reflected in the lecturers' statements and in the way the policies and documents are written. This is a culture that undervalues, despite university policy, a priority focus on good course development, teaching and learning. The lecturers and the programme as a whole act as if policy is rhetoric. Course development is not prioritised or conducted in a systemic 
programme level. Academic freedom both removes a measure of accountability and responsibility from the lecturer to develop and deliver quality courses, while at the same time allowing for other forms of accountability in the need to pass students to meet external pressure. Ownership of course design remains with the lecturers but they can to a certain extent choose their level of engagement as long as they meet their required accountabilities. The lecturer excerpts indicate that lecturers have little organised 'business as usual' communication with each other about the core educational outcomes expected of each course.

The operation of power in this sense from an organisational point of view is siloed amongst departments and individuals which in turn empowers them to act as they see fit. This is an example of the diffusion of power in the discourse and in no manner reduces the dominant neoliberal drive for growth and increased economic gain. While individual staff and departments are accountable, it is the dominant discourse of needing to meet targets running throughout the system that acts to drive practices. The drive to meet targets places the responsibility for how this is done from departments onto the academic staff. Accountability is achieved through lecturer interpretation of goals and their use of academic freedom. Scaling is one mechanism used by the lecturers to meet targets; it also allows for flexibility in course design as scaling can be used to 'cover up' for poor design and assessment practices. The lack of auditing and attention to course design is another way this discourse allows for growth, giving the lecturers time to prioritise other more accepted practices, such as research. Ownership of courses and course design is affected by the power structure of the education system which enables lecturer and university processes and actions.

The following chapter extends the discussion of this section by looking at lecturer's statements relating to issues affecting the practice of the teaching and learning within courses in more detail. 


\section{CHAPTER SEVEN: OWNERSHIP OF TEACHING AND LEARNING}

While, the previous sections have explored the broader framework of ownership of the STEM crisis, entry and courses, I look next at ownership with regard to teaching and learning. In doing so, I focus on how ownership reveals the processes of power operating in the classroom. Ownership of teaching and learning experience belongs both to the student and the lecturer. The lecturer is responsible for facilitating learning and the development of knowledge through creating a context in which this can occur. Knowledge itself is intrinsically linked to social acceptance or conformity with rules and meanings.

A key theme of this discourse lies at the heart of the educational nexus and is rooted in an Enlightenment conception of modernity. Richard Edwards and Robin Usher identify this in their 2002 book, Postmodernism and Education where they note:

Education is very much the dutiful child of the Enlightenment and, as such, tends to uncritically accept a set of assumptions deriving from Enlightenment thought. Indeed, it is possible to see education as the vehicle by which the Enlightenment ideals of critical reason, humanistic and individual freedom and benevolent progress are substantiated and realised. (p. 24)

Edwards and Usher locate the power struggle of educational discourse in the theoretical battle for ownership of 'truth'. They cite postmodernist philosopher Jean-François Lyotard (1924-1998), who argues: "that the project of modernity is deeply intertwined with education, modernity's belief being that progress in all areas will emancipate 'the whole of humanity from ignorance, poverty, backwardness, despotism...thanks to education in particular, it will also produce enlightened citizens, masters of their own destiny"' (p. 24). In doing so, they claim that education's primary rationale is founded on the humanist idea of a certain kind of subject. The humanistic idea of a subject in this educational sense is a person who has an inherent potential to be self- motivated and selfdirected. The role of education, then, is to take this subject and help them fulfil this potential. However, fulfilment takes place through the particular lens of an educational institution's teaching practices - in the broadest sense. 
From a Foucauldian perspective of power subject positions and subjectivities reveal the operation of power (Foucault, 1983). Lyotard's conception of a subject is an understanding of an imbedded assumption and normalised view within the educational discourse. It is very much taken for granted and it is this discourse around the creation of a subject that we can see how the effect of power constitutes academics and staff as subjects with subjective positions. This involves questioning how the text reveals peoples interests and encourages or negates this, and importantly what are the consequences for some in doing this. A Foucauldian approach places the subject in relation to discursively constructed practices that seek to normalise the way people are seen. For example, discourse within the tertiary higher education teaching and learning environment (a discursive field or system) normalizes the way a lecturer may be seen: lecturer, researcher, teacher, academic, colleague, employee, subject expert, supervisor, Dean, Head of School, Programme Director etc. Foucault's enquiry seeks to examine the way connections in the discourse illuminate the operation of power in discursive fields by investigating instances of what are accepted or resisted practices. For example, are there connections between these subjectifications and, say, how the lecturers see themselves (lecturer vs teacher?), or are their links between these subject positions to broader educational concepts like pedagogical and teaching practice, student empowerment or for that matter quality control, course development or the connection of education to national economic well-being or security. By questioning these positions and the processes revealed within the discourse through FDA we can illuminate the power relations in the social network uncovering practices that allow actions to be enacted upon ourselves and others (Foucault 1982). The goal here was to understand the subjectivity of people and the operation of power that constitutes control over what is normalised social behaviour not to develop an understanding of the subject as an individual.

We can see this creation of a subject in the way lecturers describe students, or the way students perform in their classes. For both the student and the lecturer; the lecturer becomes the owner of the teaching space and the director of the learning environment. The following excerpts illustrate that lecturer ownership of the teaching and learning environment creates a contested space for students, where ownership of learning only belongs to a certain type of student, with a certain ability:

Lecturer E: ... how many academics view students, is right you're at university now, you're an adult, you've paid a large amount of money to be here, it's your responsibility to engage with the course and the material, 
and if you don't you're an idiot, and you shouldn't be here... but the reality is that doesn't describe most of our students. Most of them are school leavers that think this may be something they want to do. And they struggle to motivate themselves... Particularly those average students because they probably will have struggled with motivation at high school... Exactly, so they're -they're turning up saying, 'alright I'm Tom, I'm nineteen I have the entrance requirements for this course I have sixteen credits they're all at achieved. I technically match what you on paper say that you want. Except that what we actually want is, or what our courses are set up to allow to pass are students that are motivated and are probably at the cream of the crop so the merits/excellence maths students, that will, kind of breeze through relatively easily.... They're essentially to be pretty well perfect from the get-go. [Lecturer Extract 31]

Lecturer E describes the learning space as being set up for the top students, the ones who are self-motivating, self-learning, responsible and academically excellent. This is an example of the creation of a subject position which supports one type of student over another. The lecturer also notes that most of the students ECS has do not fit this characterization. As such, the learning space is designed for a particular type, but likely a minority, of students. This conflicts with the rights and responsibilities in Table 4.1 by limiting the potential success in the learning space to a certain group of students. It is also antithetical to the university policy discussed previously, that seeks to provide a quality learning environment for all students enrolled at the university. University policy does not describe this process as only applying to a subset of students. There is a power relationship described here which sees the lecturer note that fellow academics think students are 'idiots' if they do not meet their idea of engagement with course material which is set at a standard where only the "cream of the crop" will be able to engage. This lecturer also draws attention to the fact that the entrance requirements send a message to the student that they already have what is required to succeed which seems to be at odds with the idea of only teaching the top students.

Lecturer $\mathrm{C}$, below gives their insight into why lecturers aim their teaching at a subset of students:

Lecturer C: Okay, so the academic one's straightforward yes? Because the academic stand point is looking at the top cohort, under some measure 
of the high school students so, apart from that top cohort everybody else struggles.

Int: So we pitch our courses at the top cohort?

Lecturer C: I think so... Well, of the top high school cohort which is not necessarily the wrong thing. The University doesn't want every high school graduate I think... but it's very easy then to fall in to aiming at the top ten percent of the class here, which is the top, might be one percent from high school... [Lecturer Extract 32]

Lecturer C acknowledges that, they believe university is for the "top high school cohort" and also uses the university as justification for this. The notion articulated here is about quality control in the student body in the first instance. This opinion, articulated by other teaching staff I interviewed, suggests to me that it is a common belief that university is for a specific group of students. This common belief carries with it considerable power and is part of an accepted discourse at odds with discourses of diversity and inclusivity. The discourse evidenced here is an example of resistance to the neoliberal growth agenda aimed at increasing student numbers. The desire to teach a smaller, more academically prepared subset of students increases the level of ownership of subject material and control over who gets through a course. It also enables the lecturer to avoid engagement with pedagogy or best practice in teaching methods designed to assist a broader cohort.

Lecturer L below takes this idea a little further, suggesting that the lecturers are also looking for research students at postgraduate level, and acknowledges that this is a much smaller subset of the students than the top level of students coming out of high school into tertiary study:

Lecturer L: A lot of us are looking for educational level $\mathrm{PhD}$ level students. I can understand that you can look for them and encourage them. But ninety percent of them will not work at university. Ninety percent of them will work in the industry, and in the industry, you don't have to be $\mathrm{PhD}$ level....

Int: So do you have any idea why that is, why we're pushing them all down that thing

Lecturer L: Because our standards of knowledge are pretty high. We expect much, in industry actually you don't have to know that much... Int: So we're actually selecting for academic top academic level students in our teaching 
Lecturer L: Yes [Lecturer Extract 33]

Lecturers $\mathrm{C}$ and $\mathrm{L}$ describe a notion of categorisation around the students where there is a constant desire by lecturers for the 'best' students. They describe a learning space as being set up for these so-called top students. Lecturer $\mathrm{C}$ locates this desire as being driven by the university, whereas Lecturer L sees this drive coming from a desire by academics for graduate students. Both of these views contrast with university and government policy that wants increased numbers of engineering students and graduates. These excerpts show a disregard for the rights and responsibilities (see Table 4.1) of the involved parties in providing an appropriate education for the students who have been accepted into university. Lecturer ownership of the teaching and learning allows the academic teaching staff the ability to target the teaching at a specific group of students. The student is largely removed from ownership of their learning, as they may be completely out of touch with the academic level the material is taught at. Students are unable to be engaged in their own learning, and thus the lecturer's view that university is only for a subset of students can become a self-fulfilling prophecy.

This is also apparent in the following excerpt which discusses an introductory course in physics and the pathway for students into the core first-year physics papers:

Int: How does Physics-A fit students going from that path going into Physics-B or Physics-C in trimester two...?

Lecturer K: Not well... It's a big jump, because I mean the ones who do well in Physics-A ... many of them have leapt streets ahead, I mean they've really made good progress... They've gone the distance, but even so, there is a big difference in the level of sophistication... And it has to do, I think, with the academics, some of the other subject lecturers there having very high expectations, maybe excessively high. Perhaps less prepared to make allowances for their entry level... For where they are and where they've come from.

Int: So are they not seeing it as, like you say you take a student here and your job is to get them to the finish line? So you need to change the way they think and help them learn in a different way. Is that not how the other Subject papers are taught?

Lecturer K: I can think of some people who would agree with that, and others who would just ignore it, and this is this is the standard they have to reach and they have to do it by themselves and the plonkers won't... That's 
a word I've heard before, plonkers... And you know I mean I find that that rather difficult to accept, that I think everybody would benefit from a further education of some kind or another. [Lecturer Extract 34]

Lecturer $\mathrm{K}$ also describes differing opinions amongst his colleagues about the role of education and expresses the perception that higher education should benefit all - not just a certain group. If we consider the various roles within education as identified in Table 4.1, there is a discrepancy between the ways lecturers perceive their rights and responsibilities. This difference seems to centre of the belief that the students academics are getting are not adequately prepared by high school and, as such, they are unable to provide an adequate and aligned curriculum and assessment methods that can cater to these students. To do so would be to reduce the academic level of the material, and put at risk the education of those perceived as the 'top' group of students. The refusal to alter their teaching practice to cater to the broader group of students is an act of resistance by academics against university enrolment policy. Unfortunately, it also impacts on the learning experience of any incoming student who does not fit this narrow characterisation. In a hypothetically ideal educational environment, all the ECS students would be academically prepared for higher education and have been adequately assessed by the VUW/ECS entry criteria. However, as discussed earlier in chapters five and six, exactly what level of preparation is required is complicated by the varying enrolment messages and the lack of cohesive course design.

The perception by academic staff that the quality of the intake is to blame for the poor pass rates is a truth-making process - in that it has established a norm of belief amongst the lecturers who see this 'fact' for why things are the way they are. For example, Lecturer $\mathbf{J}$ notes below that the quality of the intake is to blame for low course pass rates:

Int: Okay well what do you think the most important problem is [regarding poor pass rates]

Lecturer J: There's so many! Okay, most important (laughs)... Yeah, my perception is one to do with the quality of the intake... ...I suspect that a lot of the really strongest students that we would love to have, um are just choosing other places... [If] all the brightest people in New Zealand were coming here a lot a lot of our problems would go away. In all kinds of ways, we'd have this big substantial cohort a strong cohort of students who would pull other students the more middling ones along with them... Um, probably the whole culture would change. [Lecturer Extract 35] 
Lecturer $\mathbf{J}$ emphasises that problems in pass rates are related to the quality of the intake. In doing so, the lecturer also places the blame on the student intake - the students themselves, and on VUW's failure to get the 'brightest people' who are choosing another place. By suggesting the problem is with the intake and the students themselves, Lecturer $\mathrm{J}$ shifts responsibility for the teaching and learning experience to the university management for recruiting academically weaker students, and to the students for their own learning. I believe that the lecturer here is illustrating just how pervasive the discourse around student subjectification is. The students are accountable in a system where the neoliberal discourse on economic growth of student numbers is partly responsible for the position they find themselves in. The lecturer is accepting the normalised messages in the discourse around growth and student incoming ability without seeing their place in the process. By accepting growth and seeing this as a student or university fault they exclude themselves from the situation, becoming outsiders with no need to be accountable or responsible. The hypothetical (and mythical) strong cohort suggested by Lecturer $\mathbf{J}$ would pull themselves along and teach themselves. Having a learning environment that targets a certain type of student allows freedom from the responsibility of ownership for the learning of students who do not fit the view of what is a good student. Lecturers have the power to, and appear to, judge students as good or bad, strong or weak.

This ownership over judging the level of academic preparation and choosing not to adjust courses or teaching in an educationally sound way to improve these so-called weak students is a clear act of resistance to the messages the university is sending academics in the course design and assessment handbooks. It is also an example of how academic freedom to set educational practices within courses enables lecturers to decide on what level they wish to engage with the teaching and learning environment. Failure to possess the required level of academic ability, motivation and independent learning, positions these students as subjects who are unsuitable for the current system. We have an environment where the enlightenment ideals of teaching, and making a certain subject who has an inherent potential to be self- motivated and self-directed are inbuilt within the educational system and represents a truth-making process within the discourse. As such, these lecturer excerpts reveal the operation of power in action within the teaching and learning environment.

There is a consistent but implicit acknowledgement by lecturers that successful students - the subject - in the educational context have inherent qualities that remove 
ownership of the need to develop extensive teaching skills or teaching materials that would help an 'other' type of student. Lecturer E illustrates this:

Lecturer E: So it's two-fold, um, the biggest problems I think are that we don't teach for the students that we have, we teach for the students we would like to have... ...that's both of those problems, so one is we don't get perhaps, we-we don't get the best of the best students, although over time we can perhaps tweak that with recruitment, um and the other big problem that overlaps that is that we don't teach for even a third of the students that we get

Int: Yeah so we're teaching at the top

\section{Lecturer E: Yeah}

Int: Those people you described at the beginning with the (.) lots of credits and motivated and intelligent and...

Lecturer E: The stupid thing is those are the cream of the crop students they probably don't actually need any teaching, so you could equally say that we're probably not teaching at all 'cause surely teaching... Is improving the learning outcomes for the average student... 'Cause the good students, they're gonna succeed whatever you do, put them in a freezer, and they'd be fine...

Int: So is that the people you think we're teaching for - the very top

Lecturer E: Um, yeah, I mean if we're speaking in broad speaking sweeping generalisations then... That's certainly what our part one and our first-year courses select for

Int: Is that because we're only really interested in Masters and PhD students at the end?

Lecturer E: No, I think there's a certain amount of pride in having - in setting and having the content of certain courses, um... ...I mean if I make my first-year physics course easy I'm doing a disservice to physics... I'm cheapening my domain sort of thing... 'Cause what if I let, God forbid, what if I let a, um student get an A in a physics paper that I don't think deserves to get an $\mathrm{A}$ in a physics paper. [Lecturer Extract 36]

The creation of the student as the learning subject responsible for their own education as independent learners coupled with the belief that lecturers are the gatekeepers of quality is illustrative of the complex power relations at work. Lecturer E gives some indication 
of how the teaching and learning environment is controlled by lecturers. For example, we have teaching aimed at the hypothetical good students, who will apparently succeed no matter what. This is the less than a third of the students referred to above. In turn, this process excludes those students with 'deficits' in academic preparation.

However, for Lecturer E, what lies behind this process is a quality control mentality, expressed as pride in the setting of content and a desire not to cheapen their own subject domain. Lecturers perceive that it is their duty to be the gatekeepers of knowledge and it is an exclusionary process. It is accepted that if a student gains entry into a course at university there is no guarantee they will pass, but Lecturer E articulates another layer of control outside of the student's ability to influence. Students may enter a programme where, despite being given entry and a chance to complete the course, they actually have no realistic chance of passing due to the control exerted by academics over the level, delivery, and quality of teaching and learning materials. Thus, the skillset and related mindset of the lecturer impacts the teaching and learning environment. The powerrelation here is exclusionary and at the same time normalising.

Another example of lecturer power in action within the teaching and learning environment at first-year can be seen in the ECS Part 1 programme and its set of core programming courses. The core first-year programming courses are a central part of a student's pathway through Part 1. Passing either COMP102 with a B- or higher grade or completing COMP112 (with any passing grade) in trimester 1 and then completing COMP103 (with any passing grade) is central to a student's progression within the engineering degrees and majors offered by ECS. COMP102 requires no prerequisite NCEA entry criteria or programming skills and is the Part 1 programming course most students take. COMP112 requires 14 NCEA level 3 digital technology credits for entry, and is aimed at students with a good level of programming skill. COMP103 follows completion of either COMP102 or 112 and failing this course denies a student entry into second year programing courses. The grades students obtain in these courses also contribute to the calculation of the Part $1 \mathrm{~B}$ average required for progression in the $\mathrm{BE}$. Expecting students with no programming knowledge in COMP102 and those with good programming skills in COMP112 to meet in COMP103 at the same level of preparedness is unrealistic, based on consideration of past cohorts. These courses are well known amongst ECS staff as being 'hard' courses, especially COMP112 and COMP103 and poor pass rates in all 102/112/103 classes effectively reduce the number of students getting into second year programming courses. 
The 2015 Academic Programme Review of the Computer Science Programme final report (Victoria University of Wellington, 2016) acknowledged as part of its findings that the COMP courses were failing many students, and recommended establishing a course to support students who were less skilled. However, this was partially dismissed by ECS management:

[Programme Review] Recommendation 5. Develop an approach to accommodate the less skilled students in the Programme. This approach could [a] include splitting COMP 102 into two courses so as to offer less well prepared students a gentler pathway to COMP 103; and [b] offering a recovery pathway for students who are at risk of failing COMP 102 [ECS] Response: Partially Accepted.

A very important action towards this goal of splitting COMP112 from COMP102 and making COMP102 easier was taken 3 years ago. We do not believe that a further split is justified, although a different split might be. We are also not convinced that an alternative entry pathway is feasible (or to the benefit of students), particularly because students have no effective way of determining whether they would need to take a slower and longer pathway (and there is no known mechanism for predicting performance in programming!), and few students who would benefit from it are likely to take it. (We have seen similar issues with mathematics in the $\mathrm{BE}$ ). Furthermore, we provide a wide variety of help for weaker students in COMP102 already; we are not convinced that the students who find COMP 102 very challenging would cope with the rest of the COMP major, even if provided much more support in order to get through COMP102. We are therefore not convinced that the investment required to attempt to enable the "less skilled" students get through COMP102 is worth the investment or that it is good for the students to lead them to think that they will cope with a COMP major when it might merely delay the point at which they are forced to change disciplines. [Non-Interviewed Extract 29]

In this response statement by programme leadership, it appears that the investment in teaching weaker "less skilled" students is considered not worth the effort - as they will most likely not succeed. The only evidence supporting this claim is the high failure rate of students in the subsequent COMP103 paper. This failure rate could be due to many 
things and has not been fully investigated as per the concerns around the exam and assignment marks discrepancy discussed previously. It is not certain that improvements could not be made to COMP102, or its subsequent COMP103 course, in both teaching method and teaching materials to improve student learning successes. There is also no consideration that improvements in these courses could improve student performance in the second year programming papers. Instead, in conjunction with the illustrative extracts provided here, one might argue that there is a culture of relative inaction taking place where the academic staff are resistant to approaching and investigating course design and teaching.

For example, there is a deliberate culture of aiming the courses at the academically stronger students and within this environment, lecturers discourse speaks to intentional acts mitigating the teaching responsibility, not through malicious intent, but as a response to competing work pressures (for elaboration, see chapter eight). Behind the face-to-face teaching, there are background lecturer attitudes and processes that establish what is normal in the ECS first-year teaching environment and, in the case of the core programming courses, ownership of their teaching content and method is controlled to select for certain students. This process of student selection in a professional engineering degree is not necessarily bad, inappropriate, or necessarily flawed. If we consider that many of the lecturers making these decisions are not practising professional engineers or more importantly qualified teachers engaged in best practice pedagogy, uncertainties about the appropriateness of teaching practices and decisions need to be asked. This is a disturbing notion given the extensive work undertaken overseas to redress the discrimination of minority groups, and gender imbalances in STEM (see chapter one and two). For example, the seminal work, Unlocking the Clubhouse, by Jane Margolis and Allan Fisher (2003), outlines a pervasive gender imbalance in STEM and argues for substantial changes in order to redress this. This work is considered seminal in the field which attempts to uncover systemic issues of inequality. The authors argue for change as absolutely necessary to engage with disadvantaged groups and in contrast the reluctance of ECS to engage with the need for change suggests that the discourse on improving STEM education is not the dominant one in the teaching and learning environment. The role and use of education as a teaching and learning experience discourse is largely silenced. The following section investigates some of the possibilities for this silence. 


\subsection{Teacher Training}

There is a systemic lack of adult educational training in the university sector. New Zealand maintains no official requirement that higher education staff obtain and maintain a teacher training qualification. In contrast, to teach in NZ public high schools, a teacher must have a NZ teaching qualification. The message from the Institution, as perceived by academic staff, is that in a research-intensive and competitive environment, teaching is not a sufficiently high priority skill to justify training. Experience at university in an academic position is considered on the job training:

Int: So teaching skills, I mean, you've read some pedagogy you're involved in that, have you thought about it?

Lecturer A: Not much

Int: Okay so

Lecturer A: Have I thought about it yes

Int: Okay, so you've thought about it based on obviously what?

Lecturer A: Experience

Int: Okay.... are lecturers trained teachers at all

Lecturer A: No. [Lecturer Extract 37]

Lecturer A's comments indicate that educational teacher training or engagement with best practice educational pedagogy is not common with experience providing the basis for improving teaching skills.

Lecturer B describes below that obtaining university training in teaching is up to the individual:

Int: Yeah so nobody teaching first year has a teaching qualification?

Lecturer B: No. Not that I know of

Int: And has anyone - do people do the CAD [Centre for Academic

Development] training?

Lecturer B: I've done a couple of workshops... And I know other people who've done a couple of workshops as well... But that ends up largely being personal choice. [Lecturer Extract 38]

Lecturers have the freedom to ignore or disengage with pedagogy, as much as the freedom to actively engage with these things. Lecturer B refers to CAD, the University Centre for Academic Development who conduct academic development for lecturers. These offerings include courses of formal study and teaching support around educational best 
practice in course design, assessment methods and teaching, and all other aspects of the academic teacher role description. CAD represents the University expression of ownership over the teaching and learning space. These courses are voluntary for academics and can be taken to certificate and diploma level. Attendance in these courses is low for ECS with few staff having undertaken a certification level of training with CAD.

The decision by lecturers to ignore engagement with pedagogy reveals a specific operation of power in ECS. The choice to ignore this does not automatically imply that academics would ignore pedagogy. It is in this choice that the operation of power occurs. Foucault notes that the operation of power takes place where there is a freedom of action or choice (Foucault, 1978). Academic staff exercise their choice to resist additional teacher training or to develop or understand effective pedagogy as it sits outside their primary interest. The university by making it voluntary unwittingly confirms a message in the discourse that it is not an essential component of being an academic. From a Foucauldian understanding off power the choice not to engage by the academic staff represents them exhibiting control over their actions and places them in a self-defined subject position. They do not see themselves as needing to do this. This does not mean that on some level they may not agree it should be done, but that this understanding does not result in affirmative action. There are however consequences in the teaching and learning environment for not undertaking this training and pedagogical engagement. The lecturers have a certain ownership over their actions which have been normalised by reinforcement in the discourse by making it a non-enforced responsibility that can be ignored in favour of other actions.

The failure of the university to impose teacher or educational training coupled with the lecturers' reluctance to engage in these aspects of their role leads to a lack of expertise in this area as Lecturer F implies:

Int: is there any kind of educational theory you apply in your teaching?

\section{Lecturer F: No}

Int: So it's how you were taught you then teach?

Lecturer F: No, I kind of just make it up as I go along... [Lecturer Extract 39]

The lack of control or influence by VUW or ECS over teaching practices gives individual lecturing staff considerable ownership and freedom within the learning environment. We can see this lack of emphasis on teaching skills as an invisible power structure at work 
imparting this message by virtue of not promoting a culture where educational pedagogical knowledge is overtly prioritised. For example, criteria for promotion to Associate Professor includes the statement "In all cases a very high standard of research, and at least a high standard of teaching is required, including, where possible, supervision of postgraduate students. If, however, a candidate's teaching performance is of an especially high quality, a somewhat lower (but still high) standing in research will be accepted." (VUW Academic Promotions Booklet, p. 15) which may be interpreted as privileging research capability over teaching capability. Evidence of this power exerted upon them may be seen in the fact that 14 out of the 15 lecturers interviewed do not have teacher training qualifications. These lecturers describe reliance on hands-on experience learned on the job, informal conversations with other staff and the occasional attendance at a CAD course or seminar.

The excerpt below from Lecturer $\mathrm{F}$ describes how they view discussion on teaching practice between lecturers:

Int: But I think what more I'm talking about is the way you approach the fundamental teaching of problems or skills

Lecturer F: Yeah, that's black boxed, you know?

Int: And do you think that's an issue?

Lecturer F: It's a difficult question because it opens a can of worms. Yeah I don't know. Oh I would enjoy such a discussion if my point of view was to win but not if I was being told how to teach. [Lecturer Extract 40]

Lecturer F describes the discussion between colleagues as "black boxed" meaning that it is not talked about. The lecturer follows this up by saying that they would not like being told how to teach. As discussed earlier in the ownership of courses section it is very difficult to have an agreed teaching policy or standard. Course teaching methods and practices are owned by the individual academic who can choose to work with their colleagues or not.

There is a general absence of a culture of teaching pedagogy and best-practice within ECS first year despite the efforts of a few staff. This failure is due to a tertiary culture and environment of VUW that promotes academic freedom, while not prioritising or mandating teaching qualifications. Moreover, this puts pressure on academics as Lecturer M explains below in his experience of having to design courses and teach:

Lecturer M: I would never say to someone 'ah you're great as a manager or educationalist, here write some computer programmes'. And I would 
never say to someone 'hey you're great at computer programmes write an educational course' ((laughs)) you know I don't hold to the belief that writdesigning educational courses is a trivial skill, that because I can programme I can do (.) I might be interested in it, but it's not my skill base ...and you know realistically members of staff have gotta keep their research and keep that up to track record. So how much time and effort do they have? Do they have any skill in that well of course not we haven't been tr- we're engineers we're programmers. I'm a mathematician and a programmer I have no training in education I have an interest I read papers, but it doesn't mean I'm I've got skills. So designing courses - oh wow really interesting, but like hell, I don't have that! [Lecturer Extract 41

Lecturer M identifies the separation of skill sets between educational skill in designing courses and research subject knowledge for academics. Lecturer M may have an interest in designing courses but acknowledges that it's not their skill base and that they do not have the time to develop these skill. For Lecturer $M$ they describe themselves as a programmer and a mathematician not an educator.

Lecturer $\mathrm{C}$ makes the point that the lack of consensus regarding teaching goals and methods can be difficult for lecturers:

Lecturer C: I guess what's our goal?

Int: Well who sets that goal?

Lecturer C: Academics, it it's an academic goal of

Int: So our levels are all set by self-assessment of individuals deciding what is appropriate

Lecturer C: Yes, there's some outside feedback. But from the universities to make sure that at certain places like at Honours level, at certain high levels. ...the experienced people may have seen sort of fights... or arguments going on... About how things should be settled and they've come to the agreement for really good reasons, but it's not always clear especially to new people, new lecturers for instance why things are where they are in terms of material topics, standards, strategy. [Lecturer Extract 42]

This confusion has implications for the way course are taught and what material is in them. Ownership of what to teach and how, is complicated when decisions have been made but not necessarily communicated to those engaged in the face-to-face teaching. As Lecturer C notes, with "certain high levels" (senior academics) believing that they own 
courses or programme strategy in contrast with the freedom of academics to change the courses they teach, it is not surprising that there have been "fights... or arguments".

These disputes are themselves about ownership and the right to exercise power in the teaching and learning space. They also represent further evidence hinting at a lack of cohesion in the programme due to the relative individualistic nature of the teaching and learning culture within the university. The lack of a formally agreed programme and associated processes allow academics to manifest ownership and resist attempts at control by other staff.

\subsection{Course Delivery}

The operation of ownership and its effect can be seen in the way ECS courses are delivered. ECS courses are taught primarily through a combination of lectures, tutorials and labs. This is the traditional university model common in many universities across the world. During the interviews, I asked the lecturers questions about how we teach and what they thought was the best way to teach. In doing so, I received numerous responses that revealed the operation of power, both experienced and manifested by the lecturers. Given the predominance of lectures in the VUW educational practice, it was surprising that many of the lecturers interviewed did not believe lectures were a very good educational method and identified that lectures were often just time-saving devices. Lecturer L below makes this very clear:

Lecturer L: Ah (.) lectures are pardon my French (.) useless ... lectures are useless they [students] should be given the opportunity to get used to the lectures it should be very hands-on (.) not (.) er (.) theoretical material or intro- or theoretical material introduced very gradually. [Lecturer Extract 43]

It is not within the scope of this thesis to assess the effectiveness or validity of lectures as a method of education, rather these comments by lecturers show a perception of lectures by some ECS academic staff. Lecturer L notes that the lectures are very theoretical and alludes to a disconnect in delivery for students who require time to get used to this approach. This difference refers to the change in the system of education students have experienced in high school and what they experience at VUW. 
Lecturer J expresses similar positions to Lecturer L. They acknowledge that the lectures are central for framing the learning experience, however the tutorials or labs are, where the "pennies drop", and where the most significant learning takes place:

Lecturer J: I think that um they're learning. So in the lecture what's well known about lectures is they're not a place where anyone, loosely speaking people don't learn anything in them, and that's not quite true (laughs) if the lectures are kind of you know engaging and have some you know tick a bunch of boxes then some learning can happen in a lecture it's true. Um as well as just sort of framing and knowing where stuff fits in, that's learning as well, um but I don't think the pennies drop in lectures that's true, but they do drop a lot more potentially in this engagement with the student has with a second or third-year tutor who's got their own take on it, ah and they are students having their voices in operation more and there's more of a dialogue. [Lecturer Extract 44]

Ownership of student learning is, in this sense, given to the tutors and can be seen in the comment: "a second or third-year tutor who's got their own take on it". The notion that tutors have more dialogue and more contact with students in the interpersonal space shows a separation by academics from the students and a deference of power to tutors. Lecturer ownership of courses then becomes related to ownership of course management, assessment and content rather than teaching, especially if lectures are seen as mostly useless.

Lecturer $\mathrm{N}$ also suggests below that the laboratories and tutorials are where the "light bulbs go off":

Lecturer N: Um the biggest responsibility for time management falls on the academic

Int: It does (.) so so you said the um dry lecture the lecture there (.) I mean do you think lecturing is the best way to teach

Lecturer N: I think more and more we're gonna move away from lecturing. Um going to or should, um-ah if I think if the examples when I've seen light bulbs go off it's in laboratories, um it's in tutorials. Um, students tend to respond really well when they have one to one contact...

[Lecturer Extract 45]

Lecturer $\mathrm{N}$ indicates that the learning experience is better when you get "one to one contact" with students and teaching staff. We continue to have a traditional university 
teaching system and culture dominated by lectures, where the one-to-one student and staff contact often only takes place in the tutorials and labs taken by tutors. First-year lectures are often very large, with up to several hundred students in the largest and, as a result, one-to-one contact with students during lectures is difficult. At the third and fourth years of the degree, when the class sizes are considerably smaller, often less than twenty students per class, the lecturers have the opportunity to connect with students more.

When questioned about why ECS uses lectures for teaching, Lecturer M noted that lectures are cost effective and the expected way of teaching:

Int: So if lectures aren't (.) where the learning takes place

Lecturer M: Yeah

Int: Well why do we have them

Lecturer M: ((Laughs)) it's cost effective (.) one person lots of students...

Int: Is it cost effective if the learning's not occurring in them

Lecturer M: Um (.) yeah because it (.) if we (.) basically it costs very little Int: Yeah

Lecturer M: It's what everyone expects and is happy with (.) ah and you don't get criticised for doing it (.) um whether it's effective or not is a completely different question. [Lecturer Extract 46]

Lecturer $M$ is drawing attention to the fact that the academics use lectures because the educational system at VUW is set up to use them as a way to teach large numbers of students cost-effectively. Lecturer M's statement is an example of the numbers discourse, inherent in neoliberal educational policy, that equates learning with business models. These business models equate numbers of students passing with financial benefits for society. Control of how the lecturer must teach by having lectures as the dominant form of teaching practice limits the ability with which academics can influence the individual learning experience of students. The university campus is made up of predominantly large lecture rooms, set up for the delivery of lectures, not one-to-one, or group-based learning. As such, the campus space also conveys that large lectures are the norm. Lecturer $\mathrm{M}$ also raises the idea that nobody will criticise you for doing what has always been done. This notion of not being criticised is an example of following an accepted social process and shows an operation of power. Power, in this case, is exercised as and through the traditional and normalised practice of giving lectures. This practice appears void of active lecturer resistance, despite the academics articulating misgivings about the extent to which lectures are the best form of education. 
The extracts above illustrate the notion that the actual learning takes place mostly in the tutorials or labs where students have more one-to-one contact with tutors who discuss and help the student work through examples. In contrast, lectures provide a background for what is covered in the labs or tutorials. However, with the academic staff questioning the effectiveness of lectures it does raise the question: why don't lecturers, the more experienced subject experts, deliver the tutorials and labs where the so-called actual learning takes place. Lecturer $\mathrm{E}$ indicates the complete lack of training provided to tutors who deliver the ECS labs and tutorials:

Lecturer E: Ah, labs are, depending on the lab, ah labs are pretty positive 'cause that's where the students are doing something.

Int: The lecturers don't take the labs though very often

Lecturer E: No. There is tangential relationship between them.

Int: So essentially what you've got is tutors who for the most part are good or bad at engaging in a lab

Lecturer E: Um, it depends on the ah, it depends on the lab unfortunately Int: So they're not really trained though are they, they're not trained to be an effective teacher in an educational sense

Lecturer E: No, um, the students that we have tutoring in our labs tend to be by and large pretty good. We get a few negative comments from the first years about them but by and large given that we've never trained them to be tutors. We just like [say] 'go and tutor' they do pretty well. [Lecturer Extract 47]

Lecturer E indicates that student feedback on labs is "pretty positive", which is a good thing but not a holistically effective measure of a quality teaching and learning experience. First-year students, new to university, are not in a position of experience to be able to adequately assess what and how they are being taught. While VUW mandates centralised training for first-time tutors, this occurs inconsistently because course coordinators may not themselves be aware of the requirement. The frank admission by Lecturer E that "we" (meaning ECS) have never trained tutors reveals the operation of power by academic staff. Tutors are required to take responsibility for their fellow students learning. The lack of responsibility by academics for the training of tutors who teach in their courses is an example of the resistance by academics to the Government and TEC assumption that academic staff are coordinating and delivering an accountable 
quality educational experience for students. This lack of tutor training is an abdication of teaching responsibility beyond the designing of the labs or tutorials.

The "tangential relationship" between lectures and labs is assumed to be quality control or an appropriate mechanism for curriculum alignment and teaching quality but, as Lecturer O notes, sometimes lecturers do not design the labs and have no idea of what is occurring in them:

Int: Do they get much training, yeah-the tutors in your experience

Lecture O: About er, the engineering 122, I have no idea, and personally

I don't know how to do the labs. [Lecturer Extract 49]

A lecturer's lack of knowledge about labs or tutorials can be as a result of another lecturer on the course or a senior tutor designing them. For example, in some cases the labs were designed by a lecturer who took the course a previous year but is no longer involved. What is important is that there is no actual adequate mechanism for quality control in either the design or delivery of teaching and learning in ECS first year. Ownership of the teaching and learning in ECS courses, while predominantly lying with the academics, is also shared with tutors. However, in both cases, the lack of teaching training or guidance is a common experience. It is possible that the lack of emphasis or focus on educational training for tutors is carried on within the system as systemic behaviours by those tutors who eventually become academics. Most of the academic staff will have been tutors themselves and will have had similar experiences of on the job training which comprises of: 'go and tutor'. The norm of behaviour in not having educational training (other than hands-on learnt experience) is embedded as a process in the system.

Academic staff prioritise their engagement in the teaching and learning process. For example below, Lecturer J expresses a desire to be more involved but acknowledges that they are "removed from the students for the most part":

Int: How would you teach it, how would you organise your courses, if let's say you had some unlimited finances. Would you be more involved, would you like to go to the labs and work through problems with students and...

Lecturer J: Yeah-yeah I would definitely be more in touch with how to deliver stuff say in lectures better and how to advise the tutors better if I was actually in the labs more with the students, listening to what they say, working sitting right beside them, seeing how they're thinking, um, I think 
there's a disconnect there. I'm removed from the students for the most part....

Int: So why is that, so when we're talking about resources is that just because your other job is so busy or what. What prevents you?

Lecturer J: Ah for me it's just its just busyness. [Lecturer Extract 48] There is a system in place where the aspiration to meeting educational goals break down during the educational process. In ECS, some academics do take tutorials or labs, but this is generally for second, third or fourth-year courses where the number of students is markedly smaller. The ECS policy is to hire tutors unless a course has twenty or fewer people, though in practice ECS has made exceptions and hired tutors for third-year courses with less than 20 students. Relatively few courses enrol fewer than 20 students, however, and those that do are typically advanced-level courses that are, as a result of the issues identified in this thesis, more likely to be the academically stronger students.

Like Lecturer $\mathrm{J}$, most of the lecturers interviewed were all clear that the main reason that they do not take tutorials or labs is due to either their heavy workload deriving from other responsibilities (research, supervision of thesis students and administration work, etc) or because the workload of taking tutorials and labs would be too heavy. As a result, ECS employs a number of student tutors. There is no official policy on training student tutors in subject material or teaching skills in ECS, and central training provided deals with generic skills and issues. Tutors are largely chosen by academics from the pool of applicants and are usually known to them as students who have received good grades in relevant classes - therefore a self-selected and potentially atypical group of people.

We do have several 'senior tutors' who are not students, however. In my role I manage the tutorial administration and senior tutors alongside pastoral care, as such, I am quite well versed in what occurs regarding student tutoring in tutorials and labs. In ECS the number of senior tutors has increased from two part-time senior tutors in 2015 to one part-time and two permanent tutors in 2017 (with a third to be employed in 2018) - though senior tutors are not unheard of in other parts of the university, ECS has more than other Schools. One of these part-time senior tutors has always been primarily focused on administration and allocation of student tutors to courses, and runs induction meetings to explain how to tutor from a delivery point of view. The two full-time tutors are employed to assist in delivering upskilling for student tutors, as well as student support, running labs and tutorials and occasionally teaching on first-year courses. The teaching support for student tutors is a new initiative. Until recently the student tutors received little actual 
training, and it has been left to academics to meet regularly to discuss and prepare labs with their tutors. It should also be acknowledged that like lecturers the senior tutors do not currently have any formal teaching qualifications. However, ECS senior tutors have been enrolled in VUW CAD teacher training qualifications or other higher educational study as part of professional development since 2017 to upskill their educational training.

The lack of training for both lecturers and tutors and the lack of involvement by lecturing staff in tutor training, or in the key tutorials and laboratory teaching spaces illustrate that the teaching and learning environment at first year is not a model for cohesive educationally sound process. Nor are these processes in alignment with our official VUW policy (see chapter six). Lecturers appear not to be able to, or are not equipped to, design courses that follow educationally sound methods or best practice, as they do not have educational teacher training. Tutors are also historically untrained in disciplinary teaching delivery. This situation exists because the prevailing set of norms in the tertiary teaching and learning space, manifesting in a particularly extreme form in ECS, do not encourage and emphasise the obtaining of teaching skills through formal means. Lecturer M's comment below exemplifies this:

Int: ... when you design a course I mean (.) and you decide what's gonna be assessed in it

\section{Lecturer M: Mm}

Int: And you obviously talk to other people when you do this

Lecturer M: Yeah yeah

Int: And you come up with something (.) when you set that standard or the assessment (.) various assessment items be they an assignment a tutorial lab or a test or exam

Lecturer M: Mm (.) $\mathrm{mm}$

Int: I mean how do you know the students can do them (.) and how do you know

Lecturer M: You don't. [Lecturer Extract 50]

The lack of educational expertise is built into a system which is responsible for providing mass public education. Lecturers, as a result of their own lack of systemic training, teach as they see fit and do not know how to design courses for a wide range of students with diverse academic backgrounds. As such, academics treat all students as having the same approximate level of ability by designing courses that meet their hypothetical international 'standard' required. 
Ownership of the teaching by academics is therefore practised as content-driven with little to no insight into appropriate methods or understanding of the student's ability. This places some ownership of success as the responsibility of the student and, to a certain extent, the tutors. Ownership is in fact held by multiple parties in the education system, all of which can take or decline responsibility. As such, accountability is fluid in the tertiary system, with educational accountability being visible in the enrolment, course completion and retention figures. One result of this in the discourse is that it creates a resistance to owning certain aspects of the teaching and learning environment. The concept of ownership allows us to see where in the teaching and learning environment tension exists as visible and invisible processes. Students are seen as responsible for their own learning, but only in so far as they receive competent and effective teaching and learning experiences. Yet, what constitutes a good teaching and learning experience is not understood by the student, or necessarily understood by the tutors and, academic teaching staff. This aspect of the teaching and learning environment creates an invisible operation of power for the students. The academic staff choose to make this invisible by not engaging in best-practice. But this resistance creates or as Foucault describes 'produces' an effect in the social situation as actions that carry meanings as accepted 'truths' (Foucault, 1980).

The academic discourse in the excerpts above is at odds with the neoliberal business growth goals of the government and university, and the educational goals identified in VUW policy. However, the discourse also indicates a counter resistance to these policies. The processes and interactions of the academic staff operate to resist spending time and effort in pedagogy, course design and appropriate teaching practices and in doing so reveals a discourse which divides students into good or bad. The removal of ownership for ongoing improvement in teaching practice by academics is a response to competing pressures in the academic work environment, and a result of the wider university policies that act to make this an acceptable process. As such what can be seen here are multiple messages in the discourse that compete for dominance. Power-relations are push/pull actions centred around the level of ownership exerted in regard to the rights and responsibilities of groups and individuals.

My interviews mirror Ramsden's (2003) acknowledgement of major demands on lecturers which impact their ability to spend the time and effort developing the skills and resources to be effective teachers. Additionally, and more importantly, Ramsden argues that to improve teaching and learning: 
Improvement requires intervention at several different levels of the enterprise of higher education. The level of the individual academic is an important point of influence, but it is not the only one. Although university teaching is still in many cases a private affair, no lecturer works alone. Many well intentioned changes to curriculum and teaching fall foul of the apathy or jealousy of departmental colleagues. Focusing on this level alone is likely to create frustration, conflict and, ultimately, regression to the status quo. To achieve change in the quality of teaching and learning, we ought rather to look carefully at the environment in which a lecturer works and the system of ideas which that environment represents. This means an emphasis on teams, curricula, courses and department, as well as on individual academics. ...We should also look to the management of academic units: to what extent does a head of department understand and encourage effective teaching in his or her field of study? The highest point of intervention... is the institution itself. What understanding of teaching is evident in its public statements and its internal procedures. (p. 9)

It is obvious that the system in our first year is part and parcel of an even larger tertiary system where the success of a course is measured quantitatively in course completion rates rather than educational quality. This is, in effect, a disciplinary practice that reveals relations of power in the tertiary educational landscape (Anderson \& Grinberg, 1998).

Research by Fanghanel (2007) investigated university lecturer's pedagogical constructs in their work and teaching practice. Fanghanel interviewed eighteen lecturers from seven institutions covering fifteen disciplines with the aim to qualitatively analyse the way lecturers conceptualise, approach and relate to teaching and learning. This research identified seven filters within teaching practice that overlap and affect practice: the institution, external factors, academic labour, the research-teaching nexus, department and discipline, and individual pedagogical beliefs. Though not focused on a Foucauldian notion of power, this research did reveal impressions or perceptions of lecturer's relationships to the operation of power and constructed meaning. All of Fanghanel's (2007) areas have in some way been identified in this thesis, but two of these filters are particularly pertinent to the way staff operate in their cultural context: the department and the institution. Power-relations are at work here across the many levels of the tertiary space from the micro to macro level and these relations are not linear expressions of power. 


\subsection{Summary}

The analysis presented in this chapter suggests that institutional norms of practice allow lecturers to behave in certain ways. These institutional norms of practice include the use of academic freedom as a justification for actions and inactions. Standard operational practice within VUW isolates lecturers from the integration of teaching discussion and development of course curriculum and assessment, and even from the teaching space "light bulbs go off" - the laboratories and tutorials. The cultural practice of the institution and department has allowed the notion of academic freedom and ownership, to be utilised by staff to reduce the level of input they need to put into designing appropriate course materials and assessment items, allowing for other job requirements to be prioritised over best practice in pedagogy. Course design and teaching are perceived as secondary for many lecturers due to the messages they perceive from the university, government and to a certain degree their colleagues. As such, what can be said and done by people is caught up in the power-relations around practice. The day to day practices of the staff and ECS as a whole contain certain messages imbued with meanings around what is accepted or not, encouraged or discouraged.

The following chapter on ownership of academics will cover the impact of these messages and in particular the effect of research duties on lecturer practice in more detail. 



\section{CHAPTER EIGHT: OWNERSHIP OF ACADEMICS}

This chapter explores how academics, as university employees, navigate the expectations relating to research and teaching, and reflects on the effect of these expectations on practice in the tertiary educational space. The way that academics respond to the pressure and messages around research reveal how they experience, and in turn manifest power, in the teaching and learning environment. This has an implicit connection to the neoliberal policies and processes in higher education described by Ball (2015), who describes neoliberalism in universities as impacting on 'performativity'. Neoliberalism emerges in the VUW/ECS context as a connection between economic goals and performance goals which are measured creating a competitive environment for academic staff. This exploration follows on from the analyses provided in previous chapters, in particular chapter seven, as ownership of the teaching and learning space and of academics are very closely interconnected and contested. Ownership is both experienced and enacted by all involved through control over people's actions in this space and can be witnessed in the extent to which academics embrace or resist policy, messages, and norms of practice and, in doing so, revealing the operation of power.

\subsection{The Need to Research}

The theme of research impacting on the teaching and learning environment is not a new one. It is routinely discussed in universities and has been investigated in higher educational research (Fanghanel, 2007; Knight \& Trowler, 2000; Brown \& Smith, 2013; Charles, 2018; Robertson, 2007; Knight et al., 2014; Lightfoot \& Piotukh, 2015; VisserWijnveen et al., 2010). For example, Knight and Trowler's (2000) study of teaching and learning in department cultures noted:

The pressure to give research precedence over teaching, the diminution in resources, the codes of signification associated with the teaching effort and the unintended as well as the intended consequences of many other features of the work context militate against the teaching and learning practices we have identified as beneficial. (p. 77) 
The pressure on academics to research can, and does, compromise some of the core educational goals of the higher education system.

Fanghanel (2007), discussed earlier (chapter seven), echoes this point. Fanghanel's interview respondents noted that teaching was seen as secondary to research, and that in research institutions prioritising teaching was detrimental to advancement. The way research was emphasised over teaching prioritised the lecturers' time and affected the way university communities worked - time potentially spent on discussing education and teaching, was spent instead on grant applications and research. One result was that if a lecturer was good at research, then they were given more time to research over teaching to pre-empt research assessment exercises that are common in many countries. The respondents felt that the "strong separation between the teaching and research functions, in terms of policy, funding, operationalisation, and perceptions were having detrimental effects on teaching practices..." and that "Interest in teaching can even be explicitly curbed, as indicated by Respondent 16: Our own Head of Department is under pressure from the higher authorities in the School, and he passes these pressures down on us. And if you are seen to be spending too long on your teaching, you are told" (Fanghanel, 2007, p. 14). Fanghanel's findings were echoed in my own interviews, and within the directives of the university to its staff, though I explain this as the result of the operation of power and ownership directives in the discourse.

The explicit directive to research originates in the connection between university funding and research. ECS' foundational business case illustrates this link:

In a PBRF [Performance-Based Research Funding] environment, there is strong emphasis on the quality and quantity of research undertaken by tertiary institutions. The PBRF score impacts on the level of TEC funding received by tertiary institutions and their ability to recruit new staff and students. Engineering presents new opportunities to engage in high quality research and to strengthen Victoria's reputation by developing capability (Victoria University of Wellington, 2005). [Non-Interviewed Extract 30] This extract identifies that underpinning the creation of an Engineering programme was the desire to increase funding from the Performance-Based Research Fund (PBRF) by developing additional high-quality research to VUW's existing portfolio and from the increase in staff and student numbers. The very creation of the Engineering programme at VUW was the result of connecting educational goals - providing engineering graduates 
- to PBRF business opportunities for the university. PBRF performance, not teaching, is the underpinning framework for ECS's academics.

PBRF was described earlier in this thesis (see chapter one). However, a brief reminder is included here. PBRF is the performance-based funding system applied to tertiary institutions and academics in New Zealand and, according to the TEC, it is designed to "encourage and reward excellent research in New Zealand's degree-granting organisations. It does not fund research directly but supports research, including postgraduate level teaching support" (TEC, 2016, p. 7). PBRF is an audit process which provides funding and recognition for NZ publically-funded universities and as such brings with it auditing and monitoring processes all under the guise of improving university education (TEC, 2016). Shore (2010) summarizes PBRF thus:

The 'PBRF' is a peer review system designed to assess the performance of researchers and assign scores based an individual's publications, contribution to the research environment, peer esteem, external research income obtained and number of PhD student completions. (p. 25)

The effect of PBRF on university policy and staff has been significant. Shore found in his study of 40 senior academics in New Zealand tertiary institutions that PBRF had fuelled institutional rivalry and internal divisions and created a two-class system: those who "have the research successful who have millions of dollars, big research groups, lots of $\mathrm{PhD}$ students... [and] people who don't have funding or any research students" (Shore, 2010, p. 25).

Humes (2000) has also noted that the effect of central governments in delivering educational policy reforms aimed at improving competence, accountability and raising standards of achievement had invited contrasting interpretations. The most damning of which is that:

some academics - have succumbed to the pressure to concentrate narrowly on matters of implementation, without any serious reflection on the justification for official policies. They simply wait for the directives from above and pass them down the line. They have found, in some cases from bitter experience, that compliance and conformity are rewarded while resistance is penalised. (pp. 35-53)

Humes describes the operation of power in the teaching and learning space that 'encourage' academic staff through organisational behaviour to focus towards conforming to policy outcomes or deliverables such as PBRF. With teaching being poorly 
rewarded in comparison to research, we can see that particular government or institutional bodies can impact what happens in the teaching and learning space through policy directives.

Lecturer A suggests that the funding from the Government for PBRF ranking is very small, but that the reputation of having a high PBRF ranking is the real value to the university:

Lecturer A: PBRF is not governed by funding. The amount of money wrapped up in there is relatively small... If we came third in the ranking versus coming first the additional money we get as a result of that is very very small, you get some more. As good, you'll do better but... But the funding is not governed by your ranking it's governed by your actual standing and how many students you've produced and all that sort of thing and universities if they do better then they'll get a bit more... But most of it just comes in it's not funding

Int: So what is it then?

Lecturer A: Reputation... Now, what is the financial value of reputation I don't know, and I wish they would work it out and tell me... Yeah, you couldn't do more an a than an estimate... I suspect it's quite high...I suspect it's not as high as some of them are acting as if... But the whole university has us operating under the view that that PBRF ranking is absolutely mission critical. [Lecturer Extract 51]

For Lecturer A, the university operational message is directed towards research-based PBRF success: "the whole university has us operating under the view that that PBRF ranking is absolutely mission critical". Lecturer A points out that the actual value of PBRF ranking success is in the reputation the university gains, and the financial benefit that accompanies that.

This concept of needing a high reputation can also be seen in a recent message by the Vice-Chancellor, titled "The Victoria vacuum":

For those of us familiar with the quality of this institution, it can come as a surprise to learn how little is known about Victoria in other parts of the globe. Those from offshore who have had interactions with our staff (and students) are usually very complimentary. However, throughout much of the world our university's standing is not in keeping with our teaching and research quality. Our failure to convert our institutional quality into 
international prominence is problematic. Contrary to popular belief, suboptimal international standing creates challenges for institutions that extend well beyond the contests of international rankings. For instance, rightly or wrongly, our alumni, staff and students are denied the career benefits conferred by studying and working at an esteemed institution. Furthermore, we are less well positioned to collaborate with top-ranked institutions or to compete for international research grants and our ability to recruit and retain international staff and students is compromised. During 2018, we will be exploring some of the factors that have conspired to undermine Victoria's international standing and we will step up our efforts to earn the international reputation we deserve. (Guilford, 2018, p.

\section{1). [Non-Interviewed Extract 31]}

The message delivered at the beginning of the academic year, aimed at academic staff, is an example of the business language used to frame our educational objectives. For example, “throughout much of the world our university's standing is not in keeping with our teaching and research quality" delivers the point that academic staff (our in the text) are not being recognised for how good we are. And somehow because of "Our failure", "we" are missing out as "our alumni, staff and students are denied the career benefits", and the university misses out on collaboration "with top-ranked institutions or to compete for international research grants and our ability to recruit and retain international staff and students is compromised".

This text is a powerful message incorporating all staff (willing or not) through the repeated use of 'our', as partners in a corporate image enhancement programme. It is not that the message is necessarily bad or good but, in a Foucauldian sense, it displays a meaning which suggests a course of action and the operation of power (Foucault, 1978). It is a truth-making statement: staff must rectify a supposed failing to improve a given situation, and in this case, it is enhancing VUW's reputation. Reputation is generated from our university ranking, and this is generated from research outputs and VUW's standing in the NZ PBRF ranking.

ECS academic staff must research and contribute to their university PBRF ranking, and enhance VUWs reputation, while also attracting, teaching and graduating more engineers. The messages here are a clear example of the discourse at work, reflecting a set of responsibilities that academic staff must undertake as part of their job. These contributions are not viewed as equal components of an academic's job. For 
example, Lecturer M describes the pressure for publications and research outputs as allpervasive in the university environment:

Lecturer M: Yeah well the government's pressure is you know we've gotta have a PBRF ranking, so you've gotta have a publication count. Ah, so I have to do these things. As long as the students are happy and tick the box at the end of the student assessment to say you know you're a nice lecturer people are not that worried about the teaching. The key thing from government policy down is you've gotta focus on PBRF. Ah, I can't change that alas.

Int: So is that that pressure that comes from the government and how do you know that? [Or] is it are your bosses telling you this?

Lecturer M: Yes I mean it is very clear that we know that we have to keep our PBRF up because funding depends upon it, ah we also know that we are not allowed to fail too many students because the government says we've gotta... and this is not a personal attack on ever on me, but this is just we know that.

Int: So [in] your experience is it's the same for all lecturers

Lecturer M: Yeah (.) yeah

Int: So in terms of like that message filtering through to you is that coming through Dean, Head of School, programme Director?

Lecturer M: Yeah oh yeah yeah yeah

Int: Colleagues is it everywhere

Lecturer M: Everywhere. I mean... this is common knowledge I mean it's not something anyone keeps a secret.... [Lecturer Extract 52]

The pressure to research does not just originate with the government, but extends to all levels of management and staff at VUW. Lecturer M notes that academics "gotta" have research and publications and do well in PBRF. Lecturer $M$ also identifies that the focus for academics is not on teaching because: "people are not that worried about the teaching". The "people" in this sense are the academic staff and management of VUW. There is a dominant message in the higher education discourse: 'publish or perish' and much has been said about the detrimental effect of this message on educational practices (Baumann, 2002; Roland, 2007; De Rond \& Miller, 2005; McGrail, Rickard, \& Jones, 2006; Smith, 1990; Miller, Taylor, \& Bedeian, 2011). Unfortunately, this is an all too commonly used term in informal conversations within ECS. 
While there exists a dominant message that an academic must prioritise research and publishing, academics may also resist these imperatives. Lecturer A is a senior, latecareer academic and, as such, promotion and a need to research is less vital for them than for an early- or mid-career academic, and as such can prioritise teaching over research and publishing:

Lecturer A: Research will do more for your promotion than other things. It's not as exclusively that at the lower levels as some people seem to think but it's... The other reason is... most individuals are actually driven by their research... That's why they're here, and teaching is what they have to pay in order to do what they want Int: So it's seen as a bit of a chore?

Lecturer A: It's a chore a reasonable number of them view it as - a chore for which they will take responsibility, and they do care about it because it does actually affect other people... But most of them would still rather have a fellowship... If they could... Don't give me one. I do not want one. I'm not going on research leave again bother it...Six months doing nothing but research yuck... But I'm unusual, and I'm foolish... And it's not just promotion it's also the ability to move and go somewhere else... For a lot of people promotion, especially at the higher levels... is by moving to another place. [Lecturer Extract 53]

Lecturer A identifies the personal gain for an academic if they follow the dominant messages: the ability to gain promotion and seek promotion by shifting university. Failure to follow the messages leads to difficulties remaining employed and gaining promotion if you prioritise teaching over research, and can be seen in the personal belief by Lecturer A that they are foolish. Lecturer A also recognises that many academics are here because they want to research: "most individuals are actually driven by their research... That's why they're here, and teaching is what they have to pay in order to do what they want". Lecturer A implies that the choice to follow the message of research over teaching is not much of a choice for many academics. The lack of prioritisation at VUW of teaching qualifications would seem to reflect a systemic acceptance that teaching is less important, and as discussed in chapter six and seven the discourse operates to make this so while also presenting teaching as important. Teaching while important is just not as much of a priority as research within the discourse. 
In contrast, Lecturer $\mathrm{N}$ is a relatively junior lecturer and has a slightly different view - he has not experienced any pressure, or help, to either improve teaching or increase research outputs. However, they have received a clear message that for promotion they should prioritise research over teaching for promotion:

Lecturer N: I'm given a huge amount of autonomy. Nobody has told me 'you need to publish more or less or differently'. Ah similarly nobody has yet come up and said 'your teaching is appalling fix it' (general laughter). Or-or 'you're spending too much time on your teaching back off and do something useful', um but what I have done is been to promotion seminars. Um ah, productivity seminars. And the message there is consistent, ah do as much as you can on research, do the bare minimum on teaching. And that way you'll get promoted. Now you know I started right at the bottom of the salary scale, so promotion is-is important. [Lecturer Extract 54]

The autonomy described by Lecturer $\mathrm{N}$ reflects that lack of input from VUW and ECS management or colleagues in terms of hands-on involvement regarding research or teaching support is common for academics. Academic staff are largely self-autonomous, and as such can interpret the messages they receive and act accordingly. Most academics perceiving the message: "do as much as you can on research, do the bare minimum on teaching. And that way you'll get promoted" would see this as a policy directive, especially when it is coming from seminars run by VUW management. Promotion seminars referred to as 'productivity seminars' are an example of the connection between the idea that if you are researching you are being productive and will be promoted, having future career opportunities and an increase in salary, is a compelling message to receive. This is the normalisation of meaning in the discourse and helps to create a subject position for academics with a set of understanding generated from these meanings that depicts what it is to be an academic - what makes up their rights and responsibilities.

This message, coupled with academics' own desires to research, has an impact on lecturer's involvement in teaching, as Lecturer J states below:

Int: ...another lecturer said this to me I don't know if it's true, is that because like you have to do your PBRF and your publishing and other stuff. What makes it so hard for you for example to do that?

Lecturer J: Mm it is just prioritising um, I'm desperate to find hours free to. I'm not thinking PBRF, um, well I try not to, um, there's things I'm really hungry to think about 


\section{Int: Yep, so that's research and stuff}

Lecturer J: Yeah research. And that that pulls me. And those hours are you know precious and hard to find, and I think... it's probably already right but um it comes down to a choice between do I spend this hour go find someone in the lab and just try and get more in tune with what's happening in first-year students. And an hour ah to think about the things that set me on fire, um I'm gonna choose the fire. And that probably happens repeatedly, and that ends up being a pattern. [Lecturer Extract 55]

Lecturer $\mathbf{J}$ acknowledges the tensions academics experience in prioritisation of teaching and research, particularly when the lecturer equates researching with "things that set me on fire". The tension occurring here, and the ability to choose are examples of just where Foucault's theories believe power is in operation (Foucault, 1983). The lecturer makes a choice and prioritises research over working with the students in classes. The notion that this "probably happens repeatedly and that ends up being a pattern" suggests a normalisation of this practice. This is privileging some actions over others, such as the role of an academic as a researcher rather than a teacher. The effect of this on the teaching and learning environment by prioritising research over teaching can potentially have an effect on the student learning experience.

In the case of ECS, the prioritisation of research is actively encouraged. Priorities or at least a perception of what is more important affects the choices made by academics about which of these interrelated demands receives more attention. Lecturer B below describes how research is the accepted, common sense choice for an academic's work efforts:

Lecturer B: ... everything that you then do towards learning how to teach better sucks out administrative time or research time and to be honest the perception is still the case and it's probably still reality that you're not going to get anywhere without a decent research portfolio especially with PBRF hanging over everyone's heads

Int: So essentially there's no incentive for you to spend the time?

Lecturer B: There's a wee bit of incentive, there's still an incentive because you do have to submit your teaching portfolio (TPP) with your [promotion] application... So if you're on the extremes... It can either help or severely hinder... But let's say that you're in the middle you're neither excellent nor pathetically awful you just get solid I don't know 2.1s to 
whatever $2.2 \mathrm{~s}$ to $1.8 \mathrm{~s} \ldots$ Right. That's not going to be the thing that drags the attention of the promotion committee. It's going to be what's your research like, what is your service to the university as well, what boards and committees do you serve on, but also you mentioned the key things like you know publications administration and teaching but the actual the fourth job which doesn't get counted is actually service to the profession which actually takes up a fair bit of time...

\section{Int: So academics in reality just don't have time?}

Lecturer B: Yes or that you could spend more time on teaching at the cost of research yeah. No one here I don't think with perhaps a few exceptions would work less than forty-five to fifty hours a week on average... Now some of them choose to put far more hours into their research to be fair... Not all of them are putting two days of out of five into teaching, and not a lot of them are putting one day, in fact, there's a few staff who aren't putting in any instruction at all but they put in lots of research, and that comes out in research publications. [Lecturer Extract 56]

Lecturer B is a senior academic and suggests that while teaching is considered in promotion applications, research, and service to the university on boards and committees, rather than teaching has a greater impact on promotion. The lecturers alluded to in this excerpt are described as working forty-five to fifty hours a week but that many academics are spending less than two days per week teaching or developing teaching materials. If we consider these two days per week are involved in the designing of course materials, and assessment, delivering lectures and marking for two courses per trimester 1 and 2 (1 March to 30 November - ECS does not teach in Trimester 3) it is unlikely to allow reasonable time for curriculum review, or improving teaching practice. It is not always the case that the academic staff member does not want to spend time on improving teaching but rather that the system is sending a direct message to academics to focus on research and PBRF.

Lecturer J suggests that the message about researching being more important than teaching is common amongst the academic staff in ECS:

Int: Is there a reward for teaching. I mean are you incentivised to go and become a good teacher 
Lecturer J: Ah not so much, not very much. ...there's not an incentive to become really excellent at-excel at one's teaching, you're probably gonna just do something that's a bit more fun (laughs).

Int: Would it be correct to say that you see your job primarily and the bit that gets you excited is you're here to be a researcher.

Lecturer J: I do see it that way, yeah

Int: Is that common among first-year lecturers do you think, or lecturers in general, are they actually primarily see themselves as researchers

Lecturer J: I suspect it is common, yeah

Int: Yeah, is that the way the university's set up. I mean is that is that what you're employed to do

Lecturer J: I see, ah no I'm employed to teach first years (laughs) as well as do research

Int: So is the blow torch worse if you're not a good teacher or you're not a good researcher

Lecturer J: Mm, oh I see, um I think it's probably if you're not a good researcher at the moment

Int: Do you think that affects things

Lecturer J: Yeah-yeah it does you can certainly compensate for being a poor teacher by being a good researcher. But I'm not sure the other one would apply

Int: Is that a problem, is the incentivising or prioritising of the fact that people should be really good researchers

Lecturer J: Yeah it is a problem, in a sense, I feel like it is a big problem... The whole fucking university ((general laughter)) is complete crap... um yeah, there's this mon- what's the word um like mon- not monolithic, uniform homogeneous, the value system that's applied carte blanche, and applies to everyone... And says this is better than that, um is sort of fundamentally um against diversity, and I just believe in diversity as a good thing. Pretty much universally, and having some really good fantastic, passionate student ah teachers, um and some fantastic ah high performing ah researchers as well that's all great, and everyone in the middle. Um, but attempts to sort of make everyone have zero um, zero 
poor researchers. Seems to me it's counter-productive. [Lecturer Extract 57]

Lecturer J also identifies that the university "value system" expecting people to be both good researchers and good teachers does not allow for diversity, or for that matter use people's expertise effectively. At VUW it is extremely uncommon for people to be employed in full-time teaching-only or research-only positions. However, academic staff may 'buy out' their teaching obligations if they obtain research money for the university. Lecturer J sees the "value system" imposing a set of rules on academic staff but has chosen to focus on the research obligations of the system over the implied but poorly enforced teaching obligations. This is the same for the people I interviewed, with the exception sole exception of Lecturer A - a late-career senior academic.

Lecturer $\mathrm{H}$ reiterates the opinion of Lecturer $\mathrm{J}$, by suggesting that the university values quality teaching as well as research:

Int: So do we work in an environment, this is Victoria, do we work in an environment that acknowledges recognises and supports quality teaching?

Lecturer H: So that's a moving target, that's changed a lot during my time here. University says it cares about quality teaching - my impression for academics is that they care about quality teaching and they care about quality teaching, and that's genuine. Provided it doesn't interfere with their research. ...the teaching staff are always second-class citizens, always... Always second-class citizens, but that's their choice.... [Lecturer Extract $58]$

Lecturer $\mathrm{H}$ also makes the point that there is a negative association with being teaching focused rather than research-focused, and hints that having both is quite difficult. Lecturer $\mathrm{H}$ offers a good example of the perception academics have of the norms in their working environment. These norms create the social rules in the system, and despite academics being semi-autonomous employees with a certain degree of academic freedom, their actions are owned by social processes that encourage some behaviours over other behaviours. The imperative to prioritise research has overshadowed the expectation for lecturers to be good teachers.

The higher educational discourse around teaching at VUW does not openly come out and say be a bad teacher - or don't care about teaching, in fact, it says the opposite, but it delivers a clearer message around prioritising research which unlike teaching has both incentives and penalties for academics. The gains from research regarding 
promotion, career development and interest outweigh the intangible intrinsic benefits of teaching, especially when staff who focus on teaching through "their choice" "are always second-class citizens". The effect of this on the teaching and learning environment has been to make research the place where lecturers devote the largest amount of their time.

The nature of academics being semi-autonomous allows for academics to have a choice of action. For example, they can spend more or less of their time in either research or teaching. However, as Lecturer G notes below, academic staff can be unaware that the lack of time spent on teaching is a problem for students:

Int: So why don't academics - why don't you kind of learn some teaching skills?

Lecturer G: Well first of all, 'do all academics realise that this is a problem?' is the first question that you should ask, you know, because unless it is - well for me you know it wasn't really clear that that was a problem yet... Until you saw that they [students] really don't get, even the first - the simplest thing that - even to us the simplest thing that we wanted to teach. When they [students] don't get that, then there's a problem... Okay, and I think it is to really make them [academics] see that it is a problem, first, and then that's when- that realisation will trigger you know - okay how can the feedback look to say that, how can I actually improve on this?... So the first step is that the lack of this awareness that that is a problem... Ah, and then, going to further so, what is the best way to actually deal with this? You know I'm sure you know if you start reading up there'll be some books you know. Even just doing some self-reading on how to improve, this would really go a long way to help the students... So I think that they are equipped with that skill go and study how to do - how to do better teaching. But with time restraints, research and all this and that... They [academics] probably don't have the time to do it, don't want to do it, don't see any incentive to do it, and don't realise there is a problem. [Lecturer Extract 59]

Lecturer $G$ points out that academics need to be made to see that the lack of effort in developing teaching skills is a problem. However, it remains unclear who should be making them do this, the Government, the VUW university senior management or ECS senior managers. It appears to be that the power to act, to improve training or performance, lies with the academic. However, it is complicated further as the 
Government places the responsibility for teaching quality on the university, but the university makes it the individual academic's responsibility. Ownership of teaching quality becomes a contested space around accountability. The operation of power here in the neoliberal accountability system of higher education acts to prioritise some actions over others and establishes a hierarchy of meaning. The messages can be resisted or altered, but at a cost to the academic staff, as noted earlier by Lecturer A. But, as Lecturer $\mathrm{G}$ notes, the freedom to change what your priorities are is not necessarily understood in the face of the existing processes.

At the same time, the Government and the university control the mechanisms and have ownership of the system that allows the academics to assume ownership of their actions regarding research or teaching. This notion of empowerment hides the observational practices of the university which measures the performance of academics and at the same 'allows' for an alternative choice by an individual academic. However, in this situation it is unclear that the academic actually has much of a choice in the face of the normalising behaviour. There is certainly the ability to choose a different action and for example focus more on teaching but this would require considerable resistance in the face of established practices and messages. Ownership by an academic over their rights and responsibilities coupled with ownership over the academic staff's actions by the Government through PBRF and then by VUW senior management policy makes the current situation academics face a place of tension, as Lecturer $\mathrm{G}$ explains below:

Lecturer G: Well I would say in New Zealand you know... I think it it's a mess. You're there there's no clear instruction if you want to do teaching where's the pathway you're not told you're not providing clear guidelines on you know... If you're an academic your main job is to teach, okay or in a teaching-based university, you know... And then, on the other hand, you go off and say you know oh, PBRF [Performance-Based Research Fund] is, you know, what is the message? It's actually completely - as an academic I find that this message is conflicting... You know there's no clear instruction whatsoever okay, so, I just do what I can which is, I try to teach as well as I can... but that that may just because of yourself your personal values and so on you know... and at the same time you know you're interested in doing research, and you want to because of promotion and all those other... So, for me I recognise that, if you look at the job 
description it was actually to teach... Okay, but then on the ground you know very well it's actually based on your research....

Int: But are there any actual career penalties that you know of if you are a bad teacher?

Lecturer G: Well you can suck at teaching, and you can do good research and no one no one's going to come knocking on your door Int: Okay, yep, so do you think that affects the way we teach our courses? Lecturer G: Well the inaction actually promotes, just by virtual inaction... You know you are in fact promoting it... Not actively we are promoting, but by not doing anything we are in fact promoting it. [Lecturer Extract 60]

The conflicting messages Lecturer $G$ describes regarding research and teaching requirements is a key aspect of the way academic staff experience the effect of power in the workplace social system. Lecturer $G$ recognises that despite the conflicting messages: "if you look at the job description it was actually to teach" but sees the underlying message in the discourse as one of not concentrating on teaching: "Okay, but then on the ground you know very well it's actually based on your research". With this realisation Lecturer $\mathrm{G}$ also notes that there are limited penalties for not being a good teacher if you are a good researcher: "Well you can suck at teaching, and you can do good research and no one no one's going to come knocking on your door". This lack of accountability in one aspect of the job, if the other compensates, is evidence of a process that contains a meaning for behaviour. It is a truth-making process in the discourse - which is to say it is what is accepted as the correct or true way of acting. Lecturer $G$ further provides evidence of this process when they identify that by failing to improve teaching or prioritise it by not acting to address or improve it VUW and ECS and the academic staff are at the least, effectively promoting the system where teaching is undervalued, or at the worst promoting bad teaching.

Ownership of the academics identifies that there are visible reactions and responses by staff to the perceived exercise of power from management to focus on research over teaching, which involves individual academics' perception of their role within the teaching and learning environment. This, of course, does not suggest that there is not the pressure to teach well, as there most certainly is, but academic staff have only so much time in which to meet the competing demands, and research performance is perceived as a non-negotiable priority. 


\subsection{Too Many Demands - Too Little Time}

Academic staff are time-poor in a workplace with an abundance of expectations. Workload was identified by staff at VUW in the 2015 Victoria Staff Survey as a priority problem with staff reporting that workload was unmanageable and that they did not have enough time, this was acknowledged by the Vice-Chancellor in the Victoria News (Guilford, 2016). Intensification of work demands, the pressure to prioritise aspects of the job over others, is a major factor in the lecturer statements of this thesis and has been identified in the literature as a common occurrence in tertiary higher education. For example, Gill's (2009) research investigated the labour processes, organisational governance and conditions of production within the academic community and noted that the intensification of workload is "an endemic feature of academic life" that rarely gets serious discussion (p. 234). Gill's examination of emails, conversations, university memos, and her own experiences as a lecturer in the United Kingdom, led her to conclude that academics are overloaded in an expanding workplace that epitomises an audit culture leaving staff no-time to do anything other than what is immediately required. This culture promotes unpaid overtime to keep up, which is silenced or rendered invisible as there is no institutional discussion or collective pushback by academics. It is, as Gill describes, a collective structural problem where resistance is met with the rhetoric that this is all part of the job and if you cannot handle it you should leave academia.

Gill (2009) argues that the university structure individualises academics as work demands are directed to individuals as their responsibility rather than a collective university responsibility. In turn, this structure fits with an academic's own understanding of their perceived freedom to be, self-governing and self-disciplined. For Gill this causes academics to:

model neoliberal subjects whose working practices and 'psychic habitus' (to stretch Bourdieu a little towards my psychosocial concerns) constitute us as self-regulating, calculating, conscientious and responsibilised. The 'freedom', 'flexibility' and 'autonomy' of neoliberal forms of governmentality has proved far more effective for extracting 'surplus value' or at least vastly more time spent working, then any older modalities of power (though, of course, feudal and other forms co-exist quite comfortably with these in the operation of Universities). (p. 237) 
The academic is at the centre of a power struggle connecting business demands, academic freedom and educational goals. The normalised behaviour for academic staff has embraced business models of accountability and neoliberalisation in the guise of freedom and autonomy of agency, but in reality, there is a breakdown of autonomy as work demands increase. Gill notes, where this pressure is felt the most by academics is the need to publish because this is where academics are subject to surveillance and assessment for both quality and quantity of output with continued employment a constant threat. This is in effect a disciplinary process of control.

Anderson and Grinberg (1998) argue that educational systems, like universities, control the behaviour of students, faculty, administrators, and staff through rules and laws and accepted norms. Self-discipline and group control is achieved by individuals internalising what is accepted as correct behaviour which has some effect on reducing the need for explicit control. Individuals become complicit in acting within the boundaries of accepted dissent or acquiescence in the social context. Thus the decision to act or respond in a particular way to given social situations helps propagate what is considered correct behaviour if enough people do it. For example when enough lecturers decide to spend more time researching than developing teaching, then this becomes normal practice and may be propagated further to the next generations of academics.

This practice is in direct contrast to the university's message that there should be a connection between research and teaching. Research-led Teaching is another example of the interaction between rules and norms of behaviour. It is a Government requirement and expectation of the university that staff use Research-led Teaching, however due to there being no time available for academics to develop this, or any institutional guidance for how to do this, it does not form a deliberate practice. So just what is Research-led Teaching? According to the VUW Learning and Teaching Strategy, it is considered a central aspect of what makes a university different to other tertiary institutions, such as polytechnics:

Research-led teaching is among the features that distinguish universities from tertiary institutions of other kinds. Victoria's strength as a researchintensive university can add particular value to the linkage of research and teaching. Research-led teaching, properly understood, is a reflective process benefiting both activities. Most undergraduate teaching is geared to content delivery, but the content that is delivered must be continually shaped and contextualised by research in the area. Staff and students are 
thereby able to engage actively and productively in research that informs and improves teaching and in teaching that generates new directions for research. Researchers face the challenges of contributing to continuously renewed curriculum, of providing opportunities for students to develop their own research and inquiry skills and of communicating their own research to new audiences. Students can benefit from the intellectual excitement of discovery in a research environment, as well as from the development of skills and attributes that fit them well for employment or further study. Placing a stronger emphasis on the scholarship of teaching will enable the University to ensure that current research on the theory and practice of teaching informs educational practices. Both the Research Strategy and the Learning and Teaching Strategy are predicated on the importance of this integration as a basis for the delivery of academic programmes. The Learning and Teaching Strategy sets out actions to support the development of research-led teaching practice of excellent quality (Victoria University of Wellington, 2009, p. 5). [Non-Interviewed Extract 32]

Beyond this statement, very little official policy documentation is available on how research led teaching should be, or is, done at VUW despite its importance being stressed in government and university documents (Ministry of Education, 2014; Victoria University of Wellington, Learning and Teaching Strategy 2009 \& Strategic Plan 2004). The understanding of what Research-Led Teaching means for actual practice seems to have no official guidance despite its continued reference.

Moeung's (2013) comparative study of Research-Led Teaching in higher education noted that the NZ Government and all NZ universities stressed the significance of Research-Led Teaching in both documentation and mission statements. This suggests that at least on some level it is perceived as a core mission imperative and with that an assumption that it has positive effects on the teaching and learning nexus. Moeung conducted semi-structured interviews with academics (including those at VUW) and combined this with document analysis. This research concluded that the PBRF system in NZ supported and encouraged research but that:

$\mathrm{NZ}$ participants found it $[\mathrm{PBRF}]$ a challenge for them as this program tend to focus too much on research but not teaching or learning. Also, so much 
time was spent on conducting research that it restricted academics from having much teaching time with students. (Moeung, 2013, p. 79)

Moeung found that research activities were actively supported as this improved university rankings and funding, but little to no support was given to how research might be used to inform teaching practice and enhance student learning. Academics reduced the time spent on teaching and prioritised their time for research (Moeung, 2013).

Lecturers ignore or resist institutional demands to incorporate Research-Led Teaching into their practice due to their perception of an excessive workload, priority directives to research and an inability to know how to incorporate their research into teaching. This action represents a choice for the academic staff, and a place within the social situation where the choice is easy to make, as it is an accepted practice. The university message does not bring any form of serious accountability for an academic that does not develop research-led teaching. The discourse promotes other messages in a more dominant way. This is a normalising process where we can see power-relations in action. For example, Moeung cites two Victoria lecturers:

There has been an external challenge which had been around the PBRF pushing all staff to be research active. (NZL\#3)

The suspicion was that, last year, the PBRF would not care if academics did not teach as long as academics got research projects done for the university. (NZL\#1). (p. 70)

Moeung's example illustrates lecturers experiencing the operation of power and this experience shown in the lecturer interviews is also common for lecturers in the ECS first year teaching and learning environment.

Hemer (2014) draws similar conclusions. Workload and the rewards system for research provide very little incentive for academics to spend time on learning better pedagogical practices and improving teaching practice (Hemer, 2014). Hemer noted that this situation reflected structural changes within universities associated with neoliberalisation, and a managerialist accountable environment which has increased control over policies and processes of staff (Hemer, 2014). Hemer concluded that:

While there is research being done around innovations to teaching practices that promote quality, this study indicates that most academics on the ground have little knowledge of it. There appears to be a level of disconnect between the research literature and those people practising teaching. As it stands, there is little in the rewards structure at 
universities...in promotion criteria or in awards, to motivate academics to find the time to keep up-to-date with the literature and research on pedagogy and quality. (pp.492-493)

Academic staff interpret the messages they receive as part of the institutional discourse and, in turn, decide how best to operate within these demands. Some institutional directives like Research-Led Teaching can be ignored as they have fewer negative implications than others, such as actual research. Academic staff have a certain amount of freedom to navigate the institutional demands and can see which demands have more impact on their day to day practice revealing power at work in the discourse. The power to ignore the Research-Led Teaching policy directive by academic staff is afforded by senior leadership as no checks and balances exist to ensure the policy is complied with. Moreover, in the absence of clear guidelines or developed institutional practices, academic staff are free to interpret exactly what Research-Led Teaching means. In contrast, there are penalties for not spending time researching, and there are very real career implications for academic staff who do not spend time delivering research outputs. The university is, in effect, controlling the behaviour of its academic staff through the operation of power in the discourse and is exerting a form of ownership of action over academic staff.

\subsection{Summary}

This chapter has explored how ownership in the educational space is exercised in a way that both empowers academic staff to own their role at the university, but also removes ownership from them through systemic Government and university processes. These processes operate through the dissemination of meanings (and absence of meanings), norms and beliefs, and results in forms of control over the actions lecturers choose to undertake or not. The discourse at work is complex, with multiple meanings in operation giving rise to tension in the teaching and learning space as academic staff navigate the need to meet competing demands which ultimately prioritise research over teaching. This is an artefact of the neoliberal university which seeks to organise and manage academic staff in relation to business models and outputs underpinned by a desire for higher education to be economically accountable. Academic staff describe themselves as individuals with a sense of freedom of action but at the same time as employees with 
limited freedom. The notion of freedom centres on their understanding of their rights and responsibilities in relation to the messages they receive in the discourse. There is a contradiction of purpose at work between teaching and research. How much time and effort should an academic spend on teaching and developing teaching best-practice versus the time spent on research and developing research outputs? The analysis presented here suggests that despite a feeling of frustration by some academics regarding how little time they get for developing teaching, the need to do research is regarded as more important. Thus, the tension between ownership of action - rights and responsibilities, illuminates power-relations at work in the discourse. While academic staff have an understanding of their right to certain actions the dominant messages in the discourse have normalised their actions in particular ways. The lecturers are experiencing power and in turn manifesting it in the teaching and learning environment.

In the following (and final) chapter, I give my reflections on the analysis and discussion of previous chapters. I also offer some suggestions for alternatives to the current situation at VUW and ECS, and finish with a reflection on my experiences of using FDA in a workplace environment involving analysis of colleagues. In doing so, I hope to provide insight for people who wish to explore FDA as a research approach. 



\section{ChAPTER Nine: MY REFLECTIONS}

This final chapter presents my reflection on the research presented in this thesis; the contribution to existing literature, my position and my recommendations about how the teaching and learning environment may be improved in ECS - based on my analysis.

Foucauldian Discourse Analysis provided the primary philosophical and theoretical approach used in this thesis. It is worth reiterating that FDA is an analytical tool facilitating the statements, observations and conclusions made by me. However, those statements, observations and conclusions do not have the status of 'truth', but neither are they speculation or purely relativistic - rather they are a critique of possible truths, and contingent on my subjectivity. What is clear to me, both ethically and philosophically, is that this thesis contains my subjective interpretations of the texts, and environment I work in, with an FDA-inspired analysis. All observations and analysis around the primary sources (whether textual or interview-based) are mine, informed by my interpretation of the discourse.

The goal of this thesis was to explore how power is experienced and manifested by lecturers in the Bachelor of Engineering (Hons) first-year teaching and learning environment at Victoria University of Wellington (VUW), New Zealand. Moreover, in doing so illuminate the impact of the operation of power-relations in the teaching and learning environment.

I originally set out to understand the challenge of STEM students recruitment and success through analysis of interviews with students themselves, conducting, recording and analysing more than a hundred such interviews. Paradoxically, this analysis, though alluded to only briefly in the introductory sections of this thesis, laid the foundation for the work that came to be the focus of this research - on the institution and its employees. The educational-social situation examined in this thesis was framed through the conception of ownership as a means to identify the operation of power in the teaching and learning environment, and bears some similarities with Foucault's notion of governmentality. The lecturer discourse drawn from transcribed interviews was the primary focus of the analysis, as this provided an alternative way to examine this environment from the traditional student-focused research in STEM education (discussed in chapter one). In conjunction with these lecturer interviews, textual material from 
Government and university sources were also examined. The combined analysis of the lecturer interviews and the government and university documentation provides one view of how the operation of power can be understood, and its effects explained. Consistent with the philosophical underpinnings of this analysis, this explanation should not be taken as an absolute truth or a definitive understanding of the situation, but one way of seeing the discourse.

I've tried to provide readers with an FDA perspective. That is to say, the information presented in the chapters above is not a discretely compartmentalised teleological narrative. Instead, the chapters present the teaching and learning environment as a complex discursive field, with components constantly on the move, creating and disseminating particular forms of meaning, while simultaneously resisting and excluding other forms of meaning. This is the operation of power. Power is not a thing in itself, but is witnessed in the operation of society and enacted by people.

The operation of power in the discursive field illustrates a nexus of interconnected messages and processes, revealed through discourse, and the lecturers play a central part in shaping actions within the teaching and learning space. Recognising the need to consider the actions of academic staff, or their resistance to suggested actions, is perhaps the single most significant contribution this thesis makes. As discussed in chapter one, studies that examine teaching and learning environments from a purely student-centred approach, while extremely important, run the risk of missing other, equally important, processes that shape the learning space students experience.

The teaching and learning environment is a system in which individuals (in particular, the academic staff) form a central part. The similarity of responses by lecturers to the interview questions presented in this thesis suggests that they share a common understanding of messages in the discursive field. From an FDA perspective, this indicates that there are meanings being conveyed, acted upon, or resisted in the discourse. These lecturers are not separate from the effects of power in this space, but rather are integral components of the system, both acting and acted upon. Lecturers experience, interpret, and reinterpret and manifest, messages in the discourse and are thus able to shape further meaning through the unfolding discourse.

What does this all mean for understanding the impact on those involved? It means that we need to look beyond individual situations like, the classroom experience, and examine the larger situation if we are to make significant changes to the way we educate people. 
The operation of power discussed in this thesis highlights a sense of ownership, over rights and responsibilities considered to be a series of social "actions upon actions" or rather processes "to structure the possible field of action of others" (Foucault, 1983, p. 221). Government, business, and university policy, coupled with lecturer perceptions, actions and inactions, reveal the operation of power networks in the teaching and learning environment. For example, Government and businesses are looking for engineering graduates. Government-derived university funding is conditional on a mixture of recruitment, course completion and graduation numbers, with an additional and outsize demand for research outputs. VUW looks to meet all of these targets and have high national and international university rankings. Within VUW, faculties and schools seek to meet their course completion and graduation targets, while maintaining the quality of student outcomes. All while also being accountable for the quality of their research. As a result, lecturers experience multiple pressures to maintain their standards of educational quality, teach courses and conduct research while also contributing to administrative duties.

To date, despite several attempts to reshape courses, ECS has been unable to undertake a comprehensive, student-centred, curriculum or teaching review to identify where and why students are not achieving Part 1. My conclusion, based on the research summarised in this thesis, is that ECS' previous reviews have been unsuccessful in improving student pass rates because the staff have not considered, or been warranted the opportunity to consider, solid pedagogical evidence or practices relating to teaching and curriculum design. The question remains why? My analysis suggests that the institution, rather than the individuals that comprise the teaching staff in ECS, have enabled an environment that does not in turn enable staff to develop the necessary skills or devote the necessary time required to do so. There is a constant push and pull on the individual academic staff which creates a sense of frustration in many about not being able to meet all of their workplace demands.

While Government and business exert ownership over the university, it, in turn, applies it over lecturers who react with counter-ownership. This exercise of power is a continuous series of actions and reactions, compliance and resistance. For example, as discussed earlier, ECS's inability to exercise meaningful control over VUW entry standards for the BE leads to the reluctance of lecturers to amend the academic demands of their courses. The resistance to making courses that can cater to a diversity of student 
capability leads to the scaling of course marks to pass enough students to meet government and university targets.

There is a growing gap between the responsibility and rights of all the groups listed in Table 4.1. The lecturers have ownership over the right to construct curriculum, but do not have to do so in cooperation, or even communication, with each other; some lecturers want to share their teaching and curriculum development, while others do not. This lack of communication and integration results in an individualistic first year teaching culture and course design. The acquisition of teaching skills by academic staff is not emphasised in the operational procedures and imperatives of the university. Despite this, there is a growing realisation that we need to operate differently to meet the needs of the students, and lecturing staff.

Above all, there is a constant message in the interviews of increasing and competing pressures on academics. Lecturers describe a lack of time to meet the pressures historically placed upon them, let alone the added demands remediation would necessitate. Ownership of the course and classroom teaching is given to academics, but not in a way where they feel empowered to improve content, context or process. This problem is exacerbated by the competing demands of research, publishing, administration, and the agenda of recruitment and retention. 'Ownership' in the teaching and learning space represents a manifestation of power, and also of resistance to power, by the multiple parties who have 'ownership'. The consequence of competing ownership on the teaching and learning space suggests negative effects for students. This is where we see the operation of power not in a delineated conscious directional sense, but a series of interlocking actions that shape the discourse and create a sense of truth - a sense of a certain way of operating that appears to be normal or natural. Moreover, as Borch (2005) notes, this is where power is at work in systems to order the actions of individuals as reproducible rational choices. The actions taken appear coherent, as they are the actions of individuals operating in relation to a constructed rationality of purpose in the socialinstitutional milieu, which comprises and encompasses society, and people who operate in it. For example, we can describe a society in many ways: the global world, the national environment, the workplace, the home, an almost infinite series of situations can be defined. These situations interact and influence others and yet sometimes do not come into contact with others. The operation of power can be witnessed, in specific contexts, like ECS. 
However, it is vital to see, as Foucault did, that power relations in society do not conform to a single central force or plan. While particular individuals, groups and institutions (such as the Church or government) operate to disseminate or direct actions upon others, there is no coordinated master plan that predetermines exactly how things will happen (Deacon, 2002). To be clear, that is not to say; we are not all part of systems and processes that include the construction of apparatuses - such as governmentality or neoliberalism that emerge within the societies as producers of actions upon others - it is just that this operation is not the sole central point of primacy for the operation of power. As I have discussed, there is a neoliberal STEM crisis discourse at work in the discursive field influencing the operation of power. However, it is not the sole owner or operator of power in the teaching and learning environment. Power is in operation at all levels of society and is both top down and bottom up.

The actions of governments and social institutions are some of the places where we can witness the operation of power over individuals and groups, but these are not universal or autonomous sources of power. Policies and processes within these institutions are dynamic, changing over time (Jessop, 2006). For example, pressures within the current neoliberal process affect social interactions, and it is individuals acting within these systems that exhibit a certain degree of freedom of practice to accept and act, or reject and resist, these practices of power within the context of their specific social environment (Foucault, 1980).

With that in mind, the university, and in this case ECS, represents a particular collective social context that reacts to the exercise of government policy exercised through its senior management structures and policy directives. Department management, in turn, filters this and reacts accordingly, as do the lecturers and students. This action and reaction is always conducted by individuals or groups within the system via means of accountabilities (See Table 4.1) and it is through this complex network that the operation of power takes place, as both visible and invisible actions of either conformity or resistance. In this operation, power is diffuse within what is effectively a disciplinary society.

There is a visible colonising of the university system by neoliberal economic pressures, including the drive for universities to be accountable economic contributors. This neoliberal process is the creation of a discursive regime that has formed a normalised truth to its operation and is interpreted by lecturers as 'how it is', which in turn subjugates 
and subjectifies both the lecturer and the student and, one could argue, university management and government.

While this thesis has not focused on examining the effect of the operation of power on students, it would be fair to suggest that the situations described by the lecturers impact student success, and contribute to the reification of practices that become selfperpetuating. Further research that connects the teaching and learning environment and the way academic staff operate in it to the student experience would, I argue, greatly improve our understanding of barriers to student success.

\subsection{The Contribution to Existing Research}

In this thesis I used discourse analysis inspired by the work of Michel Foucault (FDA) to describe power-relations in an interconnected social situation. My research sits within a sub-field of the broader field of discourse analysis that investigates higher educational institutions, as organisations, cites of politics, policy and marketplaces, spaces of teaching and learning and as places of social behaviour. This research is in keeping with other FDA research, some of which was described and discussed in chapter two, that focused on the operation of power and discourse.

My application of FDA shares similarities and objectives with the work of other discourse analysts that have used Foucault to examine power in higher education, and health studies (see, chapter two). For example, my FDA approach is similar to that used in CDA by Fairclough, although I did not start with the intention of having a political view of power, hence my desire to call it FDA rather than CDA. My research focused initially on the operation of the discourse in creating actions within the particular setting of ECS and saw the actions being practices of social relations. This is not purely a domination process but rather a way of seeing how certain practices may come in acceptance and at the same time come to be resisted. As the lecturer interviews developed, it became clear to me that there were political discourses at work. I certainly had a desire to investigate what was occurring in ECS with a view to eventually improving student outcomes.

In doing so, I had an agenda common to FDA/CDA research, which seeks to solve a social problem or at least have some practical relevance. I did not use the level of linguistic analysis often seen in CDA which also focuses on grammar, vocabulary, 
phonology. Instead, I focused more on the thematic and semantic aspect of the text (Van Dijk, 2011). In this sense I was concerned with discursive practices, which simply put is where the rules of a social situation allow something to be said or not said, thus revealing norms of behaviour and the operation of power. I also did not start with a position that saw the dominance of social power as a form of abuse and injustice as some CDA proponents do (Jorgensen \& Philips, 2002; Van Dijk 2009.). This final point is a significant difference between FDA and CDA, power is always at work in text and social practices, but for the proponent of FDA it is not always negative and does not always produce inequity, rather power produces particular kinds of knowledge (Foucault, 1978).

Similarly, my work did not seek to frame the examination of power-relations within a specific concept like biopower, or governmentality, from Foucault's toolkit. Instead, I drew from across Foucault's corpus about discourse analysis and power. I share the same belief as O'Farrell (2005) who sees Foucault's concept of Governmentality as being the same as his notion of discursive practice: "Thus, even if Foucault does not specifically use the term 'discursive practice' in his discussion of anti-Machiavellian literature in his famous lecture on 'Governmentality' (1978v), he is still clearly referring to this notion" (p.74). Governmentality inspired by Foucault has, according to McIlvenny, Klausen, and Lindegaard (2016) become a field of research in its own right (p.1). Though they also note that within DA "there have not been many attempts to connect up the notion of discourse with the later work of Foucault and even fewer have attempted to explicitly investigate discourse and governmentality". (p.2). For McIlvenny and colleagues (2016), most discourse analysts have largely ignored Foucault's later work on Governmentality favouring his earlier works, in particular, The Order of Discourse. I confess to being one of these analysts. As such, in this study, I have drawn from the work of Foucault, but have stopped short of suggesting that this study is solely an archaeological analysis or analysis of biopower or governmentality. Rather this is a Foucauldian-inspired discourse analysis of power relations that focuses on discursive themes and contributes an expansion of knowledge about how staff in a university department operate in relation to the operation of power.

Looking forward, I can see an interpretation, and perhaps explicit development of my work that focuses on Governmentality as a means of further investigating and theorising about the rationalities, programmes and techniques and subjectivities - the places governance over conduct is given shape in the discursive practices of the social. And for that matter an explicit unpicking of the control of indiividuals and groups from a 
perspective of biopower. These works would not alter the substance of my current Foucauldian findings but would instead allow for more in-depth analysis of specific aspects of the use of power.

My study forms part of a small but growing engagement in STEM education with the work of Foucault (discussed in chapter two). This developing literature is being used to critique power-relations within education, with efforts particularly focused on gender imbalance and racial inequality (e.g., Henwood, 1998; Riley \& Sciarra, 2006; Phipps, 2007; Riley 2008; Riley, Pawley, Tucker, \& Catalano, 2009; Riley \& Claris, 2009; Claris \& Riley 2012; Beddoes, 2011; Beddoes, Schimpf \& Pawley, 2013). My work does not specifically look at inequality of gender and race in the student or staff cohort. However, it does share in the underlying desire to examine in-house practices that may be the root cause of some of the failures in STEM departments to increase course completion numbers of students, be they male, female, transgender, or non-gender specific, or for that matter from a racially or economically disadvantaged or advantaged.

I share a similar desire with this group, and my work has common ground with that of Beddoes, Schimpf and Pawley (2013) who investigated female career pathways and experiences with parental leave policy in STEM faculty. Their research looked at the discourse within institutions from a perspective of interviews with 29 female staff and identified within the discourse practices that established negative meanings towards pregnancy in an academic role. Their Foucauldian examination, like that of my own, illustrates that in higher education subjectification and normalisation of behaviour has a powerful effect on the day-to-day processes of people. A fear culture is experienced and inadvertently recreated through the actions of the female staff. This is similar to the finding in my study which shows that the discourse creates accepted beliefs and practices even when staff note that there are other perhaps more ethical ways of acting, for example, spending time improving teaching or conducting research. Beddoes et al. (2013) note that there is a strong message that if you want to have children as a female staff member, then academia is not the place to be. VUW and ECS, in turn, have the message that being an academic means prioritising research over teaching. What is occurring here are truthmaking processes. It is not that these notions represent the truth but that they represent a correct way of acting in a specific situation - this is the operation of power.

Foucault has also been used to stimulate engagement with STEM educational practices as a means of critiquing power-relation and the notions of truth, the creation of 
subject positions, and how discourses have traditionally presented knowledge. As Bazzul and Carter (2017) note the theories of Foucault can be used to:

render science education discourses and practices so they can no longer stand the way they stood before. Science educators can go further than acknowledging 'bias' by outlining how science education, among many other things, carries the effects of power and can work to constitute the subjectivities of students, teachers, and researchers in particular ways (p.446).

This is an important step for STEM education researchers who for many years have presented a predominantly positivistic understanding and assumption of educational practices (see discussion in chapter one). The notion of critiquing STEM education with Foucault is gaining popularity (e.g., Bencze \& Carter, 2011; Pierce, 2012; Sharma \& Muzaffar, 2012; Melville \& Bartley 2013). STEM work in FDA such as that of Melville and Bartley (2013) has focused on examining discourse to challenge dominant powerrelations, arguing that the resistance to dominant discourse in teacher identity and issues in national curriculum would require a bringing together of teachers across multiple sites. Similarly, my thesis was concerned with lecturer's identity, but more about how they fitted into the operation of power in ECS.

My focus adds to this by focusing on the staff rather than the students, though in my case it was an examination of one specific engineering department and an attempt to cross multiple sites of discourse. I used FDA to look at the micro-analytical level where I examined lecturer interviews, meso-analytical in that I drew on practices within the department and university, and macro-analytical level to examine connections between government and university policy documents. I believe my study makes a good attempt to bride the micro, meso and macro levels, but I must also point out that in many cases my research could only scratch the surface of this process. Alvesson and Karreman (2000) note that attempting to analyse micro and macro levels of discourse are "not easy to account for both in the same study. This should not, however, discourage such efforts. Rigour should sometimes be downplayed for the benefit of social relevance" (p.1134). My aim was to reveal the tensions in the discourse between these levels and how they impacted on academic staff and how this may problematise the teaching and learning environment. It was not a top-down approach beginning with an acute understanding of the problem; rather it started with an examination of the interview texts as the starting point for pattern recognition of themes. In this sense, it was located in an FDA theoretical 
basis by starting from the bottom (the lecturers' interviews) and looking at themes within the discourse for social practices that revealed power-relations. These were the themes where the lecturers described processes (their description of issues affecting them and students and their description of their practices). By using the themes in the interviews, I expanded my analysis to look for corresponding or diverging themes within university and government policy documents.

The interview texts were examined and where similar thematic content appeared were selected for further analysis of meaning and subjected to the questioning process described in chapter three. The interview texts provided the basis for the selection of policy texts as I connected the themes to processes in the university, it was here also the embedded nature of my place in ECS and VUW enabled me to have an understanding of what the lecturers were referring too. Only concepts that were identified in the majority of the interviews were used for the analysis. These concepts were in turn questioned on their own with regards to meaning in the text using Thomson's (2011) set of questions and then again questioned regarding the way the other academics discussed the same concept - for example, such as the concept of PBRF or the concept of course design. While meaning was derived through analysis of text contents through discourse analysis but is not free from my own biases as a staff member in ECS, the only method of reliability in selecting specific aspects of the text for interpretation reflect my experiences of the teaching and learning environment in ECS education.

The findings were discussed with my supervisory team as a means of validating the choice of texts and cross-checking that I was not misreading the connections or themes. While all attempts to make this data reliable and verifiable, discourse analysis does present particular challenges to these concepts. Cross-checking with my three supervisors enabled me to question the categorisation of the data and obtain different reference points for looking at the text from what would have been possible on my own. A central aspect of this analysis was the construction of a map of the discursive field seen in Table 4.1 chapter four.

My aim with this table was to map the discursive field while conforming to a Foucauldian concept of power and resistance, where all power-relations are productive but at the same time enables sites of tension to be examined for the operation of power. Table 4.1 as such represents a map of groups where ownership is expressed as a right or a responsibility. Inherent in the concept of ownership is a Foucauldian understanding of power in that people also have the ability not to exert ownership. And by not exerting 
ownership can present resistance to the normalising process of ownership. Ownership as a social function has an inherent ethical and economic component. In this manner, I conceive of ownership as a concept that incorporates Foucault's notion of power-relations in discourse that seek to govern the conduct of individuals and groups, their actions and conduct as a subjectifying and normalising process (see discussion in chapter two). I used ownership as a word/concept for a way to see subject positions and their overlapping power-relations in the context under investigation. In FDA, this means examining the discourses within the lecturer interviews, and the government and university documents, alongside relevant literature to see how academic staff became subjectified in the discourses through their experience of power and how in turn they manifested their own power, as compliance or resistance in the teaching and learning environment. In essence, Table 4.1 while being a map of the discursive field also represents a depiction of the higher education neoliberal teaching and learning environment resplendent with accountabilities.

There is an alignment between my work here and the extant research of Ball (2015), Shore and Wright (1999, 2000, 2003 and 2015) and Morley (2003) who examined higher educational discourses in relation to neoliberalism and its accountability and audit culture using a Foucauldian notion of power-relations. These authors, who examined primarily educational policy suggested that the construction of meaning in higher education has an impact on the way micro and meso-level practices become established as taken-for-granted by institutions and staff. My thesis like their work is an attempt to unpick the dominant discourses operating in higher education and its impact, including an understanding of resistance to what is a normalising process. These authors use the very form of critique espoused by Foucault as a means of challenging what they see as the negative consequence of neoliberalism. Importantly, these authors see the connection between daily practices of accountability and an audit culture which conditions the possibility of actions.

For example, Morley (2003) applied a Foucauldian understanding of powerrelations to her interview texts analysis to "begin to uncover some of some of the ways in which quality, as a regime of power, is experienced by academics and managers in higher education" (p.vii). As such, her work has a connection to my own. She set out to investigate "power in terms of macro-systems of accountability, surveillance and regulation, and also in the microprocesses of organizational life, that is, how quality assurance influences culture, relationships, subjectivities and identities in the academy" 
(p.vii). In doing so, she uncovered a pervasive process in universities regarding quality assurance whereby resistance to the dominant discourse of improvement through accountability was undermined by managers who utilised a language of improvement to elicit compliance lest staff be seen as not wanting to improve outcomes. In a similar vein my concept of ownership expressed through rights and responsibilities also questions autonomy and accountability seeing the perceived threat to autonomy from the desire to increase the number of engineering students and graduates, and contribute to the economic well-being of ECS, the university and the nation. This is the operation of power in discourse shaping practice and belief in shared (or normalised) neoliberal moral and economic goals. At the same time, there is an opportunity for resistance by academic staff through a constructed identity of academic freedom which enables academic staff to decide on how to act and the very act of criticism expressed in the lecture texts towards university and government policy. However, a significant finding of my research is that this notion of free action or free will to resist or conceptualise of an alternative is relegated to a form of criticism against policy, whereas academic staff practice acts to normalise the process being criticised.

\subsection{My Position in this Research}

One of the major challenges of this study was my proximity to my research subjects and situation - my colleagues and workplace. Given my closeness to the situation I have studied, as a VUW and ECS staff member for ten years, I have a perspective of events and situations that can affect my interpretation of events. I have been a student advisor and project manager, and I am currently the manager of our student retention and development team working in pastoral care and managing tutor support in ECS, an academic, first-year programme director and a member of the ECS senior executive management team. As such I am embedded and invested in the ECS programme. I care about the education of students and the delivery of a quality programme, and this is something I cannot easily separate from my research; indeed, it is the reason for my research. This does not suggest that my research is invalid but, rather, that as a researcher I have to be reflexive while undertaking and presenting my research. To assist in this, my supervisory team, comprising a Lecturer who is a linguist and academic developer, a Professor in psychology and a Professor in electronic and computer systems (who is also 
the Dean of Engineering) worked closely with me to ensure the material was the result of analysis rather than prejudgement.

The proximity to the research subjects and environment is also a major strength, as I am part of the discourse at work in the teaching and learning environment giving me a unique perspective. As an insider, I was able to have insight into both the daily and strategic operations of ECS. The lecturers, knowing me personally, enabled for what I believe was very honest and confronting set of interviews. In my experience, these answers reflected my own, and my supervisory team's understanding of academic experiences in ECS and other places across VUW. Indeed, these existing relationships provided me access to participants and discourses that might otherwise have been inaccessible, allowing me to paint a representative picture based on the representative collection of contributors to the first-year Programme.

While I have described literature from the broader STEM and educational literature suggesting that similar experiences may be occurring elsewhere, my findings, by necessity are restricted to ECS within VUW. Furthermore, my research used the lecturer interviews as the primary sources of discourse for analysis and were restricted by what academic staff said in a particular and contrived context. As such, while there were other areas of investigation (for example, the relationship to teaching and student feedback) that could have been explored, if they were not raised in the interview, I did not follow them up. I felt it was more robust for me to only work within the information contained in the discourse I had at hand.

One strength of my position is that it offers an insider's view of an educational department in a neoliberal educational environment. Without my employment position and proximity to the situation, the information contained in this thesis would not have been accessible. As a result of this access, I was able to see a version of events that offer a particular perspective on the operation of power (while also being an agent and subject of power). Individuals are not the sole perpetrators of action without cause. The academic staff are intrinsically connected to the messages they receive, and interpret, and enact as operational behaviour. The messages inherent in the discourse and interpreted by the academic staff affect the education of students and the ability of the institution to deliver quality education. These messages are followed or ignored, dependent on the level of resistance or acquiescence applied by the academic staff. This is often a collective action rather than the actions of specific individuals and perhaps here lies a new way of looking 
at the situation. The teaching and learning environment should not be viewed as only student-centred or academic-centred but as discourse centred.

\subsection{Recommendations and Future Research}

If the roots of many of these challenges lie in a superordinate neoliberal discourse, Governments and institutions must look to a common educational goal and challenge the neoliberal funding environment that disempowers the view of education as a social good, and empowers a view of education as primarily an economic gain.

The effects of ownership and control over policies and practices are suggestive that the operation of power is entrenched in Government, VUW and ECS. It is also entrenched in the beliefs and practices of many staff. The STEM 'crisis' situates the university and its staff in a position where the need for engineering students is critical for meeting the business goals of the government and funding. The ownership of entry processes by the university enables relative open entry enrolment. This in turn impacts on the quality control of students and potentially student success in courses that do not, and will not, cater for academically diverse students. The ownership of courses by individual academics impacts on the processes of course design and delivery. This directly connects with ownership of the teaching and learning whereby academic staff prioritise and exercise reactionary methods to cope with workload priorities and demands and raises questions over the operation of educational best practice and university ideals. The ownership of academics presents a picture of the operation of power that suggests that academics are encouraged to operate as individuals within the system, but there are both personal and institutional accountabilities for their actions.

Academic departments and their parent universities should consider their practices in relation to the messages that they receive and disseminate. FDA STEM educational research offers STEM departments a way to look at their own processes, and how these are affected by power-relations. This is the very thing that feminist and gender researcher (like Henwood, 1998; Riley \& Sciarra, 2006; Phipps, 2007; Riley 2008; Riley, Pawley, Tucker, \& Catalano, 2009; Riley \& Claris, 2009; Claris \& Riley 2012; Beddoes, 2011; Beddoes, Schimpf \& Pawley, 2013) have been arguing in recent years. My research offers ECS an opportunity to question what is occurring and reconceptualise our own processes be they resistance to what is occurring or not. At the least it shifts the discussion 
(seen in chapter one) away from the students as being the dominant place STEM educational researchers have looked to identify issues around poor completion rates in STEM courses. This is especially the case because FDA, whilst being interested in language, is also fundamentally interested in exploring the context beyond where language is being spoken and: "asks questions about the relationship between discourse and how people think or feel (subjectivity), what they may do (practices) and the material conditions within which such experiences may take place" (Willig, 2001, p. 107). Future government and university policy aimed towards increasing engineering student numbers and success rates must take into account the capacity for programmes like ECS to increase the time and effort needed by academic staff to develop inclusive and best practice curriculum and teaching. For example, maintaining relative open entry obliges the development of bridging courses to provide appropriate pathways for academically diverse students and, until then, VUW should consider not allowing some students into specific majors within the degree until we can be confident they can satisfy the demands expected of them.

Research and teaching should be a shared collective goal. Academic staff should not be encouraged to incentivise one over the other. The lack of institutional mechanisms for lecturers to push-back, or to encourage and support, balanced work commitments is a fault of the senior managers and organisational leaders. The role of senior management in failing to identify issues and actively work towards the improvement of practices helps perpetuate bad practices which undermine the core educational values VUW purports to adhere too. Senior management should actively encourage, participate in, and support research into higher education practices in the institution and programme. Armed with this knowledge, VUW and ECS should work towards a positive culture change within the institution. This will require a critical mass, as Melville and Bartley (2013) noted in their study discussed in chapter two. For these authors systemic change was beyond the capacity of individual staff and only through collective and shared practices of resistance can widespread change occur. I would add to this that the work of other researchers in FDA within STEM education is another possible avenue for future change. In my case one result of this thesis was the agreement to set up an active teaching and learning committee in ECS, starting in 2019. It is from thes places that at the very least discussion can form the basis of change.

Future endeavours will ideally assist in improving an academic's engagement with pedagogy. Excellent teaching and curriculum must be an aspiration, but not only an 
aspiration - it should be common practice and part of the culture of the university and ECS. Paramount in the thinking of all educators should be the process of teaching and learning, and how students can be educated following best practice. Tertiary institutions and educators have a duty of care and conduct that, if not constantly kept in mind (and valued to be kept in mind), can be rapidly side-lined by business goals that focus on money and research accountability and personal goals around research and career promotion. The university should consider engaging in more dialogue with the government about current practices.

Research should investigate the curriculum and the methods used to teach it and identify to what extent these are affecting student success in ECS. It may be possible to make improvements in this through a dedicated investigation into STEM teaching pedagogy. There is also room for a wider institutional and pan-institutional research into the way academic departments operate within universities, with a focus on understanding how practices can be improved.

I look forward to a future where STEM recruitment and success has been more successful, perhaps because initiatives have been informed by a less traditionally quantitative focus on diagnostics and grades of students, but rather a more holistic consideration of the dynamic environment in which students 'learn rather than earn'. This future would also provide a more-structured teaching and learning environment which focuses on teaching as an equal to research while maintaining a balanced workload for academic staff. 


\section{References}

Ackerman, P. L., Kanfer, R., \& Calderwood, C. (2013). High school advanced placement and student performance in college: STEM majors, non-STEM majors, and gender differences. Teachers College Record, 115(10), 1-43. Retrieved from http://www.tcrecord.org/library/content.asp?contentid=17149

Adamson, J., \& Clifford, H. (2002). An appraisal of A-level and university examination results for engineering undergraduates. International Journal of Mechanical Engineering Education, 30(3), 265-279. https://doi.org/10.7227\%2FIJMEE.30.3.8

Adema, W., Ali, N., Frey, V., Kim, H., Lunati, M., Piacentini, M., \& Queisser, M. (2014). Enhancing women's economic empowerment through entrepreneurship and business leadership in OECD Countries. Retrieved from OECD website http://www.oecd.org/gender/Enhancing\%20Women\%20Economic\%20Empower ment_Fin_1_Oct_2014.pdf

Alvesson, M., \& Karreman, D. (2000). Varieties of discourse: On the study of organizations through discourse analysis. Human relations, 53(9), 1125-1149. Retrieved from https://journals.sagepub.com/doi/pdf/10.1177/0018726700539002

Anderson, G. L. (2001). Disciplining leaders: A critical discourse analysis of the ISLLC National Examination and Performance Standards in educational administration. International journal of Leadership in Education, 4(3), 199-216. https://doi.org/10.1080/13603120110062699

Anderson, G. L., \& Grinberg, J. (1998). Educational administration as a disciplinary practice: Appropriating Foucault's view of power, discourse, and method. Educational administration quarterly, 34(3), 329-353. Retrieved from http://journals.sagepub.com/doi/pdf/10.1177/0013161X98034003004 Ashcroft, C. (2007). Constituting Academics as Neo-Liberal Subjects: Research Assessment in a New Zealand Context. New Zealand Journal of Educational Studies, 42(1/2), 77-93. Retrieved from https://search.informit.com.au/documentSummary;dn=607789871085246;res=IEL HSS

Astin, A.W. (1993). Engineering outcomes. ASEE PRISM, 3(1), 27-30. Retrieved from http://www.jstor.org/stable/24152705

Auckland University of Technology. (2018). Study at AUT. Retrieved from http://www.aut.ac.nz/study-at-aut/study-areas/engineering-computer-andmathematical-sciences/undergraduate-study/bachelor-of-engineering-honours

Australian Industry Group. (2013) Lifting our Science, Technology, Engineering and Maths (STEM) Skills. Retrieved from http://www.aigroup.com.au/portal/binary/com.epicentric.contentmanagement.serv let.ContentDeliveryServlet/LIVE_CONTENT/Publications/Reports/2013/Ai_Gro up_Skills_Survey_2012-STEM_FINAL_PRINTED.pdf

Ball, S. J. (2001). Performativities and Fabrications in the Eduation Economy: Towards the Performative Society. In D. Gleeson \& C. Husbands (Eds.), The Performing School: Managing Teaching and Learning in a Performance Culture (pp. 15-30). London: Routledge Falmer.

Ball, S. J. (2003). The Teacher's Soul and the Terrors of Performativity. Journal of Education Policy 18 (2): 215-228. https://doi.org/10.1080/0268093022000043065

Ball, S. J. (2005). Education policy and social class: The selected works of Stephen J. Ball. London: Routledge.

Ball, S. J. (2005). SERALecture 2005: Educational Reform as Social Barberism: Economism and the End of Authenticity. Scottish Educational Review 37 (1): 4- 
16. Retrieved from http://www.revistas2.uepg.br/index.php/praxiseducativa/article/view/4003/2807

Ball, S. J. (2008). Performativity, Privatisation, Professionals and the State. In B. Cunningham (Ed.), Exploring Professionalism, (pp. 50-72) London: Institute of Education.

Ball, S. J. (2012). Performativity, Commodification and Commitment: An I-Spy Guide to the Neoliberal University. British Journal of Educational Studies, 60(1), 17-28. https://doi.org/10.1080/00071005.2011.650940

Ball, S. J. (2015). Living the Neo-liberal University. European Journal of Education, 50(3), 258-261. https://doi.org/10.1111/ejed.12132

Ball, S. J. (2016). Subjectivity as a site of struggle: Refusing neoliberalism? British Journal of Sociology of Education, 37(8), 1129-1146. https://doi.org/10.1080/01425692.2015.1044072

Ball, S. J., \& Olmedo, A. (2013). Care of the self, resistance and subjectivity under neoliberal governmentalities. Critical studies in education, 54(1), 85-96. https://doi.org/10.1080/17508487.2013.740678

Barry, A., Osborne, T., \& Rose, N. (1996). Foucault and political reason: Liberalism, neo-liberalism and rationalities of government. London: Routledge.

Baumann, H. (2002). Publish and Perish?. Journal of Industrial Ecology, 6(3-4), 13-26. Retrieved from http://publications.lib.chalmers.se/records/fulltext/local_3504.pdf

Bazzul, J. (2012). Neoliberal ideology, global capitalism, and science education: Engaging the question of subjectivity. Cultural Studies of Science Education, 7(4), 1001-1020. https://doi.org/10.1007/s11422-012-9413-3

Bazzul, J. (2014a). Science education as a site for biopolitical engagement and the reworking of subjectivities: Theoretical considerations and possibilities for research. In Bencze, L., \& Alsop, S. (Eds.). (2014). Activist science and technology education (Vol. 9) (pp. 37-53). Dordrecht, The Netherlands: Springer.

Bazzul, J. (2014b). Critical discourse analysis and science education texts: Employing Foucauldian notions of discourse and subjectivity. Review of Education, Pedagogy, and Cultural Studies, 36(5), 422-437. https://doi.org/10.1080/10714413.2014.958381

Bazzul, J. (2015a). Tracing "ethical subjectivities" in science education: How biology textbooks can frame ethico-political choices for students. Research in Science Education, 45(1), 23-40. https://doi.org/10.1007/s11165-014-9411-4

Bazzul, J. (2015b). Towards a politicized notion of citizenship for science education: Engaging the social through dissensus. Canadian Journal of Science, Mathematics and Technology Education, 15(3), 221-233. https://doi.org/10.1080/14926156.2015.1051670

Bazzul, J. (2016). Ethics and science education: How subjectivity matters. Switzerland: Springer International Publishing. https://doi.org/10.1007/978-3-319-39132-8

Bazzul, J. (2017a). Biopolitics and the 'subject'of labor in science education. Cultural Studies of Science Education, 12(4), 873-887. https://doi.org/10.1007/s11422017-9840-2

Bazzul, J. (2017b). The 'subject of ethics' and educational research OR Ethics or politics? Yes please! Educational Philosophy and Theory, 1-11. doi:10.1080/00131857.2016.1270184.

Bazzul, J., \& Carter, L. (2017). (Re) considering Foucault for science education research: considerations of truth, power and governance. Cultural Studies of Science Education, 12(2), 435-452. https://doi.org/10.1007/s11422-016-9800-2 
Bazzul, J., \& Siatras, A. (2011). "Enough has yet to be said": Dialoguing neoliberal ideology, pedagogy, and subjectivity in science education. Journal for Activist Science and Technology Education, 3(2). Retrieved from file:///C:/Users/wattercr/Downloads/21204-Article\%20Text-50642-1-1020140502\%20(1).pdf

Beddoes, K. (2011). Practices of brokering: Between STS and feminist engineering education research (Doctoral dissertation, Virginia Tech). Retrieved from https://vtechworks.lib.vt.edu/bitstream/handle/10919/77992/etd-12012011185427_Beddoes_KD_D_2011_1.pdf?sequence $=1 \&$ isAllowed $=\mathrm{y}$

Beddoes, K., Schimpf, C., \& Pawley, A. L. (2013, June). Engaging Foucault to better understand underrepresentation of female STEM faculty. In American Society for Engineering Education Annual Conference, Atlanta, GA. Retrieved from https://www.researchgate.net/profile/Kacey_Beddoes/publication/236899309_Eng aging_Foucault_to_Better_Understand_Underrepresentation_of_Female_STEM_ Faculty/links/02e7e51add63f5d42a000000.pdf

Beede, D., Julian, T., Langdon, D., McKittick, G., George, K., Khan, B., \& Doms, M. (2011). Women in STEM: A gender gap to innovation. US Department of Commerce, Economics and Statistics Administration. Retrieved from https://files.eric.ed.gov/fulltext/ED523766.pdf

Belzile, L. M. (2008). Good for all students: A Foucauldian interrogation of teachers' discourse of inclusion. (Unpublished doctoral dissertation). University of Alberta: Edmonton, Canada.

Bencze, L., \& Carter, L. (2011). Globalizing students acting for the common good. Journal of Research in Science teaching, 48(6), 648-669. Retrieved from https://onlinelibrary.wiley.com/doi/pdf/10.1002/tea.20419

Berger, J. B. (2000). Organizational behavior at colleges and student outcomes: a new perspective on college impact. The Review of Higher Education, 23(2), 177-198. https://doi.org/10.1353/rhe.2000.0001

Berger, P. L., \& Luckmann, T. (1991). The social construction of reality: A treatise in the sociology of knowledge. London: Penguin Books.

Beutel, A. M., \& Nelson, D. J. (2005). The gender and race-ethnicity of faculty in top science and engineering research departments. Journal of Women and Minorities in Science and Engineering, 11(4), 389-402. https://doi.org/10.1615/JWomenMinorScienEng.v11.i4.50

Billig, M. (1997). Rhetorical and discursive analysis: How families talk about the royal family. In N. Hayes (Ed.). Doing qualitative analysis in psychology. (pp. 39-54). Sussex: Lawrence Erlbaum.

Billig M. (2003) Critical Discourse Analysis and the Rhetoric of Critique. In: Weiss G., Wodak R. (Eds.), Critical Discourse Analysis. Palgrave Macmillan, London

Blaikie, N. (2007). Approaches to social enquiry: Advancing knowledge. Cambridge UK: Polity.

Boereboom. J. (2016). University entrance always a bridesmaid. Education Review Post Grad and Research (October 2016), 14-16. Retrieved from http://www.educationreview.co.nz/magazine/october-2016/university-entrancealways-a-bridesmaid/\#.WESsaLJ97uo

Boereboom. J. (2016). NCEA pass rate targets: A wolf in sheep's clothing? Education Review - Post Grad and Research (October 2016), 26. Retrieved from http://www.educationreview.co.nz/magazine/october-2016/ncea-pass-rate-targetsa-wolf-in-sheeps-clothing/ 
Boles, W. (2009). Barriers to student learning in engineering: Annotated bibliography. Australian Learning and Teaching Council. Retrieved from http://www.altcexchange.edu.au/barriers-learning-annotated-bibliography

Boston, J., Mischewski, B., \& Smyth, R. (2005). Performance-Based Research Fund: Implications for research in the social sciences and social policy. Social Policy Journal of New Zealand, 24(1), 55-84. Retrieved from http://go.galegroup.com/ps/i.do?ty=as\&v=2.1\&u=vuw\&it=DIourl\&s=RELEVAN $\mathrm{CE} \& \mathrm{p}=\mathrm{AONE} \& \mathrm{qt}=\mathrm{TI} \sim \% 22 \mathrm{Performance}-$

Based\%20Research\%20Fund\%20Implications\%22 SP 55 IU 1 SN 11724382 VO 24\&lm=DA 120050000\&sw=w

Boughton, J. M., \& Mourmouras, A. (2002). Is policy ownership an operational concept? (No.2-72). International Monetary Fund. Retrieved from https://www.imf.org/external/pubs/ft/wp/2002/wp0272.pdf

Borch, C. (2005). Systemic power: Luhmann, Foucault, and analytics of power. Acta Sociologica, 48(2), 155-167. Retrieved from http://www.jstor.org/stable/20059932

Bosworth, D., Lyonette, C., Wilson, R., Bayliss, M., \& Fathers, S. (2013). The supply of and demand for high-level STEM skills (UKCES evidence report; no. 77). Wathupon-Dearne, England: UKCES. Retrieved from http://www.ukces.org.uk/publications/er77-high-level-stem-skills-supply-anddemand

Boyne, R. (1990). Foucault and Derrida: The other side of reason. London: Unwin Hyman Ltd.

Bradbury-Jones, C., Sambrook, S., \& Irvine, F. (2007). The meaning of empowerment for nursing students: a critical incident study. Journal of Advanced Nursing, 59(4), 342-351. Retrieved from https://onlinelibrary.wiley.com/doi/full/10.1111/j.13652648.2007.04331.x

Braun, V., \& Clarke, V. (2013). Successful qualitative research: A practical guide for beginners. London: Sage.

Brew, A., \& Boud, D. (1995). Teaching and research: Establishing the vital link with learning. Higher Education, 29, 261-273. Retrieved from https://link.springer.com/content/pdf/10.1007/BF01384493.pdf

Brody, L. E. (2006, September 26). Measuring the effectiveness of STEM talented initiatives for middle and high school students. Paper prepared for Identifying and Developing STEM Talent: A Planning Meeting. Washington DC: National Academy of Sciences. Retrieved from https://dst.sp.maricopa.edu/DWG/STPG/JuniorACE/Shared\%20Documents/STE M/Measuring\%20the\%20Effectiveness\%20of\%20STEM\%20Talent\%20Initiative s\%20for\%20M.pdf

Brown, L., \& Holloway, I. (2008). The adjustment journey of international postgraduate students at an English university: An ethnographic study. Journal of Research in International Education, 7(2), 232-249. Retrieved from http://journals.sagepub.com/doi/pdf/10.1177/1475240908091306

Brown, S., \& Smith, B. (2013). Research, teaching and learning in higher education. New York: Routledge.

Building Engineering \& Science Talent (BEST). (2004). A bridge for all: Higher education design principles to broaden participation in science, technology, engineering, and mathematics. Retrieved from http://www.bestworkforce.org/PDFdocs/BEST_High_Ed_Rep_48pg_02_25.pdf 
Burchell, G., Gordon, C., \& Miller, P. (1991). The Foucault effect: Studies in governmental nationality: With two lectures by and an interview with Michel Foucault / edited by Graham Burchell, Colin Gordon, Peter Miller. London: Harvester Wheatsheaf.

Burke, R. J., \& Mattis, M. C. (Eds.). (2007). Women and minorities in science, technology, engineering, and mathematics: Upping the numbers. Cheltenham, UK: Edward Elgar Publishing.

Butler, P., \& Mulgan, R. (2013). Can academic freedom survive performance based research funding. Victoria University of Wellington Law Review, 44(3/4), 487520. Retrieved from https://heinonline.org/HOL/Page?handle=hein.journals/vuwlr44\&div=31\&g_sent $=1 \&$ casa_token $=\&$ collection $=$ journals $\#$

Cambridge International Association of Cambridge Schools NZ (Inc). (2017). University entrance. Retrieved from http://www.acsnz.org.nz/universityentrance.cfm

Campbell, A., Künnemeyer, R., \& Prinsep, M. R. (2008). Staff perceptions of higher education science and engineering learning communities. Research in Science \& Technological Education, 26(3), 279-294. https://doi.org/10.1080/02635140802276504

Carmichael, H. (2010). Clinical supervision in mental health: A Foucauldian discourse analysis (Doctoral dissertation). University of Essex. Retrieved from http://ssudl.solent.ac.uk/2950/1/carmichael_2011_PhD_thesis.pdf

Carnegie, D. A., \& Watterson, C. (2012). Tertiary Education Commission Pff 838, engineering pathways project report. Retrieved from http://ecs.victoria.ac.nz/Main/TechnicalReportSeries

Carnegie, D. A., Watterson, C., Andreae, P., \& Browne, W. N. (2012). Prediction of success in engineering study. Paper presented at the IEEE Engineering Education Conference: EDUCON. https://doi.org/10.1109/EDUCON.2012.6201020

Carnevale, A.P., Smith, N., \& Melton, M. (2011). STEM: Science, technology, engineering, mathematics. Washington, DC: Georgetown University Center on Education and the Workforce. Retrieved from http://www.ccrscenter.org/products-resources/resource-database/stem-sciencetechnology-engineering-mathematics

Carter, L. (2016). Neoliberalism and STEM education. Journal for Activist Science and Technology Education, 7(1), 31-41. Retrieved from http://jps.library.utoronto.ca/index.php/jaste/article/download/26825/19849

Carter, S. M., \& Little, M. (2007). Justifying knowledge, justifying method, taking action: Epistemologies, methodologies, and methods in qualitative research. Qualitative health research, 17(10), 1316-1328. Retrieved from http://journals.sagepub.com/doi/pdf/10.1177/1049732307306927

Case, J. M., \& Light, G. (2011). Emerging research methodologies in engineering education research. Journal of Engineering Education, 100(1), 186-210. https://doi.org/10.1002/j.2168-9830.2011.tb00008.x

Charles, M. (2018). Teaching, in Spite of Excellence: Recovering a Practice of Teaching-Led Research. Studies in Philosophy and Education, 37(1), 15-29. https://doi.org/10.1007/s11217-017-9568-1

Charmaz, K. (2000). Constructing grounded theory: A practical guide through qualitative analysis. Thousand Oaks, CA: Sage. 
Charmaz, K. (2000). Grounded theory methodology: Objectivist and constructivist qualitative methods. In N. K. Denzin \& Y. S. Lincoln (Eds.), Handbook of Qualitative Research (2nd ed., pp. 509-535). Thousand Oaks, CA: Sage.

Charmaz, K. (2006). Constructing Grounded Theory: A Practical Guide Through Qualitative Analysis. London: Sage.

Cheryan, S., Siy, J. O., Vichayapai, M., Drury, B. J., \& Kim, S. (2011). Do female and male role models who embody STEM stereotypes hinder women's anticipated success in STEM?. Social Psychological and Personality Science, 2(6), 656-664. https://doi.org/10.1177\%2F1948550611405218

Claris, L., \& Riley, D. (2012). Situation critical: critical theory and critical thinking in engineering education. Engineering Studies, 4(2), 101-120. https://doi.org/10.1080/19378629.2011.649920

Clark, B. R. (1983). The contradictions of change in academic systems [1]. Higher Education, 12(1), 101-116. Retrieved from https://link.springer.com/content/pdf/10.1007/BF00140275.pdf

Clark, J., Dodd, D., \& Coll, R. K. (2008). Border crossing and enculturation into higher education science and engineering learning communities. Research in Science \& Technological Education, 26(3), 323-334. https://doi.org/10.1080/02635140802276793

Clegg, S., Hudson, A., \& Steel, J. (2003). The emperor's new clothes: globalisation and e-learning in higher education. British journal of sociology of education, 24(1), 39-53. https://doi.org/10.1080/01425690301914

Coll, R. K., \& Eames, C. (2008). Developing an understanding of higher education science and engineering learning communities. Research in Science \& Technological Education, 26(3), 245-257. https://doi.org/10.1080/02635140802276413

Collin, S. O. (1998). Why are these islands of conscious power found in the ocean of ownership? Institutional and governance hypotheses explaining the existence of business groups in Sweden. Journal of Management Studies, 35(6), 719-746. https://doi.org/10.1111/1467-6486.00117

Comber, B., \& Nixon, H. (2009). Teachers' work and pedagogy in an era of accountability. Discourse: studies in the cultural politics of education, 30(3), 333345. https://doi.org/10.1080/01596300903037069

Connell, R. (2013). The neoliberal cascade and education: An essay on the market agenda and its consequences. Critical Studies in Education, 54(2), 99-112. https://doi.org/10.1080/17508487.2013.776990

Cotton, J. L., Vollrath, D. A., Froggatt, K. L., Lengnick-Hall, M. L., \& Jennings, K. R. (1988). Employee participation: Diverse forms and different outcomes. Academy of Management review, 13(1), 8-22.

Crisp, G., Nora, A., \& Taggart, A. (2009). Student Characteristics, Pre-College, College, and Environmental Factors as Predictors of Majoring in and Earning a STEM Degree: An Analysis of Students Attending a Hispanic Serving Institution. American Educational Research Journal, 46(4), 924-942. Retrieved from http://www.jstor.org/stable/40284742

Crocombe, G. T., Enright, M. J., \& Porter, M. E. (1991). Upgrading New Zealand's competitive advantage. Auckland: Oxford University Press.

Cronje, T., \& Coll, R. K. (2008). Student perceptions of higher education science and engineering learning communities. Research in Science \& Technological Education, 26(3), 295-309. https://doi.org/10.1080/02635140802276587 
Dagan, H. (2007). The social responsibility of ownership. Cornell Law Review 92(6), 1255-1274. Retrieved from https://heinonline.org/HOL/Page?handle=hein.journals/clqv92\&div=46\&g_sent= $1 \&$ casa_token $=\&$ collection $=$ journals\#

Dale, K., \& Burrell, G. (2007). The spaces of organisation and the organisation of space: Power, identity and materiality at work. New York: Palgrave Macmillan.

Deacon, R. (2002). An analytics of power relations: Foucault on the history of discipline. History of the Human Sciences, 15(1), 89-117. Retrieved from http://journals.sagepub.com/doi/pdf/10.1177/0952695102015001074

d'Entrèves, M.P. (2000) Critique and Enlightenment: Michel Foucault on 'Was ist Aufklärung?'. In Geras N., \& Wokler R. (Eds.), The Enlightenment and Modernity (pp. 184-203). London: Palgrave Macmillan. https://doi.org/10.1057/9780333983300_10

Department of Labour. (2008). Engineers in the New Zealand labour market. Retrieved from http://www.dol.govt.nz/services/LMI/tools/skillsinsight/ipenz/engineers_06.asp

Deem, R. (1998). 'New managerialism' and higher education: The management of performances and cultures in universities in the United Kingdom. International Studies in Sociology of Education, 8(1), 47-70. https://doi.org/10.1080/0962021980020014

Deem, R. (2001). Globalisation, New Managerialism, Academic Capitalism and Entrepreneurialism in Universities: is the local dimension still important?. Comparative education, 37(1), 7-20. https://doi.org/10.1080/03050060020020408

Denzin, N. K., \& Lincoln, Y. S. (2008). Strategies of qualitative inquiry (Vol. 2). Sage.De Rond, M., \& Miller, A. N. (2005). Publish or perish: bane or boon of academic life?. Journal of Management Inquiry, 14(4), 321-329. Retrieved from http://journals.sagepub.com/doi/pdf/10.1177/1056492605276850

Diaz-Bone, R., Bührmann, A. D., Rodríguez, E. G., Schneider, W., Kendall, G., \& Tirado, F. (2008). The field of Foucaultian discourse analysis: Structures, developments and perspectives. Historical Social Research/Historische Sozialforschung, 7-28.

Dreyfus, H. L., \& Rabinow, P. (1983). Michel Foucault: Beyond structuralism and hermeneutics. With an afterword by and an interview with Michel Foucault (2nd ed.). Chicago, IL: University of Chicago Press. Retrieved from https://monoskop.org/images/d/d4/Dreyfus_Hubert_L_Rabinow_Paul_Michel_Fo ucault_Beyond_Structuralism_and_Hermeneutics_2nd_ed.pdf

Duncan, G. (2007). Shifting discourses in higher education: The performance-based research fund in New Zealand. In I. Morley (Ed.). The value of knowledge: At the interface (pp. 229-238). Oxford: Inter-disciplinary Press. Retrieved from http://citeseerx.ist.psu.edu/viewdoc/download?doi=10.1.1.101.3973\&rep=rep1\&t ype $=$ pdf\#page $=240$

Dunkle, I. D. (2010). Foucauldian genealogy as situated critique or why is sexuality so dangerous? (Master's thesis). Retrieved from https://scholarworks.gsu.edu/cgi/viewcontent.cgi?article=1062\&context=philosop hy_theses

Durning, B., \& Jenkins, A. (2005). Teaching/research relations in departments: the perspectives of built environment academics. Studies in Higher Education, 30(4), 407-426. https://doi.org/10.1080/03075070500160046 
Eames, C., \& Stewart, K. (2008). Personal and relationship dimensions of higher education science and engineering learning communities. Research in Science \& Technological Education, 26(3), 311-321. https://doi.org/10.1080/02635140802276686

Edwards, R., \& Usher, R. (2002). Postmodernism and education: Different voices, different worlds. London: Routledge. (Original work published 1994)

Ellis, L. M., \& Chen, E. C. (2013). Negotiating identity development among undocumented immigrant college students: A grounded theory study. Journal of Counseling Psychology, 60(2), 251-264. http://dx.doi.org/10.1037/a0031350

ENGR121 - Engineering mathematics foundations. (2 December 2016). Retrieved from http://www.victoria.ac.nz/courses/engr/121/2017

Entwistle, N., McCune, V., \& Hounsell, J. (2002). Approaches to studying and perceptions of university teaching-learning environments: Concepts, measures and preliminary findings. ETL Project Occasional Paper, No. 1. Edinburgh: University of Edinburgh. Retrieved from html:/www.ed.ac.uk/etl/publications

Exworthy, M. and Halford, S. (Eds.), (1998), Professionals and the New Managerialism in the Public Sector. Buckingham: Open University Press.

Fairclough, N. (1992). Discourse and text: Linguistic and intertextual analysis within discourse analysis. Discourse \& Society, 3(2), 193-217. https://journals.sagepub.com/doi/pdf/10.1177/0957926592003002004

Fairclough, N. (1993). Critical discourse analysis and the marketization of public discourse: The universities. Discourse \& Society, 4(2), 133-168. Retrieved from http://journals.sagepub.com/doi/pdf/10.1177/0957926593004002002

Fairclough, N. (2013). Critical discourse analysis: The critical study of language. Routledge. In Van Dijk, T. A. (Ed.) (2011). Discourse studies: A multidisciplinary introduction London: SAGE Publications Ltd. https://doi.org/10.4135/9781446289068

Fairclough, N., Mulderrig, J. \& Wodak, R. (2011). Critical discourse analysis. In T. A. Van Dijk (Ed.), Discourse studies: A multidisciplinary introduction (pp. 357-378). London: SAGE Publications Ltd. https://doi.org/10.4135/9781446289068.n17

Fanghanel, J. (2007). Investigating university lecturers' pedagogical constructs in the working context. York: The Higher Education Academy. Retrieved from https://www.researchgate.net/profile/Joelle_Fanghanel/publication/267797006_In vestigating_university_lecturers\%27_pedagogical_constructs_in_the_working_co ntext/links/55dd8fcf08aeb41644aef56d/Investigating-university-lecturerspedagogical-constructs-in-the-working-context.pdf

Fantz, T. D., Siller, T. J., \& Demiranda, M. A. (2011). Pre-Collegiate Factors Influencing the Self-Efficacy of Engineering Students. Journal of Engineering Education, 100(3), 604-623. Retrieved from https://search.proquest.com/docview/889963752?accountid=14782

Fejes, A. (2008). Governing nursing through reflection: a discourse analysis of reflective practices. Journal of Advanced Nursing, 64(3), 243-250. https://doi.org/10.1111/j.1365-2648.2008.04800.x

Fimyar, O. (2008). Educational policy-making in post-communist Ukraine as an example of emerging governmentality: Discourse analysis of curriculum choice and assessment policy documents (1999-2003). Journal of Education Policy, 23(6), 571-594. https://doi.org/10.1080/02680930802382920

Fusch, P. I., \& Ness, L. R. (2015). Are we there yet? Data saturation in qualitative research. The Qualitative Report, 20(9), 1408-1416. Retrieved from https://search.proquest.com/docview/1721368991 ?accountid=14782 
Forret, M., Eames, C., Coll, R., Campbell, A., Cronjé, T., Stewart, K., \& Prinsep, M. (2007). Understanding and enhancing learning communities in tertiary education in science and engineering. Wellington, NZ: Teaching and Learning Research Initiative. Retrieved from https://www.researchgate.net/profile/Crispin_Maclean/publication/228637043_Un derstanding_and_enhancing_learning_communities_in_tertiary_education_in_scie nce_and_engineering/links/00463534b16b97ed85000000.pdf

Foucault, M. (1971). Orders of discourse. Social Science Information, 10(2), 7-30.

Retrieved from

http://journals.sagepub.com/doi/pdf/10.1177/053901847101000201

Foucault, M. (1972). The archaeology of knowledge. (AOK). New York: Vintage. (Original work published 1969)

Foucault, M. (1973). Madness and civilization. (MAC). New York: Vintage. (Original work published 1961)

Foucault, M. (1975). The birth of the clinic. (BOC). New York: Vintage. (Original work published 1963)

Foucault, M. (1975). Discipline and punish: The birth of the prison. (DAP) New York: Random House

Foucault, M. (1978). The History of Sexuality. Vol. 1, An Introduction. Translated by Robert Hurley. New York: Pantheon.

Foucault, M. (1980). Power/knowledge: Selected interviews and other writings, 19721977. C. Gordon (Ed.). New York: Pantheon.

Foucault, M. (1983). Afterword: The subject and power. In H. L. Dreyfus \& P. Rabinow. Michel Foucault: Beyond structuralism and hermeneutics. With an afterword by and an interview with Michel Foucault (2nd ed., pp. 208-226).

Chicago, IL: University of Chicago Press. Retrieved from https://monoskop.org/images/d/d4/Dreyfus_Hubert_L_Rabinow_Paul_Michel_Fo ucault_Beyond_Structuralism_and_Hermeneutics_2nd_ed.pdf

Foucault, M. (1984). The order of discourse. In M. J. Shapiro (Ed.). Language and politics (pp. 108-138). Oxford: Basil Blackwell.

Foucault, M. (1994). The order of things: An archaeology of the human sciences. (TOT) 1966. Reissue of 1971 edition. New York: Random House.

Foucault, M. (1994). An Interview with Michel Foucault. In J. D. Faubion (Ed.), Power (Vol. 3, pp. 239-297). New York: The New Press.

Foucault, M. (1984). Truth and power. In P. Rabinow (Ed.). The Foucault reader (pp. 51-75). New York: Pantheon.

Foucault, M. (1991). The Foucault effect: Studies in governmentality. Chicago: University of Chicago Press.

Foucault, M. (1998). Interview with Didier Eribon, 1981. In L. Kritzman (Ed.), Foucault: Politics, philosophy, culture (p. 155). New York: Routledge.

Foucault, M. (2000). Power. Essential works of Foucault, 1954-1984, (Vol. 3). New York: New Press

Foucault, M. (2003) Society must be defended: Lectures at the Collège de France 19751976. New York: Picador.

Foucault, M. (2005). The Hermeneutics of the Subject: Lectures at the Collège de France, 1981-1982, F. Gros (ed.), G. Burchell (trans.). Basingstoke: Palgrave Macmillan.

Foucault, M. (2006). Psychiatric Power: Lectures at the Collège de France 19731974, J. Lagrange (ed.), G. Burchell (trans.). Basingstoke: Palgrave Macmillan. 
Foucault, M. (2007). Security, Territory, Population: Lectures at the Collège de France 1977-1978, M. Senellart (ed.), G. Burchell (trans.). Basingstoke: Palgrave Macmillan

Foucault, M. (2008). The Birth of Biopolitics: Lectures at the Collège de France, 197879, G. Burchell (trans.). Basingstoke: Palgrave Macmillan.

French, B. F., Immekus, J. C., \& Oakes, W. C. (2005). An examination of indicators of engineering students' success and persistence. Journal of Engineering Education, 94(4). 419-425. Retrieved from https://search.proquest.com/docview/217950320?accountid=14782

Gabb, R., Milne, L., \& Cao, Z. (2006). Understanding attrition and improving transition. Melbourne: Victoria University. Retrieved from https://www.researchgate.net/profile/Lisa_Milne3/publication/237632757_Unders tanding_attrition_and_improving_transition_A_review_of_recent_literature/links/ 543f06f10cf2eaec07e80d58.pdf

Gale, T. (2001). Critical policy sociology: Historiography, archaeology and genealogy as methods of policy analysis. Journal of Education Policy, 16(5), 379-393. https://doi.org/10.1080/02680930110071002

Georgaca, E., \& Avdi E. (2012). Discourse analysis. In D. Harper \& A. R. Thompson (Eds.), Qualitative research methods in mental health and psychotherapy: A guide for students and practitioners (pp. 147-162). Oxford: John Wiley \& Sons.

Gill, R. (2009). Breaking the silence: The hidden injuries of neo-liberal academia (pp. 228-244). In R. Flood \& R.C. Gill (Eds.), Secrecy and Silence in the Research Process: Feminist Reflections. London: Routledge

Given, L. M. (2008). The SAGE encyclopedia of qualitative research methods (Vols. 10). Thousand Oaks, CA: SAGE Publications, Inc. https://doi.org/10.4135/9781412963909

Glaser, B. G., \& Strauss, A.L. (1967). The discovery of grounded theory: strategies for qualitative research. Chicago: Aldine

Gluckman, P. (2011). Looking ahead: Science education for the twenty-first century. Auckland: Office of the Prime Minister's Science Advisory Committee. Retrieved from http://www.pmcsa.org.nz/wp-content/uploads/Looking-ahead-Scienceeducation-for-the-twenty-first-century.pdf

Godfrey, E. (2001). Defining culture: The way we do things round here. Paper presented at the 2001 American Society for Engineering Education Annual Conference and Exposition. Albuquerque, NM: American Society for Engineering Education. Retrieved from https://peer.asee.org/defining-culture-the-way-we-dothings-round-here.pdf

Godfrey. E. (2009) Exploring the Culture of Engineering Education: The Journey. Australasian Journal of Engineering Education, 15(1), 1-12. https://doi.org/10.1080/22054952.2009.11464019

Gold, R. L. (1997). The ethnographic method in sociology. Qualitative inquiry, 3(4), 388-402. Retrieved from http://journals.sagepub.com/doi/pdf/10.1177/107780049700300402

Graham, M. J., Frederick, J., Byars-Winston, A., Hunter, A. B., \& Handelsman, J. (2013). Increasing persistence of college students in STEM. Science, 341(6153), 1455-1456. https://doi.org/10.1126/science. 1240487

Graves, S. B., \& Waddock, S. A. (1990). Institutional ownership and control: Implications for long-term corporate strategy. The Executive, 4(1), 75-83. Retrieved from https://www.jstor.org/stable/pdf/4164935.pdf 
Gruenewald, D. A. (2004). A Foucauldian analysis of environmental education: Toward the socioecological challenge of the Earth Charter. Curriculum Inquiry, 34(1), 71107. https://doi.org/10.1111/j.1467-873X.2004.00281.x

Guilford, G. (2016, March, 23). Growing Victoria. From the Vice Chancellor. Victoria News. Retrieved from https://www.victoria.ac.nz/staff/news-events/vc

Guilford, G. (2016, April, 19). Working at Victoria. From the Vice Chancellor. Victoria News. Retrieved from https://www.victoria.ac.nz/staff/news-events/vc

Guilford, G. (2018, February, 139). The Victoria vacuum. From the Vice Chancellor. Victoria News. Retrieved from https://www.victoria.ac.nz/staff/news-events/vicnews/2018/02/13-February-2018.pdf

Gutting, G. (Ed.). (2005). The Cambridge companion to Foucault. New York: Cambridge University Press.

Gutting, G. (2013). Michel Foucault. In E. N. Zalta (Ed.), The Stanford Encyclopedia of Philosophy (Summer 2013 Edition). Retrieved from http://plato.stanford.edu/archives/sum2013/entries/foucault/

Hall, S. (2001). Foucault: Power, knowledge and discourse. In M. Wetherell, S.Taylor \& S. J. Yates (Eds.). Discourse theory and practice: A reader (pp. 72-81). London: Sage.

Hall, C., Morris Matthews, K., \& Sawicka, T. (2003). Performance Based Research Fund (PBRF): Policy and practice. New Zealand Annual Review of Education, 13, 79-104. Retrieved from https://www.victoria.ac.nz/education/research/nzaroe/issues-index/2003/pdf/texthall.pdf

Halonen, M. (2002). Reputation and the allocation of ownership. The Economic Journal, 112(481), 539-558. Retrieved from https://www.jstor.org/stable/pdf/798519.pdf

Hammer, T. H., \& Stern, R. N. (1980). Employee ownership: Implications for the organizational distribution of power. Academy of Management Journal, 23(1), 78100. Retrieved from http://www.jstor.org/stable/255497

Harold. S. (2007). Globalization of $R \& D$ and innovation: Implications for U.S. S\&E workforce and policy. Testimony before the U.S. House Subcommittee on Technology and Innovation. Retrieved from http://policy.rutgers.edu/faculty/salzman/901129_salzman_S\&E_workforce.pdf

Harrison, M. (2012) Jobs and growth: The importance of engineering skills to the UK economy. London: Royal Academy of Engineering. Retrievd from https://www.raeng.org.uk/publications/reports/jobs-and-growth

Hattie, J., \& Marsh, H. W. (1996). The relationship between research and teaching: A meta-analysis. Review of Educational Research, 66(4), 507-542. Retrieved from http://journals.sagepub.com/doi/pdf/10.3102/00346543066004507

Heaton, J. (1999). The gaze and visibility of the carer: a Foucauldian analysis of the discourse of informal care. Sociology of Health \& Illness, 21(6), 759-777. Retrieved from https://onlinelibrary.wiley.com/doi/pdf/10.1111/1467-9566.00182

Heilbronner, N. N. $(2011,12)$. Stepping onto the STEM pathway: Factors affecting talented students' declaration of STEM majors in college. Journal for the Education of the Gifted, 34, 876-899. Retrieved from https://search.proquest.com/docview/1355902727?accountid=14782

Hemer, S. R. (2014). Finding time for quality teaching: An ethnographic study of academic workloads in the social sciences and their impact on teaching practices. Higher Education Research \& Development, 33(3), 483-495. https://doi.org/10.1080/07294360.2013.841647 
Henderson, C., Beach, A., \& Finkelstein, N. (2011). Facilitating change in undergraduate STEM instructional practices: An analytic review of the literature. Journal of Research in Science Teaching, 48(8), 952-984. https://doi.org/10.1002/tea.20439

Henkel, M. (2004). Teaching and research: The idea of a nexus. Higher Education Management and Policy, 16(2), 19-30. Retrieved from http://citeseerx.ist.psu.edu/viewdoc/download?doi=10.1.1.113.2532\&rep=rep1\&t ype $=$ pdf\#page $=17$

Henwood, F. (1998). Engineering difference: discourses on gender, sexuality and work in a college of technology. Gender and education, 10(1), 35-49. https://doi.org/10.1080/09540259821087

Herman, E. S. (1981). Corporate control, corporate power. Cambridge: Cambridge University Press.

Hernandez, P. R., Schultz, P. W., Estrada, M., Woodcock, A., \& Chance, R. C. (2013). Sustaining optimal motivation: A longitudinal analysis of interventions to broaden participation of underrepresented students in STEM. Journal of Educational Psychology, 105(1), 89-107. doi:http://dx.doi.org/10.1037/a0029691

Hersh, M. (2000). The changing position of women in engineering worldwide. IEEE Transactions on Engineering Management, 47(3), 345-359. https://doi.org/10.1109/17.865903

Hicks, S. R. (2004). Explaining postmodernism: Skepticism and socialism from Rousseau to Foucault. Tempe: Scholargy Publishing, Inc.

Hicks, D. (2012). Performance-based university research funding systems. Research policy, 41(2), 251-261. https://doi.org/10.1016/j.respol.2011.09.007

Hill, C., Corbett, C., \& St Rose, A. (2010). Why so few? Women in science, technology, engineering, and mathematics. Washington, DC: American Association of University Women.

Hipkins, R., Bolstad, R., Baker, R., Jones, A., Barker, M., Bell, B., Coll, R., Cooper, B., Forret, M., Harlow, A., Taylor, I., France, B., \& Haigh, M. (2002). Curriculum, learning and effective pedagogy: A literature review in science education. Wellington: Ministry of Education. Retrieved from http://www.nzcer.org.nz/system/files/science-ed.pdf

Hipkins, R., \& Bolstad, R. (2005). Staying in science students' participation in secondary education and on transition to tertiary studies. Report prepared for the Ministry of Research, Science and Technology. Wellington: New Zealand Council for Educational Research. Retrieved from http://www.nzcer.org.nz/system/files/14606.pdf

Hipkins, R., Roberts, J., Bolstad, R., \& Ferral, H. (2006). Staying in science 2:

Transition to tertiary study from the perspectives of New Zealand year 13 science students. Wellington: New Zealand Council for Educational Research. Retrieved from http://www.nzcer.org.nz/research/publications/staying-science-2-transitiontertiary-study-perspectives-new-zealand-year-13-s

Hipkins, R. (2010). The evolving NCEA: Findings from the NZCER national survey of secondary schools 2009. Wellington: New Zealand Council for Educational Research. Retrieved from https://www.researchgate.net/profile/Rosemary_Hipkins/publication/259346535_ The_evolving_NCEA/links/0deec52b2581cb69a8000000/The-evolvingNCEA.pdf

HL Paper 37. House of Lords Select Committee on Science and Technology 2nd Report of Session 2012-13. (2012). Higher education in science, technology, engineering 
and mathematics (STEM) subjects. London: The Stationery Office Limited. Retrieved from http://www.publications.parliament.uk/pa/ld201213/ldselect/ldsctech/37/37.pdf

HM Treasury and BIS. (2011). The plan for growth, London: HM Treasury. Retrieved from

https://www.gov.uk/government/uploads/system/uploads/attachment_data/file/315 84/2011budget_growth.pdf

Hoareau, C. (2011). Globalization and higher education policy-making in France: Love it or hate it? French Politics, 9(3), 222-239. http://dx.doi.org/10.1057/fp.2011.9

Hodder, A. P. W., \& Hodder, C. (2010). Research culture and New Zealand's performance-based research fund: some insights from bibliographic compilations of research outputs. Scientometrics, 84(3), 887-901. https://doi.org/10.1007/s11192-010-0201-0

House of Commons. (2009). Innovation, Universities, Science and Skills Committee, 'Engineering: turning ideas into reality', Fourth Report of Session 2008-2009, Volume I, House of Commons, Retrieved from http://www.publications.parliament.uk/pa/cm200809/cmselect/cmdius/50/50i.pdf

Humes, W. (2000). The discourses of educational management. Journal of Educational Enquiry, 1(1), 35-53. Retrieved from https://www.ojs.unisa.edu.au/index.php/EDEQ/article/view/570/440

IB Schools NZ. (2017). Universities and institutions that recognize the IB diploma. Retrieved from IB Schools website http://www.ibschoolsnz.org.nz/recognition.html

Institute of Professional Engineers (IPENZ). (2009). The demand for and supply of engineers. Retrieved from http://www.ipenz.org.nz/ipenz/Education_Career/Final_Statement_on_Demand_a nd_Supply.pdf

Institute of Professional Engineers (IPENZ). (2010). Minority groups in engineering education. Retrieved from http://www.ipenz.org.nz/ipenz/education_career/Report_Minority_Groups_in_En gineering.pdf

James, A., Montelle, C., \& Williams, P. (2008). From lessons to lectures: NCEA mathematics results and first-year mathematics performance. International Journal of Mathematical Education in Science and Technology, 39(8), 1037-1050. https://doi.org/10.1080/00207390802136552

Jenkins, A., Healey, M., \& Zetter, R. (2007). Linking teaching and research in departments and disciplines. York: The Higher Education Academy. Retrieved from https://www.heacademy.ac.uk/system/files/jenkins_healey_zetter_linking_tandr_i n_disciplines_and_departments_summary.pdf

Jessop, B. (2006). From micro-powers to governmentality: Foucault's work on statehood, state formation, statecraft and state power. Political geography, 26(1), 34-40. Retrieved from http://eprints.lancs.ac.uk/506/1/-_E-2007a_FoucaultPG.pdf

J.M. Consulting (2000). Interactions between research, teaching, and other academic activities. Report for Higher Education Funding Council for England. Bristol: Higher Education Consulting Group.

Johnson, S. L. (2013). An exploration of discourses of workplace bullying of organizations, regulatory agencies and hospital nursing unit managers (Doctoral dissertation, University of Washington). Retrieved from 
https://digital.lib.washington.edu/researchworks/bitstream/handle/1773/23598/Joh nson_washington_0250E_11775.pdf?sequence=1

Jørgensen M. W., Phillips L. (2002) Discourse Analysis as Theory and Method, London: SAGE

Joyce, S. (2012, November, 23). 1000 more engineering-places 2013. (Minister of Education New Zealand Parliamentary Press Release). Retrieved from https://www.beehive.govt.nz/release/1000-more-engineering-places-2013

Joyce, S. (2016, August, 8). More students completing qualifications in STEM subjects. (Minister of Education New Zealand Parliamentary Press Release). Retrieved from https://www.beehive.govt.nz/release/more-students-completingqualifications-stem-subjects

Kavanagh, E. (2008). Communities of practice: A relational view of organizing, power, and possibilities (Doctoral dissertation, Tilburg University, Netherlands).

Retrieved from

https://pure.uvt.nl/portal/files/1047979/Proefschrift_Earon_Kavanagh_251108.pdf

Kelly, M. G. (2009). The political philosophy of Michel Foucault. New York: Routledge.

Kempster, S., \& Parry, K. W. (2011). Grounded theory and leadership research: A critical realist perspective. The Leadership Quarterly, 22(1), 106-120. https://doi.org/10.1016/j.leaqua.2010.12.010

Kendall, G., \& Wickham, G. M. (1999). Using Foucault's methods. London: Sage.

King, R, (2008). Addressing the supply and quality of engineering graduates for the new century. Chippendale: Carrick Institute for Learning and Teaching in Higher Education. Retrieved from http://www.olt.gov.au/system/files/resources/Grants_DBIprojec_engineeringquali ty_project\%20report_25march08.pdf

Kirkup, G., Zalevski, A., Maruyama, T., \& Batool, I. (2010). Women and men in science, engineering and technology: the UK statistics guide 2010. Bradford: the UKRC. Retrieved from http://oro.open.ac.uk/29517/1/UKRC_Statistics_Guide_2010.pdf

Klein, K. J. (1987). Employee stock ownership and employee attitudes: a test of three models. Journal of Applied Psychology, 72(2), 319-332. http://dx.doi.org/10.1037/0021-9010.72.2.319

Knight, P. T., \& Trowler, P. R. (2000). Department-level cultures and the improvement of learning and teaching. Studies in Higher Education, 25(1), 69-83. Retrieved from https://www.tandfonline.com/doi/pdf/10.1080/030750700116028

Knight, S. L., Lloyd, G. M., Arbaugh, F., Gamson, D., McDonald, S. P., Nolan Jr, J., \& Whitney, A. E. (2014). Performance assessment of teaching: Implications for teacher education. Journal of Teacher Education 65(5), 372 - 374. https://doi.org/10.1177\%2F0022487114550475

Knights, D., \& Morgan, G. (1991). Corporate strategy, organizations, and subjectivity: A critique. Organization Studies, 12(2), 251-273. Retrieved from http://journals.sagepub.com/doi/pdf/10.1177/017084069101200205

Kreps, D. (2016). Gramsci and Foucault: A Reassessment. London: Routledge.

Lam, P. C., Srivatsan, T., Doverspike, D., Vesalo, J., \& Mawasha P, R. (2005). A ten year assessment of the pre-engineering program for under-represented, low income and/or first generation college students at the university of Akron. Journal of STEM Education: Innovations and Research, 6(3/4), 14-20. Retrieved from https://search.proquest.com/docview/222842557?accountid=14782 
Lather, P. (2006). Foucauldian scientificity: Rethinking the nexus of qualitative research and educational policy analysis. International Journal of Qualitative Studies in Education, 19(6), 783-791. https://doi.org/10.1080/09518390600976006

Laverty, S. M. (2008). Hermeneutic phenomenology and phenomenology: A comparison of historical and methodological considerations. International Journal of Qualitative Methods, 2(3), 21-35. https://doi.org/10.1177/160940690300200303

Lee, M., \& Koh, J. (2001). Is empowerment really a new concept? International Journal of Human Resource Management, 12(4), 684-695. https://doi.org/10.1080/713769649

Lightfoot, S., \& Piotukh, V. (2015). The research-teaching nexus in politics and international relations in the UK: A survey of practices and attitudes. Politics, 35(1), 99-110. https://doi.org/10.1111\%2F1467-9256.12045

Lloyd, C. (1993). The structures of history, Oxford: Blackwell.

Loader, M., \& Dalgety, J. (2008). Students' transition between school and tertiary education. Demographic and Statistical Analysis Unit, Ministry of Education. Wellington: Ministry of Education. Retrieved from www.educationcounts.govt.nz

Lucas, L., Healey, M., Jenkins, A., \& Short, C. (2008). Academics' experiences and perceptions of 'research' and 'teaching': Developing the relationship between these activities to enhance student learning within different disciplines and institutions. York: Higher Education Academy Report.

Macdonald, A. (2014). "Not for people like me?" Under-represented groups in science, technology and engineering. Leeds: WISE Campaign. Retrieved from https://www.winchestersciencecentre.org/media/1759/not_for_people_like_me.pd $\mathrm{f}$

Madison, D. S. (2011). Critical ethnography: Method, ethics, and performance. London: Sage.

Madjar, I., McKinley, E., Deynzer, M., \& Van Der Merwe, A. (2010). Stumbling blocks or stepping stones? Students' experience of transition from low-mid decile schools to university. Auckland: Starpath Project, The University of Auckland Starpath. Retrieved from https://cdn.auckland.ac.nz/assets/education/about/research/docs/starpath/Stumblin g-blocks-or-stepping-stones-Research-Report-25-March-2010.pdf

Manning, R., \& Ginger, C. (2007). An owner's manual to "ownership": A reply to Lachapelle and McCool. Society \& Natural Resources, 20(2), 187-192. https://doi.org/10.1080/08941920601052578

Marginson, S., Tytler, R., Freeman, B., \& Roberts, K. (2013). STEM: country comparisons: international comparisons of science, technology, engineering and mathematics (STEM) education. Final report. Melbourne: Australian Council of Learned Academies. Retrieved from http://dro.deakin.edu.au/eserv/DU:30059041/tytler-stemcountry-2013.pdf

Margolis, J., \& Fisher, A. (2003). Unlocking the clubhouse: Women in computing. Massachusetts: MIT press.

Marra, R. M., Rodgers, K. A., Shen, D., \& Bogue, B. (2009). Women engineering students and self-efficacy: A multi-year, multi-institution study of women engineering student self- efficacy. Journal of Engineering Education, 98(1), 2738. Retrieved from https://search.proquest.com/docview/217966834?accountid=14782 
Massey University. (2018). Learning. Retrieved from website https://www.massey.ac.nz/massey/learning/programmecourse/programme.cfm?prog_id=93353\&tab=plan

Matthews, J. I. (2009). Power, management and complexity in the NHS: a Foucauldian perspective. (Doctoral dissertation). Retrieved from https://core.ac.uk/download/pdf/388377.pdf

May, G. S., \& Chubin, D. E. (2003). A retrospective on undergraduate engineering success for underrepresented minority students. Journal of Engineering Education, 92(1), 27-39. Retrieved from https://search.proquest.com/docview/217947116?accountid=14782

McGrail, M. R., Rickard, C. M., \& Jones, R. (2006). Publish or perish: a systematic review of interventions to increase academic publication rates. Higher Education Research \& Development, 25(1), 19-35. https://doi.org/10.1080/07294360500453053

McIlvenny, P., Klausen, J. Z., \& Lindegaard, L. B. (Eds.). (2016). Studies of Discourse and Governmentality: New perspectives and methods (Vol. 66). Amsterdam: John Benjamins Publishing Company.

McKinley, E., Gan, M., \& Buntting, C., \& Jones, A. (2015). Towards inclusive STEM education for all students. In B. Freeman, S. Marginson \& R. Tytler (Eds.), The Age of STEM: Educational policy and practice across the world in science, technology, engineering and mathematics, (pp.201-214). London: Routledge.

McLaughlin, M. (2003). Tertiary education policy in New Zealand. Ian Axford Fellowship in Public Policy Report. Retrieved from https://www.fulbright.org.nz/wpcontent/uploads/2011/12/axford2002_mclaughlin.pdf

Meabon Bartow, S. L. (2013). Teaching with Social Media: A Multiple Case Foucaudian Discourse Analysis of Participatory and Egalitarian Potential (Doctoral dissertation, Miami University). Retrieved from https://etd.ohiolink.edu/!etd.send_file?accession=miami1372339719\&disposition $=$ inline

Melguizo, T., \& Wolniak, G. C. (2012). The earnings benefits of majoring in STEM fields among high achieving minority students. Research in Higher Education, 53(4), 383-405. https://doi.org/10.1007/s11162-011-9238-z

Melville, W., \& Bartley, A. (2013). Constituting identities that challenge the contemporary discourse: Power, discourse, experience, and emotion. Science Education, 97(2), 171-190. Retrieved from https://onlinelibrary.wiley.com/doi/pdf/10.1002/sce.21047

Miller, A. N., Taylor, S. G., \& Bedeian, A. G. (2011). Publish or perish: academic life as management faculty live it. Career development international, 16(5), 422-445. https://doi.org/10.1108/13620431111167751

Mills, J., Bonner, A., \& Francis, K. (2006). Adopting a constructivist approach to grounded theory: Implications for research design. International Journal of Nursing Practice, 12(1), 8-13. https://doi.org/10.1111/j.1440-172X.2006.00543.x

Ministry of Business, Innovation \& Employment. (2014). The business growth agenda: Future direction 2014. Retrieved from http://www.mbie.govt.nz/infoservices/business/business-growth-agenda/pdf-and-imagelibrary/2014/Business\%20Growth\%20Agenda\%20Future\%20Direction\%202014. pdf 
Ministry of Business, Innovation \& Employment. (2017). The business growth agenda: Building a digital nation. Retrieved from http://www.mbie.govt.nz/infoservices/science-innovation/digital-economy/building-a-digital-nation.pdf

Ministry of Education. (2009). Advanced trade, technical and professional qualifications: Trends in supply. Ministry of Education: Wellington, New Zealand. Retrieved from http://hdl.voced.edu.au/10707/46630

Ministry of Education. (2013). The draft tertiary education strategy for 2014 - 2019. Retrieved from http://www.minedu.govt.nz/ /media/MinEdu/Files/TheMinistry/Consultation/Dra ftTertiaryEducationStrategy2013/MOE23TES2014_2019_finalV1.pdf

Ministry of Education. (23 Jan 2014). Tertiary education - Budget 2013 factsheet. Retrieved from http://www.minedu.govt.nz/theMinistry/Budget/Budget13/FactsheetsBudget2013/ TertiaryFacts.aspx

Ministry of Education. (2014). The tertiary education strategy for $2014-2019$. Retrieved from http://www.education.govt.nz/further-education/policies-andstrategies/tertiary-education-strategy/

Ministry of Education. (2014). Statement of intent 2014-2018. Retrieved from http://www.education.govt.nz/assets/Documents/Ministry/Publications/Statements -of-intent/2014SOI.pdf.

Ministry of Education. (2015). An international comparison of performance-based research funding systems (PBRFS). Retrieved from http://www.education.govt.nz/assets/Documents/Ministry/Strategies-andpolicies/InternationalComparison.pdf

Ministry of Education. (2015, July 9). Tertiary administration. Retrieved from http://www.education.govt.nz/further-education/tertiary-administration/

Ministry of Education. (2016). What did they do? The field of study of domestic graduates 2008-2015. Retrieved from http://www.educationcounts.govt.nz/publications/80898/what-did-they-do-thefield-of-study-of-domestic-graduates-2008-2015

Ministry of Education. (2016). Profile \& trends: New Zealand's tertiary education system 2015. Retrieved from https://www.educationcounts.govt.nz/_data/assets/pdf_file/0008/179405/Profileand-Trends-2015-New-Zealands-Tertiary-Education-System-Part-5-of-6.pdf

Ministry of Education. (2018). Retention of students in senior secondary schools. Retrieved from https://www.educationcounts.govt.nz/statistics/indicators/main/studentengagement-participation/retention_of_students_in_senior_secondary_schools

Moeung, S. (2013). Research-led teaching in higher education: Perspectives of Cambodian and New Zealand academics. (Master's thesis, Victoria University of Wellington). Retrieved from http://researcharchive.vuw.ac.nz/bitstream/handle/10063/3056/thesis.pdf?sequenc $\mathrm{e}=2$

Morley, L. (2003). Quality and power in higher education. Berkshire (UK): McGrawHill Education.

Morton, L. (2013). A critique of the Tertiary Education Advisory Commission's policies on university education in New Zealand from a stakeholder theory perspective (Doctoral dissertation, Lincoln University). Retrieved from http://dspace.lincoln.ac.nz/bitstream/handle/10182/5738/morton_phd.pdf?sequenc $\mathrm{e}=3$ \&isAllowed $=\mathrm{y}$ 
Museus, S. D., Palmer, R. T., Davis, R. J., \& Maramba, D. C. (Eds.). (2011). Racial and ethnic minority student success in STEM education. Hoboken: New Jersey: Jossey-Bass.

Naidoo, R., \& Jamieson, I. (2005). Empowering participants or corroding learning? Towards a research agenda on the impact of student consumerism in higher education. Journal of Education Policy, 20(3), 267-281. https://doi.org/10.1080/02680930500108585

Nash, R. (2005). A change of direction for NCEA: On re-marking, scaling and normreferencing. New Zealand Journal of Teachers' Work, 2(2). 100-106. Retrieved from http://studylib.net/doc/18435135/a-change-of-direction-for-ncea--on-remarking

Nathan, M. J., Tran, N. A., Atwood, A. K., Prevost, A., \& Phelps, L. A. (2010). Beliefs and expectations about engineering preparation exhibited by high school STEM teachers. Journal of Engineering Education, 99(4), 409-426. Retrieved from https://search.proquest.com/docview/763224301? accountid=14782

National Academy of Sciences, National Academy of Engineering, and Institute of Medicine. 2007. Rising above the gathering storm: Energizing and employing America for a brighter economic future. Washington, DC: The National Academies Press. https://doi.org/10.17226/11463.

National Engineering Education Plan (NEEP) Project Governing Group. (2010). National engineering education plan (Online). Prepared For The Tertiary Education Commission. Institute of Professional Engineers New Zealand Engineers New Zealand (IPENZ). Retrieved from http://www.ipenz.org.nz/ipenz/forms/pdfs/NEEP_Project_Report.pdf

National Research Council. (2012). Discipline-based education research: understanding and improving learning in undergraduate science and engineering. Washington, DC: The National Academies Press. Retrieved from http://www.nap.edu/catalog/13362/discipline-based-education-researchunderstanding-and-improving-learning-in-undergraduate

National Science Board. (2002). Science and engineering indicators - 2002. National Science Foundation (NSB-02-1). Retrieved from http://www.nsf.gov/statistics/seind02/pdfstart.htm

Nelson, D. J., \& Rogers, D. C. (2003). A national analysis of diversity in science and engineering faculties at research universities. National Organization for Women. Retrieved from http://users.nber.org/ sewp/events/2005.01.14/Bios+Links/Krieger-rec4Nelson+Rogers_Report.pdf

New Zealand Government, (1989). Education Act, Retrieved from http://www.legislation.govt.nz/act/public/1989/0080/latest/DLM175959.html

New Zealand Government, (1990). Education Amendment Act, Section 161: inserted, on 23 July 1990, by section 36 of the Education Amendment Act 1990 (1990 No 60). Retrieved from http://www.legislation.govt.nz/act/public/1989/0080/latest/DLM183665.html.

New Zealand Productivity Commission. (2016). New models of tertiary education: draft report September 2016. Retrieved from www.productivity.govt.nz/inquirycontent/tertiary-education

New Zealand Universities Council. (2016, August 2nd). The NZ university system. Retrieved from http://www.universitiesnz.ac.nz/nz-university-system 
New Zealand Qualifications Authority (NZQA). (Email communication, June, 2016). University Entrance: Summary of feedback received from the workshops with the eight universities and one ITP.

New Zealand Qualifications Authority (NZQA). (2016). NCEA assessment mathematics. Retrieved from http://www.nzqa.govt.nz/ncea/assessment/search.do?query=Mathematics\&view=a 11\&level=03

New Zealand Qualifications Authority (NZQA). (2016, December 2). Understanding NCEA. Retrieved from http://www.nzqa.govt.nz/qualificationsstandards/qualifications/ncea/understanding-ncea/.

Norris, C. (1994). What is enlightenment? Kant according to Foucault. In G. Gutting, (Ed.), The Cambridge companion to Foucault (pp. 159-196). New York: Cambridge University Press.

OECD. (2013). OECD Economic surveys: New Zealand 2013. OECD Publishing. Retrieved from http://dx.doi.org/10.1787/eco_surveys-nzl-2013-en.

O'Farrell, C. (2005). Michel Foucault, London: SAGE Publications. ProQuest Ebook Central, https://ebookcentral.proquest.com/lib/vuw/detail.action?docID=343952

O'Farrell, C. (2013). Michel Foucault: the unconscious of history and culture. In N. Partner \& S. Foot (Eds), The SAGE handbook of historical theory (pp. 162-182). London: SAGE.

Olssen, M. (2002). The restructuring of tertiary education in New Zealand: Governmentality, neo-liberalism, democracy. McGill Journal of Education, 37(1), 57-87. Retrieved from http://mje.mcgill.ca/article/view/8605/6548

Olssen, M. (2014). Discourse, Complexity, Normativity: Tracing the elaboration of Foucault's materialist concept of discourse. Open Review of Educational Research, 1(1), 28-55. https://doi.org/10.1080/23265507.2014.964296

Olssen, M., \& Peters, M. A. (2005). Neoliberalism, higher education and the knowledge economy: From the free market to knowledge capitalism. Journal of Education Policy, 20(3), 313-345. https://doi.org/10.1080/02680930500108718

Ong, M., Wright, C., Espinosa, L. L., \& Orfield, G. (2011). Inside the double bind: A synthesis of empirical research on undergraduate and graduate women of color in science, technology, engineering, and mathematics. Harvard Educational Review, 81(2), 172-208,389-390. Retrieved from https://search.proquest.com/docview/874155317?accountid=14782

Ostler, E. (2015). STEM education: An overview of contemporary research, trends, and perspectives. Des Moines: Cycloid Publications.

Palmer, R., Maramba, D., \& Dancy, T. (2011). A Qualitative Investigation of Factors Promoting the Retention and Persistence of Students of Color in STEM. The Journal of Negro Education, 80(4), 491-504. Retrieved from http://www.jstor.org/stable/41341155

Parker, I. (1992). Discourse dynamics: Critical analysis for social and individual psychology. London: Routledge.

Parker, I. (Ed.). (1998). Social constructionism, discourse and realism. Sage.

Parker, I. and Burman, E. (1993) Against discursive imperialism, empiricism and constructionism: thirty-two problems with discourse analysis, in E. Burman and I. Parker (eds) Discourse Analytic Research: Repertoires and Readings of Texts in Action. London: Routledge

Parkinson, T.J., Hughes, H., Gardner, D.H., Suddaby, G.T., Giling, M., \& MacIntyre, B.R. (2011). Engaging learners effectively in science, technology and engineering: The pathway from secondary to university education. Wellington, 
New Zealand: Ako Aotearoa. Retrieved from https://akoaotearoa.ac.nz/projects/engaging-learnerseffectively-sciencetechnology-and-engineering-pathway-secondary-university-educat

Patterson, G. (2001). The applicability of institutional goals to the university organisation. Journal of Higher Education Policy and Management, 23(2), 159169. https://doi.org/10.1080/13600800120088652

Pearse, E. A. (2014). University self-identity narratives: A Foucauldian critical discourse analysis (Doctoral dissertation). Retrieved from https://s3.amazonaws.com/academia.edu.documents/39190032/PEARSE_ERIC__Doctoral_Dissertation_-

_Final_1.pdf?AWSAccessKeyId=AKIAIWOWYYGZ2Y53UL3A\&Expires $=152$ 7208651\&Signature=tnpIWYaK\%2BbdI19vv5IhD3KAynIo\%3D\&responsecontent-disposition=inline $\% 3 \mathrm{~B} \% 20$ filename\%3DUniversity_Selfidentity_Narratives_A_Fo.pdf

Peters, M. A. (2007). Foucault, biopolitics and the birth of neoliberalism. Critical Studies in Education, 48(2), 165-178.

Peters, M. (2009). Education, enterprise culture and the entrepreneurial self: A Foucauldian perspective. The Journal of Educational Enquiry, 2(2), 58-71. Retrieved from https://ojs.unisa.edu.au/index.php/EDEQ/article/viewFile/558/428

Peters, M. A. (2013). Managerialism and the neoliberal university: Prospects for new forms of open management in higher education. Contemporary Readings in Law and Social Justice 5(1), 11-26. Retrieved from file:///C:/Users/wattercr/Downloads/MichaelAPetersManageriali.pdf

Peters, M. A., \& Fitzsimons, P. (2001). Neoliberalism and social capital: Re-inventing community. Sites: A Journal for South Pacific Cultural Studies, 37, 32-48.

Retrieved from http://www.amat.org.nz/Neoliberalism.pdf

Pierce, C. (2012). The Promissory Future (s) of Education: Rethinking scientific literacy in the era of biocapitalism. Educational Philosophy and Theory, 44(7), 721-745. https://doi.org/10.1111/j.1469-5812.2010.00736.x

Pierce, J. L., Rubenfeld, S. A., \& Morgan, S. (1991). Employee ownership: A conceptual model of process and effects. Academy of Management Review, 16(1), 121-144. https://doi.org/10.2307/258609

Pierce, J. L., Kostova, T., \& Dirks, K. T. (2001). Toward a theory of psychological ownership in organizations. Academy of Management Review, 26(2), 298-310. https://doi.org/10.2307/259124

Pham, N. D., \& Triantis, A. J. (2015). Reaching the full potential of STEM for women and the US economy. Washington, DC: US Chamber of Commerce Foundation. Retrieved from https://www.uschamberfoundation.org/reports/reaching-fullpotential-stem-women-and-us-economy

Phipps, A. (2007). Re-inscribing gender binaries: Deconstructing the dominant discourse around women's equality in science, engineering, and technology. The Sociological Review, 55(4), 768-787. https://doi.org/10.1111/j.1467954X.2007.00744.x

Popper, K. (1965). The logic of scientific discovery (4th Rev. ed.). London: Hutchinson $\&$ Co.

Potter, J. (1996). Representing reality: Discourse, rhetoric and social construction. London: Sage.

Potter, J. (2003). Discourse analysis and discursive psychology. In P. M. Camic, J. E., Rhodes \& L. Yardley (Eds.), Qualitative research in psychology: Expanding 
perspectives in methodology and design (pp. 73-94). Washington: American Psychological Association.

Potter, J. and Hepburn, A. (2007). Discursive psychology: mind and reality in practice. In Weatherall, A., Watson, B.M. and C. Gallois (Eds.), Language, Discourse and Social Psychology (pp.160 - 181). Basingstoke: Palgrave Macmillan.

Potter, J. \& Wetherell, M. (1987). Discourse and social psychology: Beyond attitudes and behaviour. London: Sage.

President's Council of Advisors on Science and Technology. (2012). Report to the President, engage to excel: Producing one million additional college graduates with degrees in science, technology, engineering and mathematics. Retrieved from http://www.whitehouse.gov/sites/default/files/microsites/ostp/pcastexecutive-report-final_2-13-12.pdf

Professionals Australia. (2014). Women in STEM in Australia: what is the current state of play, what are the key issues and why does it matter? Professionals Australia: Melbourne. Retrieved from http://www.professionalsaustralia.org.au/professionalwomen/wp-content/uploads/sites/48/2014/03/WOMEN_IN_STEM_v2.pdf

Qin, J. (2016). An empirical study of New Zealand secondary school performance under the qualification system of national certificate of education achievement (NCEA) (Master's thesis). Retrieved from http://aut.researchgateway.ac.nz/bitstream/handle/10292/10131/QinJ.pdf?sequenc $\mathrm{e}=3$ \&isAllowed $=\mathrm{y}$

Rainer, J. D., \& Matthews, M. W. (2002). Ownership of learning in teacher education. Action in Teacher Education, 24(1), 22-30. https://doi.org/10.1080/01626620.2002.10463264

Randle, K., \& Brady, N. (1997). Further education and the new managerialism. Journal of Further and Higher Education, 21(2), 229-239. https://doi.org/10.1080/0309877970210208

Ramirez, F. O., \& Kwak, N. (2015). Women's enrollments in STEM in higher education: Cross-national trends, 1970-2010. In W. Pearson Jr., L. M. Frehill, \& C. L. McNeely (Eds.), Advancing women in science (pp. 9-49). Dordrecht: Springer. https://doi.org/10.1007/978-3-319-08629-3_2

Ramsden, P. (2003). Learning to teach in higher education. New York: Routledge.

Ramsden, P and Moses, I. (1992). Association between research and teaching in Australian higher education. Higher Education, 23(3), 17-22. Retrieved from https://link.springer.com/content/pdf/10.1007/BF00145017.pdf

Reisigl, M., \& Wodak, R. (2005). Discourse and discrimination: Rhetorics of racism and antisemitism. London: Routledge.

Riley, D. (2008). Engineering and social justice. Synthesis Lectures on Engineers, Technology, and Society, 3(1), 1-152. Retrieved from https://pdfs.semanticscholar.org/a22c/c6a5c1f298b8faddaca54d4d4db0581bce61. pdf

Riley, D., \& Claris, L. (2009). From persistence to resistance: Pedagogies of liberation for inclusive science and engineering. International Journal of Gender, Science and Technology, 1(1). Retrieved from file:///C:/Users/wattercr/Downloads/25225-1-PB.pdf

Riley, D., Pawley, A. L., Tucker, J., \& Catalano, G. D. (2009). Feminisms in engineering education: Transformative possibilities. NWSA Journal, 21-40. Retrieved from https://www.jstor.org/stable/pdf/20628172.pdf

Riley, R., \& Manias, E. (2002). Foucault could have been an operating room nurse. Journal of Advanced Nursing, 39(4), 316-324. Retrieved from 
https://s3.amazonaws.com/academia.edu.documents/45679261/j.1365-

2648.2002.02292.x20160516-10100-

x9y9pp.pdf?AWSAccessKeyId=AKIAIWOWYYGZ2Y53UL3A\&Expires=15271

99567\&Signature $=$ VPkYGsk3QEuszhVrFS2KhSsJaN0\%3D\&response-content-

disposition=inline\%3B\%20filename\%3DFoucault_could_have_been_an_operatin g_ro.pdf

Roberts, G. Sir. (2002). SET for success: the supply of people with science, technology, engineering and mathematics skills. Retrieved from HM Treasury

http://webarchive.nationalarchives.gov.uk/+/http:/www.hm-

treasury.gov.uk/d/robertsreview_introch1.pdf

Roberts, P. (2007). Neoliberalism, performativity and research. International Review of Education, 53(4), 349-365. https://doi.org/10.1007/s 11159-007-9049-9

Robertson, J. (2007). Beyond the 'research/teaching nexus': Exploring the complexity of academic experience. Studies in Higher Education, 32(5), 541-556. https://doi.org/10.1080/03075070701476043

Rogers, R., Malancharuvil-Berkes, E., Mosley, M., Hui, D., \& Joseph, G. O. G. (2005). Critical discourse analysis in education: A review of the literature. Review of Educational Research, 75(3), 365-416. Retrieved from http://journals.sagepub.com/doi/pdf/10.3102/00346543075003365

Roland, M. C. (2007). Publish and perish. EMBO reports, 8(5), 424-428. https://doi.org/10.1038/sj.embor.7400964

Rouse, J. (2005). Power/knowledge. In G. Gutting (Ed.), Cambridge companion to Foucault, (2nd ed.) (pp. 95-122). Cambridge, UK: Cambridge University Press.

Royal Academy of Engineering. (2012). Jobs and growth: The importance of engineering skills to the UK economy. Retrieved from http://www.raeng.org.uk/publications/reports/jobs-and-growth

Royal Society of Edinburgh. (2012) Tapping all our talents: women in science, technology, engineering and mathematics: A strategy for Scotland. Retrieved from http://www.rse.org.uk/wp-content/uploads/2016/09/Tapping-talentsreport_FINAL.pdf

Ryan, G. W., \& Bernard, H. R. (2003). Techniques to identify themes. Field Methods, 15(1), 85-109. https://doi.org/10.1177/1525822X02239569

Sanders, M. (2009). STEM, STEM education, STEMmania. The Technology Teacher,68(4), 20-26. Retrieved from https://search.proquest.com/docview/235307933? accountid=14782

Savage, D. C. (2000). Academic freedom and institutional autonomy in New Zealand universities. In R. Crozier (Ed.), Troubled times: Academic freedom in New Zealand, (pp. 13-225). Palmerston North: Dunmore Press.

Schagen, S., \& Hodgen, E. (2009). Why engineering, technology, or science? The views of first-year tertiary students. New Zealand Council for Educational Research. Retrieved from http://www.nzcer.org.nz/research/publications/why-technologyengineering-or-science-survey-first-year-tertiary-students

Sharma, A., \& Muzaffar, I. (2012). The (non) making/becoming of inquiry practicing science teachers. Cultural Studies of Science Education, 7(1), 175-191. https://doi.org/10.1007/s11422-011-9372-0

Schrift, A. D. (2006). Twentieth-century French philosophy: Key themes and thinkers. Malden, MA: Blackwell.

Scott, T. P., Tolson, H., \& Huang, T. Y. (2009). Predicting Retention of Mathematics and Science Majors at a Research One Institution and Suggested Advising Tools. Journal of College Admission, 204, 20-24. Retrieved from 
http://web.b.ebscohost.com/ehost/pdfviewer/pdfviewer?vid=0\&sid=d853490ecc2a-4b9c-b707-6d4ef3f04ad1\%40sessionmgr120

Senate Committee for Education, Employment and Workplace Relations. (2012). The

Shortage of engineering and related employment skills, final report. Retrieved from

https://www.engineersaustralia.org.au/sites/default/files/shado/Representation/Go vernment\%20Submissions/2012/engineers_australia_submission_to_senate_skills _shortage_inquiry_-_march_2012.pdf

Seymour, E., \& Hewitt, N. (1997). Talking about leaving. Boulder, CO: Westview Press.

Shapiro, J. R., \& Williams, A. M. (2012). The role of stereotype threats in undermining girls' and women's performance and interest in STEM fields. Sex Roles, 66(3-4), 175-183. http://dx.doi.org/10.1007/s11199-011-0051-0

Shore, C. (2010). Beyond the multiversity: neoliberalism and the rise of the schizophrenic university. Social Anthropology, 18(1), 15-29. https://doi.org/10.1111/j.1469-8676.2009.00094.x

Shore, C., \& Wright, S. (1999). Audit culture and anthropology: neoliberalism in British higher education. Journal of the Royal Anthropological Institute 5(4):557-575.

Retrieved from https://www.jstor.org/stable/pdf/2661148.pdf

Shore, C., \& Wright, S. (2000). Coercive accountability: the rise of audit culture in higher education. In. In Marilyn Strathern, (Ed.), Audit cultures: anthropological studies in accountability, ethics and the academy, (pp.57-89). London: Routledge.

Shore, C., \& Wright, S. (Eds.). (2003). Anthropology of policy: Perspectives on governance and power. London: Routledge.

Shore, C., \& Wright, S. (2015). Audit culture revisited: Rankings, ratings, and the reassembling of society. Current Anthropology, 56(3), 421-444. https://doi.org/10.1086/681534

Shulruf, B., Hattie, J., \& Tumen, S. (2008). Individual and school factors affecting students' participation and success in higher education. Higher Education, 56(5), 613-632. https://doi.org/10.1007/s10734-008-9114-8

Shulruf, B., Hattie, J., \& Tumen, S. (2010). New Zealand's standard-based assessment for secondary schools (NCEA): Implications for policy makers. Asia Pacific Journal of Education, 30(2), 141-165. https://doi.org/10.1080/02188791003721598

Simpson, A. (2014, December, 8). Investing in strategies for growth. Victoria News. Retrieved from website: https://www.victoria.ac.nz/staff/news-events/vc

Smaill, C., Godfrey, E., \& Rowe, G. (2007). The transition from final-year high-school physics and mathematics to first-year electrical engineering: A work-in-progress, Proceedings of the 2007 AAEE Conference, Melbourne.

Smart, W. (2009). The impact of the performance-based research fund on the research productivity of New Zealand universities. Social Policy Journal of New Zealand, 34(1), 136-151. Retrieved from https://msd.govt.nz/documents/aboutmsd-and-our-work/publications-resources/journals-and-magazines/social-policyjournal/spj34/impact-on-research.pdf

Smart, W., \& Engler, R. (2013). In pursuit of excellence: analysing the results of New Zealand's PBRF quality evaluations. Wellington: Ministry of Education.

Smith, P. (1990). Killing the spirit: Higher education in America. New York: Viking Penguin Publishing.

Smith, P., \& Bell, A. (2007). Unravelling the web of discourse analysis. In Devereux, E. (Ed.). Media studies: Key issues and debates (pp. 78-100). London: Sage. 
Soldner, M., Rowan-Kenyon, H., Inkelas, K. K., Garvey, J., \& Robbins, C. (2012). Supporting students' intentions to persist in STEM disciplines: The role of livinglearning programs among other social-cognitive factors. The Journal of Higher Education, 83(3), 311-336. https://doi.org/10.1080/00221546.2012.11777246

Springer, R. A., \& Clinton, M. E. (2015). Doing Foucault: Inquiring into nursing knowledge with Foucauldian discourse analysis. Nursing Philosophy, 16 (2), 8797. https://doi.org/10.1111/nup.12079

Statistics New Zealand. (2015). 2013 Census - Major ethnic groups in New Zealand. Retrieved from website http://www.stats.govt.nz/Census/2013-census/profile-andsummary-reports/infographic-culture-identity.aspx

Statistics New Zealand. (2015). 2013 Age and sex. Retrieved from website http://www.stats.govt.nz/Census/2013-census/profile-and-summaryreports/quickstats-about-national-highlights/age-and-sex.aspx

Stead, G. B., \& Bakker, T. M. (2010). Self in career theory and counselling: a discourse analysis perspective. British Journal of Guidance \& Counselling, 38(1), 45-60. https://doi.org/10.1080/03069880903408646

Stokes, P. A. (2002). Philosophy, 100 essential thinkers. London: Enchanted Lion Books.

Stubbe, M., Lane, C., Hilder J., Vine E., Vine B., Marra M., Holmes J., \& Weatherall, A. (2003) Multiple Discourse Analyses of a Workplace Interaction. Discourse Studies, 5(3), 351-388. Retrieved from https://journals.sagepub.com/doi/pdf/10.1177/14614456030053004

Subotnik, R. F., Tai, R. H., Almarode, J., \& Crowe, E. (2013). What Are the ValueAdded Contributions of Selective Secondary Schools of Mathematics, Science and Technology?-Preliminary Analyses from a US National Research Study. Talent Development \& Excellence, 5(1), 87-97. Retrieved from http://web.b.ebscohost.com/ehost/pdfviewer/pdfviewer?vid=0\&sid=9507e6bfcd7b-4d4f-a425-77c6f4f07723\%40sessionmgr101

Tai, R. H., Sadler, P. M., \& Mintzes, J. J. (2006). Factors influencing college science success. Journal of College Science Teaching, 36(1), 52-56. Retrieved from www.jstor.org/stable/42993900

Taylor, G. W. \& Ussher, J. M. (2001). Making sense of S\&M: A discourse analytic account. Sexualities, 4(3), 293-314. Retrieved from https://journals.sagepub.com/doi/pdf/10.1177/136346001004003002

Tenorio, E. H. (2011). Critical discourse analysis, an overview. Nordic Journal of English Studies, 10(1), 183-210. Retrieved from http://ub016045.ub.gu.se/ojs/index.php/njes/article/viewFile/658/609

Tertiary Education Commission (2012, May 24) Universities. Retrieved from website http://www.tec.govt.nz/Funding/Budget/Budget-2012/Universities/

Tertiary Education Commission. (2013). Educational Performance Indicators:

Definitions and Methodology (Version 6). Retrieved from

http://www.tec.govt.nz/Documents/Reports\%20and\%20other\%20documents/EPIs -SAC-funded-TEOs-2013.pdf

Tertiary Education Commission, (2013). General supplementary plan guidance for 2013 plans for all TEOs. Retrieved from http://www.tec.govt.nz/Documents/Forms\%20Templates\%20and\%20Guides/Gen eral-Supplementary-Plan-Guidance-for-2013-Plans-Jun12.pdf

Tertiary Education Commission. (2014). General plan guidance for 2015 and 2016. Guidance for TEOs seeking plan-based funding from the TEC from 1 January 
2015. Retrieved from http://www.tec.govt.nz/funding/funding-andperformance/investment/plan-guidance

Tertiary Education Commission. (2015). Funding mechanisms. Retrieved from http://www.tec.govt.nz/assets/Funding-mechanisms/SAC-L3-2015.pdf

Tertiary Education Commission. (2016, November 3). Qualification completion rates. Retrieved from website http://www.tec.govt.nz/funding/funding-andperformance/performance/teo/qualification-completion-rates/

Tertiary Education Commission. (2016). Performance based research fund (PBRF) user manual, version 4: November 2016. Retrieved from http://www.tec.govt.nz/assets/Forms-templates-and-guides/PBRF-user-manualNovember-2016-2.pdf

Tertiary Education Commission. (2016). Performance based research fund. Retrieved from http://www.tec.govt.nz/Funding/Fund-finder/Performance-Based-ResearchFund-PBRF-/

The Treasury. (2013, Jun 28). Education key to economic growth and equity. Retrieved from website http://www.treasury.govt.nz/economy/education

Thomasian, J. (2011). Building a science, technology, engineering, and math education agenda: An update of state actions. NGA Center for Best Practices. Retrieved from http://www.nga.org/files/live/sites/NGA/files/pdf/1112STEMGUIDE.PDF

Thomas, J. W. (2000). A review of research on project-based learning. San Rafael, CA: Autodesk Foundation. Retrieved from http://www.newtechnetwork.org.590elmp01.blackmesh.com/sites/default/files/dr/ pblresearch2.pdf

Thompson, R., \& Bolin, G. (2011). Indicators of success in STEM majors: A cohort study. Journal of College Admission, 212, 18-24. Retrieved from https://files.eric.ed.gov/fulltext/EJ939062.pdf

Thompson, P., \& McHugh, D. (2009). Work organisations: A critical approach. London: Palgrave Macmillan.

Thomson, P. (2011, July 10). A Foucauldian approach to discourse analysis. Retrieved from website https://patthomson.net/2011/07/10/a-foucualdian-approach-todiscourse-analysis/

Thornton, P. H., \& Ocasio, W. (1999). Institutional logics and the historical contingency of power in organizations: Executive succession in the higher education publishing industry, 1958-1990. American Journal of Sociology, 105(3), 801-843. Retrieved from https://www.journals.uchicago.edu/doi/pdfplus/10.1086/210361

Thrupp, M., \& Alcorn, N. (2011). A little knowledge being a dangerous thing? Decilebased approaches to developing NCEA league tables. New Zealand Annual Review of Education, 20, 52-73. Retrieved from https://www.victoria.ac.nz/education/research/nzaroe/issuesindex/2010/pdf/text_thrupp.pdf

Tietjen, J. S. (2004). Why so few women, still? Spectrum, IEEE, 41(10), 57-58. Retrieved from https://ieeexplore.ieee.org/stamp/stamp.jsp?arnumber=1338788

Titscher, S., Meyer, M., Wodak, R. and Vetter, E. (2000) Methods of Text and Discourse Analysis, London: Sage. https://doi.org/10.4135/9780857024480.n11

Tobin, K. (2011). Global reproduction and transformation of science education. Cultural Studies of Science Education, 6(1), 127-142. https://doi.org/10.1007/s11422-010-9293-3

Traynor, M. (2006). Discourse analysis: theoretical and historical overview and review of papers in the Journal of Advanced Nursing 1996-2004. Journal of Advanced 
Nursing, 54(1), 62-72. Retrieved from http://www.askforce.org/web/Discourse/Traynor-Analysis-2006.pdf

Trowler, P. R. (1998). Academics Responding to Change. New Higher Education Frameworks and Academic Cultures. Philadelphia: Open University.

Trowler, P. (2001). Captured by the discourse? The socially constitutive power of new higher education discourse in the UK. Organization, 8(2), 183-201. Retrieved from https://journals.sagepub.com/doi/pdf/10.1177/1350508401082005

Tumen, S., Shulruf, B., \& Hattie, J. (2008). Student pathways at the university: patterns and predictors of completion. Studies in Higher Education, 33(3), 233-252. https://doi.org/10.1080/03075070802049145

Umbach, P. D., and Porter, S. R. (2002). How do academic departments impact student satisfaction? Understanding the contextual effects of departments. Research in Higher Education, 43(2), 209-234. Retrieved from https://link.springer.com/content/pdf/10.1023/A:1014471708162.pdf

UNESCO. (2010). Report, Engineering: Issues challenges and opportunities for development. Retrieved from www.unesco.org

Universities New Zealand -Te Pōkai Tara. (2016). Executive summary: Submission to the productivity commission inquiry into new models of tertiary education.

Retrieved from http://www.universitiesnz.ac.nz/files/u12/Universities\%20NZ\%20Submission\%2 0to $\% 20$ the $\% 20$ Productivity $\% 20$ Commission $\% 20-\% 20$ Executive $\% 20$ Summary $\% 2$ 002May2016.pdf

University of Auckland. (2016). National Certificate of Educational Achievement (NCEA). Retrieved from https://www.auckland.ac.nz/en/study/applications-andadmissions/entry-requirements/undergraduate-entry-requirements/new-zealandsecondary-school-applicants/national-certification-educational-achievement.html

University of Auckland. (2017, January 25). Engineering entry requirements NCEA. Retrieved from website

http://www.engineering.auckland.ac.nz/en/for/futureundergraduates/fu-admissionand-enrolment/behons-ncea.html

University of Canterbury. (2018). Undergrad prospectus. Canterbury (NZ): University of Canterbury. Retrieved from http://www.canterbury.ac.nz/media/documents/brochure/Undergrad_Prospectus.p $\mathrm{df}$

U.S. Congress. Commission on the Advancement of Women and Minorities in Science, Engineering, and Technology Development. (2000). Land of Plenty: Diversity as America's Competitive Edge in Science, Engineering and Technology: Report of the Congressional Commission on the Advancement of Women and Minorities in Science, Engineering, and Technology Development. Congressional Commission on the Advancement of Women and Minorities in Science, Engineering, and Technology Development. Retrieved from https://www.nsf.gov/pubs/2000/cawmset0409/cawmset_0409.pdf

U.S. Congress Joint Economic Committee. (2012). STEM education: Preparing for the jobs of the future. Retrieved from http://www.jec.senate.gov/public/_cache/files/6aaa7e1f-9586-47be-82e7326f47658320/stem-education---preparing-for-the-jobs-of-the-future-.pdf

U.S. Department of Commerce, Economics and Statistics Administration.(2011). STEM: Good jobs now and for the future. ESA Issue Brief 3(11). Retrieved from http://www.esa.doc.gov/Reports/stem-good-jobs-now-and-future 
U.S. Department of Education. (2008). A nation accountable: twenty-five years after a nation at risk. Retrieved from http://www2.ed.gov/rschstat/research/pubs/accountable/accountable.pdf

U.S. Senate Joint Economic Committee. (2012). STEM education: Preparing for the jobs of the future. Retrieved from http://www.jec.senate.gov/public/index.cfm?p=Reports $1 \&$ ContentRecord_id=92c 8daf4-47c8-416a-bfa4-984cc8b6525a

Ussher, S. (2007). Tertiary education choices of school leavers. Wellington: Ministry of Education.

Van Dijk, T. A. (1997). Discourse as Structure and Process: Discourse Studies: A Multidisciplinary Introduction. London: SAGE Publications.

Van Dijk, T. A. (2009). Society and discourse: How social contexts influence text and talk. Cambridge U.K.: Cambridge University Press.

Van Dijk, T. A. (Ed.), (2011). Discourse studies: A multidisciplinary introduction London: SAGE Publications Ltd https://doi.org/10.4135/9781446289068

Van Dyne, L., \& Pierce, J. L. (2004). Psychological ownership and feelings of possession: Three field studies predicting employee attitudes and organizational citizenship behaviour. Journal of Organizational Behavior, 25(4), 439-459. https:// doi.org/10.1002/job.249

Vannier, D. M. (2012). Primary and secondary school science education in New Zealand (Aotearoa): Policies and practices for a better future. Wellington: Fulbright New Zealand.

Vaughan, K. (2008). Student perspectives on leaving school, pathways, and careers. New Zealand Council for Educational Research Ministry of Education, New Zealand. Retrieved from www.educationcounts.govt.nz/publications.

Veenstra, C. P., Dey, E. L., \& Herrin, G. D. (2008). Is Modeling of Freshman Engineering Success Different from Modeling of Non-Engineering Success?. Journal of Engineering Education, 97(4), 467-479. https:// doi.org/10.1002/j.2168-9830.2008.tb00993.x

Victoria University of Wellington, (n.d.). Learning and teaching. Retrieved from website http://www.victoria.ac.nz/learning-teaching

Victoria University of Wellington. (n.d.). Academic office. Retrieved from website $\mathrm{http} / / / \mathrm{www}$.victoria.ac.nz/about/governance/academic

Victoria University of Wellington. (n.d.). Academic governance and policy. Retrieved website from http://www.victoria.ac.nz/learning-teaching/strategies-and-policies

Victoria University of Wellington. (n.d.). Graduate profile. Retrieved from website http://www.victoria.ac.nz/learning-teaching/learning-partnerships/graduate-profile

Victoria University of Wellington. (2005). Draft business case for the establishment of a bachelor of engineering. Retrieved from internal departmental files.

Victoria University of Wellington. (2005). Finance committee abridged business plan: Draft BE business case. Retrieved from internal departmental files.

Victoria University of Wellington. (2005). Senior management team memo for draft BE business plan. Retrieved from internal departmental files. Retrieved from internal departmental files.

Victoria University of Wellington. (2006). Business case for introduction of bachelor of engineering 2006. Retrieved from internal departmental files.

Victoria University of Wellington. (2009). Learning and teaching strategy 2010-2014. Retrieved from http://www.victoria.ac.nz/documents/policy/strategies/learningteaching-strategy.pdf 
Victoria University of Wellington, School of Engineering and Computer Science. (2011, July 14). July 14, 2011 Minutes: ECS management committee meeting Retrieved from internal departmental files.

Victoria University of Wellington. (2014). Strategic plan. Retrieved from http://www.victoria.ac.nz/documents/policy/strategies/strategic-plan.pdf

Victoria University of Wellington. (2014). Academic approvals handbook. Retrieved from http://www.victoria.ac.nz/documents/policy/governance/academicapprovals-handbook.pdf

Victoria University of Wellington, School of Engineering and Computer Science. (2015, February 11). February 11, 2015 Minutes: ECS faculty meeting Retrieved from internal departmental files.

Victoria University of Wellington. (2015). Academic freedom policy draft. Retrieved from http://www.victoria.ac.nz/staff/your-university/consultation/consultationacademic-freedom-policy/academic-freedom-policy-draft.docx

Victoria University of Wellington. (2015). Assessment handbook. Retrieved from http://www.victoria.ac.nz/documents/policy/staff-policy/assessment-handbook.pdf

Victoria University of Wellington. (2015). Evaluation and review handbook (AB15/3). Retrieved from http://www.victoria.ac.nz/documents/policy/academic/evaluationand-review-handbook.pdf

Victoria University of Wellington. (2015). The programme and course design handbook (AB15/60-2). Retrieved from

http://www.victoria.ac.nz/documents/policy/governance/programme-and-coursedesign-handbook.pdf

Victoria University of Wellington. (2015). Academic programme review: Computer science programme self-review document. Retrieved from

https://ecs.victoria.ac.nz/foswiki/pub/Faculty/DisciplineReviews2015/Comp-SelfReview.pdf

Victoria University of Wellington. (2016). Interview with the Vice Chancellor, 2016 Annual Report. Retrieved from https://www.victoria.ac.nz/_data/assets/pdf_file/0011/238853/vicechancellor.pdf

Victoria University of Wellington. (2016). Academic programme review: Computer science programme final report. Retrieved from https://ecs.victoria.ac.nz/foswiki/pub/Faculty/DisciplineReviews2015/ComputerS cienceFinalReport.pdf

Victoria University of Wellington. (2016). Academic programme review: Engineering self-review document. Retrieved from

http://ecs.victoria.ac.nz/foswiki/pub/Faculty/DisciplineReviews2016/Engineering _Self-Review_2016.pdf

Victoria University of Wellington. (2017). Academic programme review: Engineering programme final report. Retrieved from https://ecs.victoria.ac.nz/foswiki/pub/Faculty/DisciplineReviews2016/Engineering Report-FINAL.pdf

Victoria University of Wellington. (2017). Academic board minutes 30 May 2017. Retrieved from https://www.victoria.ac.nz/staff/your-university/boardscommittees/academic-board/agendas-papers-minutes

Victoria University of Wellington. (2017, June 12). Our international rankings. Retrieved from website https://www.victoria.ac.nz/staff/newsevents/vc/2017/06/12-june-2017/\#our-international-rankings 
Visser-Wijnveen, G. J., Van Driel, J. H., Van der Rijst, R. M., Verloop, N., \& Visser, A. (2010). The ideal research-teaching nexus in the eyes of academics: Building profiles. Higher Education Research and Development, 29(2), 195-210. https://doi.org/10.1080/07294360903532016

Volkmann, M. J., \& Anderson, M. A. (1998). Creating professional identity: Dilemmas and metaphors of a first-year chemistry teacher. Science Education, 82(3), 293310.Waikato University. (2018). Study. https://doi.org/10.1002/(SICI)1098237X(199806)82:3\%3C293::AID-SCE1\%3E3.0.CO;2-7

Wai, J., Lubinski, D., Benbow, C. P., \& Steiger, J. H. (2010). Accomplishment in science, technology, engineering, and mathematics (STEM) and its relation to STEM educational dose: A 25-year longitudinal study. Journal of Educational Psychology, 102(4), 860-871. doi:http://dx.doi.org/10.1037/a0019454

Waitere, H. J., Wright, J., Tremaine, M., Brown, S., \& Pausé, C. J. (2011). Choosing whether to resist or reinforce the new managerialism: The impact of performancebased research funding on academic identity. Higher Education Research \& Development, 30(2), 205-217. https://doi.org/10.1080/07294360.2010.509760

Walker, J. L. (2012). The use of saturation in qualitative research. Canadian Journal of Cardiovascular Nursing, 22(2). 37-46. Retrieved from http://www.cccn.ca

Wang, X. (2013). Why Students Choose STEM Majors: Motivation, High School Learning, and Postsecondary Context of Support. American Educational Research Journal, 50(5), 1081-1121. Retrieved from http://www.jstor.org/stable/23526124

Watterson, C \& Carnegie, D. A. (2013). Pastoral care and student support: Developing a method of retention. Paper presented at Frontiers in Education (FIE) Conference. https://doi.org/10.1109/FIE.2013.6685006

Wetherell, M., Taylor, S., \& Yates, S. J. (Eds.). (2001). Discourse theory and practice: A reader. London: Sage.

Wetherell, M., Taylor, S., \& Yates, S. J. (Eds.). (2001). Discourse as data: A guide for analysis. London: Sage.

Whalen, D. F., \& Shelley, M. C. (2010). Academic success for STEM and non-STEM majors. Journal of STEM Education: Innovations and Research, 11(1), 45-60. Retrieved from https://search.proquest.com/docview/356806733?accountid $=14782$

Whitehead, C. R. (2011). The good doctor in medical education 1910-2010: A critical discourse analysis (Doctoral dissertation). Retrieved from https://tspace.library.utoronto.ca/bitstream/1807/32161/3/Whitehead_Cynthia_R_ 201111_PhD_thesis.pdf

Wiggins, S. \& Potter, J. (2008). Discursive psychology. In C. Willig \& W. StaintonRogers (Eds.), The Sage handbook of qualitative research in psychology (pp. 7390). London: Sage.

Willig, C. (2001). Introducing qualitative research in psychology: Adventures in theory and method. Buckingham (UK): Open University Press.

Willig, C., \& Stainton-Rogers, W. (Eds.). (2007). The SAGE handbook of qualitative research in psychology. London: Sage.

Wilson, H. V. (2001). Power and partnership: a critical analysis of the surveillance discourses of child health nurses. Journal of Advanced Nursing, 36(2), 294-301. https:// doi.org/10.1046/j.1365-2648.2001.01971.x

Wilson, S. C. (2014). Mental health crisis intervention: a discourse analysis involving service users, families, nurses and the police (Doctoral dissertation). Retrieved from https://www.researchgate.net/profile/Stacey_Wilson/publication/266022807_Men 
tal_health_crisis_intervention_A_discourse_analysis_involving_service_users_fa milies_nurses_and_the_police/links/54233fa40cf238c6ea6e367e.pdf

Winch, S., \& Creedy, D. (2002). Governing nursing conduct: the rise of evidence-based practice. Nursing inquiry, 9(3), 156-161. Retrieved from

http://www.nurseone.ca/ /media/nurseone/page-content/pdf-

en/governing_nursing_conduct_the_rise_of_evidence-based_practice.pdf

Winslade, J. M. (2005). Utilising discursive positioning in counselling. British Journal of Guidance \& Counselling, 33(3), 351-364. https://doi.org/10.1080/03069880500179541

Wodak R. (1990). The Waldheim affair and antisemitic prejudice in Austrian public discourse. Patterns of Prejudice, 24(2-4), 18-33.

https://www.tandfonline.com/doi/pdf/10.1080/0031322X.1990.9970049

Wodak, R. (1991). Turning the tables: antisemitic discourse in post-war Austria. Discourse \& Society, 2(1), 65-83. https://journals.sagepub.com/doi/pdf/10.1177/0957926591002001004

Wodak, R., \& Meyer, M. (2009). Critical Discourse Analysis: History, Agenda, Theory, and Methodology. In R. Wodak, \& M. Meyer (Eds.), Methods for Critical Discourse Analysis (pp. 1, 33). London: Sage.

Wolf, A. (2002). Does education matter: Myths about education and economic growth. London: Penguin Books.

Yates, S. J. (2002). Power and subjectivity: a Foucauldian discourse analysis of experiences of power in learning difficulties community care homes (Doctoral dissertation). Retrieved from https://www.dora.dmu.ac.uk/handle/2086/4322

Youdell, D. (2004). Engineering school markets, constituting schools and subjectivating students: The bureaucratic, institutional and classroom dimensions of educational triage. Journal of Education Policy, 19(4), 407-431. https://doi.org/10.1080/0268093042000227474

Zhang, G., Anderson, T.J., Ohland, M.W., \& Thorndyke, B.R. (2004). Identifying factors influencing engineering student graduation: A longitudinal and crossinstitutional study. Journal of Engineering Education, 93, 313-320. Retrieved from https://search.proquest.com/docview/217959967?accountid=14782 


\section{Author's Publications}

Watterson, C., \& Carnegie, D. A. (2011). Increasing student retention and success: Survey results and the success of initiatives to create an engineering student community. Paper presented at the IEEE Engineering Education Conference: EDUCON. https://doi.org/ 10.1109/EDUCON.2011.5773136

Carnegie, D. A., Watterson, C., Edwards, J., \& Exley, T. (2011). Increasing engineering awareness through targeted outreach. Paper presented at the IEEE Engineering Education Conference: EDUCON. https://doi.org/10.1109/EDUCON.2011.5773126

MacKay, J., Lock, M., Carnegie, D., Watterson, C., \& Pitawala, S. (2011). Inducting students into the engineering community: A case study of the development of a project based engineering foundation programme. Paper presented at the New Zealand Association for Research in Education Conference (NZARE). Tauranga, New Zealand.

Carnegie, D. A., Watterson, C., Andreae, P., \& Browne, W. N. (2012). Prediction of success in engineering study. Paper presented are the IEEE Engineering Education Conference: EDUCON. https://doi.org/10.1109/EDUCON.2012.6201020

Carnegie, D. A., Watterson, C., Browne, W. N., MacKay, J., Lock, M., Williams, J., \& Forret, M. (2012). Strategies to improve engineering retention. Paper presented are the IEEE Engineering Education Conference: EDUCON. https://doi.org/10.1109/EDUCON.2012.6201030

Carnegie, D. A., \& Watterson, C. (2012). Get those geeks: an innovative recruitment strategy for a new engineering provider. Paper presented at the American Society for Engineering Education (ASEE) Annual Conference. (Paper AC2012-3585, Session T225, 12 pages).

Carnegie, D. A., \& Watterson, C. Tertiary Education Commission Pff 838, Engineering Pathways Project Report, 30 July 2012, Technical Report Resides http://ecs.victoria.ac.nz/Main/TechnicalReportSeries.

Carnegie, D. A., Watterson, C. A., Andreae, P., \& Browne, W. N. (2011). NCEA as a predictor of success in tertiary engineering study. Proceedings of the 19th Electronics New Zealand Conference (ENZCon). 7-12. ISBN: 978-0-473-23275-7 (print); ISBN 978-0-473-232764 (CD_ROM), ISBN 978-0-473-23277-1 (online).

Watterson, C. A., Browne, W. N., \& Carnegie, D. A. (2011). Increasing student engagement in first year engineering. Proceedings of the 19th Electronics New Zealand Conference (ENZCon). 31-36. ISBN: 978-0-473-23275-7 (print); ISBN 978-0-473-23276-4 (CD_ROM), ISBN 978-0-473-23277-1 (online).

Watterson, C., \& Carnegie, D. A. (2013). Pastoral care and student support: Developing a method of retention. Paper presented at Frontiers in Education Conference (FIE). https://doi.org/10.1109/FIE.2013.6685006

Carnegie, D. A., Watterson, C. A., Browne, W. N., Cliffe, R., \& Andreae, P. (2013). Issues of recruitment and retention for a new engineering provider. Paper presented at Frontiers in Education Conference (FIE). https://doi.org/10.1109/FIE.2013.6684910

Watterson, C. A., Browne, W. N., \& Carnegie, D. A. (2013). Steps to increase student engagement and retention in first year engineering. Paper presented at IEEE International Conference on Teaching, Assessment and Learning for Engineering (TALE). https://doi.org/ 10.1109/TALE.2013.6654388

Carnegie, D. A., \& Watterson, C. A. (2013). Improving retention rates at first year for modern engineering students. Paper presented at IEEE International Conference on Teaching, Assessment and Learning for Engineering (TALE). https://doi.org/ 10.1109/TALE.2013.6654400 
Watterson, C. A., \& Carnegie, D. A. (2014). What surveys and interviews tell us. Paper presented are the IEEE Engineering Education Conference: EDUCON. https://doi.org/ 10.1109/EDUCON.2014.6826068.

Carnegie, D. A., Kapur, A., Gouws, G., \& Watterson, C. (2014). Student retention in a mechatronics programme: Motivating engineers to learn through music and creativity. Paper presented at the $15^{\text {th }}$ International Workshop on Research and Education in Mechatronics (REM). https://doi.org/10.1109/REM.2014.6920223

Watterson, C. A., Carnegie, D. A., Wilson, M., \& Knewstubb, B. (2016). A potential theoretical method for exploring the engineering first year retention problem. Paper presented are the IEEE Engineering Education Conference: EDUCON. https://doi.org/ 10.1109/EDUCON.2016.7474660

Carnegie, D. A., Andreae, P., Watterson, C. A., \& Bubendorfer, K. (2016). The development of postgraduate ICT programmes: For an industry that does not want traditional postgraduate students. Paper presented are the IEEE Engineering Education Conference: EDUCON. https://doi.org/10.1109/EDUCON.2016.7474627.

Moore, C., Watterson, C., \& Eldridge, J. (2016). Practical laboratory classes to improve engagement and achievement amongst engineering students taking first-year mathematics. Paper presented at Frontiers in Education Conference (FIE). https://doi.org/10.1109/FIE.2016.7757667

Watterson C., Knewstubb B., Carnegie D., \& Wilson M. (2017). Who owns the teaching and learning environment?. In: Auer M., Guralnick D., Uhomoibhi J. (Eds.), Interactive Collaborative Learning. ICL 2016. Advances in Intelligent Systems and Computing, vol 544 (pp. 294-308). Springer, Cham.

Carnegie D. A., Watterson C. A., Murphy J., \& Zareei M. (2017). An inclusive musical mechatronics course. In: Auer M., Guralnick D., Uhomoibhi J. (Eds.), Interactive Collaborative Learning. ICL 2016. Advances in Intelligent Systems and Computing, vol 544 (pp. 201-208). Springer, Cham.

Eldridge, J., Watterson, C., Lukefahr, H., \& Carnegie, D. A. (2017). Are introductory courses suitable pathways for success in the BE(Hons). Paper presented at Frontiers in Education Conference (FIE). https://doi.org/10.1109/FIE.2017.8190574

Carnegie, D. A., Eldridge, J., \& Watterson, C. A. (2017). Beyond academic quality: Lessons from the creation of a new engineering degree. Paper presented at Frontiers in Education Conference (FIE). https://doi.org/10.1109/FIE.2017.8190668

Forthcoming: Carnegie, D. A., Eldridge, J., Atkins, M., \& Watterson, C. A. (2018). Differences in graduate outcomes between ICT engineering and computer science degrees. IEEE Frontiers in Education Conference (FIE).

Forthcoming: Carnegie, D. A., Lukefahr, H., \& Watterson, C. A. (2018). The impact of integrated tutorials in supporting first year student progression. IEEE Frontiers in Education Conference (FIE). 


\section{Appendix A}

\section{VUW Staff Interview}

Size of interview: 1 staff member and the Pastoral Support Manager

Length of interview: max of 50 minutes

Location: in a quiet and contained office.

\section{Staff guidelines for questions}

\section{Barriers:}

What do you think are the main enablers and barriers facing students in the First Year of the BE?

Do you think First Year of the BE is a problem for the students? If so, why?

What do you think are the main issues involved in the student transition from school to university study: For example, what are the main differences? (Intellectual, social, organizational, degree of support, teaching style...)

Do you do anything specific in your courses to help students overcome these barriers?

\section{Teaching/learning style and relationship with lecturers/tutors/students:}

What kind of teaching style do you use most commonly?

What aspects of your papers do you find most effective in helping students understand the content?

Do you get to know your students/tutors on a personal level?

Do your lecturers/tutors get to know you as an individual?

What are the characteristics of a good lecturer/tutor?

How long does it take for students to settle into the new environment? Your class?

Do you know if many students you know make use of the support services? Why? Why not?

How do you feel students do in your papers?

Do the students have any specific difficulty in your papers?

If so, why do you think that is?

Are you clear about what is expected of you in lecturing your papers?

What specific barriers do you face in teaching your papers?

What have you tried to do to overcome any of these barriers?

\section{Organisational:}

How long have you been lecturing at Victoria University and what do you mainly lecture?

Why did you choose to lecture at Victoria University?

Are the reasons still valid now?

Does the first year programme meet your expectations? If not, why not?

Do you normally get help with your lecturing from other lecturer/tutors, institutional support services, CAD etc?

Are you aware of the support services for students and staff at VUW, and if so can you tell me what they are?

Do you feel any sense of commitment or loyalty to this institution? Why? Why not?

Are there any other things you would like to discuss? 


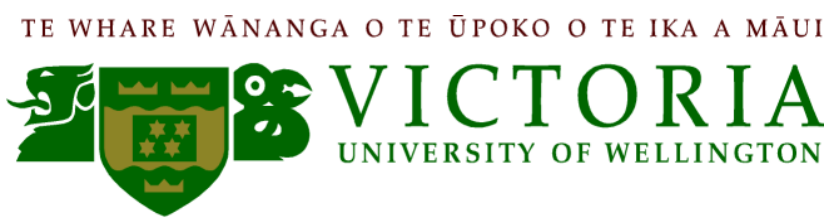

\title{
Barriers to Success in First Year Engineering \\ Craig Watterson PhD research project Victoria University of Wellington Staff Interview and Invitation Form
}

This is an invitation to take Part $1 \mathrm{n}$ an interview. This involves being interviewed about your ideas, expectations, teaching experiences, and feelings about the first year of the Bachelor of Engineering (BE) at Victoria University of Wellington and the students. These interviews are designed to assist in identifying issues affecting the first year of students study.

You are invited for an interview of up to 50 minutes, during which notes will be taken.

The interview will cover your experiences and opinions of students and the first year of the BE. The data from your interview will be aggregated and reported in a non-identifiable way. Quotations from what you share will be used.

The material will be used in a $\mathrm{PhD}$ thesis; in addition articles and presentations may be also given on this data to inform discussion on how to better assist students.

Please note participation or non-participation will not influence your employment in any way.

You may withdraw from this study at any stage up until the beginning of the interview.

The interviews will be conducted by the Pastoral Support and Outreach Manager, Craig Watterson.

The results will form part of a Victoria University $\mathrm{PhD}$ research project by Craig Watterson into the barriers to teaching and learning in Part One of the Bachelor of Engineering.

\section{Thesis title}

Barriers to Success in First Year Engineering

\begin{abstract}
About the research
In 2007, Victoria University of Wellington, New Zealand (VUW), began offering a four year Bachelor of Engineering degree (BE). In 2012 the degree achieved full accreditation from the Institution of Professional Engineers New Zealand (IPENZ). The degree offers three specialisations, Electronic and Computer Systems Engineering (ECEN), Network Engineering (NWEN) and Software Engineering (SWEN).

In response to poor enrolment numbers and low retention rates in 2009, VUW and Wellington Institute of technology (WelTec) partnered in a joint Tertiary Education Commission: Engineering Pathways Project 2009-2012 (EPP), which finished in 2012. This project investigated barriers to student recruitment and retention, and focused much of its work on developing methods of encouraging potential and existing engineering students and investigating student academic performance. As a result, the project increased its support network for struggling students and instituted a Pastoral Support staff member embedded within Engineering to monitor and assist students in accessing help.

The EPP results make it clear that academic grade performance in Secondary School National Certificate of Educational Achievement (NCEA), which forms the basis of assessing entry into the BE, does not support prediction of academic grade success at the tertiary level for first year engineering students at VUW. This study revealed that between over 60-70 per cent of first year students were failing to attain the necessary B average across their core specialisations in their first attempt and thus failed to achieve Part 1. In subsequent years repeating students increased the percentage of students who achieved Part 1 in each cohort, but so far has never passed more than 44 per cent of any given cohort.
\end{abstract}


Survey and focus group results noted that students were having learning difficulty in many first year classes that could not be easily explained by grade analysis. However, little in-depth qualitative work was done to capture and investigate what students and lecturers actually think is affecting successful study in first year engineering.

This study hopes to address this by identifying:

What factors affect first year student completion of Part 1, a compulsory requirement of the Bachelor of Engineering Degree (BE) at Victoria University of Wellington, New Zealand (VUW)?

By gathering and analyzing staff and student perceptions of their experiences relating to, but not exclusively, the first year of the BE, this study seeks to extend the work done in the EPP and add value to the emerging engineering education field of inquiry into barriers to teaching and learning facing current tertiary engineering programmes.

Lecturer and student semi-structured interview notes will be examined and coded for individual, group, and organisational phenomena to reveal particular themes that may impact on first year student success.

This research has been approved by the Victoria University Human Ethics Committee.

If I have any concerns about your participation in this research project please contact the director of the research project:

Professor Dale Carnegie

Professor, School

dale.carnegie@vuw.ac.nz

of Engineering and Computer Science

PH: 044637485 


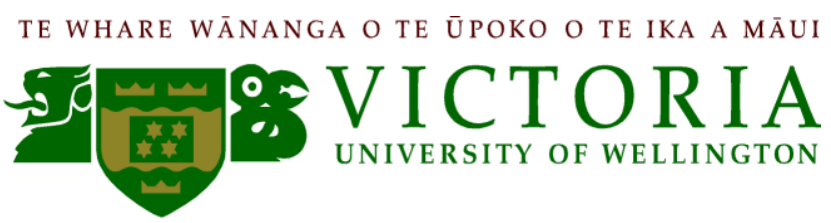

\section{Barriers to Success in First Year Engineering Craig Watterson PhD research project Victoria University of Wellington \\ Consent Form}

\section{Declaration}

Before agreeing to take Part $1 \mathrm{n}$ these interviews, please read the following declaration and then, if you agree with the terms listed below, sign the form.

Regarding my participation in the interview, I understand and agree that:

My participation in this research is voluntary.

I will be involved in Craig Watterson's PhD study and I give permission for the information I provide in the interview to be used in this research project and may be published in articles and presentations to inform discussion on how to better assist students.

I will not be identified in any way other than a code number or pseudonym in data records, reports or publications of the research findings.

I will be interviewed on my experiences and opinions of students and the first year of the BE. The data from my interview will be aggregated and reported in a non-identifiable way.

Quotations from what I share may be used in a non-identifiable way.

Please note participation or non-participation will not influence your employment in any way.

You may withdraw from this study at any stage up until the beginning of the interview.

I have had the opportunity to read the information sheet and have any questions answered.

If I have any concerns about my participation in this research project I can contact the director of the research project:

Professor Dale Carnegie

Professor, School

dale.carnegie@vuw.ac.nz

of Engineering and Computer Science

PH: 044637485

This research has been approved by the Victoria University Human Ethics Committee.

Name

Signature

Date 


\section{Appendix B}

TE WHARE WÃNANGa O TE Ũ POKO O TE IKA A MĀUI

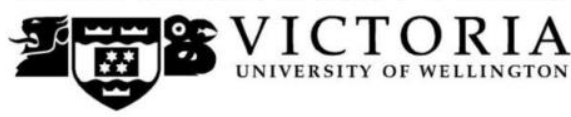

MEMORANDUM

Phone $\quad 0-4-4635676$

Fax $\quad 0-4-4635209$

Email Allison.kirkman@vuw.ac.nz

\begin{tabular}{l|l}
\hline TO & Craig Watterson \\
\hline COPY TO & $\begin{array}{l}\text { Dale Carnegie } \\
\text { Will Browne } \\
\text { Rob Strathdee }\end{array}$ \\
\hline FROM & Dr Allison Kirkman, Convener, Human Ethics Committee \\
\hline
\end{tabular}

\begin{tabular}{l|l}
\hline DATE & 19 April 2013 \\
\hline PAGES & 1 \\
\hline
\end{tabular}

SUBJECT

Ethics Approval: 19727

Analysis of Bachelor of Engineering students achievement at

Secondary School and at Victoria University of Wellington

Thank you for your application for ethical approval, which has now been considered by the Standing Committee of the Human Ethics Committee.

Your application has been approved from the above date and this approval continues until 19 April 2016. If your data collection is not completed by this date you should apply to the Human Ethics Committee for an extension to this approval.

Best wishes with the research.

Allison Kirkman

Human Ethics Committee 
ON V I CT O R I I A

MEMORANDUM
Phone 0-4-4635480

Email susan.corbett@vuw.ac.nz

\begin{tabular}{l|l}
\hline TO & Craig Watterson \\
\hline COPY TO & Dale Carnegie \\
\hline FROM & AProf Susan Corbett, Convener, Human Ethics Committee \\
\hline
\end{tabular}

\begin{tabular}{l|l}
\hline DATE & 1 September 2015 \\
\hline PAGES & 1 \\
\hline SUBJECT & $\begin{array}{l}\text { Ethics Approval: } 22240 \\
\text { Investigating Engineering Discourse }\end{array}$ \\
\hline
\end{tabular}

Thank you for your application for ethical approval, which has now been considered by the Standing Committee of the Human Ethics Committee.

Your application has been approved from the above date and this approval continues until 1 September 2018. If your data collection is not completed by this date you should apply to the Human Ethics Committee for an extension to this approval.

Best wishes with the research.

Kind regards

\section{Susan Corbett}

Convener, Victoria University Human Ethics Committee 
